\title{
ADP and thrombin during thromboembolism in vivo: a vital imaging approach
}

Citation for published version (APA):

van Gestel, M. A. (2004). ADP and thrombin during thromboembolism in vivo: a vital imaging approach. [Doctoral Thesis, Maastricht University]. Universiteit Maastricht. https://doi.org/10.26481/dis.20040101mg

Document status and date:

Published: 01/01/2004

DOI:

$10.26481 / \mathrm{dis} .20040101 \mathrm{mg}$

Document Version:

Publisher's PDF, also known as Version of record

\section{Please check the document version of this publication:}

- A submitted manuscript is the version of the article upon submission and before peer-review. There can be important differences between the submitted version and the official published version of record.

People interested in the research are advised to contact the author for the final version of the publication, or visit the DOI to the publisher's website.

- The final author version and the galley proof are versions of the publication after peer review.

- The final published version features the final layout of the paper including the volume, issue and page numbers.

Link to publication

\footnotetext{
General rights rights.

- You may freely distribute the URL identifying the publication in the public portal. please follow below link for the End User Agreement:

www.umlib.nl/taverne-license

Take down policy

If you believe that this document breaches copyright please contact us at:

repository@maastrichtuniversity.nl

providing details and we will investigate your claim.
}

Copyright and moral rights for the publications made accessible in the public portal are retained by the authors and/or other copyright owners and it is a condition of accessing publications that users recognise and abide by the legal requirements associated with these

- Users may download and print one copy of any publication from the public portal for the purpose of private study or research.

- You may not further distribute the material or use it for any profit-making activity or commercial gain

If the publication is distributed under the terms of Article $25 \mathrm{fa}$ of the Dutch Copyright Act, indicated by the "Taverne" license above, 


\section{ADP and thrombin during thromboembolism in vivo: \\ a vital imaging approach}




\section{Promotor:}

Prof. dr. D.W. Slaaf

\section{Co-promotores:}

Dr. M.G.A. oude Egbrink

Dr. J.W.M. Heemskerk

Beoordelingscommissie:

Prof. di. H. ten Cate (voorzitter)

Prof. dr. J.W.N. Akkerman (Universiteit Utrecht)

Dr. M.J. Lindhout

Prof. dr. M.J. Post

Prof. dr. G.W.J.M. Tangelder (Vrije Universiteit, Amsterdam)

Financial support by the Netherlands Heart Foundation and the Dr. Ir. van de Laar Stichting for the publication of this thesis is gratefully acknowledged.

Additionally, gratitude is expressed to the AZD6140 GPT and the Exanta Team from AstraZeneca R\&D for their financial support. 
Life is like a shooting star, it don' 'I matter who you are If you only run for cover, it's just a waste of iime from: 'The dolphin's ery' by Live 



\section{Abbreviations}

A3P5P

$\mathrm{ACD}$

ADP

AMP

AR-C(MX)

ATP

BSA

$\left[\mathrm{Ca}^{2+}\right]$,

cAMP

CCD

CD40L

cGMP

COX

EPT

$\mathrm{Fbg}$

Gas6

GGACK

GP

G-protein

MAP

$\mathrm{mBT}$

MMP

NO

NTPDase

OCS

PAF

PAR

$\mathrm{PGI}_{2}$

PKC

PLC

PPACK

PPP

PRP

PS
Adenosine 3'5'-biphosphate

Acid citrate dextrose

Adenosine diphosphate

Adenosine monophosphate

AR-C69931MX

Adenosine triphosphate

Bovine serum albumin

Intracellular/cytosolic free calcium concentration

Cyclic adenosine monophosphate

Charge-coupled device

CD40 ligand

Cyclic guanidine monophosphate

Cyclooxygenase

Embolus production time

Fibrinogen

Growth arrest specific gene 6

Glu-Gly-Arg-chloromethylketone

Glycoprotein

GTP-binding protein

Mean arterial blood pressure

Microvessel bleeding time

Matrix metalloproteinase

Nitric oxide

Nucleoside triphosphate diphosphohydrolase

Open canalicular system

Platelet activating factor

Protease activated receptor

Prostacyclin

Protein kinase C

Phospholipase C

Phe-Pro-Arg-chloromethylketone

Platelet-poor plasma

Platelet-rich plasma

Phosphatidylserine 
RBCV

$\mathrm{SD}$

SEM

TF

TFPI

$\mathrm{TXA}_{2}$

vWF
Red blood cell velocity

Standard deviation

Standard error of the mean

Tissue factor

Tissue factor pathway inhibitor

Thromboxane $\mathrm{A}_{2}$

von Willebrand Factor 


\section{Contents}

1. General introduction

2. Interactions between platelets, coagulation factors, and the vessel wall during thromboembolism: a survey of the literature

2.1 Introduction

2.2 Blood platelets

Platelet structure and morphology

Platelet adhesion and aggregation

Intracellular signaling pathways: a central role for cytosolic calcium

$2.3 \quad$ Coagulation

The coagulation cascade

Interactions between coagulation and platelet activation

2.4 Endothelium

Antithrombotic properties of the endothelium

Prothrombotic properties of the endothelium

2.5 Platelet-vessel wall interactions in vivo

2.6 Methods to induce platelet-vessel wall interactions

In vivo induction of platelet-vessel wall interactions

The thromboembolic reaction after wall puncture

2.7 References

3. Real-time detection of activation patterns in individual platelets during thromboembolism in vivo: differences between thrombus growth and embolus formation

Introduction

Methods

Results

Discussion

References

4. In vivo blockade of the platelet ADP receptor $P 2 Y_{12}$ reduces embolus and thrombus formation, but not thrombus stability

Introduction

Methods

Results

Discussion 
5. Antithromboembolic effects of blocking $A D P$ receptors $P 2 Y_{1}$ and $\mathrm{P} \mathrm{Y}_{12}$ in vivo: no additive effects of simultaneous blockade

Introduction $\quad 77$

$\begin{array}{ll}\text { Methods } & 78\end{array}$

Results 81

Discussion $\quad 86$

References 88

6. Effects of thrombin inhibition on thrombus formation and embolization in arterioles and venules in vivo 91

Introduction $\quad 93$

Methods $\quad 94$

Results $\quad 97$

Discussion 105

$\begin{array}{ll}\text { References } & 107\end{array}$

7. General discussion 111

$\begin{array}{lll}7.1 & \text { Introduction } & 113\end{array}$

7.2 Thiomboembolism: a vital imaging approach $\quad 113$

7.3 The thromboembolic reaction in arterioles $\quad 114$

Thrombus formation $\quad 114$

Embolization $\quad 116$

$A D P$ and thrombin during thromboembolism in vivo $\quad 118$

7.4 Involvement of platelets and coagulation in arterial and venous thromboembolism $\quad 119$

$\begin{array}{lll}7.5 & \text { Clinical implications of the present research } & 120\end{array}$

7.6 Different animal models of thromboembolism 121

$\begin{array}{lll}7.7 & \text { Conclusions and future directions } & 122\end{array}$

$\begin{array}{lll}7.8 & \text { References } & 123\end{array}$

$\begin{array}{ll}\text { 8. Summary/Samenvatting } & 127\end{array}$

$\begin{array}{ll}\text { Summary } & 129\end{array}$

Samenvatting 133

Dankwoord 139

Curriculum vitae 141.

$\begin{array}{ll}\text { Publications } & 142\end{array}$

Awards 143 
General introduction

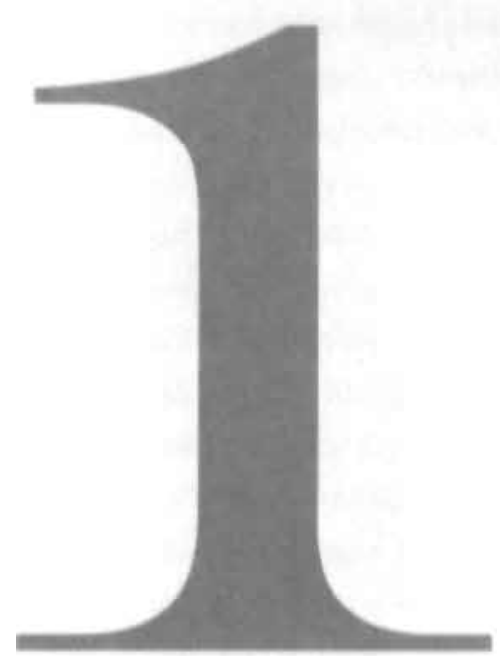


Interactions between blood platelets and the vessel wall play an important role in the reaction of blood to vessel wall injury, as in hemostasis and thrombosis. Traditionally, hemostasis is considered a physiological process that stops bleeding from an injured vessel through the formation of a hemostatic plug, while thrombosis represents pathophysiological plug formation that may lead to vessel occlusion. ${ }^{1-3} \mathrm{~A}$ hemostatic plug is formed when blood platelets (thrombocytes) adhere to a damaged vessel wall and assemble into an aggregate (thrombus). Concomitantly, the plug is stabilized by fibrin formed through coagulation. This thrombus, rich in platelets and fibrin, limits blood loss from the injured vessel and promotes healing.

In diseased vessels, the endothelial phenotype can change from antithrombotic to prothrombotic, ${ }^{4}$ which may lead to pathophysiological thrombus formation. During progression of atherosclerotic lesions, for example, there is an increased potential for platelet-endothelial cell interactions, ${ }^{5}$ which may result in the formation of a thrombus that impairs blood flow, ${ }^{5,6}$ In addition, continuous recruitment of platelets from the bloodstream can lead to the growth of new aggregates that are repeatedly shed from the downstream side of the thrombus, a process referred to as embolization. The emboli can cause downstream vessel occlusion and, hence, ischemia. ${ }^{6}$ Indeed, in patients with atherothrombotic disease in the carotid arteries, cerebral emboli are shed from carotid atherosclerotic plaques, and while these emboli are often asymptomatic, transient ischemic attacks or stroke may occur due to a high frequency or long duration of embolization. ${ }^{8}$ In addition, venous thrombosis often manifests as pulmonary embolism, which can lead to heart failure, pulmonary hypertension, and death. ${ }^{9}$

Thromboembolism and atherothrombosis (i.e. thrombus formation at the surface of atherosclerotic plaques) $)^{6}$ are main causes of morbidity and mortality in the Western world. ${ }^{10}$ The multicausal nature of these diseases, with both genetic and environmental components, " has hampered research. To optimize treatment, a better understanding of the factors involved in thromboembolism in vivo is needed. Important knowledge of the pathogenesis of thromboembolism has been and is still gained from in vitro studies, where biochemical and cellular reactions to changes in one factor are tested under controlled conditions, even in flowing blood. In these circumstances, however, important stimuli from the vessel wali are lacking. In vivo, the course and outcome of a thromboembolic process are defermined by multiple, simultaneously acting factors at the biochemical (e.g. plasma coagulation factors), cellular (platelets, endothelial cells), fluid dynamic (e.g. shear stress), and tissue level. The precise nature and relative importance of such factors, as well as their possible interactions, are still not well known. Data from in vitro and in vivo studies should be integrated to eventually obtain an optimal concept of the pathogenesis of thromboembolism.

The main goal of the present thesis is to increase knowledge regarding individual platelet behavior during a thromboembolic process, as well as the contribution of several prothrombotic factors to the process. To this purpose, an in vivo model was used in which rabbit mesenteric 
microvessels are mechanically injured by puncturing a hole in the vessel wall. This results in a thromboembolic reaction, which is visualized with intravital microscopy. The model was developed by oude Egbrink and colleagues and was first described in $1988 .{ }^{12}$ It has since been applied to study the influence of blood gases and fluid dynamic parameters on thrombus formation and embolization, ${ }^{13,14}$ and to investigate the interactions with leukocytes ${ }^{15}$ and the role of antithrombotic factors from the vessel wall in physiological and pathophysiological conditions. ${ }^{16-19}$

Chapter 2 of this thesis provides an overview of the current literature on platelet. activation, coagulation, endothelial cell function, and their involvement in thromboembolism. In chapter 3 , a new method is described that allows in vivo assessment of intracellular calcium responses of platelets participating in the thromboembolic reaction. Single platelet calcium responses appear to be related to morphological differences between platelets in the thrombus. and platelets in the emboli, suggesting that thrombus formation and embolization are regulated by different mediators. Subsequently, the contribution of different platelet agonists to the thromboembolic process is investigated. As described in chapters 4 and 5 , the role of adenosine diphosphate (ADP) in the thromboembolic reaction is studied using antagonists for the platelet. $\mathrm{ADP}$ receptors, $\mathrm{P} 2 \mathrm{Y}_{1}$ and $\mathrm{P} 2 \mathrm{Y}_{12}$. These studies show that $\mathrm{ADP}$ is largely involved in embolization through both receptors. In addition, $\mathrm{P} 2 \mathrm{Y}_{1}$-but not $\mathrm{P} 2 \mathrm{Y}_{12}$ - appears to play a role in Ihrombus stabilization. The stabilization of a thrombus, i.e. its effectiveness to stop bleeding, also depends on fibrin, which is formed by thrombin. In addition, thrombin is a potent platelet. agonist that can be important in the recruitment of platelets to the thrombus and/or the emboli. Because thrombin may be differentially involved in arterial and venous thromboembolism, its. role in the thromboembolic reaction in arterioles and venules is investigated in chapter 6 . The results of this study confirm that thrombin is important for the stabilization of the thrombus, and show that thrombin is not significantly involved in embolization. in addition, thrombin appears. to be responsible for the difference in thrombus stability normally found between arterioles and venules. The thesis ends with a general discussion (chapter 7), in which an overview is given of the current knowledge of factors involved in thrombus formation and embolization.

\section{References}

1. Born GVR. Platelets and blood vessels. J Cardiovasc Pharmacol. 1984;6:S706-S713.

2. Ruggeri ZM. Platelets in atherothrombosis. Nat Med. 2002;8:1227-1234.

3. Bates SM, and Weitz JI. Emerging anticoagulant drugs. Arterioscler Thromb Vasc Biol. 2003:23:1491-1500. 
4. Cines DB, Pollak ES, Buck CA, Loscalzo J, Zimmerman GA, McEver RP, Pober JS, Wick TM, Konkle BA, Schwartz BS, Barnathan ES, McCrae KR, Hug BA, Schmidt AM, and Stern DM. Endothelial cells in physiology and in the pathophysiology of vascular disorders. Blood. 1998;91:3527-3561.

5. Ruggeri ZM. Von Willebrand factor, platelets and endothelial cell interactions. J Thromb Haemost. 2003;1:1335-1342.

6. Badimon L. Atherosclerosis and thrombosis: lessons from animal models. Thromb Haemost. 2001;86:356-365.

7. Spencer MP. Transcranial Doppler monitoring and causes of stroke from carotid endarterectomy. Siroke. 1997;28:685-691.

8. Markus H. Monitoring embolism in real time. Circulation. 2000;102:826-828.

9. Goldhaber SZ. Thrombolysis in pulmonary embolism: a debatable indication. Thromb Haemost. $2001 ; 86: 444-451$.

10. Murray CJL, and Lopez AD. Mortality by cause for eight regions of the world: Global Burden of Disease Study. Lancet. 1997;349:1269-1276.

11. Rosendaal FR, van Hylckama Vlieg A, Tanis BC, and Helmerhorst FM. Estrogens, progestogens and thrombosis. J Thromb Haemost. 2003;1:1371-1380.

12. oude Egbrink MGA, Tangelder GJ, Slaaf DW, and Reneman RS. Thromboembolic reaction following wall puncture in arterioles and venules of the rabbit mesentery. Thromb Haemost. 1988:59:23-28.

13. oude Egbrink MGA, Tangelder GJ, Slaaf DW, and Reneman RS. Effect of blood gases and pH on thromboembolic reactions in rabbit mesenteric microvessels. Eur J Physiol, 1989:414:324-330.

14. oude Egbrink MGA, Tangelder GJ, Slaaf DW, and Reneman RS. Fluid dynamics and the thromboembolic reaction in mesenteric arterioles and venules. Am J Physiol, 1991;260:H!826-HI833.

15. oude Egbrink MGA, Tangelder GJ, Slaaf DW, and Reneman RS. Influence of platelet-vesse! wall! interactions on leukocyte rolling in vivo. Circ Res. 1992;70:355-363.

16. oude Egbrink MGA, Tangelder GJ, Slaaf DW, and Reneman RS. Different roles of prostaglandins in thromboembolic processes in arterioles and venules in vivo. Thromb Haemost. 1993;70:826-833.

17. Broeders MAW, Tangelder GJ, Slaaf DW, Reneman RS, and oude Egbrink MGA. Endogenous nitric oxide protects against thromboembolism in venules but not in arterioles. Arterioscler Thromb Vasc Biol. 1998;18:139-145.

18. Broeders MAW, Tangelder GJ, Slaaf DW, Reneman RS, and oude Egbrink MGA. Endogenous nitric oxide and prostaglandins synergistically counteract thromboembolism in arterioles but not in venules. Arterioscler Thromb Vasc Biol. 2001;21:163-169.

19. Broeders MAW, Tangelder GJ, Slaaf DW, Reneman RS, and oude Egbrink MGA. Hypercholesterolemia enhances thromboembolism in arterioles but not in venules; complete reversal by L-Arginine. Arterioscler Thromb Vasc Biol. 2002:680-685. 


\section{Interactions between platelets, coagulation}

factors, and the vessel wall during thromboembolism: a survey of the literature 


\subsection{Introduction}

In healthy, intact vessels most blood platelets flow in close proximity of the vessel wall, but do not stick to it due to antithrombotic properties of the endothelium. ${ }^{2}$ Upon vessel wall injury, however, platelets rapidly adhere to thrombogenic components of the exposed subendothelium (adhesion). They then become activated via a complex series of intracellular signaling mechanisms. As a result, platelets may loose their discoid shape (shape change), adhere to one another (aggregation), release their storage granule contents (secretion), produce thromboxane $\mathrm{A}_{2}\left(\mathrm{TXA}_{2}\right)$, and promote coagulation at their surface (procoagulant response), ${ }^{3,4}$ Altogether, this leads to the formation of a hemostatic plug or thrombus that has a protective function in limiting blood loss from the injured vessel and in promoting healing. In diseased vessels, the endothelial phenotype can change from antithrombotic to prothrombotic, ${ }^{2}$ which may lead to pathophysiological thrombus formation and vessel occlusion. In addition, new aggregates may grow at the downstream side of the thrombus, due to continuous recruitment of platelets from the blood. These aggregates are shed downstream as emboli, where they may occlude distal vessels and cause ischemia.

The formation of a hemostatic plug is traditionally characterized by two phases: the initial activation and assembly of platelets into a thrombus is called primary hemostasis, while the stabilization of the thrombus due to coagulation is referred to as secondary hemostasis. There is no doubt, however, that platelet activation and blood coagulation are complementary, mutually dependent processes. This chapter will provide an overview of current knowledge on platelets, coagulation, and the vessel wall, as well as their interactions during thromboembolism.

\subsection{Blood platelets}

\section{Platelet siructure and morphology}

Platelets are the smallest cellular elements in human blood, circulating in concentrations of $150-400 \times 10^{9} / \mathrm{l}$. Platelets are anuclear fragments originating from the cytoplasmi of megakaryocytes in bone marrow and lung. Once released, they circulate in the human body for 7-10 days, after which they are cleared by spleen, liver, and bone marrow. Resting platelets are heterogeneous in volume and size, but in general they have a discoid shape with an average longitudinal diameter of $3 \mu \mathrm{m}$, a thickness of I $\mu \mathrm{m}$, and a volume of $6-8 \mu \mathrm{m}^{3}$ in humans. ${ }^{3.5}$ In rabbits, the species used in the present thesis, platelets are smaller $\left(3.3-5.1 \mu \mathrm{m}^{3}\right)$ and have a life span of about 3 days, ${ }^{5}$ but the platelet count is generally higher than in humans $\left(200-800 \times 10^{9} /\right.$; this thesis). Beside their importance in thrombosis and hemostasis, platelets may also contribute to the integrity of the endothelium ${ }^{6}$ and participate in inflammatory processes ${ }^{7.8}$ and tumor dissemination. ${ }^{9}$ 
Platelets respond rapidly to changes in their environment, particularly during vessel wall damage. To this purpose they are equipped with several striking features, such as an extensive membrane system (Figure 2.1). Platelets are surrounded by a plasma membrane, which is essential for external interaction with blood and vascular tissue. For optimal external interaction, numerous receptor proteins are anchored in the lipid bilayer, and the surface area is largely increased by the multiple channels of the open canalicular system (OCS) extending inward from the plasma membrane. ${ }^{4}$ The extended smooth endoplasmic reticulum (ER) in platelets is called the dense tubular system. As in other cell types, ER is the site where calcium, an important intracellular messenger during platelet activation, is stored bound to calcium-binding proteins. The ER membrane binds several enzymes, including those needed for the conversion of arachidonic acid to $\mathrm{TXA}_{2}$, i.e. cyclooxygenase $(\mathrm{COX}) \mathrm{I}$ and $\mathrm{TXA}_{2}$-synthase. ${ }^{4}$

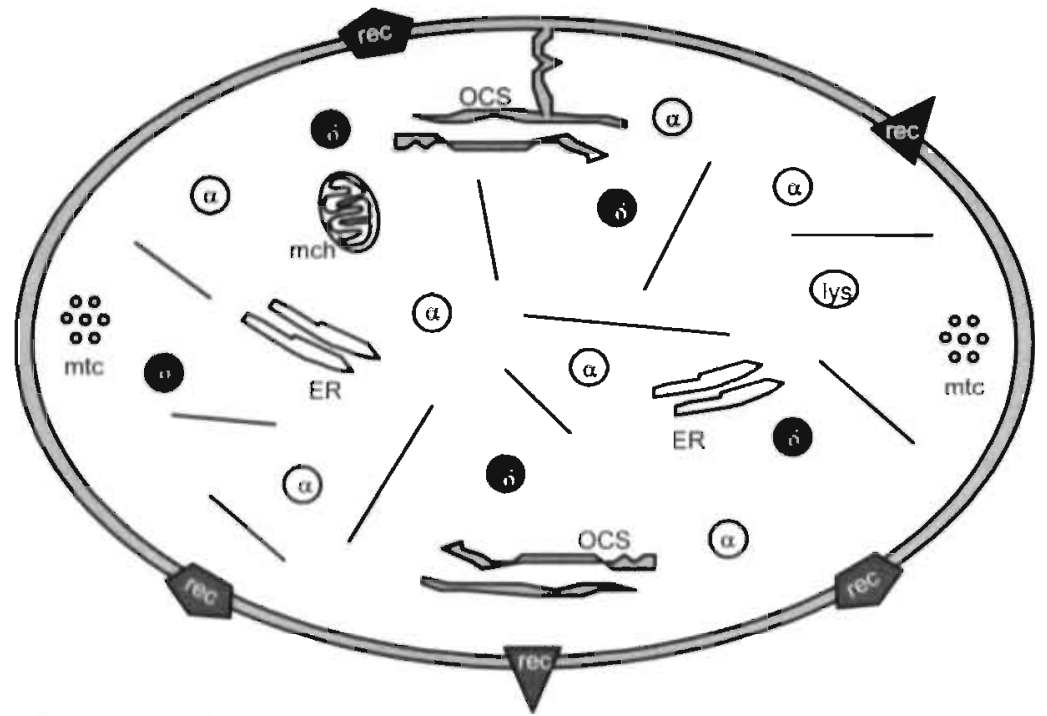

Figure 2.1. Platelet morphology. In this schematic cross-sectional representation of a platelet, the plasma membrane surrounding the platelet and its extensions of the open canalicular system (OCS) are shown in grey; embedded in the plasma membrane are several fypes of receptors (rec). ER = endoplasmic reticulum; mtc $=$ microtubule coil; $\alpha=\alpha$ granuic; $\delta$ - dense granule; mch = mitochondrion; lys = lysosome. Microfilaments and intermediate filaments of the cytoskeleton are represented by the straight lines.

The shape of the platelet is controlled by the cytoskeleton, consisting of microtubules, microfilaments, and intermediate filaments. A thick bundle of microtubules in the periphery of the platelet (microtubule coil) forms a solid loop that is solely responsible for the discoid form of the platelet, ${ }^{10}$ whereas actin microfilaments and intermediate filaments (mainly desmin and vimentin) form an integrated cytoskeletal network that is connected to the plasma membrane and is involved in platelet shape change (see below) ${ }^{4,10}$ 
Platelets also contain several types of secretory granules randomly distributed within the cytoplasm (Figure 2.1), the contents of which are released upon platelet activation and strongly support aggregate growth. The largest population of granules are the $\alpha$-granules, which contain a multifunctional array of proteins, including fibrinogen, von Willebrand Factor (vWF), P. selectin, coagulation factor $\mathrm{V}$, and growth arrest specific gene 6 (Gas6). The dense granules, the second largest granule population, serve as storage pools for serotonin, the divalent cations $\mathrm{Ca}^{2+}$ and $\mathrm{Mg}^{2+}$, and the non-metabolic pool of adenosine diphosphate (ADP) and adenosine triphosphate (ATP). In addition, a few lysosomes, containing acid hydrolases, and peroxysomes, containing catalase, are present. ${ }^{4}$ Recently, an intracellular pool of tissue factor (TF) has been described, ${ }^{11,12}$ but its origin and intracellular distribution are subject to debate.

\section{Platelet adhesion and aggregation}

Adhesion of platelets to the vessel wall occurs when endothelium is activated or endothelial integrity is disturbed and platelets come into contact with thrombogenic components of the subendothelium, e.g. some types of proteoglycans, laminin, and various types of fibrillar collagen (Figure 2.2). The main stimulus for platelet adhesion is probably the exposure of collagen. ${ }^{13}$ Platelets bind to collagen via two glycoprotein (GP) receptors, GPVI and GPlalla (integrin $\alpha 2 \beta 1$ ). Under arterial (high shear) flow conditions adhesion to collagen is initiated by vWF derived from plasma, activated platelets, or endothelial cells. Platelets tether to vWF immobilized on collagen via their GPIb-V-IX receptor, or through GPIIbIlla (integrin $\alpha$ IIb $\beta 3$ ). Next, direct interactions between collagen and platelets can stabilize adhesion. ${ }^{14.16}$ Binding of platelet adhesion receptors to collagen induces platelet activation, which is predominantly mediated by GPVI. ${ }^{15}$ Subsequent shape change allows platelets to adhere more efficiently to the subendothelial surface and to each other. This is characterized by a change from discoid to round shape due to contraction of the microtubule coil. In addition, reorganization of the microfilament network allows the OCS to flow outward and the plasma membrane to extend pseudopods. ${ }^{4}$

Platelets adherent to the vessel wall can recruit flowing platelets to form a platelet aggregate that limits blood loss at the site of injury. Aggregation is dependent on the integrin $\alpha$ Ilb $\beta 3$ receptor, which upon activation binds adhesive molecules that form crosslinks between the aggregating platelets (Figure 2.2). ${ }^{17} \mathrm{~A}$ main crosslinking molecule is fibrinogen, an extended dimeric molecule of about $0.45 \mu \mathrm{m}$ in length with binding sites for $\alpha$ Ilb $\beta 3$ on both ends, which is derived from plasma or platelet $\alpha$-granules. ${ }^{3}$ Binding of vWF to GPIb-V-IX plays a supporting role in platelet aggregation, especially in high shear conditions. ${ }^{18}$ In the absence of fibrinogen and vWF aggregation can be achieved by other adhesive molecules like fibronectin. ${ }^{14,19.20}$ 


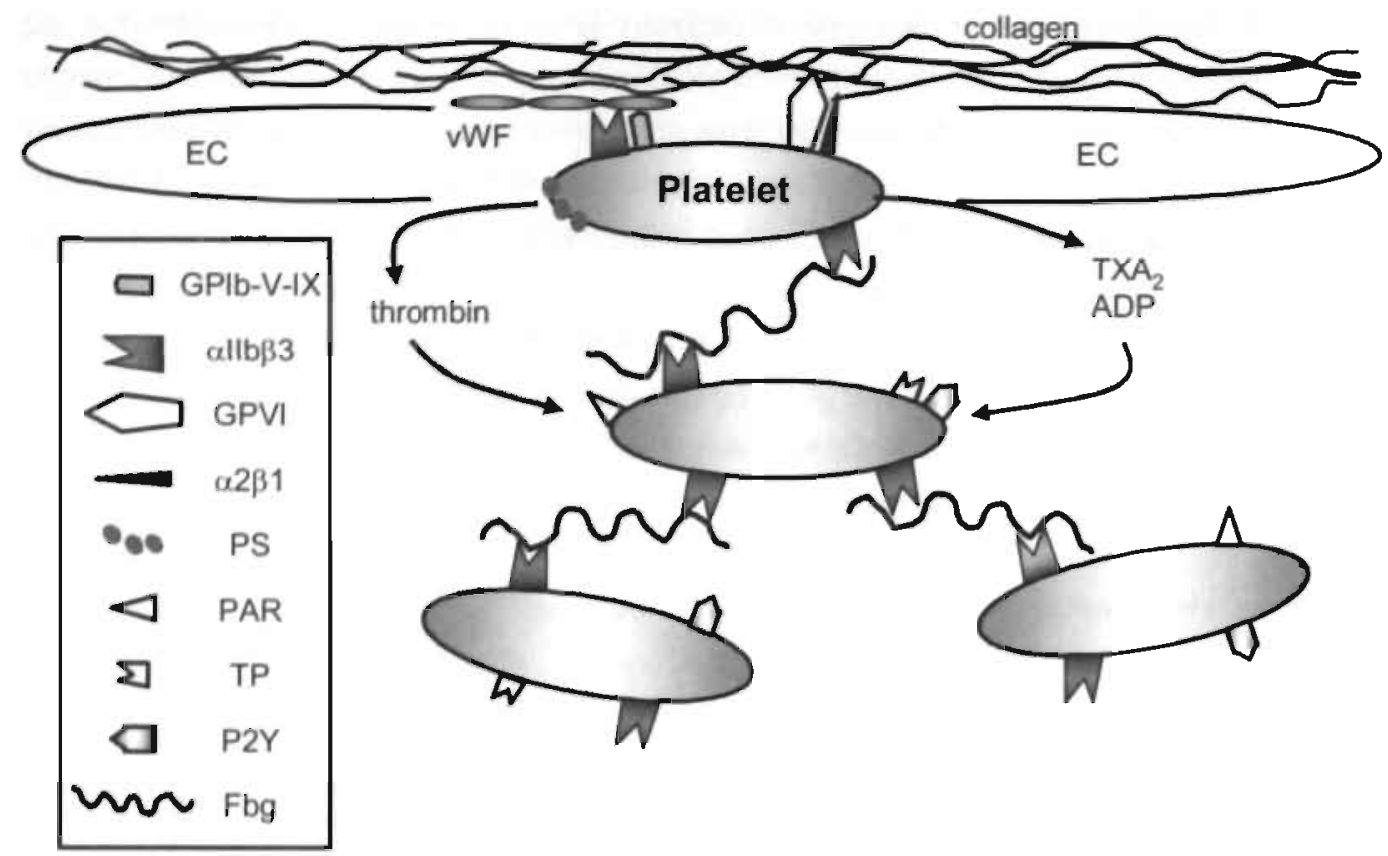

Figure 2.2. Simplified model of platelet-vessel wall interactions leading to thrombus formation. After endothelial cell (EC) disruption, platelets tether to subendothelial collagen fibers by binding to von Willebrand factor (vWF) via GPIb$\mathrm{V}-\mathrm{IX}$ and integrin $\alpha \mathrm{Ilb} \beta 3$. Adhesion to collagen is stabilized via direct interaction with the platelet GPVI and integrin $\alpha 2 \beta 1$ receptors, after which platelets become activated. Activated platelets release TXA: and ADF and expose procoagulant phospholipids (PS) at their surface, which promotes the formation of thrombin. Together, these agonists activate other platelets via their receptors PAR (for thrombin), TP (for TXA2), and P2Y (for ADP). Platelets adhere (aggregate) to each other via crosslinks provided by fibrinogen ( $\mathrm{Fbg}$ ) bound to $\alpha \mathrm{ll} b \beta 3$, which leads to the formation of a thrombus. Other adhesive proteins, like vWF and fibronectin, can also serve as crosslinks between platelets.

The growth of a thrombus (and downstream emboli) is enhanced by the release of several autocrine agents from activated platelets, i.e. via formation of $\mathrm{TXA}_{2}$ and secretion of storage granule contents. TXA 2 is metabolized from arachidonic acid which is liberated from membrane phospholipids by phospholipase $\mathrm{A}_{2}$ upon platelet activation. ${ }^{4}$ Subsequently, TXA $\mathrm{A}_{2}$ can diffuse through the platelet membrane and recruit platelets to the growing thrombus by binding to its receptors TP $\alpha$ and TP $\beta .^{21}$ Secretion of storage granule contents (degranulation) is characterized by the appearance of P-selectin, a transmembrane protein localized in the $\alpha$-granule membrane of resting platelets, on the plasma membrane. ${ }^{22}$ During the initial stages of activation, storage granules centralize and come close to the membranes of the OCS. Upon strong activation the granule membranes fuse with that of the OCS, which leads to exocytosis of granule contents like ADP, ATP, serotonin, and fibrinogen. The released products, in particular ADP, activate other platelets and provide positive feedback during aggregate growth (Figure 2.2). ADP-induced platelet activation involves two receptors: the $\mathrm{P} 2 \mathrm{Y}$, receptor is reported to mediate shape change 
and initiate aggregation, whereas the $\mathrm{P} 2 \mathrm{Y}_{12}$ receptor is thought to be necessary for complete aggregation. ${ }^{23}$ Platelets also express the $\mathrm{P} 2 \mathrm{X}_{1}$ receptor, which was thought to be a receptor for ADP, ${ }^{23}$ but instead has been shown to enhance platelet aggregation by mediating a rapid ATPinduced $\mathrm{Ca}^{2+}$-influx. ${ }^{24}$

Another functional response during platelet activation is the so-called procoagulant response, during which platelets provide a catalytic surface for the formation of thrombin (Figure 2.2). The procoagulant response can be elicited by adhesion to collagen and by stimulation with thrombin itself, ${ }_{n}^{25}$ and is characterized by the appearance of procoagulani phospholipids on the platelet surface. Thrombin is crucial for the formation of fibrin which serves to stabilize the thrombus. (see paragraph 2.3), but it is also a potent platelet agonist. Thrombin-induced platelet activation occurs via protease-activated receptors (PAR), three of which have been identified on platelets. In human platelets intracellular signaling events are triggered by PAR-1 and PAR-4, whereas in rodent platelets PAR-3 and PAR-4 mediate thrombin-induced platelet activation. While PAR-I and PAR-3 are able to respond to low doses of thrombin, PAR-4 is involved in the response to high thrombin concentrations. ${ }^{26,27}$ In addition to the PARs, the GPIb-V-IX complex has been reported to act as a thrombin receptor and mediate thrombin-induced platelet responses. ${ }^{27,28}$

Rabbit platelets are similar in morphology to human platelets, but contain less ADP, more ATP, and more serotonin in their dense granules. Despite the fact that expression of surface receptors may differ from human platelets (e.g. like mouse platelets, rabbit platelets probably lack PAR-1), ${ }^{29}$ the responses to platelet agonists (thrombin, collagen, ADP, TXA inhibiting agents (prostacyclin, ADP receptor antagonists) are very similar to those of human platelets. $^{5,29}$

\section{Intracellular signaling pathways: a central role for cytosolic calcium}

Platelet activation is achieved via binding of platelet agonists to their receptors embedded in the platelet membrane, which activates a complex network of intracellular signaling pathways (Figure 2.3). In vitro, many of the functional platelet responses, including secretion, TXA formation, and the procoagulant response, are directly dependeni on a rise in the cytosolic free $\mathrm{Ca}^{2+}$ concentration $\left(\left[\mathrm{Ca}^{2+}\right]_{i}\right)$. The contribution of platelet $\left[\mathrm{Ca}^{2+}\right]_{i}$ rises during various stages of a thromboembolic reaction in vivo is as yet unclear, and is investigated in the study described in chapter 3 of this thesis.

$\left[\mathrm{Ca}^{2+}\right]_{i}$ is increased due to phospholipase $\mathrm{C}$ (PLC) activation, which induces hydrolysis of phosphatidylinositol 4,5-biphosphate to form the second messengers inositol I,4,5-triphosphate $\left(\mathrm{IP}_{3}\right)$ and diacylglycerol (DAG). $\mathrm{IP}_{3}$ binds to receptors in the endoplasmic reticulum resulting in release of $\mathrm{Ca}^{2+}$ into the cytosol; ${ }^{30,31}$ this $\mathrm{Ca}^{2+}$ store depletion then triggers influx of extracellular $\mathrm{Ca}^{2+}$ into the cell. ${ }^{31}$ Together, this results in a series of transient $\left[\mathrm{Ca}^{2+}\right]$, increases (spikes) 
occurring with irregular frequency and amplitude, but in some cases (i.e. when stimulated by collagen or high doses of thrombin) a prolonged rise in $\left[\mathrm{Ca}^{2+}\right]_{i}$ is seen. ${ }^{31}$ DAG is the main activator of protein kinase $\mathrm{C}$ (PKC) isoforms, which phosphorylate many effector molecules in platelets. Activated PKC and elevated $\left[\mathrm{Ca}^{2+}\right]_{i}$ synergistically cause secretion of granule contents and activation of cytosolic phospholipase $\mathrm{A}_{2} \cdot{ }^{30}$ The rise in $\left[\mathrm{Ca}^{2+}\right]_{\mathrm{i}}$ is also involved in full $\alpha$ Ilb $\beta 3$ activation and subsequent aggregation, and in myosin light chain kinase dependent shape change. ${ }^{30,31}$ In addition, increased $\left[\mathrm{Ca}^{2+}\right]_{\mathrm{i}}$ is necessary to activate phospholipid scramblase, the enzyme that is thought to be responsible for the procoagulant response. ${ }^{25,32,33}$

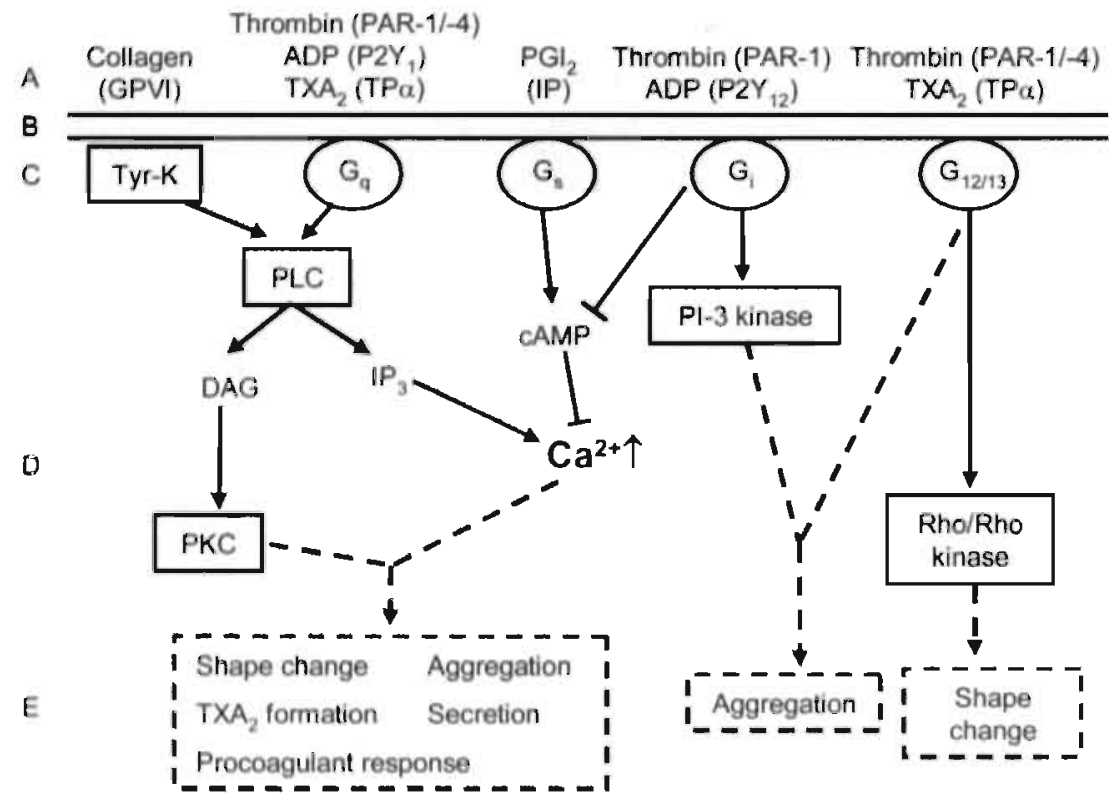

Figure 2.3. Schematic overview of signaling pathways in platelets. Agonists bound to extraceilular receptors (A: receptors in brackets) embedded in the platelet plasma membrane (B) can activate G-proteins (C); collagen binding to GPVI (A) specifically activates tyrosine kinases (C). This leads to the activation of several intracellular effector proteins and the formation of second messengers (D); $\mathrm{Ca}^{2+}$ is of central importance. Depending on the extracellular stimulus, intracelhalar signaling results in various platelet responses $(\mathbf{E})$. The signaling pathway of the platelet antagonist $\mathrm{PGI}_{2}$ is also shown. Solid arrows $=$ activation/formation; $\perp=$ inhibition; dashed arrows $=$ result. Tyr $-\mathrm{K}=$ tyrosine kinase; PLC $=$ phospholipase $\mathrm{C}: \mathrm{DAG}=$ diacylglycerol; $\mathrm{IP}_{3}=$ inositol triphosphate; $\mathrm{PI}-3=$ phosphoinositide $-3 ;$ PKC $=$ protein kinase $\mathrm{C}$.

The PLC/Ca ${ }^{2+}$ pathway is iriggered by collagen via the GPVI receptor through a cascade. of protein tyrosine phosphorylation reactions, ${ }^{34}$ and by receptors coupled to $\mathrm{G}_{\mathrm{q}}$ (PAR-1, PAR-4, P2 $\mathrm{Y}_{1}$. TP $\alpha$; Figure 2.3), ${ }^{31} \mathrm{G}_{\mathrm{q}}$ is a member of the family of heterotrimeric GTP-binding (G-). proteins that mediate interaction of cell surface receptors with intracellular effector molecules, several types of which are expressed on platelets. ${ }^{35}$ The importance of the $\mathrm{G}_{\mathrm{q}}$ pathway is demonstrated by the fact that $\mathrm{G}_{\mathrm{q}}$-deficient platelets show severely impaired responses to 
thrombin, ADP, and the TXA 2 analogue U46619. ${ }^{36}$ However, these platelets are still able to change their shape in response to thrombin and U46619. This $\left[\mathrm{Ca}^{2+}\right]_{\text {-independent shape change }}$ is attributed to another $\mathrm{G}$-protein pathway involving $\mathrm{G}_{12 / 3}$, which activates a Rho/Rho-kinase dependent mechanism after binding of thrombin or $\mathrm{TXA}_{2}$ to their receptors (Figure 2.3). ${ }^{34,37} \mathrm{~A}$ recent study with $\mathrm{G}_{12^{-}}$and $\mathrm{G}_{13}$-deficient mice has shown that $\mathrm{G}_{13}$ is mainly responsible for the $\mathrm{G}_{1213}$-mediated effects in platelets. ${ }^{38} A$ third pathway involves $G_{i}$, which is activated by thrombin (PAR-1), ADP (P2Y $\left.\mathrm{Y}_{12}\right)$, and possibly $T X A_{2}(\mathrm{TP} \beta)$, and mediates blockade of adenylate cyclase. ${ }^{21,39}$ This reduces inhibitory cyclic adenosine monophosphate (cAMP) levels in platelets. However, the effect on adenylate cyclase does not account for the essential role of $\mathrm{G}_{\mathrm{i}}$ in platelet activation; ${ }^{40} \mathrm{G}_{i}$-mediated platelet responses are probably achieved via activating the phosphoinositide 3 (PI-3) kinase pathway, which is involved in weak integrin $\alpha$ Ilb $\beta 3$ activation and potentiation of secretion. ${ }^{41.42}$ It has been shown that stimulation of two of the three pathways $\left(G_{4}, G_{1}, G_{12 / 3}\right)$ is sufficient to achieve some degree of platelet aggregation and activation. ${ }^{23,43,44}$ However, the three pathways are tightly connected and are all important for in vivo platelet responses in mice ${ }^{36,38}$ as well as in humans. ${ }^{45,46}$

Some platelet antagonists also bind to G-protein coupled receptors. For example, prostacyclin $\left(\mathrm{PGl}_{2}\right)$ binds to its IP receptor coupled to $\mathrm{G}_{5}$, which increases cyclic adenosine monophosphate (cAMP) levels in platelets, thereby suppressing the $\left[\mathrm{Ca}^{2+}\right]$, signal (Figure 2.3). ${ }^{30,31,40}$ The effects of nitric oxide (NO), another important platelet inhibitor, are not Gprotein mediated; instead, NO diffuses through the platelet membrane and increases cyclic guanidine monophosphate (cGMP) levels. ${ }^{47}$ cGMP can inhibit platelet functions through several mechanisms, ${ }^{47}$ including the downregulation of $\mathrm{Ca}^{2+}$ mobilization. ${ }^{48,49}$

\subsection{Coagulation}

\section{The coagulation cascade}

The platelet plug covering a site of vessel wall injury is stabilized by a fibrin network. This network is the endpoint of a complex cascade of enzymatic reactions in which coagulation factors, present in plasma as inactive proteins, are activated upon proteolytic cleavage (Figure 2.4). This so-called coagulation cascade results in the formation of thrombin. Besides acting as a platelet agonist, thrombin can proteolytically cleave fibrinogen -present in the platelet plug as crosslink between platelets- to fibrin. Thrombin formation is mainly achieved by the extrinsic pathway, which is initiated by tissue factor (TF) derived from the damaged vessel wall, leukocytes, or platelets. ${ }^{11,50}$ TF binds activated factor VII (activated state is indicated by adding the letter 'a' as a suffix, i.e. VIIa) or inactive factor VII which is then rapidly activated by

several proteases. ${ }^{51,52}$ TF-bound factor VIla cleaves factors IX and X (the latter being the more 
efficient substrate) to their active forms: IXa and Xa. Factor IXa associates with factor VIIIa into the intrinsic tenase complex, which also activates factor $\mathrm{X}$ to $\mathrm{Xa}$. Factor $\mathrm{Xa}$ in turn associates with factor $\mathrm{Va}$ into the prothrombinase complex, which rapidly cleaves prothrombin (factor II) to its active form, thrombin (IIa). ${ }^{33.51,52}$ The formation and activity of both the tenase and the prothrombinase complex are strongly dependent on the presence of a procoagulant platelet membrane (see below). ${ }^{25,33,51,52}$ When TF activity is low (e.g. due to inhibition by tissue factor pathway inhibitor; TFPI), factor IXa formation can be maintained by factor XIa, which is activated by thrombin and bound to the platelet membrane. ${ }^{52.53}$ This so-called intrinsic coagulation pathway can also be initiated by the contact activation system (consisting of proteases factor XII, prekallikrein, and high molecular weight kininogen) on negatively charged surfaces, e.g. in tubes (Figure 2.4). . $^{51-53}$

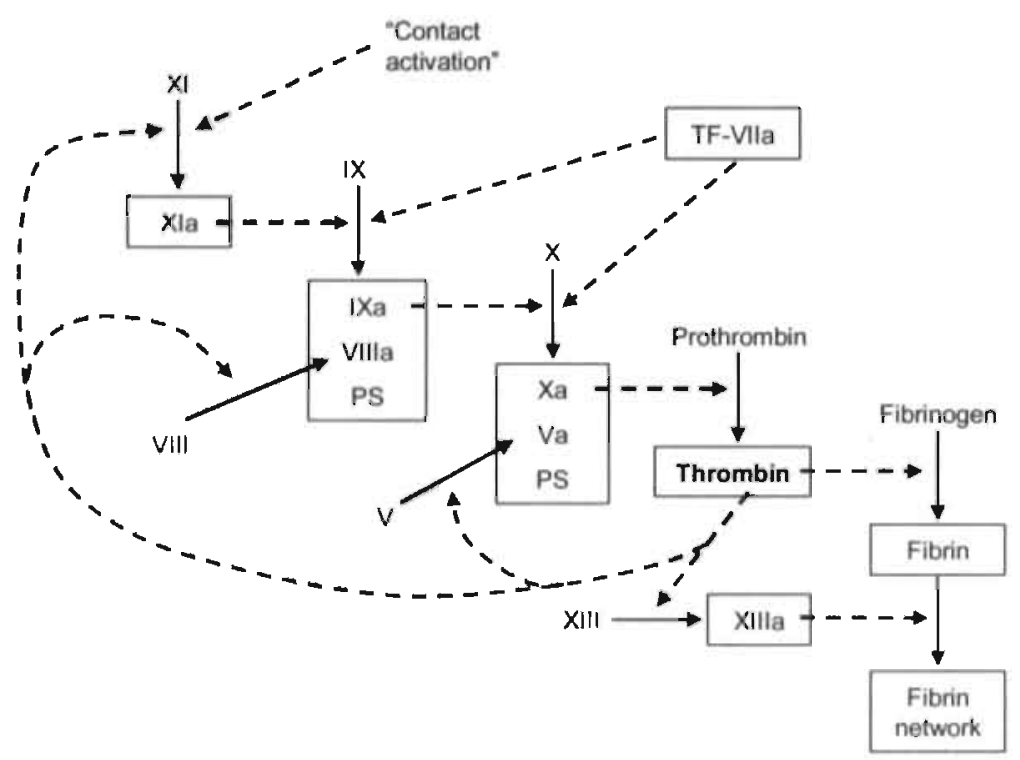

Figure 2.4. The coagulation cascade. Coagulation leads to the formation of a fibrin network, and is achieved by a series. of enzymatic reactions in which inactive coagulation factors (in roman numerals) are protealytically cleaved (solid arrows) to their active forms (indicated by suffix ' $a$ '); activation is catalyzed by another protein in the cascade (dashed arrows). Formation, of facior Xa can be achieved by the TF-VIIa ('extrinsic tenase') complex, or by the intrinsic tenase complex consisting of factors IXa, VIIls, and X, together with procoagulant phospholipids (PS) at the surface of activated platelets. Similarly, the prothrombinase complex, which catalyses thrombin formation, is composed of factors $\mathrm{Xa}, \mathrm{Va}$, prothrombin, and PS. Thrombin converts fibrinogen to fibrin and stimulates the formation of factors XIIIa, Va, VIIIa, and Xla. Anticoagulant pathways are not indicated.

Thrombin is the key regulating enzyme in the coagulation cascade. Once small traces of thrombin (insufficient to cleave fibrinogen to fibrin) are formed, thrombin potently amplifies its own production via several positive feedback mechanisms: by cleaving coagulation factors $\mathrm{V}$, $\mathrm{VIII}$, and XI, and by activating platelets resulting in secretion of factor $\mathrm{V}$ from $\alpha$-granules. ${ }^{51-53}$ 
Thrombin also cleaves factor XIII to XIIla, which is responsible for crosslinking fibrin monomers into a network (Figure 2.4). ${ }^{54}$ Besides acting as a procoagulant feedback activator, thrombin is also an effective feedback anticoagulant: associated with thrombomodulin, expressed on the surface of endothelial cells, thrombin is unable to cleave fibrinogen or to activate platelets. Instead, it cleaves protein $\mathrm{C}$ to activated protein $\mathrm{C}$, which downregulates coagulation by binding and inactivating factors $\mathrm{Va}$ and $\mathrm{VIIIa}{ }^{52.55}$

The general mechanism of coagulation is well conserved across species, and despite some structural differences, rabbit coagulation factors exhibit a high degree of similarity with human factors. ${ }^{56.37}$ This is supported by the findings that factor $\mathrm{Xa}$ inhibitors have similar binding affinities for rabbit and human $\mathrm{Xa},{ }^{57,58}$ and that rabbits respond well to anticoagulants designed for treatment of thrombosis in patients (for example, see references 58-61). ${ }^{58-61}$

\section{Interactions between coagulation and platelet activation}

Platelet activation and blood coagulation are mutually dependent processes. Products of the coagulation cascade canı stimulate platelets (thrombin), and stabilize the platelet plug (fibrin), In turn, coagulation strongly depends on activated platelets: by binding coagulation factors to their membrane, platelets provide a catalytic surface composed of procoagulant phospholipids that greatly enhances the speed of coagulation reactions and restricts coagulation activity to areas of injury. In addition, microvesicles shed from activated platelets also expose procoagulant phospholipids and promote coagulation. ${ }^{33}$

Several coagulation factors (i.e. vitamin K-dependent factors, including factors IX and X) can bind to activated platelets via phospholipids that become exposed at the platelet surface during the procoagulant response. In resting platelets, phospholipids are distributed asymmetrically within the plasma membrane, the outer leaflet containing mostly cholinephospholipids, whereas the inner leaflet is occupied by the aminophospholipids phosphatidylserine (PS) and phosphatidylethanolamine (PE). This asymmetry is maintained by an aminophospholipid translocase. ${ }^{25}$ Upon platelet activation, an increase in $\left[\mathrm{Ca}^{2+}\right]$, occurs which inhibits this enzyme and activates phospholipid scramblase, resulting in the appearance of PS and PE on the outer surface of the platelet. ${ }^{25.32}$ This procoagulant response requires a prolonged rise in $\left[\mathrm{Ca}^{2+}\right]_{1}$, which can be mediated by collagen or by high doses of thrombin; secreted ADP is known to potentiate the response. ${ }^{33,62}$ Exposure of PS on the platelet membrane strongly accelerates two important reactions in the coagulation cascade. Factor $\mathrm{X}$ activation requires a procoagulant membrane for assembly with factors IXa and VIIIa into the tenase complex and. similarly, prothrombinase assembly ( $\mathrm{Va}, \mathrm{Xa}$, and prothrombin) and thrombin formation are very much enhanced by procoagulant phospholipids. ${ }^{33}$

Platelets also contain non-lipid binding sites for coagulation proteins: integrin $\alpha \mathrm{llb} \beta 3$, for example, was shown to bind prothrombin, ${ }^{63}$ and the vWF receptor complex GPIb-V-IX can bind 
factor XI. ${ }^{64}$ In addition, platelets contain an intracellular pool of TF that becomes available on the platelet surface after stimulation ${ }^{11,12}$ and may facilitate TF-VIIa mediated reactions in the coagulation cascade. Furthermore, activated platelets support coagulation by releasing factor $\mathrm{V}^{51}$ and possibly also factor $\mathrm{XI} .^{53}$

\subsection{Endothelium}

Along the entire vascular system, the luminal side of the vessel wall is covered by a single layer of endothelial cells. Endothelium has long been considered a passive barrier between blood and surrounding tissue, but is currently known as an organ with important functions in several biological processes (see Cines et al., 1998 for extensive review). ${ }^{2}$ Endothelial cells throughout the vascular system have quite diverse properties, depending on their local function. This heterogeneity is not only displayed between different organs, but also between large and small vessels and between the arteriall and venous side within an organ. ${ }^{65}$ Moreover, even endothelial cells within the same vessel may display functional differences. ${ }^{66}$ The difference between arteriolar and venular endothelium is illustrated by the finding that a thromboembolic reaction after wall puncture continues about 4-6 times longer in arterioles than in venules. ${ }^{67}$ This finding cannot be explained by different fluid dynamic conditions in these vessel types, ${ }^{68}$ or by differences in blood gas or $\mathrm{pH}$ values, ${ }^{69}$ but has been shown to result from different endothelial properties. ${ }^{70-72}$

\section{Antithrombotic properties of the endothelium}

Healthy vascular endothelium exhibits antithrombotic properties that prevent platelet adhesion and coagulation, as well as fibrinolytic activity that destabilizes thrombi (Table 2.1). Anti-platelet properties include release of platelet activation-inhibiting substances $\mathrm{NO}, \mathrm{PGI}_{2}$, and matrix metalloproteinase 9 (MMP-9), as weil as expression of ecto-ADPase (CD39), NO and $\mathrm{PGI}_{2}$ inhibit platelet activation by increasing intraplatelet cGMP and cAMP levels, respectively, which downregulate platelet responses. ${ }^{2,49,55,72} \mathrm{MMP}-9$ has been shown to reduce platelet aggregation via an as yet unidentified mechanism. ${ }^{73}$ The platelet-inhibiting properties of CD39 are based on metabolization of ADP, released from activated platelets, to adenosine monophosphate (AMP), which reduces platelet recruitment. ${ }^{74}$ In addition, negatively charged heparan sulfate molecules at the luminal side of endothelial cells directly prevent platelet adhesion. $^{75}$

Endothelium also expresses anticoagulant properties to limit thrombin formation, e.g. production of heparan sulfate and other glycosaminoglycans that promote antithrombin (AT) activity, release of TFPI, and expression of thrombomodulin. AT is able to deactivate both 
thrombin and factor $\mathrm{Xa}$, while TFPI inhibits the effects of the TF-VIla complex and of factor $\mathrm{Xa}^{2.855,75}$ Thrombomodulin downregulates thrombin activity and is involved in protein $\mathrm{C}$ activation. ${ }^{28.55,75}$ The anticoagulant activity of activated protein $\mathrm{C}$ is enhanced by its cofactor protein $\mathrm{S}$, which is also released by endothelial cells. ${ }^{2.55,75}$

In addition, the endothelium can stimulate fibrinolysis by producing the plasminogen activating enzymes tissue-type plasminogen activator (t-PA) and urokinase-type plasminogen activator (u-PA). These enzymes convert plasminogen to plasmin, which degrades fibrin resulting in lysis of the thrombus. ${ }^{2.55,75}$

Table 2.1. Principal antithrombotic and prothrombotic properties of vascular endothelium.

\begin{tabular}{lcc}
\hline Target & Antithrombotic properties & Prothrombotic properties \\
\hline Platelets & NO & ADP \\
MMP-9 & vWF & MMP-2 \\
CD39 (NTPDase1) & fibrinogen \\
heparan sulfate & TFPI & TF \\
thrombomodulin & binding sites for: \\
pibrinolysis & t-PA & factot IX(a), X(a), fibrin \\
& u-PA & PAI- I \\
\hline
\end{tabular}

ADP $=$ adenosine diphosphate; MMP $=$ matrix metalloproteinase; NO $=$ nitric oxide; NTPDase $=$ nucleoside triphosphate diphosphohydrolase; PAI $=$ plasminogen activator inhibitor; $\mathrm{PGI}_{2}=$ prostacyclin; TAFI = thrombin activatable fibrinolysis inhibitor; $\mathrm{TF}$ tissue factor; TFPI = tissue factor pathway inhibitor; t-PA $=$ tissue-type plasminogen activator; $\mathrm{u}-\mathrm{PA}=$ urokinase plasminogen activator; $\mathrm{vWF}=$ von Willebrand factor.

\section{Prothrombotic properties of the endothelium}

When the endothelium is disrupted, e.g. at a site of vessel wall injury, damaged and/or activated cells surrounding the site of injury rapidly create a prothrombotic environment that supports adhesion of platelets and formation of a hemostatic plug (Table 2.1). Such endotheliai prothrombotic mechanisms include release of platelet-stimulating agents such as ADP, vWF, MMP-2, and fibrinogen, and procoagulant properties like expression of $\mathrm{TF}$ and creation of binding sites for several coagulation proteins. ${ }^{2,73,75}$ In addition, fibrinolysis is inhibited by production of plasminogen activator inhibitor 1 (PAI-1), which opposes t-PA activity, and thrombin activatable fibrinolysis inhibitor (TAFI) ${ }^{2.55 .75}$ 
This endothelial transformation is usually temporary; the endothelium regenerates to its antithrombotic state when the prothrombotic stimulus has dissipated. ${ }^{2}$ However, disregulation of the balance between endothelial prothrombotic and antithrombotic properties can be an important step in the development of vascular disease. ${ }^{75}$

\subsection{Platelet-vessel wall interactions in vivo}

Initial contact of platelets to an area of vascular injury occurs through adhesion to the subendothelial surface, of which collagen is considered the most thrombogenic component. In high flow conditions, as in arterioles, platelets first tether and slowly translocate along the vessel wall, by interacting with immobilized vWF. ${ }^{16,17}$ Recently, it was shown in vivo that interaction with collagen via the GPVI receptor is also involved in tethering and, hence, recruitment of platelets to a damaged vessel wall. ${ }^{13}$ After firm adhesion, platelets empty their secretory granules and become procoagulant. As a result, several platelet-stimulating substances are released and thrombin can be formed at the platelet surface. Altogether, this leads to recruitment and activation of more platelets and formation of a thrombus (Figure 2.2), which is stabilized by fibrin.

Thrombin plays a dual role in thromboembolism in vivo, by converting fibrinogen to fibrin and by acting as a platelet agonist. Its activity has been detected in human blood in vitro and in experimental murine thrombi in vivo. ${ }^{76}$ Mice deficient of platelet thrombin receptors PAR-3 or PAR-4 exhibit increased bleeding times and appear more resistant to thrombosis than their wildtype controls. ${ }^{77,78}$ Because of the pivotal role of thrombin in platelet activation and coagulation, many strategies to inhibit thromboembolism aim at blocking thrombin generation or inhibiting its activity. ${ }^{79}$ However, its relative contribution to thrombus formation and embolization in vivo is still incompletely understood and is investigated in the study described in chapter 6 of this thesis.

Tissue factor (TF), the initial activator of coagulation, and fibrin have been demonstrated to be present in a thrombus in vivo; both initially appear at the interface with the vessel wall and subsequently spread throughout the thrombus. ${ }^{80} \mathrm{TF}$ at the thrombus-vessel wall interface is probably derived from damaged and/or activated endothelial cells. ${ }^{80}$ TF that is not directly associated with the vessel wall may be derived from P-selectin mediated capture of TF-bearing microparticles from circulating leukocytes, ${ }^{81}$ or may be released from activated platelets. ${ }^{11,12}$ Interestingly, although both fibrin and TF spread throughout the thrombus, the downstream end of the thrombus remains clear of these factors. ${ }^{80}$ Thus, coagulation does not seem to occur on the side of the thrombus where emboli are shed, which may explain the relatively unstable character of emboli compared to thrombi (see chapter 3 ). ${ }^{82}$ 
Soluble agonists released by activated platelets, like serotonin, CD40 ligand (CD40L), Gas6, TXA 2, and ADP can play an important role in thromboembolism, i.e. in the recruitment of platelets into a growing thrombus, in thrombus stabilization, and in the subsequent formation of emboli. Serotonin, a weak platelet agonist by itself, can potentiate $\mathrm{G}_{\mathrm{q}}$-mediated platelet responses evoked by other agonists, ${ }^{23}$ but its role in thromboembolic processes in vivo is not well known. CD40L and Gas6, on the other hand, have been shown to be involved in plateletvessel wall interactions in vivo, since mice deficient of Gas6 produce smaller thrombi, ${ }^{83}$ while CD40L knockout mice exhibit reduced thrombus stability. ${ }^{84} \mathrm{TXA}_{2}$ also plays an important role in thromboembolism in vivo. $\mathrm{TXA}_{2}$ is metabolized from arachidonic acid upon platelet activation, which requires activity of the COX enzyme. Aspirin (acetylsalicylic acid) effectively blocks this enzyme, and is successfully used in primary and secondary prevention of myocardial and cerebrovascular ischemia in patients. ${ }^{85}$ However, aspirin can only be used in relatively low doses, because high doses will also block the COX-dependent production of platelet-inhibiting prostaglandins like $\mathrm{PGI}_{2}$ by endothelial cells. ${ }^{70.85}$ Therefore, other anti-thromboxane agents are being investigated as well. ${ }^{86}$ Specific blockade of $\mathrm{TXA}_{2}$ receptors in vivo has been found to reduce the shedding of -potentially hazardous- emboli from a thrombus, without influencing the effectiveness of the thrombus to stop bleeding. ${ }^{70}$ This may explain the beneficial effect of TXA inhibition in patients.

Although ADP is considered a weak agonist by itself, it is an important prothrombotic factor, because it amplifies responses to other platelet agonists. ${ }^{87}$ The crucial role of ADP in thromboembolism in vivo is illustrated by the fact that one of the two ADP receptors, the recently cloned $\mathrm{P} 2 \mathrm{Y}_{12}$, is the target of the antithrombotic drugs clopidogrel and ticlopidine. ${ }^{88,89}$ In addition, patients with a defect in this receptor were described to have a mild bleeding disorder. $^{90,9 !}$ Unlike $\mathrm{P}_{2} \mathrm{Y}_{12}$, which is only expressed on platelets, the P2Y, receptor for ADP is also present on other vascular cell types. ${ }^{92}$ Nevertheless, $\mathrm{P} 2 \mathrm{Y}$, is also considered a potential target for antithrombotic drugs. ${ }^{93}$ Mice deficient of either receptor exhibit increased bleeding times, their platelets are less responsive to ADP and collagen in vitro, and thrombus formation in vivo is reduced. ${ }^{94-97}$ However, the precise role of ADP and its two receptors in a dynamic thromboembolic process is not yet clear and is investigated in chapters 4 and 5 of this thesis.

A thromboembolic process is inhibited when the influence of local antithrombotic faciors prevails over the effects of prothrombotic factors. The endothelium has proven to play an important role in this respect. For example, the negatively charged heparan sulfate present in the endothelial cell glycocalyx prevents platelet adhesion.. ${ }^{75}$ When the glycocalyx is disrupted, platelet adhesion in vivo is increased. ${ }^{98}$ In addition, CD39 (NTPDasel), the endothelial enzyme that metabolizes ADP, exerts a protective role in preventing ischemic brain damage in a mouse model of stroke. Mice lacking a functional CD39 enzyme exhibit decreased cerebral blood flow 
and increased infarct volumes, whereas opposite effects are seen in mice treated with a soluble form of $\mathrm{CD} 39 .{ }^{99} \mathrm{NO}$ and prostacyclin $\left(\mathrm{PGI}_{2}\right)$ have been shown to be important as well. In arterioles, a thromboembolic process is mainly inhibited by $\mathrm{PGI}_{2},{ }^{70}$ whereas in venules $\mathrm{NO}$ is the dominant antithrombotic mediator. ${ }^{71}$ Simultaneous inhibition of both the $\mathrm{PGI}_{2}$ and the NO pathway leads to synergistic prolongation of embolization, but only in arterioles. ${ }^{72}$ The antithrombotic role of $\mathrm{PGI}_{2}$ is also demonstrated by the finding that mice deficient of the prostacyclin receptor (IP) exhibit increased susceptibility to thrombosis. ${ }^{100}$

The forces exerted by flowing blood, i.e. wail shear stress, also influence platelet-vessel wall interactions in vivo. On the one hand, wall shear stress is known to activate platelets, ${ }^{10,102}$ but on the other it stimulates production of $\mathrm{PGI}_{2}$ and $\mathrm{NO}$ by the endothelium. Normally, no significant relation exists between wall shear rate (a measure of wall shear stress) and a thromboembolic reaction in arterioles and venules in vivo. ${ }^{67,68}$ However, when $\mathrm{PGI}_{2}$ and $\mathrm{NO}$ synthesis are inhibited, increases in shear rate enhance embolus production, indicating that in control conditions these substances counteract wall shear rate-induced platelet activation in vivo. $^{72}$

\subsection{Methods to induce platelet-vessel wall interactions}

Much knowledge on platelets has been gained from in vitro studies using blood, plateletrich plasma, or isolated platelets from healthy human subjects, patients, or animals in static conditions. These studies have yielded specific information on platelet function, but the results may not be representative of the in vivo situation because isolation of platelets from their environment can change their behavior. ${ }^{103}$ The important interaction of platelets with flowing blood $^{72,101,102}$ can be simulated in flow chambers, where blood is perfused along an adhesive surface (e.g. collagen, vWF, fibrinogen). Hence, platelet activation and thrombus formation can be quantified under controlled flow conditions. ${ }^{104,105}$ Still a functional endothelium, with its is pro- and antithrombotic properties that can influence platelet behavior, ${ }^{2,70-72,106}$ is missing. Furthermore, the collection of blood for in vitro investigations alters the responsiveness of platelets and plasma coagulation proteins due to use of platelet inhibitors and anticoagulants. ${ }^{107}$ Therefore, it is important that platelet-vessel wall interactions are also studied in vivo, where cells are in their natural environment.

\section{In vivo induction of platelet-vessel wall interactions}

Thromboembolism and platelet-vessel wall interactions in vivo are investigated using various animal models, either without damaging the vessel wall (e.g. through infusion of tissue 
factor $^{105}$ or a mixture of collagen and adrenaline ${ }^{95}$ or by topical application of ADP ${ }^{109}$ or thrombin ${ }^{110}$ ), or by inflicting vessel wall damage. Vascular injury can be inflicted in various ways (for review see e.g. Dörffler-Melly et al., 2000), ${ }^{\prime \prime \prime}$ e.g. by ferric chloride $\left(\mathrm{FeCl}_{3}\right.$ ) superfusion, ${ }^{13,19,96,112}$ with photochemical techniques, ${ }^{113,114}$ by laser light, ${ }^{80,114}$ or by causing mechanical damage. Mechanical damage can be induced by e.g. transection of vessels, ${ }^{115}$ temporary vessel ligation, ${ }^{13}$ wire-induced endothelial disruption, ${ }^{13}$ balloon catheter injury, ${ }^{110}$ pinching. ${ }^{116}$ or vessel wall puncture. ${ }^{67}$ In the present thesis, platelet-vessel wall interactions are induced mechanically by puncture of rabbit mesenteric microvessels with small micropipettes, which results in a thromboembolic reaction (Figure 2.5 ). ${ }^{67}$ With this approach, all vessel wall layers are damaged, yet little tissue trauma is induced because the damage is localized to the puncture site. In addition, since no chemical substances are used, vessel wall damage is the only stimulus for platelet-vessel wall interactions. While these arguments also hold for direct laserinduced injury, the laser light may cause hemolysis of erythrocytes with subsequent release of ADP, ${ }^{117}$ which could interfere with the thromboembolic process. In addition, laser light does probably not denude the endothelium ${ }^{114}$ and platelet-vessel wall interactions may not be caused by the exposure of subendothelial structures, as is the case with wall puncture.

\section{The thromboembolic reaction after wall puncture}

The thromboembolic reaction as a model to study platelet-vessel wall interactions in vivo. was first described by oude Egbrink et al. in $1988 .^{67}$ The wall of arterioles and venules (diameter $20-40 \mu \mathrm{m}$ ) of the rabbit mesentery is punctured with a glass micropipette (tip diameter 6-8 $\mu \mathrm{m}$ ), and the subsequent thromboembolic reaction is visualized with an intravital microscope. Rabbit mesentery is a well vascularized, transparent, and easily accessible tissue, which allows visualization of thrombus formation and embolization without fluorescent labeling; fiuorescently labeled platelets can be used to study the behavior of individual platelets during the thromboembolic reaction (Figure 2.5). Local fluid dynamic parameters can easily be assessed, and systemic parameters like blood pressure and heart rate can continuously be monitored. In addition, the rabbit mesenteric microcirculation is not vasoactive; thus, the thromboembolic reaction is not influenced by fluid dynamic changes caused by puncture or by superfusion of vasoactive substances." Finally, blood samples for ex vivo platelet function tests can be collected repeatedly from the easily accessible rabbit ear artery.

This model allows real-time imaging of platelet-vessel wall interactions, with separate quantification of thrombus formation and embolization (Figure 2.5): $;^{67}$ frequency and duration of rebleedings can be considered a measure of thrombus stability. ${ }^{115}$ In addition, intracellular processes in participating platelets can be studied with the use of fluorescent probes (Figures 2.5 and 2.6; see chapter 3 ). 


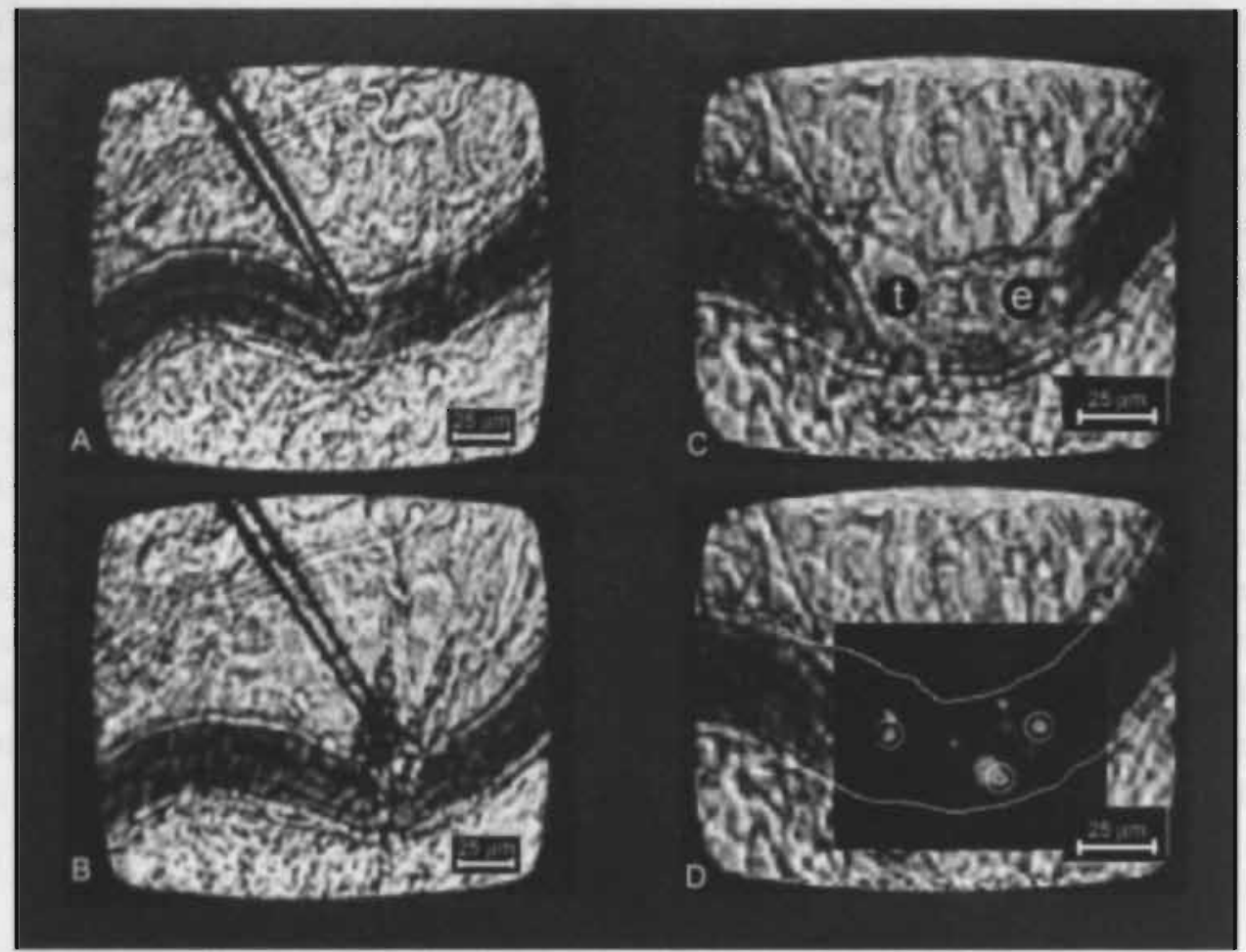

Figure 2.5. Thromboembolic reaction following vessel wall injury. A rabbit mesenteric arteriole (blood flow from left to right) is punctured with a glass micropipette (A), which leads to extravasation of red blood cells (B). Bleeding is stopped by the formation of a thrombus (t), which repeatedly sheds emboli (e) at its downstream side (C). The insert in (D) shows fluorescently labeled platelets participating in this thromboembolic reaction; in some platelets (circles) changes in fluorescence intensity, representing changes in cytosolic free $\mathrm{Ca}^{2 *}$ concentration, can be measured. Images were recorded using an intravital microscope, appropriate filters, and a CCD camera (see Figure 2.6).

\subsection{References}

1. Tangelder GJ, Teirlinck HC, Slaaf DW, and Reneman RS. Distribution of blood platelets flowing in arterioles. Am J Physiol. 1985;248:H318-H323.

2. Cines DB, Pollak ES, Buck CA, Loscalzo J, Zimmerman GA, McEver RP, Pober JS, Wick TM, Konkle BA, Schwartz BS, Barnathan ES, MeCrae KR, Hug BA, Schmidt AM, and Stern DM. Endothelial cells in physiology and in the pathophysiology of vascular disorders. Blood. 1998:91:3527-3561.

3. Tangelder GJ, oude Egbrink MGA, Slaaf DW, and Reneman RS. Blood platelets: an overview. $J$ Reconstr Microsurg. 1989;5:167-171. 


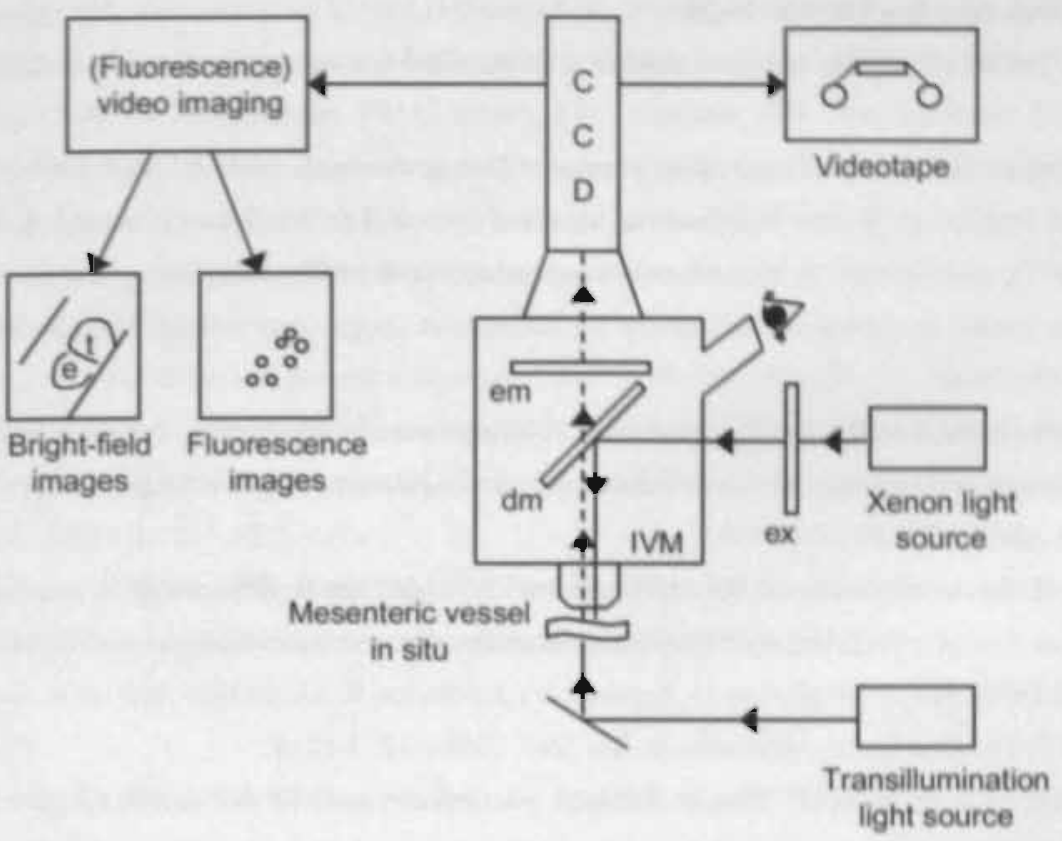

Figure 2.6. Schematic drawing of the experimental setup used in chapters 3.5 of this thesis. Puncture of rabbit mesenteric vessels was performed under transillumination by a tungsten lamp. Fluorescence microscopy was performed under incident illumination with a Xenon light source. Xenon light passed an excitation filter (ex; 485 nm band-pass). and reached the objective via a $510 \mathrm{~nm}$ dichroic mirror (dm). Emission light passed the dichroic mirror and an emission filter (em; $515 \mathrm{~nm}$ long-pass), both of which were mounted in the Ploemopak of the intravital microscope (IVM). Images were projected on an intensified CCD camera, and captured with a digital fluorescence video imaging system. This system was also used to capture bright-field images, $t=$ thrombus; $e=$ embolus.

4. Cramer EM. Platelets and megakaryocytes: anatomy and structural organization. In: Colman RW, Hirsh J, Marder VJ. Clowes AW, and George JN, eds. Hemostasis and thrombosis: basic principles and clinical practice. $4^{\text {th }}$ ed. Philadelphia: Lippincott Williams \& Wilkins; 2001:411-428.

5. Packham MA, Rand ML, and Kinlough Rathbone RL. Similarities and differences between rabbit and human platelet characteristics and functions. Comp Biochem Physiol Comp Physiol, 1992;103:35-54.

6. Kuenen BC, Levi M, Meijers JCM, van Hinsbergh VWM, Berkhof J, Kakkar AK, Hoekman K, and Pinedo HM. Potential role of platelets in endothelial damage observed during treatment with cisplatin, gemcitabine, and the angiogenesis inhibitor SU5416. J Clin Oncol. 2003;21:2192-2198.

7. McEver RP. Adhesive interactions of leukocytes, platelets, and the vessel wall during hemostasis and inflammation. Thromb Haemost. 2001;86:746-756. 
8. Levi M, Keller TT, van Gorp E, and ten Cate H. Infection and inflammation and the coagulation system. Cardiovasc Res, 2003;60:26-39.

9. Nash GF, Turner LF, Scully MF, and Kakkar AK. Platelets and cancer. Lancet Oncol. 2002;3:425430 .

10. Hartwig J, and Italiano JJ. The birth of the platelet. J Thromb Haemost. 2003;1:1580-1586.

11. Camera M, Frigerio M, Toschi V, Brambilla M, Rossi F, Cottell D, Maderna P. Parolari A, Bonzi R, De Vicenti $O$, and Tremoli E. Platelet activation induces cell-surface immunoreactive tissue factor expression, which is modulated differently by antiplatelet drugs. Arterioscler Thromb Vasc Biol. 2003;23:1690-1696.

I2. Müller I, Klocke A, Alex M, Kotzsch M, Luther T, Morgenstern E, Zieseniss S, Zahler S, Preissner K, and EngeImann B. Intravascular tissue factor initiates coagulation via circulating microvesicles and platelets. FASEB J. 2003; 17:476-478.

13. Massberg S, Gawaz M, Grüner S, Schulte V, Konrad I, Zohlnhöfer D. Heinzmann U, and Nieswandt. B. A crucial role of glycoprotein VI for platelet recruitment to the injured arterial wall in vivo. J Exp Med. 2003;197:41-49.

14. Ruggeri ZM. Platelets in atherothrombosis. Nat Med. 2002;8:1227-1234.

15. Nieswandt B, and Watson SP. Platelet collagen interaction: is GPVI the central receptor? Blood. $2003 ; 20: 449-461$.

16. Ruggeri ZM. Von Willebrand factor, platelets and endothelial cell interactions. I'Thromb Haemost. 2003:1:1335-1342.

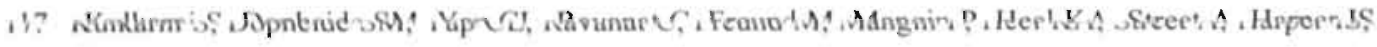
Lanza F, and Jackson SP. A revised model of platelet aggregation. J Clin Invest. 2000:105:783-791.

18. Jackson SP, Nesbiti WS, and Kulkarni S. Signaling events, underlying thrombus formation. J Thromb Haemost. 2003;1:1602-1612.

19. Ni H. Denis CV. Subbarao S, Degen IL. Sato TN, Hynes RO, and Wagner DD. Persistence of platelet thrombus fomation in arterioles of mice lacking both von Willebrand factor and fibrinogen. $J$ Clin Invest. 2000;106:385-392.

20. Ni H, Yuen PST, Papalia JM, Trevithick JE, Sakai T, Fässler R, Hynes RO, and Wagner DD. Plasma fibronectin promotes thrombus. growth and stability in injured arterioles. Proc Natl Acad Sci USA. 2003:100:24I5-2419.

21. Paul BZS, Jin J, and Kunapuli SP. Molecular mechanism of thromboxane $\mathrm{A}_{2}$-induced platelet aggregation. Essential role for $\mathrm{P}^{2} \mathrm{~T}_{\mathrm{AC}}$ and $\alpha_{2 \mathrm{~A}}$ receptors. J. Biol. Chem. 1999;274:29108-29114.

22. Furie B, Furie BC; and Flaumenhaft R. A journey with platelet P-selectin: the molecular basis of granule secretion, signalling and cell adhesion. Thromb Haemost. 2001;86:214-221,

23. Jin J, and Kunapuli SP. Coactivation of two different G protein-coupled receptors is essential for ADP-induced platelet aggregation. Proc Nat Acad Sci USA. 1998:95:8070-8074. 
24. Oury C, Kuijpers MJE, Toth-Zsamboki E, Bonnefoy A, Danloy S, Vreys I, Feijge MAH, de Vos R, Vermylen J, Heemskerk JWM, and Hoylaerts MF. Overexpression of the platelet P2X, ion channel in transgenic mice generates a novel prothrombotic phenotype. Blood. 2003;101:3969-3976.

25. Heemskerk JWM, Siljander PRM, Bevers EM, Farndale RW, and Lindhout T. Receptors and signalling mechanisms in the procoagulant response of platelets. Platelets, 2000;11:301-306.

26. Major CD, Santulli RJ, Derian CK, and Andrade-Gordon P. Extracellular mediators in atherosclerosis and thrombosis: lessons from thrombin receptor knockout mice. Arterioscler Thromb Vasc Biol. 2003;23:931-939.

27. Brass LF. Thrombin and platelet activation. Chest. 2003;124:18S-25S.

28. Ramakrishnan V, DeGuzman F, Bao M, Hall SW, Leung LL, and Phillips DR. A thrombin receptor function for platelet glycoprotein Ib-IX unmasked by cleavage of glycoprotein V. Proc Natl Acad Sci USA. 2001;98:1823-1828.

29. Kinlough Rathbone RL, Rand ML, and Packham MA. Rabbit and rat platelets do not respond to thrombin receptor peptides that activate human platelets. Blood. 1993;82:103-106.

30. Kroll MH, and Schafer Al. Biochemical mechanisms of platelet activation. Blood. 1989;74:1181. 1195.

31. Heemskerk JWM. Calcium and platelets. In: Pochet R, Donato R. Haiech J, Heizmann C, and Gerke $\mathrm{V}$, eds. The molecular basis of calcium action in biology and medicine. Dordrecht: Kluwer Academic Publishers; 2000:45-71.

32. Zwaal RFA, and Schroit AJ. Pathophysiologic implications of membrane phospholipid asymmetry in blood cells. Blood. 1997;89:1 121-1132.

33. Heemskerk JWM, Bevers EM, and Lindhout T. Platelet activation and blood coagulation. Thromb Haemost. 2002;88:186-193.

34. Prevost N, Woulfe D, Tognolini M, and Brass LF. Contact-dependent signaling during the late events of platelet activation. I Thromb Haemost. 2003;1:1613-1627.

35. Brass LF, Manning DR, Cichowski K, and Abrams CS. Signaling through G proteins in platelets: to the integrins and beyond. Thromb Haemost. 1997;78:581-589!

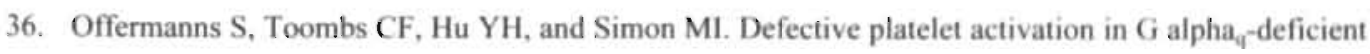
mice. Nature. 1997;389:183-186.

37. Klages B, Brandt U, Simon MI, Schultz G, and Offermanns S. Activation of G12/G13 results in shape change and Rho/Rho-kinase-mediated myosin light chain phosphorylation in mouse platelets. J Cell Biol. 1999;144:745-754.

38. Moers A, Nieswandt B, Massberg S, Wettschureck N, Grüner S, Konrad I, Schulte V, Aktas B, Gratacap MP, Simon MI, Gawaz M, and Offermanns S. $\mathrm{G}_{13}$ is an essential mediator of platelet activation in hemostasis and thrombosis. Nat Med. 2003;9:1418-1422.

39. Jantzen HM. Milstone DS, Gousset L, Conley PB, and Mortensen RM. Impaired activation of murine platelets lacking $\mathrm{G} \alpha_{i 2}$. J Clin Invest. 2001:108:477-483. 
40. Yang J, Wu J, Jiang H, Mortensen R, Austin S, Manning DR, Woulfe D, and Brass LF. Signaling through $\mathrm{G}_{\mathrm{i}}$ Family Members in Platelets. Redundancy and specificity in the regulation of adenylyl cyclase and other effectors. J Biol Chem. 2002;277:46035-46042.

41. Kauffenstein G, Bergmeier W, Eckly A, Ohlmann P, Léon C, Cazenave JP, Nieswandt B, and Gachet C. The $P 2 Y_{12}$ receptor induces platelet aggregation through weak activation of the $\alpha_{1 \mathrm{~b}} \beta_{3}$ integrin - a phosphoinositide 3-kinase-dependent mechanism. FEBS Lett. 2001;505:281-290.

42. Dangelmaier $\mathrm{C}$, Jin J, Smith JB, and Kunapuli SP. Potentiation of thromboxane $\mathrm{A}_{2}$-induced platelet secretion by $\mathrm{Gi}$ signaling through the phosphoinositide-3 kinase pathway. Thromb Haemost. 2001;85:341-348.

43. Dorsam RT, Kim S, Jin J, and Kunapuli SP. Coordinated signaling through both $\mathrm{G}_{12 / 13}$ and $\mathrm{G}_{\mathrm{i}}$ pathways is sufficient to activate GPİlb/IIIa in human platelets. $J$ Biol Chem. 2002;277:47588-47595.

44. Nieswandt B, Schulte V, Zywietz. A, Gratacap MP, and Offermanns S. Costimulation of $\mathrm{G}_{\mathrm{i}^{-}}$and $\mathrm{G}_{12} / \mathrm{G}_{13}$-mediated signaling pathways induces integrin $\alpha_{115} \beta_{3}$ activation in platelets. $J$ Biol Chem. 2002;277:39493-39498.

45. Gabbeta J, Yang X, Kowalska MA, Sun L, Dhanasekaran N, and Rao AK. Platelet signal transduction defect with $\mathrm{G} \alpha$ subunit dysfunction and diminished $\mathrm{G} \alpha_{\mathrm{q}}$ in a patient with abnormal platelet responses. Proc Nall Acad Sci USA. 1997;94:8750-8755.

46. Patel YM, Patel K, Rahman S. Smith MP, Spooner G, Sumathipala R, Mitchell M, Flynn G, Aitken $A$, and Savidge G. Evidence for a role for $\mathrm{G \alpha}_{\mathrm{il}}$, in mediating weak agonist-induced platelet aggregation in human platelets: reduced $\mathrm{G} \alpha_{i 1}$ expression and defective $\mathrm{G}_{i}$ signaling in the platelets of

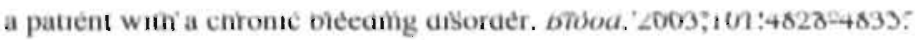

47. Walford G, and Loscalzo J. Nitric oxide in vascular biology. J Thromb Haemost. 2003;1:2112-2118.

48. Geiger J, Nolte C, Butt E, Sage SO, and Walter U. Role of cGMP and cGMP-dependent protein kinase in nitrovasodilator inhibition of agonist-evoked calcium elevation in human platelets. Proc Natl Acad Sci USA. 1992;89:103 I-I035.

49. Heemskerk JWM, Feijge MAH, Sage SO, and Walter U. Indirect regulation of $\mathrm{Ca}^{2+}$ entry by cAMPdependent and cGMP-dependent protein kinases and phospholipase $\mathrm{C}$ in rat platelets. Eur J Biochem. 1994:223:543-551.

50. Rauch U, and Nemerson Y. Tissue factor, the blood, and the arterial wall. Trends Cardiovasc Med. 2000;10:139-143.

51. Monroe DM, Hoffman M, and Roberts HR. Platelets and thrombin generation. Arterioscler Thromb. Vase Biol. 2002;22:1381-1389.

52. Mann KG, Butenas S, and Brummel K. The dynamics of thrombin formation. Arterioscler Thromb Vasc Biol. 2003;23:17-25.

53. Walsh PN. Roles of factor X1, platelets and tissue factor-initiated blood coagulation. $J$ Thromb Haemost. 2003;1:2081-2086. 
54. Lorand L. Sol Sherry lecture in thrombosis: Research on clot stabilization provides clues for improving thrombolytic therapies. Arterioscler Thromb Vasc Biol. 2000:20:2-9.

55. Selwyn AP. Prothrombotic and antithrombotic pathways in acute coronary syndromes. Am J Candiol. 2003;91(suppl):3H-11H.

56. Weinstein RE, Rickles FR, and Walker FJ. Purification and preliminary characterization of rabbit vitamin K-dependent coagulation proteins. Thromb Res. 1990:59:759-772.

57. Edwards S, Betz A, James H, Thompson E, Yonkovich S, and Sinha U. Differences between human and rabbit coagulation factor $\mathrm{X}$-implications for in vivo models of thrombosis. Thromb Res. 2002;106:71-79.

58. Leadley RJ, Jr., Chi L, Rebello SS, and Gagnon A. Contribution of in vivo models of thrombosis to the discovery and development of novel antithrombotic agents. I Pharmacol Toxicol Methods. 2000;43:101-116.

59. Liu J, Paul W, Emerson M, Cicala C, and Page CP. Thrombin inhibitors and anti-coagulants on thrombin-induced embolisation in rabbit cranial vasculature, Eur J Pharmacol, 1994;264:183-190.

60. Klement P, Carlsson S, Rak J, Liao P, Vlasin M, Stafford A, Johnston M, and Weitz J. The benefitto-risk profile of melagatran is superior to that of hirudin in a rabbit arterial thrombosis prevention and bleeding model. J Thromb Haemost. 2003;1:587-594.

61. Abendschein DR, Baum PK, Light DR, and Morser J. Effect of vascular injury on inhibition of venous thrombosis with ZK-807834, a direct inhibitor of factor Xa. J Thromb Haemost. 2003;1:19551958.

62. Heemskerk. JWM, Vuist WMJ, Feijge MAH, Reutelingsperger CPM, and Lindhout T. Collagen but not fibrinogen surfaces induce bleb formation, exposure of phosphatidylserine, and procoagulant activity of adherent platelets: evidence for regulation by protein tyrosine kinase-dependent $\mathrm{Ca}^{2+}$ responses. Blood. 1997; 90:2615-2625.

63. Byzova TV, and Plow EF. Networking in the hemostatic system. Integrin $\alpha_{110} \beta_{3}$ binds prothrombin and influences its activation. $J^{\prime}$ Biol Chem. 1997;272:27183-27188.

64. Baglia FA, Badellino KO, Li CQ, Lopez JA, and Walsh PN. Factor XI binding to the platelet glycoprotein Ib-IX-V complex promotes factor XI activation by thrombin. J Biol Chem. 2002;277:1662-1668.

65. Garlanda C, and Dejana E. Heterogeneity of endothelial cells. Specific markers, Arterioscler Thromb Vasc Biol. 1997;17:1193-1202.

66. Broeders MAW, Doevendans PA, Bekkers BCAM, Bronsaer R, van Gorsel E, Heemskerk JWM, oude Egbrink MGA, van Breda E, Reneman RS, and van der Zee R. Nebivolol: a third-generation $\beta$. blocker that augments vascular nitric oxide release : endothelial $\beta 2$-adrenergic receptor-mediated nitric oxide production. Circulation. 2000;102:677-684.

67. oude Egbrink MGA. Tangelder GJ, Slaaf DW, and Reneman RS. Thromboembolic reaction following wall puncture in arterioles and venules of the rabbit mesentery. Thromb Haemost. 1988:59:23-28. 
68. oude Egbrink MGA, Tangelder GJ, Slaaf DW, and Reneman RS. Fluid dynamics and the thromboembolic reaction in mesenteric arterioles and venules. Am J Physiol. 1991;260:H1826-H1833.

69. oude Egbrink MGA, Tangelder GJ, Slaaf DW, and Reneman RS. Effect of blood gases and pH on thromboembolic reactions in rabbit mesenteric microvessels. Eur J Physiol. 1989;414:324-330.

70. oude Egbrink MGA, Tangelder GJ, Slaaf DW, and Reneman RS. Different roles of prostaglandins in thromboembolic processes in arterioles and venules in vivo. Thromb Haemost. 1993;70:826-833.

71. Broeders MAW, Tangelder GJ, Slaaf DW, Reneman RS, and oude Egbrink MGA. Endogenous nitric oxide protects against thromboembolism in venules but not in arterioles. Arterioscler Thromb Vasc Biol. 1998;18:139-145.

72. Broeders MAW, Tangelder GJ, Slaaf DW, Reneman RS, and oude Egbrink MGA. Endogenous nitric oxide and prostaglandins synergistically counteract thromboembolism in arterioles but not in venules. Arterioscler Thromb Vasc Biol. $2001 ; 21: 163-169$.

73. Fernandez-Patron C, Martinez-Cuesta MA, Salas E, Sawicki G, Wozniak M, Radomski MW, and Davidge ST. Differential regulation of platelet aggregation by matrix metalloproteinases-9 and -2 . Thromb Haemost. 1999;82:1730-1735.

74. Marcus AJ, Broekman MJ, Drosopoulos JHF, Pinsky DJ, Islam N, Gayle RBI, and Maliszewski CR. Thromboregulation by endothelial cells. Arterioscler Thromb Vasc Biol. 2001;21:178-182.

75. van Hinsbergh VWM. The endothelium: vascular control of haemostasis. Eur J Obst Gynecol Reprod Biol. 2001;95:198-201.

76. Jaffer FA, Tung CH, Gerszten RE, and Weissleder R. In vivo imaging of thrombin activity in experimental thrombi with thrombin-sensitive near-infrared molecular probe. Arterioscler Thromb Vasc Biol. 2002;22:1929-1935.

77. Weiss Ei, Hamilton JR, Lease KE, and Coughlin SR. Protection against thrombosis in mice lacking PAR3. Blood. 2002;100:3240-3244.

78. Sambrano GR, Weiss EI. Zheng YW, Huang W, and Coughlin SR. Role of thrombin signalling in piatelets in haemostasis and thrombosis. Nature. 2001:413:74-78.

79. Weitz J. A novel approach to thrombin inhibition. Thromb Res. 2003;109:S17-S22.

80. Falati S, Gross P, Merrill-Skoloff G, Furie BC, and Furie B. Real-time in vivo imaging of platelets, issue factor and fibrin during arterial thrombus formation in the mouse. Nat Med. 2002;8:1175-1181.

81. Falati S, Liu Q. Gross P, Merrill-Skoloff G, Chou J, Vandendries E, Celi A, Croce K, Furie BC, and Furie B. Accumulation of tissue factor into developing thrombi in vivo is dependent upon microparticle P-selectin glycoprotein ligand $I$ and platelet P-selectin. J Exp Med. 2003;197:15851598.

82. van Gestel MA, Heemskerk JWM, Slaaf DW, Heijnen VVT, Sage SO, Reneman RS, and oude Egbrink MGA. Real-time detection of activation patterns in individual platelets during thromboembolism in vivo: differences between thrombus growth and embolus formation. $J$ Vasc Res. 2002:39:534-543. 
83. Angelillo-Scherrer A, de Frutos PG, Aparicio C, Melis E, Savi P, Lupu F, Amout J, Dewerchin M, Hoylaerts M, Herbert JM, Collen D, Dahlbäck B, and Carmeliet P. Deficiency or inhibition of Gas6 causes platelet dysfunction and protects mice against thrombosis. Nat Med. 2001;7:215-221.

84. André P, Prasad KSS, Denis CV, He M, Papalia JM, Hynes RO, Phillips DR, and Wagner DD. CD40L stabilizes arterial thrombi by a $\beta_{3}$ integrin-dependent mechanism. Nat Med. 2002;8:247-252.

85. Mehta P. Aspirin in the prophylaxis of coronary artery disease, Curr Opin Cardiol, 2002;17:552-558.

86. Buccellati C, Ciceri P, Ballerio R, Casagrande C, Folco G, and Nicosia S. Evaluation of the effects of anti-thromboxane agents in platelet-vessel wall interaction. Eur J Pharmacol. 2002;443:133-141.

87. Cattaneo M, and Gachet C. ADP receptors and clinical bleeding disorders. Arteriascler Thromb Vasc Biol. 1999;19:2281-2285.

88. Foster CJ, Prosser DM, Agans JM, Zhai Y, Smith MD, Lachowicz JE, Zhang FL, Gustafson E, Monsma FJ, Jr., Wiekowski MT, Abbondanzo SJ, Cook DN, Bayne ML, Lira SA, and Chintala MS. Molecular identification and characterization of the platelet ADP receptor targeted by thienopyridine antithrombotic drugs. J Clin Invest. 2001;107:1591-1598.

89. Hollopeter G, Jantzen HM, Vincent D, Li G, England L, Ramakrishnan V, Yang RB, Nurden P, Nurden A, Julius D, and Conley PB. Identification of the platelet ADP receptor targeted by antithrombotic drugs. Nature. 2001;409:202-207.

90. Nurden P, Savi P, Heilmann E, Bihour C, Herbert JM, Maffrand JP, and Nurden A. An inherited bleeding disorder linked to a defective interaction between ADP and its receptor on platelets. Its influence on glycoprotein IIb-IIla complex function. J Clin Imvest, 1995:95:16/2-1622.

91. Cattaneo M, Lecchi A, Lombardi R, Gachet C, and Zighetti ML. Platelets from a patient heterozygous for the defect of $\mathrm{P} 2 \mathrm{Crc}_{\mathrm{C}}$ receptors for $\mathrm{ADP}$ have a secretion defect despite normal thromboxane $\mathrm{A}_{2}$ production and normal granule stores - Further evidence that some cases of platelet 'primary secretion defect' are heterozygous for a defect of $\mathrm{P} 2 \mathrm{crc}$ receptors. Arterioscler Thromb Vasc Biol'. 2000;20:E101-E106.

92. Kunapuli SP, and Daniel JL. $P_{2}$ receptor subtypes in the cardiovascular system. Biochem J. 1998;336:513-523.

93. Baurand $\mathrm{A}$, and Gachet $\mathrm{C}$. The $\mathrm{P} 2 \mathrm{Y}$, receptor as a target for new antithrombotic drugs: a review of the P2Y, antagonist MRS-2179. Cardiovasc Drug Rev: 2003;21:67-76.

94. Fabre JE, Nguyen M, Latour A, Keifẹr JA, Audoly LP, Coffman TM, and Koller BH. Decreased platelet aggregation, increased bleeding time and resistance to thromboembolism in $\mathrm{P}_{2} \mathrm{Y}_{1}$-deficient mice. Nat Med. 1999;5:1199-1202.

95. Léon C. Hechler B, Freund M, Eckly A, Vial C, Ohlmann P, Dierich A, LeMeur M, Cazenave JP, and Gachet $\mathrm{C}$. Defective platelet aggregation and increased resistance to thrombosis in purinergic $\mathrm{P} 2 \mathrm{Y}$, receptor-null mice. J Clin Invest. 1999:104:1731-1737. 
96. André P, Delaney SM, LaRocca T, Vincent D, DeGuzman F, Jurek M, Koller B, Phillips DR, and Conley $\mathrm{PB} . \mathrm{P}^{2} \mathrm{Y}_{12}$ regulates platelet adhesion/activation, thrombus growth, and thrombus stability in injured arteries. J Clin Invest. 2003;112:398-406.

97. Lenain N, Freund M, Léon C, Cazenave JP, and Gachet C. Inhibition of localized thrombosis in P2 $\mathrm{Y}_{1}$ deficient mice and rodents treated with MRS2179, a $\mathrm{P} 2 \mathrm{Y}_{1}$ receptor antagonist. $J$ Thromb Haemosi. 2003;1:1144-1149.

98. Vink $\mathrm{H}$, Constantinescu AA, and Spaan JAE. Oxidized lipoproteins degrade the endothelial surface layer : implications for platelet-endothelial cell adhesion. Circulation. 2000;101:1500-1502.

99. Pinsky DJ, Broekman MJ, Peschon JJ, Stocking KL, Fujita T, Ramasamy R, Connolly ES, Jr., Huang J, Kiss S, Zhang Y, Choudhri TF, McTaggart RA, Liao H, Drosopoulos JHF, Price VL, Marcus AJ, and Maliszewski CR. Elucidation of the thromboregulatory role of CD39/ectoapyrase in the ischemic brain. J Clin Invest. 2002;109:1031-1040.

100. Murata T, Ushikubi F, Matsuoka T, Hirata M, Yamasaki A, Sugimoto Y, Ichikawa A, Aze Y, Tanaka T, Yoshida N, Ueno A, Oh-ishi S, and Narumiya S. Altered pain perception and inflammatory response in mice lacking prostacyclin receptor. Nature. 1997;388:678-682.

101. Kroll MH, Hellums JD, McIntire LV, Schafer AI, and Moake JL. Platelets and shear stress. Blood. 1996;88:1525-1541.

102. Goto S, Ikeda Y, Saldivar E, and Ruggeri ZM. Distinct mechanisms of platelet aggregation as a consequence of different shearing flow conditions. J Clin Invest. 1998;101:479-486.

103. Vollmar B, Slotta JE, Nickels RM, Wenzel E, and Menger MD. Comparative analysis of platelet isolation techniques for the in vivo study of the microcirculation. Microcirculation. 2003;10:143-152.

104. Remijn JA, Wu YP, Jeninga EH, IJsseldijk MJW, van Willigen G, de Groot PG, Sixma JJ, Nurden AT, and Nurden $\mathrm{P}$. Role of $\mathrm{ADP}$ receptor $\mathrm{P}^{2} \mathrm{Y}_{12}$ in platelet adhesion and thrombus formation in flowing blood, Arterioscler Thromb Vasc Biol. 2002;22:686-691.

105: Kuijpers MJE, Schulıe V, Bergmeier W, Lindhout T, Brakebusch C, Offermanns S, Fassler R, Heemskerk JWM, and Nieswandt B. Complementary roles of glycoprotein VI and $\alpha_{2} \beta_{1}$ integrin in collagen-induced thrombus formation in flowing whole blood ex vivo. Faseb J. 2003;17:685-687.

106. Broeders MAW, Tangelder GJ, Slaaf DW, Reneman RS, and oude Egbrink MGA. Hypercholesterolemia enhances thromboembolism in arterioles but not in venules; complete reversal by L-Arginine. Arterioscler Thromb Vasc Biol. 2002:680-685.

107. André P. LaRocca. Ts, Delaney SM, Lin PH, Vincent D, Sinha U, Conley PB, and Phillips DR. Anticoagulants (thrombin inhibitors) and aspirin synergize with $\mathrm{P} 2 \mathrm{Y}_{12}$ receptor antagonism in. thrombosis. Circulation. 2003;108:2697-2703.

108. Léon C, Freund M, Ravanat C. Baurand A, Cazenave JP, and Gachet C. Key role of the P2Y, receptor in tissue factor-induced thrombin- dependent acute thromboembolism: studies in $\mathrm{P}_{2} \mathrm{Y}_{1}$-knockout mice and mice treated with a $P_{2} Y_{1}$ antagonist. Circulation. 2001;103:718-723. 
109. Begent N, and Born GV. Growth rate in wivo of platelet thrombi, produced by iontophoresis of ADP, as a function of mean blood flow velocity. Nature, 1970;227:926-930.

110. Hatanaka K, Minamiyama M, Takaichi S, Tanaka K, Ishibashi Ueda H, Imakita M, and Yamamoto A. Thrombus formation by the application of thrombin to the outer surface of mouse mesenteric vein: comparison with the application of ADP. Thromb Res. 1985;40:731-743.

111. Dörffler-Melly J, Schwarte LA, Ince C, and Levi M. Mouse models of focal arterial and venous thrombosis. Basic Res Cardiol. 2000;95:503-509.

112. Denis C, Methia N, Frenette PS, Rayburn H, Ullman Cullere M, Hynes RO, and Wagner DD. A mouse model of severe von Willebrand disease: defects in hemostasis and thrombosis. Proc Natl Acad Sci USA. 1998;95:9524-9529.

113. Sato M, and Ohshima N. Platelet thrombus induced in vivo by filtered light and fluorescent dye in mesenteric microvessels of the rat. Thromb Res. 1984;35:319-334.

114. Rosen ED, Raymond S, Zollman A. Noria F, Sandoval-Cooper M, Shulman A, Merz JL, and Castellino FJ. Laser-induced noninvasive vascular injury models in mice generate platelet- and coagulation-dependent thrombi. Am J Pathol. 2001;158:1613-1622.

115. Bergqvist D. Haemostatic plug formation in the rabbit mesentery. A methodological study. Ups J Med Sci. 1974;79:28-38.

116. Nichols TC, Bellinger DA, Reddick RL, Read MS, Koch GG, Brinkhous KM, and Griggs TR. Role of von Willebrand factor in arterial thrombosis. Studies in normal and von Willebrand disease pigs. Circulation. 1991;83:IV56-IV64.

117. Seiffge D, and Kremer E. Influence of ADP, blood flow velocity, and vessel diameter on the laserinduced thrombus formation. Thromb Res. 1986;42:331-341. 
Chapter 2 
Real-time detection of activation patterns in individual platelets during thromboembolism in vivo: differences between thrombus growth and embolus formation

Miriam A. van Gestel, Johan W.M. Heemskerk, Dick W. Slaal, Viviane V.Th. Heijnen, Stewart O. Sage, Robert S. Reneman, \& Mirjam G.A. oude Egbrink 


\section{Abstract}

Knowledge on single platelet behavior and intracellular mechanisms during thromboembolism in vivo is scarce. In the present study we used a new method that allows realtime detection and quantification of activation of individual platelets participating in a thromboembolic process in vivo, using their intracellular free $\mathrm{Ca}^{2+}$ concentration $\left(\left[\mathrm{Ca}^{2+}\right]_{i}\right)$ as a marker of activation.

Isolated platelets were labeled with the $\mathrm{Ca}^{2+}$-sensitive fluorescense probe fluo- 3 and injected into anesthetized rabbits so that $0.5-1 \%$ of their circulating platelets was labeled. Wall puncture of mesenteric arterioles resulted in thrombus formation followed by embolization. Fluorescence intensity changes of labeled platelets participating in this process were quantified. Within 30 minutes after injection, labeled platelets behaved similarly to native platelets and fluorescence intensity was not influenced by dye leakage. Upon adherence to the stationary thrombus, platelets exhibited a prolonged $\left[\mathrm{Ca}^{2+}\right]_{\mathrm{r}}$ increase, accompanied by shape change and degranulation, which is consistent with a role for strong platelet agonists like collagen. In contrast, when platelets adhered to a growing embolus their $\left[\mathrm{Ca}^{2+}\right]_{i}$ rise was transient and they hardly showed shape change and degranulation, suggesting the involvement of weaker agonists like ADP.

These results show, for the first time, the relation between single platelet activation patterns, which are different during thrombus growth and embolus formation, and their behavior in a thromboembolic process in vivo. 


\section{Introduction}

Interactions between blood platelets and the vessel wall play an important role in hemostasis and in many vascular diseases such as arterial thrombosis.' When a vessel wall is damaged, platelets adhere to the exposed subendothelium and become activated, leading to thrombus formation often followed by embolization. This process resembles for example the clinical situation in which cerebral emboli are shed from carotid atherosclerotic plaques ${ }^{2}$ or as a consequence of atrial fibrillation. ${ }^{3}$ Often these emboli are asymptomatic, but transient ischemic attacks or stroke may occur depending on the frequency and duration of embolization. ${ }^{4}$ The course of such a thromboembolic process is determined by the balance between platelet stimulating and inhibiting agents and by other conditions at the site of origin. To date, the nature and relative contributions of these factors in vivo are still incompletely understood.

Platelet activation is extensively studied in in vitro models, using isolated platelets. Because platelet responses are influenced by factors in their natural environment, such as functional endothelium 5 and flowing blood, ${ }^{6.7}$ it is important that platelet activation is studied in vivo. As yet, most in vivo models only provide information on such endpoint-parameters as bleeding time and survival, ${ }^{8-10}$ In other studies, we $e^{11-14}$ and others ${ }^{15.16}$ have performed real-time measurements to monitor the dynamics of a thromboembolic process in vivo. However, knowledge of the activation pattern of individual platelets in vivo is lacking. Such knowledge will provide in-depth information that may help to elucidate the (intra)cellular mechanisms involved in thrombus formation and embolization.

Therefore, a new in vivo method was developed enabling real-time detection and quantification of activation of individual platelets participating in a thromboembolic process, while simultaneously quantifying this process as a whole. In this new approach, a thromboembolic process is induced by wall puncture of rabbit mesenteric vessels and visualized by intravital videomicroscopy. Because morphological signs of platelet activation fi.e., shape change, aggregation, and degranulation) are often initiated by a rise in the cytosolic free calcium concentration $\left(\left[\mathrm{Ca}^{2+}\right]_{i}\right),{ }^{17}$ this parameter was used as a marker to monitor the activation of single platelets during thromboembolism and was quantified using fluorescence imaging. After validation, this method was used to determine the activation patterns of platelets involved in thrombus growth and embolus formation. Electronmicroscopy and in vitro experiments with isolated platelets were employed to interpret the results. 


\section{Methods}

\section{Animal preparation}

Experiments were approved by the local ethical committee on the use of laboratory animals. New Zealand White rabbits $(2.0-2.5 \mathrm{~kg} ; n=6)$ of either sex were anesthetized by intramuscular injections of 40 $\mathrm{mg}$ ketamine hydrochloride (Nimatek; Eurovet) and $4 \mathrm{mg}$ xylazine hydrochloride (Sedamun; Eurovet) per $\mathrm{kg}$ body weight; anesthesia was maintained by continuous infusion of ketamine $(40 \mathrm{mg} / \mathrm{kg} / \mathrm{h})$ and $x y l a z i n e$ $(5 \mathrm{mg} / \mathrm{kg} / \mathrm{h})$, dissolved in a lactetrol solution $(15 \mathrm{~mL} / \mathrm{h}$; Eurovet), through a catheter (polyethylene(PE)-50) in the femoral vein. Another catheter (PE-50) was placed in the femoral artery for injection of fluo-3 labeled platelets (see below) and for monitoring of arterial pressure (Uniflow external pressure transducer; Baxter). The tip of this catheter was carefully moved upward into the aorta to just above the superior mesenteric artery. The catheter was kept patent by continuous infusion of saline $(3 \mathrm{~mL} / \mathrm{h})$; no heparin was used. During surgery and throughout the experiments mean arterial pressure and heart rate remained constant. Body temperature was kept at $37-38^{\circ} \mathrm{C}$ using an infrared heating lamp controlled by a thermoanalyzer system connected to a rectal probe. After surgery blood was coliected from a central ear artery $(0.9 \mathrm{ml}$ in $0.1 \mathrm{ml} \mathrm{1 \%} \mathrm{w} / \mathrm{v}$ EDTA) for electronic platelet counts (Coulter Electronics; mean $\pm \mathrm{SD}$; $441 \pm 143 \times 10^{6}$ platelets/ml).

Through a midline abdominal incision, a segment of the distal ileum was exteriorized. The mesentery was spread over a siliconized glass plate mounted on the electrically heated table of an intravital microscope $\left(37^{\circ} \mathrm{C}\right)$ and continuously superfused with a buffered Tyrode's solution $\left(37^{\circ} \mathrm{C}, \mathrm{pH} 7.35-7.40\right)$ saturated with $95 \% \mathrm{~N}_{2}$ and $5 \% \mathrm{CO}_{2}$. The exteriorized ileum was kept moist with overlying wet gauze.

\section{Isolation, loading with fluo-3, and reinjection of platelets}

To enable in vivo quantification of changes in $\left[\mathrm{Ca}^{2+}\right]_{1}$. platelets, were isolated and labeled with fluo3. a $\mathrm{Ca}^{2+}$-sensitive fluorescent probe. For each experiment $10 \mathrm{ml}$ blood of a donor rabbit was collected from a central ear artery in $2 \mathrm{ml} \mathrm{ACD}$ solution $(80 \mathrm{mmol} / \mathrm{I}$ sodium citrate, $52 \mathrm{mmol} / \mathrm{c}$ citric acid, and 183 $\mathrm{mmol} / \mathrm{l}$ glucose). Platelets were isolated and washed essentially as described for rat platelets. ${ }^{18}$ They were resuspended in a Tyrode-Hepes solution (136 mmol// NaCl, $2.7 \mathrm{mmol} / \mathrm{KCl}, 0.42 \mathrm{mmol} / \mathrm{I} \mathrm{NaH} \mathrm{PO}_{4}, 5$ $\mathrm{mmol} / \mathrm{l}$ Hepes, $2 \mathrm{mmol} / \mathrm{MgCl}, 5.6 \mathrm{mmol} / /$ glucose, and $0.1 \% \mathrm{BSA} ; \mathrm{pH} 7.45$ ) in a concentration of $2 \times 10^{8}$ platelets/ml. Platelets were incubated with fluo- 3 acetoxymethyl ester ( $5 \mu \mathrm{mol} / \mathrm{l}$; Molecular Probes) and. Pluronic 127 (0.12\%: Molecular Probes) for $45 \mathrm{~min}$ at room temperature. Labeled platelets ( $2 \mathrm{ml}$ ) were injected into an experimental rabbit via the arterial catheter; as a result, $0.5-1 \%$ of total circulating platelets was labeled.

In an additional set of 8 anesthetized rabbits, we investigated whether reinjected fluo- 3 labeled. platelets are representative of the total platelet population. For the purpose of these experiments, fluo-3 labeled platelets were injected in such an amount that about $2 \%$ of the circulating platelet population was labeled. In 4 rabbits, arterial and venous blood samples $(0.5 \mathrm{ml})$ were collected from ear vessels in sodium 
citrate $(10 \%, 0.13 \mathrm{~mol} / \mathrm{l})$ at 5,15 , and $30 \mathrm{~min}$ after injection of labeled platelets. The samples were analyzed with a fluorescence-activated cell sorter (Beckton and Dickinson) to determine the proportion of fluo-3 labeled platelets within the total platelet population. In 4 rabbits, labeled platelets were injected and thrombus formation was induced in the central ear arteries of both ears (data obtained from 7 arteries). An $18 \mathrm{G}$ needle was used to puncture the artery and to collect blood. Subsequently, the needle was withdrawn, and a clearly visible thrombus formed; blood that passed by the thrombus was collected. In both samples $(0.5 \mathrm{ml})$ platelet count and proportion of labeled platelets were determined.

\section{Vessel wall puncture and thromboembolic reaction}

A mesenteric arteriole (diameter $20-40 \mu \mathrm{m}$ ) was punctured using a glass micropipette (tip diameter 6-8 $\mu \mathrm{m}$ ), as described previously. ${ }^{11-14}$ Puncture was considered successful if red blood cells were seen leaving the vessel, indicating that all vessel wall layers had been damaged. Bleeding stopped immediately by the formation of a white platelet-rich thrombus, the shape and height of which remained constant over time. Circulating platelets continuously adhered to the downstream side of this thrombus, forming a loosely packed platelet mass that embolized repeatedly without affecting the height and shape of the stationary thrombus. Embolization stopped after some time, while the thrombus remained at the site of injury.

\section{Intravial microscopy and fuorescence imaging of platelets}

The thromboembolic reaction was visualized with an intravital microscope (Leitz) equipped with a Leitz Ploemopak incident illuminator. Puncture of a vessel was performed under transillumination by a tungsten lamp, using a long working distance objective (Leitz. LL25, numeric aperture 0.35). Immediately after puncture we switched to a high resolution water immersion objective (Leiz SW 50, numeric aperture 1.00). Fluorescence microscopy was performed under incident illumination ( $80 \mathrm{~ms}$ per image) with a Xenon lamp (100 W; Nikon). Xenon light passed a $485 \mathrm{~mm}$ excitation filter and reached the objective via a $510 \mathrm{~nm}$ dichroic mirror. Emission light passed the dichroic mirror and a $515 \mathrm{~nm}$ emission filter. Images were projected on an intensified CCD camera (Photonic Sciences); resolution was $0.3 \mu \mathrm{m} / \mathrm{pixel}$. Fluorescence intensity levels were measured with a digital fluorescence video imaging system (Quanticell; Visitech International). ${ }^{19}$ The same system was used to capture bright-field images. Four to six images per second were stored on a 128 Mbytes real-time image processor. During off-line analysis, geometric regions matching individual platelets were selected in which fluorescence intensity (defined as average intensity per pixe! in the selected area, excluding pixels below the background threshold) was measured.

\section{Electronmicroscopy}

The mesenteric tissue was fixed by superfusion with $2.5 \%$ glutaraldehyde and $4 \%$ paraformaldehyde in $0.1 \mathrm{~mol} / \mathrm{l}$ phosphate buffer $(\mathrm{pH} \mathrm{7.3)}$ for $10 \mathrm{~min}$. After excision, a piece of the tissue containing an injured vessel was postfixed in the same solution at $4^{\circ} \mathrm{C}$ for one week. After postfixation in 
$1 \% \mathrm{OsO}_{4}\left(60 \mathrm{~min}, 4^{\circ} \mathrm{C}\right)$, the tissue was dehydrated through graded alcohol and embedded in Epon. Ultrathin sections were stained with lead citrate and uranyl acetate, and examined with a Philips EM 400 microscope.

\section{In vitro experiments}

Platelets were isolated from blood of 7 rabbits and labeled with fluo- 3 as described above. Platelets from 3 of these rabbits were used to compare maximal aggregation of labeled platelets and unlabeled platelets. Aggregation was induced by ADP $(20 \mu \mathrm{mol} / \mathrm{I})$ or platelet activating factor (PAF; $500 \mathrm{nmol} / \mathrm{I})$ and measured at $37^{\circ} \mathrm{C}$ using an optical aggregometer (Chronolog). Labeled platelets from 4 rabbits were allowed to adhere to coverslips coated with type I collagen $(100 \mu \mathrm{g} / \mathrm{ml})$ or rabbit fibrinogen. The platelets immobilized on fibrinogen were stimulated with $10 \mathrm{nmol} / \mathrm{bovine}$ thrombin, 4 or $20 \mu \mathrm{mol} / \mathrm{ADP}$, or 1.5 $\mu \mathrm{mol} / / \mathrm{U} 46619$ (a thromboxane $\mathrm{A}_{2}$ analogue), in the presence of $2 \mathrm{mmol} / \mathrm{l}$ extracellular $\mathrm{Ca}^{2 *}$. Fluorescence intensity was measured at $37^{\circ} \mathrm{C}$ as described for the in vivo experiments. In each situation intensity changes were measured in at least 50 platelets.

\section{Statistical analysis}

Data are expressed as meantSEM. Differences in $\left[\mathrm{Ca}^{2+}\right]_{1}$ signals between platelets adhering to the thrombus or the emboli were tested using the Chi-square test; data from six punctured arterioles were pooled. In the validation experiments, differences between labeled and unlabeled platelets, and differences in platelet proportions before and during puncture were tested with the paired T-test. The level of significance was set at $5 \%$.

\section{Results}

\section{Validation of the method}

In the punctured arterioles (mean diameter $35 \mu \mathrm{m}$ ) fluo-3 labeled platelets participated in thrombus formation (mean height $65 \%$ of local vessel diameter) and subsequent embolization, and changes in fluorescence intensity were observed (Figure 3.1). Two important issues were investigated: first, whether the changes in fluorescence intensity truly represent changes in $\left[\mathrm{Ca}^{2+}\right]_{i}$, and second, whether the fluo-3 labeled platelets are representative of the total platelet population.

During the experiments small changes in focal plane (1-2 $\mu \mathrm{m})$ occurred, e.g. due to peristaltic movement of the tissue. The effect of such defocusing on fluorescence intensity in vivo was measured in four single platelets in a non-active thrombus. In the absence of tissue movement, defocusing was performed in steps of $1 \mu \mathrm{m}$; values were normalized to the intensity measured in the focal plane (Figure 3.2A). Defocusing of 1-2 $\mu \mathrm{m}$ resulted in less than $10 \%$ 
decrease in platelet fluorescence intensity, whereas a $50 \%$ decrease was achieved when defocusing $10 \mu \mathrm{m}$. Defocusing of a platelet was recognized by a simultaneous increase in size of the platelet image accompanied by similar changes in the surrounding labeled platelets. Loss of fluorescence yield was investigated by measuring in time the total fluorescence intensity in a thromboembolic reaction and in the stationary thrombus only (Figure 3.2B). No significant loss of fluorescence yield occurred in the first $\mathbf{3 0} \mathrm{min}$ after injection of labeled platelets. After these $30 \mathrm{~min}$, fluorescence yield decreased considerably. This decrease was similar in the thromboembolic reaction as a whole (which includes the fluorescence in the temporary emboli) compared to the stationary thrombus only (containing labeled platelets present over a long period). As a result of these findings, $\mathrm{Ca}^{2+}$ signals were only measured for 30 min following injection of labeled platelets in all further experiments.
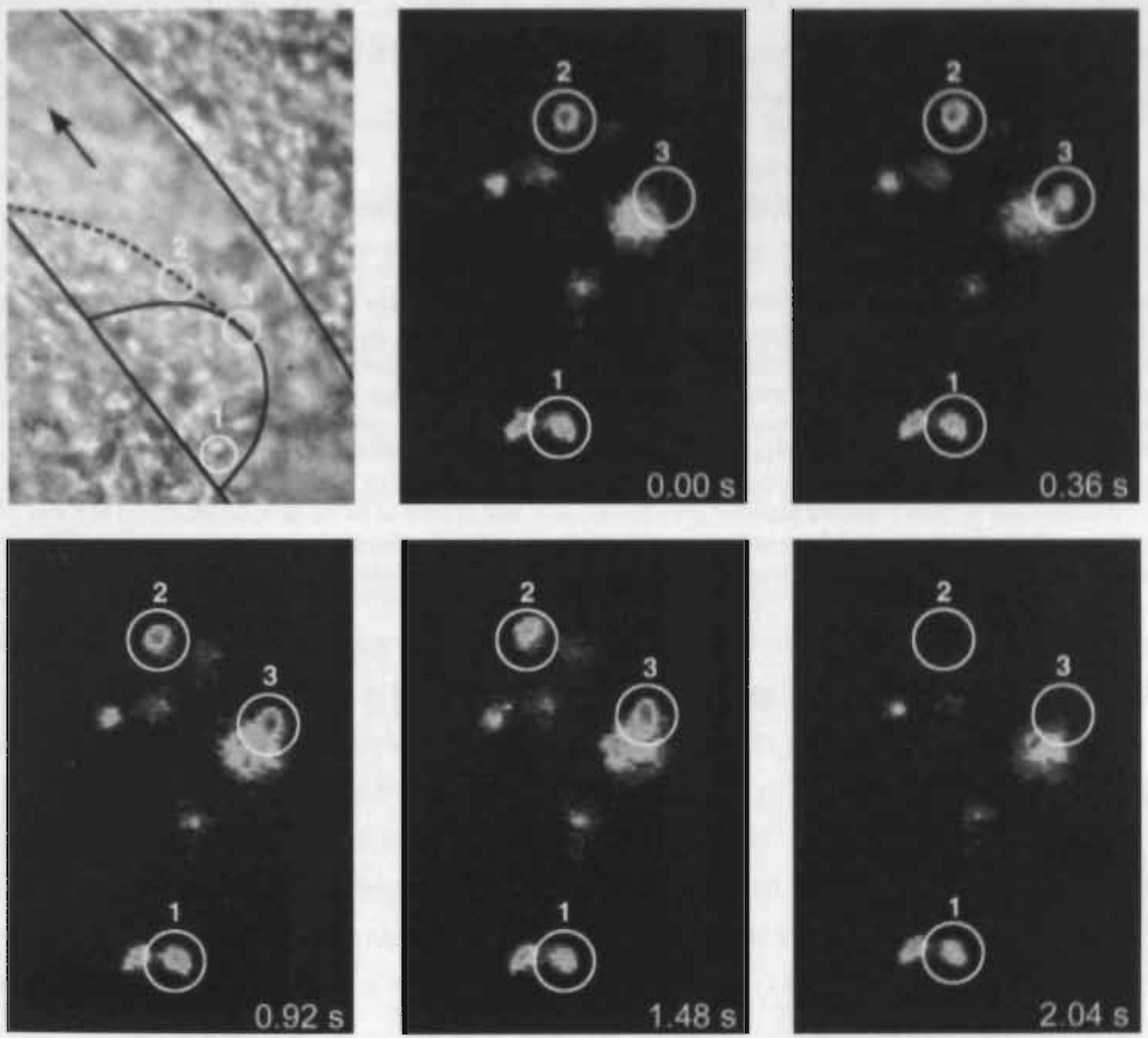

Figure 3.1. Platelets participating in a thromboembolic reaction. Bright-field and fluorescence images from a punctured arteriole (magnifications 70,000 and 125,000; respectively). In the bright-field image, the solid line indicates the position of the thrombus, whereas the dotted line indicates the position of the growing embolus. $\uparrow$ indicates direction of blood flow. In the sequence of fluorescence images the color spectrum indicates fluorescence intensity, with blue $=$ low and red = high fluorescence intensity. 1 : platelet located inside the thrombus; 2 : platelet located in the embolus; $3:$ platelet adhering to the embolus ( $\mathrm{t}=0.36 \mathrm{~s}$ ). Embolization occurred at $\mathrm{t}=2.00 \mathrm{~s}$. 

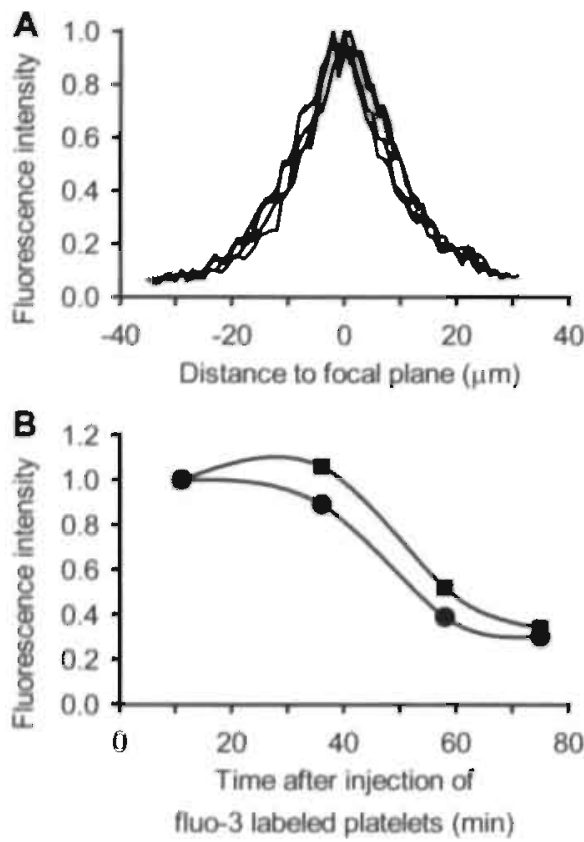
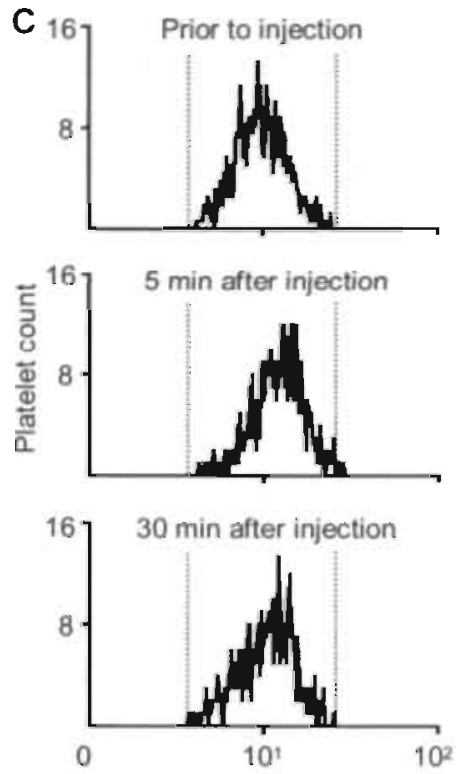

Fluorescence intensity (AU)

Figure 3.2. Validation of the method. (A) Effect of defocusing on fluorescence intensity in vivo. Fluorescence intensity of 4 single platelets in a non-active thrombus was measured, while defocusing in steps of 1 um. Values were normalized to the intensity measured in the focal plane. (B) Loss of fluorescence yield in time. Total fluorescence intensity in a thromboembolic reaction as a whole (circles) and in the thrombus only (squares) as measured repeatedly following injection of fluo-3 labeled platelets. Fluorescence in the thrombus was measured immedateiy atter embotization. Wait" puncture was performed at $1=5 \mathrm{~min}$; the rate of adherence of labeled platelets remained constant during the experiment. Values were normalized to the average intensity of the first measurement; symbols represent one measurement with an effective illumination time of $40 \mathrm{~s}$. (C) Distribution of fluorescence intensity of labeled platelets in time. Fluorescence intensity distributions of fluo-3 labeled platelets prior to injection and in arterial blood samples collected at 5 and 30 min following injection are shown. Data are representative of 3 experiments. Fluorescence intensity is in arbitrary units $(A U)$; dotted lines indicate the range of fluorescence intensity measured in platelets prior to injection.

Thrombus

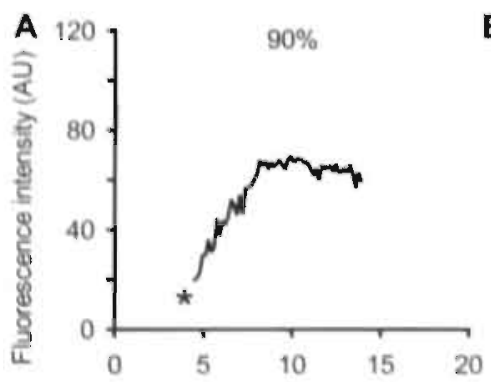

B

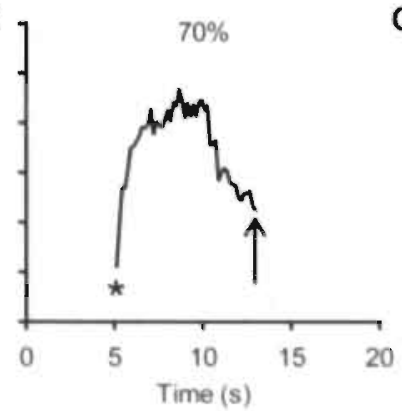

Emboli

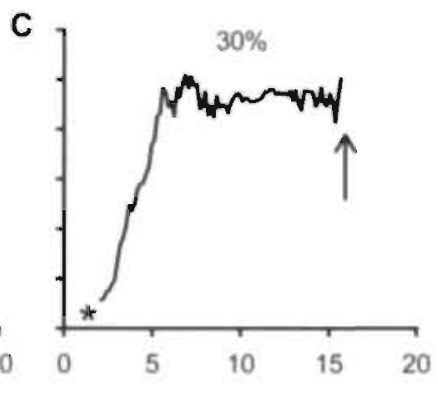

Figure 3.3. Typical platelet Ca." responses during a thromboembolic reaction in vivo. (A) Platelet adhering to a thrombus; (B, C) platelets adhering to an embolus. Ca ${ }^{2 *}$ signals are representative of $90 \%, 70 \%$, and $30 \%$, respectively. of the platelets that responded with a rapid $\left[\mathrm{Ca}^{2}\right]$, increase upon adherence. Fluorescence intensity is in arbitrary units (AU), * indicates moment of adherence; $\uparrow$ indicates moment of embolization. 
It was established in vitro that fluo-3 labeled and unlabeled platelets exhibited equal tendencies to aggregate to ADP (ratio labeled unlabeled platelets $=0.98 \pm 0.17$ ) and PAF

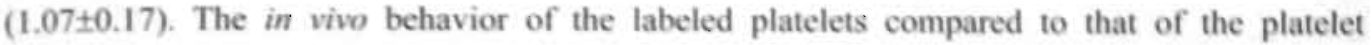
population as a whole was studied in arterial and venous blood samples collected at several moments after injection of fluo-3 labeled platelets, and before and during the formation of a thrombus in an ear artery. Between 5 and $30 \mathrm{~min}$ after the injection of labeled platelets, a limited decrease in the proportion of labeled platelets within the total platelet population was observed: $5 \pm 0.6 \%$ in arterial blood and $10 \pm 0.6 \%$ in venous blood. During this period, the fluorescence intensity distribution of the labeled platelets hardly changed (Figure 3.2C), confirming that leakage of fluo-3 is limited. Thrombus formation in a central ear artery led to a large decrease in platelet count in the blood flowing past the thrombus (by $65-93 \%$ ), whereas the proportion of labeled platelets did not change $(2.0 \pm 0.2 \%$ before and $2.0 \pm 0.1 \%$ during thrombus formation; $P=0.71$ ), indicating that labeled and unlabeled platelets were incorporated in a thrombus at the same rate.

\section{$\mathrm{Ca}^{2+}$ signals and morphology of platelets in thrombus and emboli}

Labeled platelets already present in the thrombus before the start of measurement (23 platelets) exhibited a stable $\left[\mathrm{Ca}^{2+}\right]$. The majority of platelets adhering to a thrombus ( 9 out of 11 platelets: $82 \%$ ) or an embolus (30 out of 37 platelets: $81 \%$ ) during the measurements exhibited a similar $(P=0.67)$, rapid increase in $\left[\mathrm{Ca}^{2+}\right]_{\mathrm{i}}$ that started within $0.5 \mathrm{~s}$; the overall median time-topeak was $2.4 \mathrm{~s}$. The remaining adhering platelets exhibited either a slower increase or no change in $\left[\mathrm{Ca}^{2+}\right]_{i}$. Of the platelets showing a rapid increase in $\left[\mathrm{Ca}^{2+}\right]_{1}$ upon adherence, those in the thrombus and about half of those in the emboli were present long enough $(>2 \mathrm{~s}$ after the increase) io study the further time course of $\left[\mathrm{Ca}^{2+}\right]_{i}$. In the thrombus $\left[\mathrm{Ca}^{2+}\right]_{1}$ remained at peak value during the period of observation in 8 of the 9 platelets (about $90 \%$; Figure $3.3 \mathrm{~A}$ ). In contrast, in the emboli such a prolonged increase was seen in significantly less platelets $(P \leq 0.005$ ); only 5 out of 18 platelets (about 30\%) showed this response (Figure 3.3C), whereas the initial increase was followed by a decrease in $\left[\mathrm{Ca}^{2+}\right]_{i}$ (rate of decrease $>5 \%$ of peak value per second) in the remaining 13 platelets (about $70 \%$; Figure $3.3 \mathrm{~B}$ ).

Intravital microscopic observations strongly suggest that platelets forming the emboli are only loosely aggregated, whereas the aggregate forming the thrombus is very stable. The electronmicroscopic study of a thromboembolic reaction (Figure 3.4) indeed showed that platelets in the thrombus were tightly packed, they exhibited shape change and were degranulated. In contrast, the platelets in the embolus were aggregated with a significantly lower level of shape change and degranulation. 


\section{$\mathrm{Ca}^{2+}$ signals of single rabbit platelets in vitro}

Isolated fluo-3 labeled rabbit platelets were exposed to several agonists in vitro. Platelets adhering to collagen generally showed a prolonged increase in $\left[\mathrm{Ca}^{2+}\right]_{\mathrm{i}}$, as shown in Figure 3.5A. When platelets were exposed to $10 \mathrm{nmol} / \mathrm{I}$ thrombin, $46 \%$ of them responded with a prolonged $\left[\mathrm{Ca}^{2+}\right]_{\mathrm{i}}$ increase (Figure 3.5B). The remaining platelets either showed transient increases in $\left[\mathrm{Ca}^{2+}\right]_{i}$ (spiking), or responded with a $\left[\mathrm{Ca}^{2+}\right]_{i}$ rise followed by a slow decrease. Platelets that were already adherent to collagen did not exhibit an additional $\left[\mathrm{Ca}^{2+}\right]_{i}$ increase when exposed to thrombin. Of the platelets stimulated with a low dose of ADP $(4 \mu \mathrm{mol} / \mathrm{l}), 45 \%$ exhibited a single transient $\left[\mathrm{Ca}^{2+}\right]_{i}$ increase, whereas $27 \%$ showed repetitive spiking. When stimulated with a higher dose of ADP $(20 \mu \mathrm{mol} / \mathrm{l}), 39 \%$ and $44 \%$ of platelets responded with one and more $\mathrm{Ca}^{2+}$ spikes, respectively (Figure 3.5C). After exposure to $1.5 \mu \mathrm{mol} / \mathrm{l} \mathrm{U} 46619$, a thromboxane $\mathrm{A}_{2}$ analogue, $44 \%$ responded with one and $47 \%$ with repetitive transient $\left[\mathrm{Ca}^{2+}\right]_{i}$ increases (Figure $3.5 \mathrm{D})$. The remaining platelets stimulated with ADP or $\mathrm{U} 46619$ exhibited a prolonged $\left[\mathrm{Ca}^{2+}\right]$ increase or an increase followed by a slow decrease.

\section{Discussion}

In the present study, activation of individual platelets during a thromboembolic reaction was detected in real-time, using $\left[\mathrm{Ca}^{2+}\right]_{i}$ as a marker of activation. Changes in $\left[\mathrm{Ca}^{2 \dagger}\right]_{i}$ could be distinguished from changes in fluorescence intensity due to defocusing or loss of fluorescence yield, and labeled platelets behaved in a manner that was representative of the platelet population as a whole. We applied this method in mesenteric arterioles of anesthetized rabbits, and found a striking difference between $\mathrm{Ca}^{2+}$ responses of platelets adhering to a thrombus compared to those of platelets adhering to an embolus. This statistically significant difference seems related to differences in platelet morphology, and to a specific contribution of platelet stimulating mediators in thrombus growth and embolus formation.

Fluo-3 is a fluorescent compound exhibiting a high quantum yield when bound to free calcium ions. Therefore, it is particularly useful to measure the kinetics of changes in $\left[\mathrm{Ca}^{2+}\right]_{1}^{20}$ and it has been widely used in platelet studies in vitro. In vivo excitation of fluo-3 probably induces little tissue damage, because of the relatively small amount of fluorochrome present and the platelet membrane barrier. Due to its absorption in the visible spectrum measurements are not hampered by background fluorescence from UV-light absorbing plasma proteins. Because fluo-3 does not display a spectral shift upon binding $\mathrm{Ca}^{2+}$, ratiometric measurements cannot be performed; measurements relate to changes in fluorescence intensity only. Consequently, factors independent of $\left[\mathrm{Ca}^{2+}\right]_{1}$, including defocusing due to movement artifacts and leakage of the dye from the platelets, may influence the signal. 


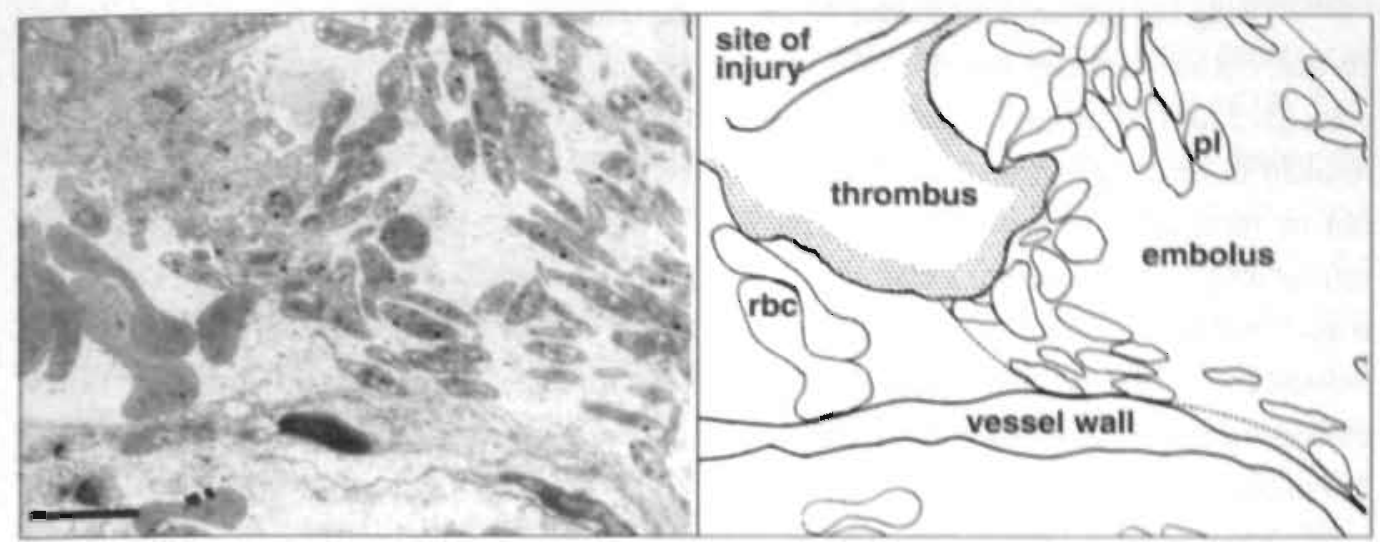

Figure 3.4. Electronmicrograph of a thromboembolic reaction in a punctured arteriole. Blood flow was from left to right. The stationary thrombus consists of tightly packed, completely degranulated and shape changed platelets, whereas the embolus contains aggregated platelets with a clearly lower level of shape change and degranulation. Bar represents 4 um; rbc $=$ red blood cell; $\mathrm{pl}=$ platelet.
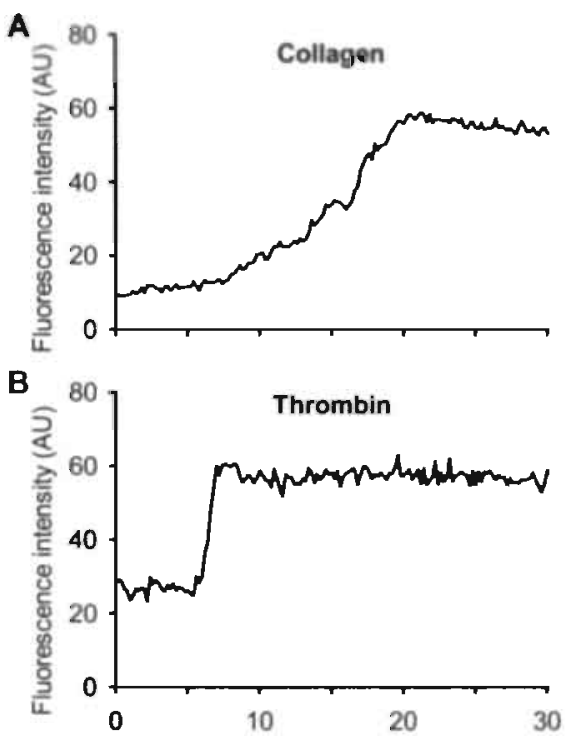

C

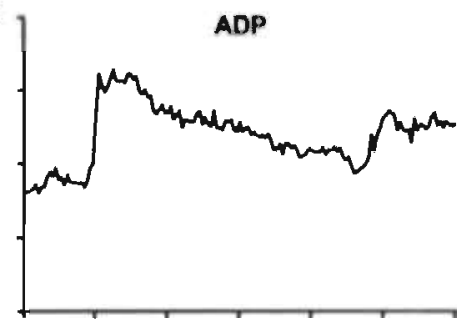

D

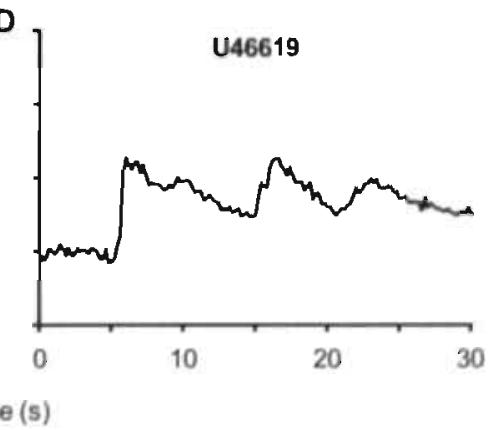

Figure 3.5. Typical $\mathrm{Ca}^{2 *}$ responses of single rabbit platelets in vitro. (A) Platelet adhering to collagen; (B-D) platelets immobilized on fibrinogen were stimulated by $10 \mathrm{nmol} / \mathrm{l}$ thrombin (B), $20 \mu \mathrm{mol} / \mathrm{ADP}$ (C), or $1.5 \mu \mathrm{mol} / \mathrm{U} 46619$ (D) at $t=5 \mathrm{~s}$. Fluorescence intensity is in arbitrary units (AU). 
Using the present microscope setup, fluorescence is sampled from a layer of more than $10 \mu \mathrm{m},{ }^{21}$ which exceeds the size of a platelet. During the experiments small changes in focal plane (1-2 $\mu \mathrm{m})$ occurred, e.g. due to peristaltic movement of the tissue. Such limited defocusing resulted in moderate decreases in platelet fluorescence intensity ( $\leq 10 \%$; see Figure $3.2 \mathrm{~A})$ and. can be recognized by a simultaneous increase in size of the platelet image; in addition, the surrounding labeled platelets defocused at the same time. Increases in platelet image size due to shape change occurred in individual platelets and were accompanied by an increase in fluorescence intensity; they could, therefore, be discriminated from defocusing effects. Hence, changes in fluorescence intensity due to defocusing can be distinguished from intensity changes due to changes in $\left[\mathrm{Ca}^{2+}\right]_{\text {i }}$.

Fluorescence intensity may also be influenced by dye loss (mainly due to leakage of fluo3 from the cytosol) or photobleaching, resulting in a loss of fluorescence yield. We established that no significant loss of fluorescence yield occurred in the first $30 \mathrm{~min}$ after injection of labeled platelets. Hence, in all further experiments $\mathrm{Ca}^{2+}$ signals were only measured for $30 \mathrm{~min}$ after injection. After these $30 \mathrm{~min}$, fluorescence yield decreased considerably, probably as a result of dye loss. The contribution of photobleaching to this decrease is likely to be relatively small, since fluorescence intensity in the thromboembolic reaction as a whole (which includes the fluorescence in the temporary emboli) declined in a manner similar to that in the stationary thrombus (containing labeled platelets present over a long period). This is not surprising because illumination was performed intermittently for relatively short periods of time (effectively $40 \mathrm{~s}$ during each measurement), and the excitation light had to pass several layers (mesenteric tissue, vessel wall, flowing blood, and surrounding unlabeled platelets in the thrombus) before reaching labejed platelets.

The behavior of the labeled platelets seems to be largely representative of that of the platelet population as a whole. Although some platelets are likely to be activated during isolation, labeling, and reinjection, most of them are probably removed from the circulation during first passage. In the period in which the thromboembolic reaction is studied (between 5 and $30 \mathrm{~min}$ after injection of labeled platelets), the proportion of labeled platelets within the total platelet population decreased only slightly, suggesting that in this period most of the circulating labeled platelets were not or only weakly activated due to isolation, labeling, and reinjection. This is supported by the finding that the rate of incorporation of labeled and unlabeled platelets in a growing thrombus was similar. In summary, isolation, labeling, and reinjection causes some activation of platelets, but this does not seem to affect the extent to which they participate in a thromboembolic process.

Altogether, the validation experiments indicate that our new method enables the quantification of $\left[\mathrm{Ca}^{2+}\right]$, changes in single platelets involved in a thromboembolic reaction in 
vivo. We applied this method to measure $\mathrm{Ca}^{2+}$ responses of platelets involved in thrombus growth and embolus formation in arterioles. In both thrombus and emboli the large majority of platelets exhibited a rapid increase in $\left[\mathrm{Ca}^{2+}\right]_{\mathrm{i}}$. However, subsequently, the shape of the $\mathrm{Ca}^{2+}$ response was strikingly different. In the thrombus $\left[\mathrm{Ca}^{2+}\right]$, remained at peak value during the period of observation in nearly all platelets, whereas in the emboli the initial increase was followed by a gradual decrease in $\left[\mathrm{Ca}^{2+}\right]_{1}$ in most platelets. This difference may be related to the different morphology that was revealed by electronmicroscopic investigation: platelets in a thrombus appeared to be highly activated, exhibiting a high level of shape change and degranulation, whereas those in an embolus had hardly shape changed or degranulated, indicating that they were only weakly activated. Our data suggest that, in general, a prolonged $\left[\mathrm{Ca}^{2+}\right]_{i}$ increase is associated, with a high level of platelet activation and the formation of a stable thrombus, whereas a temporary $\left[\mathrm{Ca}^{2+}\right]_{\mathrm{i}}$ increase corresponds with a lower level of platelet activation and the formation of emboli.

This hypothesis is supported by data from in vitro experiments with single, fluo-3 labeled rabbit platelets. A prolonged increase in $\left[\mathrm{Ca}^{2+}\right]$, was seen when platelets adhered to collagen and in about half of the platelets that were exposed to a relatively high dose of thrombin. Platelets that were already adherent to collagen did not exhibit an additional $\left[\mathrm{Ca}^{2+}\right]$ increase when exposed to thrombin, indicating that they were already maximally activated. Both agonists are likely to be involved in thrombus formation: collagen is present in the subendothelium and is exposed to blood components when a vessel wall is damaged, whereas thrombin is formed at the surface of procoagulant platelets. Interestingly, in human platelets this so-called procoagulant response, which provides conditions for stable clot formation. only occurs in situations of prolonged high $\left[\mathrm{Ca}^{2+}\right]_{i}{ }^{19}$ Temporary increases in $\left[\mathrm{Ca}^{2+}\right]_{1}$. similar to those seen in embeli, were observed in vimo when platelets were exposed to relatively weak agonists like ADP or thromboxane $A_{2}$, suggesting that these substances (both are released from activated platelets) contribute mainly to embolus formation. This hypothesis is supported by preliminary data from wali puncture experiments using ADP receptor antagonists, which a!so suggest a prominent role for ADP in embolization but not in thrombus formation, ${ }^{22}$ illustrating the usefulness of our in vivo model for investigating mechanisms of thromboembolism.

Our results indicate that platelet activation patterns differ considerabiy during thrombus growth and embolus formation. Further elucidation of these differences is likely to improve our insights into mechanisms underlying clinical disorders. For example, it is tempting to speculate that emboli containing weakly activated platelets (temporary increases in $\left[\mathrm{Ca}^{2+}\right]_{i}$ ) are asymptomatic, because they may disintegrate before occluding a downstream vessel. On the other hand, emboli with many highly activated platelets (prolonged $\left[\mathrm{Ca}^{2+}\right]_{i}$ increases) may cause clinical symptoms of ischemia. Measurements can also be related to environmental factors like wall shear rate, which in these arterioles ranges from about. 500 to 4500 per second. ${ }^{23}$ 
Furthermore, the method is also applicable to venules, which is important because the duration of embolization in these vessels is shorter, and other mediators are involved. ${ }^{12-14}$

In conclusion, we have developed a new method that allows, for the first time, real-time detection and quantification of the activation level of single platelets involved in a thromboembolic reaction in vivo, while simultaneously quantifying the reaction as a whole. Using this method, we showed that activation patterns of single platelets are significantly different during thrombus growth and embolus formation. Future experiments will further elucidate the mechanisms underlying thromboembolism, as well as the contribution of activating and inhibiting mediators involved. This will help to develop therapeutic ways to interfere selectively in thrombus formation or embolization.

\section{Acknowledgments}

We thank Mrs. Alexandra Bühler for technical assistance. Part of the study was supported by The Wellcome Trust, grant 046113 (SOS and JWMH).

\section{References}

1. Libby P. The interface of atherosclerosis and thrombosis: basic mechanisms. Vasc Med. 1998;3:225229.

2. Spencer MP. Transcranial Doppler monitoring and causes of stroke from carotid endarterectomy. Stroke, 1997:28:685-69 i

3. Goldman ME, Pearce LA, Hart RG, Zabalgoitia M, Asinger RW, Safford R, and Halperin IL. Pahophysiotogic correlates of thromboembolism in nonvalvular atrial fibrillation: 1. Reduced flow vefocity in the left atriat appendage (The Stroke Prevention in Atrial Fibrillation [SPAF] study). J Am Soc Echocardiogr. 1999;12:1080-1087.

4. Markus 11. Monitoring embolism in real time. Circulation. 2000;102:826-828.

5. Cines DB, Pollak ES, Buck CA, Losçalzo J, Zimmermạn GA, McEver RP, Pober JS, Wick TM, Konkle BA, Schwartz BS, Barnathan ES, McCrae KR, Hug BA, Schmidt AM, and Stern DM. Endothelial cells in. physiology and in the pathophysiology of vascular disorders. Blood. 1998:91:3527-3561.

6. Kroll MH, Hellums MD, Melntire LV. Schafer AI, and Moake JL. Platelets and shear stress. Blood. 1996;88:1525-1541.

7. Goto S, Ikeda Y, Saldivar E, and Ruggeri ZM. Distinct mechanisms of platelet aggregation as a consequence of different shearing flow conditions. J Clin Invest. 1998;101:479-486. 
8. Choudhri TF, Hoh BL, Zerwes HG, Prestigiacomo CJ, Kim SC, Connolly ES, Jr., Kottirsch G, and Pinsky DJ. Reduced microvascular thrombosis and improved outcome in acute murine stroke by inhibiting GP IIb/IIla receptor-mediated platelet aggregation. J Clin Invest. 1998;102:1301-1310.

9. Fabre JE, Nguyen M, Latour A, Keifer JA, Audoly LP, Coffman TM, and Koller BH. Decreased platelet aggregation, increased bleeding time and resistance to thromboembolism in $\mathrm{P}_{2} \mathrm{Y}_{1}$-deficient mice. Nat Med. 1999:5:1199-1202.

10. Léon C, Hechler B, Freund M, Eckly A, Vial C, Ohlmann P, Dierich A, LeMeur M, Cazenave JP, and Gachet C. Defective platelet aggregation and increased resistance to thrombosis in purinergic $\mathrm{P}_{2} \mathrm{Y}_{1}$ receptor-null mice. J Clin Invest. 1999:104:1731-1737.

11. oude Egbrink MGA, Tangelder GJ, Slaaf DW, and Reneman RS. Influence of platelet-vessel wall interactions on leukocyte rolling in vivo. Cire Res. 1992;70:355-363.

12. oude Egbrink MGA, Tangelder GJ, Slaaf DW, and Reneman RS. Different roles of prostaglandins in thromboembolic processes in arterioles and venules in vivo. Thromb Haemost. 1993;70:826-833.

13. Broeders MAW, Tangelder GJ, Slaaf DW, Reneman RS, and oude Egbrink MGA. Endogenous nitric oxide protects against thromboembolism in venules but not in arterioles. Arterioscler Thromb Vasc Biol. 1998:18:139-145.

14. Broeders MAW, Tangelder GJ, Slaaf DW, Reneman RS, and oude Egbrink MGA. Endogenous nitric oxide and prostaglandins synergistically counteract thromboembolism in arterioles but not in venules. Arterioscler Thromb Vasc Biol. 2001;21:163-169.

15. Kulkarni S, Dopheide SM, Yap CL, Ravanat C, Freund $\mathbf{M}_{2}$ Mangin P, Heel KA, Street A, Harper IS, Lanza F, and Jackson SP. A revised model of platelet aggregation. J Clin invest. 2000; 105:783-791.

16. Ni H, Denis CV, Subbarao S, Degerı JL, Sato TN, Hynes RO, and Wagner DD. Persistence of platele1 thrombus formation in arterioles of mice lacking both von Willebrand factor and fibrinogen. $J$ Clin Invest. 2000; 106:385-392.

17. Sage SO. The Wellcome Prize Lecture. Calcium entry mechanisms in human platelets. Exp Physiol. 1997;82:807-823.

18. Heemskerk JWM, Feijge MAH, Sage SO, and Walter U. Indirect regulation of $\mathrm{Ca}^{2+}$ entry by cAMP= dependent and cGMP-dependent protein kinases and phospholipase $\mathrm{C}$ in rat platelets. Eur J Biochem. 1994:223:543-551.

19. Heemskerk JWM, Vuist WMJ, Feijge MAH, Reutelingsperger CPM, and Lindhout T. Collagen but not fibrinogen surfaces induce bleb formation, exposure of phosphatidylserine, and procoagulant activity of adherent platelets: evidence for regulation by protein tyrosine kinase-dependent $\mathrm{Ca}^{2 *}$ responses. Blood. 1997;90:2615-2625.

20. Bootman MD, Berridge MJ, and Lipp P. Cooking with calcium: the recipes for composing global signals from elementary events. Cell. 1997;9 I:367-373. 
21. Tangelder GJ, Slaaf DW, Teirlinck HC, Alewijnse R, and Reneman RS. Localization within a thin optical section of fluorescent blood platelets flowing in a microvessel. Microvasc Res. 1982;23:214230.

22. van Gestel MA, Heemskerk JWM, Slaaf DW, Sage SO, and oude Egbrink MGA. The platelet ADPreceptor $\mathrm{P} 2 \mathrm{Y} 12$ is involved in embolization but not in thrombus formation in vivo (Abstract). Thromb Haemost. 2001;Supplement July 2001:OC1013.

23. Tangelder GJ, Slaaf DW, Arts T, and Reneman RS. Wall shear rate in arterioles in vivo: least estimates from platelet velocity profiles. Am J Physiol. 1988;254:HI059-H1064. 
In vivo blockade of the platelet ADP receptor $\mathrm{P}_{2 Y_{12}}$ reduces embolus and thrombus formation, but not thrombus stability

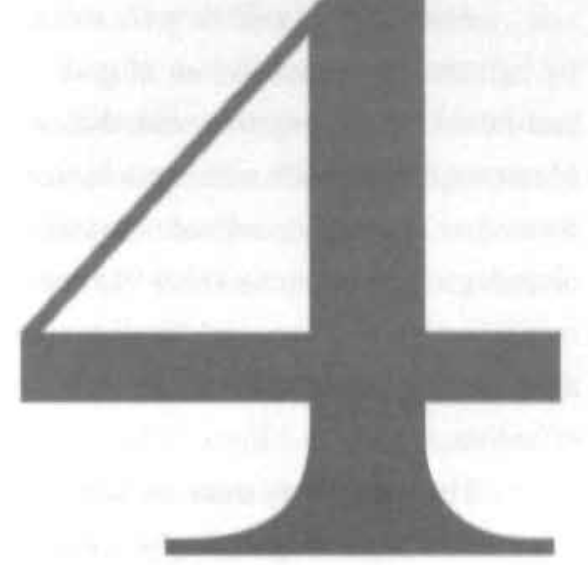

Miriam A. van Gestel, Johan W.M. Heemskerk, Dick W. Slaaf, Viviane V.Th. Heijnen, Robert S. Reneman, \& Mirjam G.A. oude Egbrink 


\section{Abstract}

ADP is a key platelet agonist in thromboembolism. One of the receptors involved in ADP-induced platelet activation is the $\mathrm{P}_{2} \mathrm{Y}_{12}$ receptor, which is a target for antithrombotic drugs. Here we present first evidence for a differential role of this receptor in thrombus and embolus formation in vivo.

Anesthetized rabbits were treated with the selective P2 $\mathrm{Y}_{12}$ antagonists AR-C69931MX (3 $\mu \mathrm{g} / \mathrm{kg} / \mathrm{min}$ intravenously) or clopidogrel ( $25 \mathrm{mg} / \mathrm{kg}$ orally). Efficacy of these treatments was monitored by aggregation and thrombin generation measurements in blood samples ex vivo. Mesenteric arterioles were mechanically injured; thrombus growth and subsequent embolus formation were visualized real-time using intravital microscopy. AR-C6993IMX and clopidogrel significantly ( $P \leq 0.05$ ) reduced the total duration of embolization (by $52 \%$ and $36 \%$, respectively), and less and smaller emboli were produced. The size of the initial thrombus was significantly reduced $(P \leq 0.005)$, but its stability was unaffected: plug formation was still effective.

These findings demonstrate that $\mathrm{ADP}$ and its $\mathrm{P} 2 \mathrm{Y}_{12}$ receptor are involved in thrombus growth and especially in the formation of emboli on the downstream side of the initial thrombus. This may explain the beneficial effects of $\mathrm{P} 2 \mathrm{Y}_{12}$ receptor antagonists in secondary prevention of ischemic events in patients with arterial thrombosis. 


\section{Introduction}

Interactions between activated platelets and the vessel wall play a key role in normal hemostasis, but also in vascular diseases such as arterial thrombosis. When platelets adhere to a damaged or diseased vessel wall, they become activated and recruit other platelets into an aggregate. Adherent platelets also expose a procoagulant surface on which thrombin can be formed; the resulting fibrin stabilizes the aggregate and bleeding is stopped. However, this primary thrombus often remains highly thrombogenic, resulting in the subsequent production of one or more emboli. These secondary emboli may cause downstream vascular occlusion and lead to ischemia. Therefore, especially the embolization phase of the thromboembolic process is potentially hazardous. For instance, in patients with atherothrombotic disease thrombi may form at the surface of an atherosclerotic plaque, and embolization may lead to myocardial or cerebral infarction or peripheral arterial ischemia.'

Adenosine diphosphate (ADP) is likely to play an important role in thromboembolism. Once released from dense granules upon platelet activation, ADP amplifies the responses to other platelet agonists like collagen and thrombin. ${ }^{2}$ ADP-induced platelet activation involves two receptors, $\mathrm{P} 2 \mathrm{Y}_{1}$ and $\mathrm{P} 2 \mathrm{Y}_{12}$, both of which contribute to full aggregation in vitro. ${ }^{3}$ The $\mathrm{P} 2 \mathrm{Y}_{1}$ receptor is coupled to the $\mathrm{G}_{4}$ protein, causing mobilization of calcium ions to the cytosol leading to shape change and initiation of aggregation. ${ }^{4.5}$ The recently cloned, platelet specific $\mathrm{P} 2 \mathrm{Y}_{12}$ receptor $^{6.7}$ signals to inhibition of adenylate cyclase via $G_{1}$ and serves to complete and amplify the aggregation response to $\mathrm{ADP}$. 6.8 The $\mathrm{P}_{2} \mathrm{Y}_{12}$-mediated signaling pathway involves the phosphoinositide 3-kinase dependent activation of the platelet fibrinogen receptor $\alpha$ Hb $\beta 3,{ }^{9}$ and has also been implicated in stabilization of platelet aggregates induced by thrombin receptor activation. ${ }^{10}$

Pharmacological agents inhibiting $\mathrm{P}_{2} \mathrm{Y}_{12}$ receptors have found wide applications as antithrombotic drugs. For instance, the thienopyridine derivatives ticlopidine and clopidogrel, forming a metabolite with potent anti- $\mathrm{P} 2 \mathrm{Y}_{\mathrm{I} 2}$ receptor activity, " significantly reduce the risk of ischemic events in symptomatic atherothrombosis. ${ }^{12,13}$ Other, novel P2 $\mathrm{Y}_{12}$ antagonists of the AR-C series, ${ }^{14.15}$ also have demonstrated efficacy as antithrombotic drugs. However, not much is known about how these drugs interfere in the dynamic process of thrombus formation and subsequent embolization, because most of the in vivo studies on the role of the $\mathrm{P}_{2} \mathrm{Y}_{12}$ receptor in thrombotic processes only provide information on such endpoint-parameters as bleeding time ${ }^{6}$ or time-to-occlusion of a vessel. ${ }^{16}$ Therefore, it was the aim of the present study to investigate the mechanism underlying the antithrombotic effects of $\mathrm{P}_{2} \mathrm{Y}_{12}$, receptor inhibition in an established rabbit model of real-time thromboembolism in vivo, ${ }^{17-20}$ using the specific antagonists ARC6993 IMX (AR-CMX) and clopidogrel. For the first time we provide evidence that blocking 
the $\mathrm{P}_{2} \mathrm{Y}_{12}$ receptor reduces thrombus formation and substantially diminishes embolization, without influencing the stability of the thrombus that sheds the emboli.

\section{Methods}

\section{Animal preparation and intravital microscopy}

Experiments were approved by the local ethical committee on the use of laboratory animals, and were performed on New Zealand White rabbits (1.8-2.8 kg; $n=33$ ) of either sex as described before. ${ }^{17-20}$ Rabbits were anesthetized by intramuscular injections of $40 \mathrm{mg}$ ketamine hydrochloride (Nimatek; Eurovet) and $4 \mathrm{mg}$ xylazine hydrochloride (Sedamun; Eurovet) per $\mathrm{kg}$ body weight; anesthesia was maintained by continuous intravenous infusion of ketamine $(40 \mathrm{mg} / \mathrm{kg} / \mathrm{h})$ and $x y l a z i n e ~(5 \mathrm{mg} / \mathrm{kg} / \mathrm{h})$, dissolved in lactetrol $\left(15 \mathrm{ml} / \mathrm{h}\right.$; Eurovet). Body temperature was kept at $37-38^{\circ} \mathrm{C}$. Arterial pressure and heart rate were continuous!y monitored using an external pressure transducer (Uniflow; Baxter) connected to a catheter in the femoral artery. Rabbits were ventilated through a tracheal cannula with a mixture of nitrogen $(74 \%)$, oxygen $(25.5 \%)$, and carbon dioxide $(0.5 \%)$, to control systemic arterial pH (mean \pm SEM:

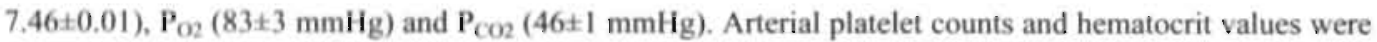
assessed before start of experimentation (Coulter Counter; Coulter Electronics). Ear bleeding time was determined by making incisions ( $1 \mathrm{~mm}$ deep and $10 \mathrm{~mm}$ long) parallel to the long axis of the ear, avoiding macroscopically visible vessels. The incision site was carefully blotted with filter paper at 30 -second intervals; bleeding time was assessed from incision until the paper was no longer stained with blood.

Through a midline abdominal incision, a segment of the distal ileum was exteriorized. The mesentery was continuously superfused with buffered Tyrode's solution $\left(37^{\circ} \mathrm{C}, \mathrm{pH} 7.35-7.40\right)$, and visualized with an intravital microscope (Leitz) using a long working distance objective (Leitz LL25, numerical aperture 0.35). Images were projected on a CCD camera (Hamamatsu) and stored on videotape for off-line analysis.

\section{Vessel wall puncture and thromboembolic reaction}

A thromboembolic reaction was induced in selected mesenteric arterioles (diameter $20-40 \mu \mathrm{m}$ ). ${ }^{17 \cdot 20}$ After a stabilization period of $30 \mathrm{~min}$ arterioles were mechanically injured by wall puncture using a glass micropipette with tip diameter 6-8 $\mu \mathrm{m}$. Puncture was considered successful if red blood cells were seen leaving the vessel, indicating that all vessel wall layers were damaged. In all vessels, bleeding stopped after a few seconds by the formation of a white, platelet-rich thrombus. Circulating platelets continuously adhered to the downstream side of this stationary thrombus, and these newly formed aggregates embolized repeatedly. Embolization stopped after some time, while the thrombus remained unchanged at the site of injury during the observation period of 600 s per vessel. Arterioles were punctured up to $3 \mathrm{~h}$ following the stabilization period. 
The following parameters were quantified off-line: duration of bleeding (microvessel bleeding time), occurrence of rebleedings, maximal thrombus height relative to local vessel diameter, total duration of embolization, number of emboli produced, size of individual emboli, and median embolus production time per vessel. Emboli were counted when their short axis, perpendicular to the vessel wall, was $>5 \mu \mathrm{m}$. Aggregates of smaller dimensions could not be distinguished from the background with sufficient accuracy. Sizes of individual emboli were measured along their short axis and categorized on a semiquantitative scale: $5-10 \mu \mathrm{m}, 10-15 \mu \mathrm{m}$, etc. Vascular diameter was measured off-line with an imageshearing device. Mean red blood cell velocity was measured on-line ${ }^{21}$ for one minute directly preceding puncture; wall shear rate was calculated using the velocity and diameter data according to Tangelder et al. ${ }^{22}$

\section{Adnministration of $A R-C M X$ and clopidogrel in vivo}

The optimally effective dose of AR-CMX was determined ex vivo by whole blood aggregometry in 4 rabbits. AR-CMX (AstraZeneca) was infused via a catheter in an ear vein. Its dose was increased. stepwise from 0 ( (saline $=$ baseline) to $0.01,0.03,0.1,0.3,1,3$, and $10 \mu \mathrm{g} / \mathrm{kg} / \mathrm{min}$. After each infusion step (20 min), $0.9 \mathrm{ml}$ arterial blood was collected in $0.1 \mathrm{ml}$ trisodium citrate $(0.129 \mathrm{~mol} / \mathrm{l})$ via the arterial catheter. Whole blood aggregation was induced by $20 \mu \mathrm{mol} / \mathrm{ADP}$ and measured with an impedance aggregometer (Chronolog) at $37^{\circ} \mathrm{C}$ in the presence of H-Phe-Pro-Arg chloromethylketone (PPACK; 40 $\mu \mathrm{mol} / 1)$ and $\mathrm{CaCl}_{2}(16.6 \mathrm{mmol} / 1)$ to achieve physiological concentrations of free $\mathrm{Ca}^{2+}$. Inhibition of the maximum level of aggregation by AR-CMX was determined relative to baseline level and calculated as ((baseline - AR-CMX) / baseline) x $100 \%$. Based on these ex vivo measurements, a dose of $3 \mu \mathrm{g} / \mathrm{kg} / \mathrm{min}$ AR-CMX was selected for wall puncture experiments.

In a group of 8 rabbits, the compound was continuously infused via an ear vein (AR-CMX group); continuous infusion was used because AR-CMX effects have beeni shown to rapidly recover upon termination of infusion. ${ }^{14}$ Control rabbits $(n=8)$ received continuous infusion of saline. In all rabbits, infusion $(5 \mathrm{ml} / \mathrm{h}$ ) was started at least $20 \mathrm{~min}$ before the first vessel was punctured. Rabbits were randornly assigned to the groups; the in vivo experiments as well as the off-line analysis were performed blindly.

To compare the effects of AR-CMX with those of another, well-known P2 $\mathrm{Y}_{12}$ antagonist, an additional group of 3 rabbits was treated with an effective dose of clopidogrel $\left(25 \mathrm{mg} / \mathrm{kg}\right.$ ). ${ }^{23}$ Clopidogre! was administered orally two hours before vessel puncture started. Arterial blood was collected in trisodium citrate $(0.129 \mathrm{~mol} / \mathrm{l}, 1 / 10$ volume $)$ before, and two and five hours after clopidogrel administration. The maximal level of ADP-induced platelet aggregation (measured in platelet-rich plasma as described below) was reduced by $62 \%$ after two hours and by $47 \%$ after five hours.

\section{Platelet aggregation and calcium measurements}

Blood was collected in $1 / 10$ volume trisodium citrate $(0.129 \mathrm{~mol} / \mathrm{l})$ from a central ear artery of 4 rabbits to prepare platelet-rich plasma (PRP; $2 \times 10^{8}$ platelets $/ \mathrm{ml}$ ). PRP was recalcified with $16.6 \mathrm{mmol} / \mathrm{l}$ 
$\mathrm{CaCl}_{2}$ and PPACK $(40 \mu \mathrm{mol} / \mathrm{l})$ was added. ADP $(20 \mu \mathrm{mol} / \mathrm{l})$ induced platelet aggregation was measured at $37^{\circ} \mathrm{C}$ using a Chronolog optical aggregometer.

To measure $\mathrm{Ca}^{2+}$ responses, isolated rabbit platelets were loaded with fluo-3 as described.. ${ }^{20}$ After immobilization on fibrinogen-coated coverslips, platelets were stimulated with $3 \mu \mathrm{mol} / \mathrm{ADP}$ and $2 \mathrm{mmol} / \mathrm{I}$ $\mathrm{CaCl}_{2}$ and fluorescence intensity changes in single platelets were measured. ${ }^{24}$ In addition, fluo-3 labeled platelets were injected into anesthetized rabbits $(n=3)$ and fluorescence intensity changes in platelets participating in the thromboembolic process were measured as described before. ${ }^{20}$

\section{Thrombin generation assay}

Thrombin generation was measured in PRP using the Thrombogram method. ${ }^{25}$ Blood was collected from 3 rabbits before (baseline) and after $30 \mathrm{~min}$ infusion with $3 \mu \mathrm{g} / \mathrm{kg} / \mathrm{min}$ AR-CMX. PRP (1.5x $10^{8}$ platelets $/ \mathrm{ml})$ was prepared and added to wells of a 96-well plate containing rabbit thromboplastin $(1 / 30,000$ volume Thromboplastin-S; Biopool International). Thrombin formation was started by adding $\mathrm{CaCl}_{2}(16.6$ $\mathrm{mmol} / \mathrm{l})$ and fluorescent thrombin substrate (417 $\mu \mathrm{mol} / / \mathrm{Z}$-Gly-Gly-Arg-AMC; Bachem), and continuously measured in time with a microtiter plate fluorometer (Fluoroskan Ascent; Labsystems) at $37^{\circ} \mathrm{C}$. Control measurements were performed with platelet-poor plasma to ascertain that thrombin generation was platelet dependent.

\section{Staristical analysis}

Data from in vivo experiments are presented as median values with (interquartile) ranges، because of their nonsymmetrical distribution. Differences between the experimental groups were tested using the nonparametric Mann-Whitney $\mathrm{U}$ test. The Spearman rank correlation test was used to test correlations. All other data are presented as mean \pm SEM; differences were tested with the paired T-test.

\section{Results}

\section{Effects of $P 2 Y_{12}$ receptor blockade on rabbit platelets}

To demonstrate whether $\mathrm{P} 2 \mathrm{Y}_{12}$ mediates activation of rabbit platelets, ADP-induced platelet aggregation in PRP was measured in vitro. AR-CMX rẹucẹ maximal aggregation by $44 \pm 5 \%$ at $1 \mu \mathrm{mol} / \mathrm{l}$ and by $66 \pm 6 \%$ at $100 \mu \mathrm{mol} / \mathrm{l}$. Complete inhibition of aggregation was only achieved when a $\mathrm{P} 2 \mathrm{Y}_{\mathrm{1}}$ receptor antagonist was added as well, indicating that $\mathrm{P} 2 \mathrm{Y}$, receptor activation accounted for the residual ADP-induced aggregation. To confirm that AR-CMX is specific for $\mathrm{P} 2 \mathrm{Y}_{12}$, we investigated the effect of $\mathrm{AR}-\mathrm{CMX}$ on $\mathrm{Ca}^{2+}$ responses in rabbit platelets. As expected, ADP-induced $\mathrm{Ca}^{2+}$ responses of single platelets in vitro were not influenced by preincubation with AR-CMX, In vivo, fluo-3 labeled platelets participated in the thromboembolic reaction and individual, labeled platelets were seen adhering to growing 
emboli. During AR-CMX infusion, the $\mathrm{Ca}^{2 *}$ responses of these platelets were not different from control (data not shown). Hence, AR-CMX seems specific for the $\mathrm{P}_{2} \mathrm{Y}_{12}$ receptor in rabbit platelets.

The optimal AR-CMX dose for in vivo experiments was established ex vivo, using whole blood aggregometry (Figure 4.1). Doses higher than $1 \mu \mathrm{g} / \mathrm{kg} / \mathrm{min}$ significantly (PS0.05) decreased maximal aggregation: infusion of $1 \mu \mathrm{g} / \mathrm{kg} / \mathrm{min}$ reduced aggregation by $49 \pm 14 \%, 3$ $\mu \mathrm{g} / \mathrm{kg} / \mathrm{min}$ by $71 \pm 6 \%$, and $10 \mu \mathrm{g} / \mathrm{kg} / \mathrm{min}$ by $80 \pm 5 \%$. Because infusion of $3 \mu \mathrm{g} / \mathrm{kg} / \mathrm{min}$ AR-CMX caused an almost maximal inhibition of aggregation (Figure 4.1), this dose was selected for subsequent in vivo experiments.

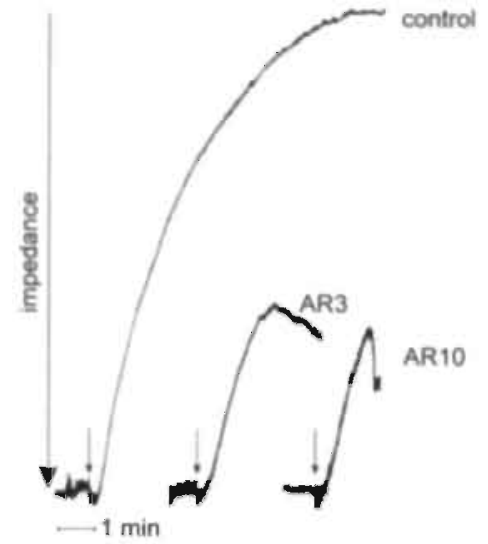

Figure 4.1. Inhibition of ADP-induced platelet aggregation in rabbit whole blood after infusion of AR-CMX. Typical aggregation tracings of whole blood collected after a $20 \mathrm{~min}$ infusion period with saline (control), $3 \mu \mathrm{g} / \mathrm{kg} / \mathrm{min}$ AR-CMX (AR3), or 10 $\mu \mathrm{g} / \mathrm{kg} / \mathrm{min}$ AR-CMX (AR10). Arrows indicate moment of ADP addition.

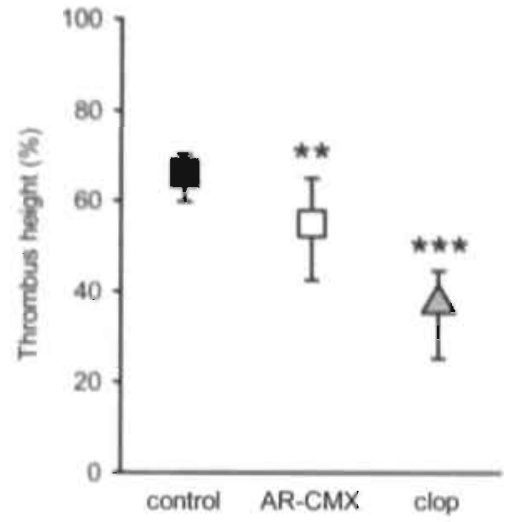

Figure 4.2. Effects of AR-CMX of clopidogrel (clop) on thrombus formation induced by wall puncture of rabbit arterioles. Thrombus height is expressed as percentage of local vessel diameter: medians with interquartile ranges are shown. * $P \leq 0.01$ and *** $P \leq 0.001$ as compared to control in Mann-Whitney U test.

\section{Effect of $\mathrm{P}_{2 Y_{12}}$ blockade on the thromboembolic reaction in vivo}

After puncture of mesenteric arterioles (control: $n=29$; AR-CMX: $n=36$; clopiudogrel: $n=19$ ) bleeding and thrombus formation started immediately; formation of the primary thrombus was completed within 1-2 s. AR-CMX reduced thrombus height by about $20 \%$ (control median: $66 \%$; AR-CMX: 54\%; $P \leq 0.005$; Figure 4.2); microvessel bleeding time was not influenced (control: $4.9 \mathrm{~s}$, interquartile range 2.3-7.7; AR-CMX: $2.9 \mathrm{~s}, 1.3-10.7 ; P=0.57$ ). After initial thrombus formation rebleeding occurred in some vessels, but this frequency was similar in both groups (control 24\%; AR-CMX 28\% of vessels). Clopidogrel had similar effects: thrombus height was reduced to $37 \%(P \leq 0.001$; Figure 4.2$)$ without significantly influencing microvessel bleeding time $(3.1 \mathrm{~s} ; 1.9-5.8 ; P=0.29)$, or rebleeding frequency $(37 \% ; P=0.52)$. Thus, although 
the thrombus was smaller during $\mathrm{P} 2 \mathrm{Y}_{12}$ blockade, its effectiveness to stop bleeding and prevent rebleeding was not influenced.

The formation of emboli on the downstream side of the thrombus was markedly reduced by AR-CMX (Figure 4.3). The total duration of embolization was decreased from $469 \mathrm{~s}$ in control to $228 \mathrm{~s}$ in AR-CMX arterioles. ( $P \leq 0.001$; Figure 4.3A). In 11 of 29 control vessels embolization continued for $>600 \mathrm{~s}$, whereas it stopped within $600 \mathrm{~s}$ in all but one AR-CMX arteriole. During the embolization period, on average 14 visible emboli (short axis $>5 \mu \mathrm{m}$ ) were produced in control arterioles and only 8 in AR-CMX vessels ( $P \leq 0.001$; Figure 4.3B). Moreover, AR-CMX decreased the size of these emboli: overall median embolus size per vessel was $10-15 \mu \mathrm{m}$ in control arterioles and only $5-10 \mu \mathrm{m}$ in AR-CMX vessels ( $P \leq 0.01$; Figure 4.3B). Because these observed emboli tended to get smaller during the course of embolization, individual emboli were compared as well. Of the first 10 emboli produced per vessel, 9 were significantly smaller in the AR-CMX arterioles compared to controls. In clopidogrel-treated animals, embolization duration was reduced to $303 \mathrm{~s}$ ( $P \leq 0.05$ compared to control; Figure 4.3A); 8 emboli were produced per vessel $(P \leq 0.05$; Figure 4.3B) with a median size of 5-10 $\mu \mathrm{m}$ $(P \leq 0.01$; Figure 4.3C).

To investigate whether the smaller size of the emboli is due to decreased platelet adhesion during $\mathrm{P}_{2} \mathrm{Y}_{12}$ blockade, the rate of adherence of individual platelets was determined in the experiments with fluo- 3 labeled platelets. Individual, labeled platelets adhered to the growing emboli at a similar rate in control (4.8 platelets/min, 2.9-9.7) and AR-CMX treated animals (3.9 platelets $/ \mathrm{min}, 2.4-5.5 ; P=0.39$ ). The seemingly incompatible combination of an unchanged platelet adherence rate and the formation of smaller emboli at a similar embolus production time (control: median $21.2 \mathrm{~s}$, interquartile range 13.8-29.7; AR-CMX: 21.6 s, 13.831.7) indicates that AR-CMX caused detachment of small platelet aggregates that did not reach the visible embolus size of $5 \mu \mathrm{m}$, in addition to the visible emboli.

\section{Platelet-dependent thrombin generation}

The effect of $\mathrm{P} 2 \mathrm{Y}_{12}$ blockade on platelet-dependent thrombin formation was tested ex vivo. Infusion of $3 \mu \mathrm{g} / \mathrm{kg} / \mathrm{min}$ AR.CMX reduced the peak value of thrombin generation by $25 \pm 7 \%$ ( $P=0.06$; Figure 4.4). This parameter was not further reduced when PRP from blood collected after infusion was preincubated with $\mathrm{AR}-\mathrm{CMX}(10 \mu \mathrm{mol} / \mathrm{l})$ in vitro, indicating that infusion of $3 \mu \mathrm{g} / \mathrm{kg} /$ min AR-CMX maximally reduced $\mathrm{P}_{2} \mathrm{Y}_{12}$-dependent thrombin formation. Preincubation of control blood with $10 \mu \mathrm{mol} / \mathrm{AR}-\mathrm{CMX}$ in vitro caused a reduction of thrombin generation of $42 \pm 11 \%$, which was not significantly different from the decrease caused by AR$\mathrm{CMX}$ infusion $(P=0.24)$. This suggests that the effective plasma concentration of AR-CMX during the in vivo experiments was in the micromolar range, near $10 \mu \mathrm{mol} /$. 

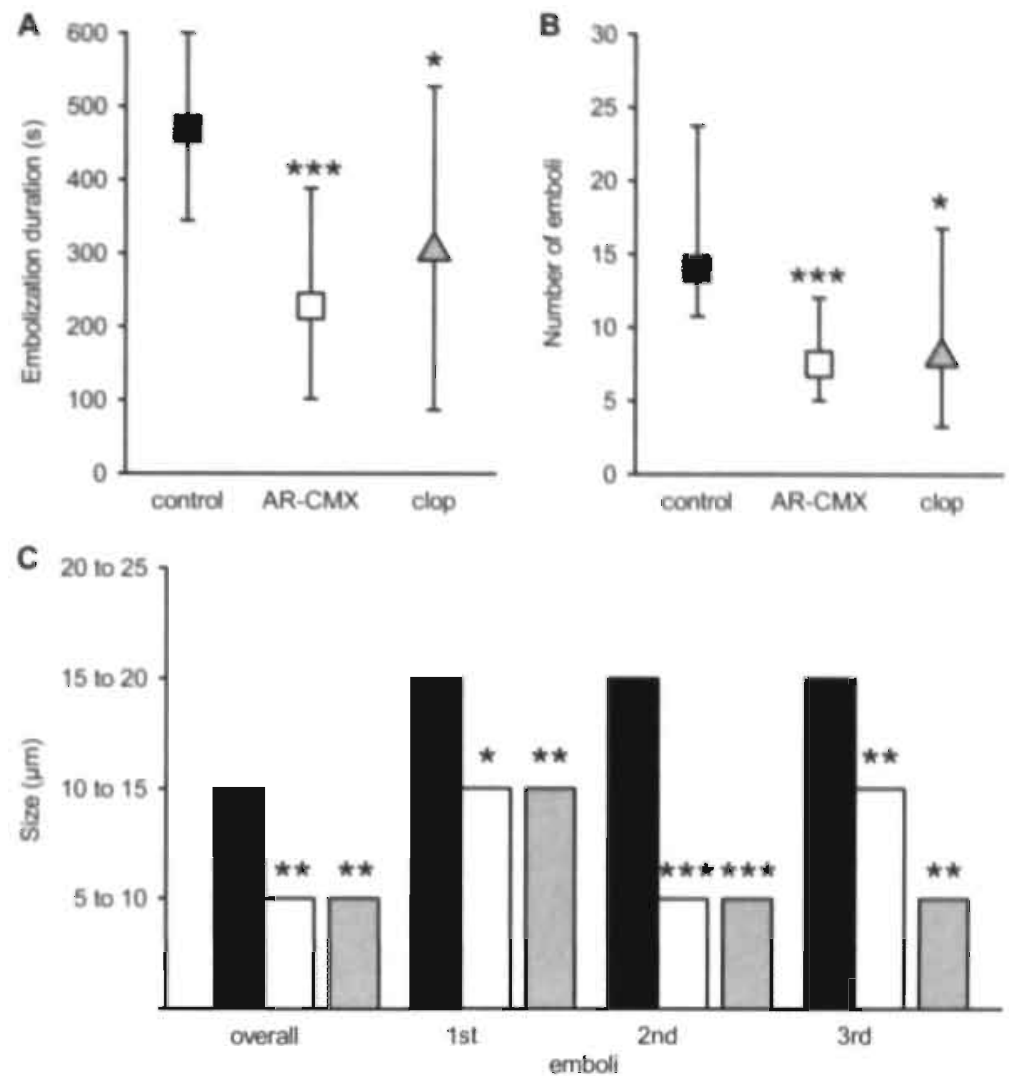

Figure 4.3، Effects of AR-CMX and clopidogrel (clop) on embolization after wall puncture in rabbit arterioles. Medians + interquartile ranges of $(\mathbf{A})$ duration of embolization, (B) number of emboh produced per vessel. (C) Median embolus size of first, second and third embolus per vessel, and overal! median per vessel. Black bars $*$ control, white bars $=A R$ CMX, grey bars $=$ clopidogrel. * $P \leq 0.05 ; * P \leq 0.01$; and *** $P \leq 0.00 \mathrm{I}$ as compared to control in Mann-Whitney U test.

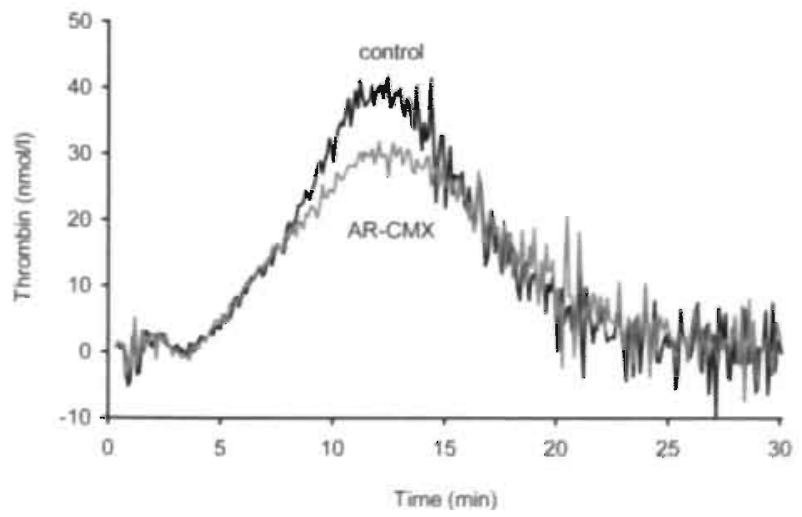

Figure 4.4. Inhibition of plateletdependent thrombin generation by ARCMX. Typical examples of thrombin generation in PRP from blood collected before (control) and after (AR-CMX) infusion of $3 \mu \mathrm{g} / \mathrm{kg} / \mathrm{min}$ AR-CMX. The reaction was started by adding fluorescent thrombin substrate ar $1=0$. 


\section{Systemic parameters and fluid dynamic conditions}

Ear bleeding time increased from 7.0 (control) to 20.5 min (AR-CMX) during $\mathrm{P}^{2} \mathrm{Y}_{12}$ inhibition. Mean arterial blood pressure (MAP), heart rate, hematocrit and platelet count were not different from control during AR-CMX or clopidogrel treatment. Overall medians and ranges were: MAP $69 \mathrm{mmHg}$ (46-93), heart rate 148 beats per min (116-192), hematocrit $40 \mathrm{I} / \mathrm{l}$ (32-53), platelet count $520 \times 10^{9} / 1(268-836)$; these values are within normal ranges for anesthetized rabbits. ${ }^{17,26}$

In addition, $\mathrm{P}_{2} \mathrm{Y}_{12}$ blockade had no significant effect on local fluid dynamic parameters: arteriolar diameter $29 \mu \mathrm{m}$ (19-46), mean red blood cell velocity $1.8 \mathrm{~mm} / \mathrm{s}(0.3-6.1)$, and wall shear rate $943 \mathrm{~s}^{-1}$ (181-3605) were not different between groups. These parameters were not significantly correlated with any of the thromboembolic parameters.

\section{Discussion}

This is the first study to show that -in damaged rabbit arterioles- blocking the platelet ADP receptor $\mathrm{P}_{2} \mathrm{Y}_{12}$ reduces initial thrombus formation and especially reduces the number and size of emboli shed by the initial thrombus, without influencing thrombus stability. The rate of embolization and the rate of adherence of individual platelets to growing emboli are not decreased. The seemingly incompatible combination of an unchanged platelet adherence rate and the formation of smaller emboli indicates that even smaller and, hence, less harmful aggregates $(<5 \mu \mathrm{m})$ are produced during $\mathrm{P} 2 \mathrm{Y}_{12}$ blockade as well, probably due to relatively loose adhesion of platelets to the primary thrombus.

$\mathrm{P} 2 \mathrm{Y}_{12}$ is the target of many antithrombotic drugs. ${ }^{12-15}$ The present in vivo findings provide insight in the way these drugs interfere in the dynamic process of thromboembolism. This study shows that blockade of $\mathrm{P}_{2} \mathrm{Y}_{12}$ is especially effective during the embolization phase of a thromboembolic process. The duration of embolization was reduced by $40-50 \%$ with a correspondingly lower number of emboii; moreover, emboli were significantly smaller. Assuming that the process of platelet adhesion and aggregation that underlies embolization is similar in small and large vessels, these data may explain the effectiveness of $\mathrm{P}_{2} \mathrm{Y}_{12}$-inhibiting drugs in reducing the risk of ischemic events like myocardial or cerebral infarction or peripheral arterial ischemia in patients with atherothrombotic disease, ${ }^{12,13}$ because such ischemic events are considered to be the result of relatively large emboli shed from a thrombus.

Taking into account that $\mathrm{P} 2 \mathrm{Y}_{1}$-mediated ADP effects are not influenced, the effects of $\mathrm{P} 2 \mathrm{Y}_{12}$ blockade (by AR-CMX or clopidogrel) on embolization clearly indicate a prominent role for ADP during this phase of the thromboembolic process. Because emboli are of a loose nature and consist of weakly activated platelets compared to platelets in the thrombus, ${ }^{20}$ it is indeed 
likely that embolization involves platelet activation caused by relatively weak platelet agonists like ADP. Activated platelets and vascular cells can also release thromboxane $\mathrm{A}_{2}\left(\mathrm{TX} \mathrm{A}_{2}\right)$, which stimulates platelet aggregation. Previously we have shown that in the same animal model specific blockade of $\mathrm{TXA}_{2}$ receptors by sulotroban (BM 13.177) significantly reduces embolization in arterioles by $>55 \%$, without influencing thrombus size and stability. ${ }^{18}$ These effects of TXA $\mathrm{T}_{2}$ receptor blockade on embolization (which can also be achieved by low doses of aspirin) are similar to those of $\mathrm{P}_{2} \mathrm{Y}_{12}$ blockade. The involvement of both TXA 2 and ADP in embolization may explain why combined blockade of ADP and TXA pathways in patients is more effective in reducing ischemic events than blocking the TXA 2 pathway alone. ${ }^{13}$

In addition to the pronounced inhibition of embolization, $\mathrm{P} 2 \mathrm{Y}_{12}$ blockade resulted in a reduction of thrombus size. The biological relevance of this reduction can be questioned because rebleeding frequency was not influenced, indicating that the stability of the thrombus was unaffected. The reduction in thrombus size during $\mathrm{P} 2 \mathrm{Y}_{12}$ blockade may be the consequence of a decrease in thrombin formation at the surface of procoagulant platelets. Because -in contrast to emboli- the primary thrombus is a stable aggregate with tightly packed, heavily shape changed, and degranulated platelets that may be procoagulant, ${ }^{20}$ it is likely that thrombin is mainly formed in the thrombus. This is confirmed by pilot experiments in which a low molecular weight heparin was used: thrombus stability decreased but embolization was unaffected (unpublished data, 2002). Thrombin can play a dual role in thrombus formation: by activating platelets it is (partially) responsible for thrombus size, and by converting fibrinogen into fibrin it stabilizes the thrombus. In the present study we show that AR-CMX infusion indeed reduces thrombin generating capacity by about $25 \%$, which may explain the decrease in thrombus size. Since thrombus stability is not influenced by $\mathrm{P}_{2} \mathrm{Y}_{12}$ blockade, the remaining thrombin is apparently able to produce sufficient fibrin. The reduction in thrombus size may also be due to inhibition of collagen-induced platelet activation, because in vitro studies have shown that collagen-induced platelet aggregation is impaired in platelets from $\mathrm{P} 2 \mathrm{Y}_{12}$ deficient mice. ${ }^{6}$ In addition, in perfusion studies over collagen surfaces thrombus size was found to be reduced in human platelets deficient for $\mathrm{P}_{2} \mathrm{Y}_{12},{ }^{27}$ or when this receptor was blocked by AR-CMX (in vitro) ${ }^{27}$ or clopidogrel (ex vivo). ${ }^{28}$

The microvessel bleeding times presented this study are relatively short and unaffected by $\mathrm{P} 2 \mathrm{Y}_{12}$ receptor blockade. Bleeding times as measured in mice ${ }^{6}$ and humans ${ }^{15}$ are substantially longer and prolonged when blocking the $\mathrm{P}_{2} \mathrm{Y}_{12}$ receptor. This discrepancy can likely be explained by the different types of vessel damage between the models used, being small in our model of vessel wall puncture and more severe in mice and men where larger vessels are transected and surrounding tissue is opened as well. This is supported by our observation that $\mathrm{P} 2 \mathrm{Y}_{12}$ blockade substantially increases bleeding time in case of more severe damage in the ear. 
In summary, this is the first study in which the role of the ADP receptor $\mathrm{P} 2 \mathrm{Y}_{12}$ is investigated in the thromboembolic process in vivo. Inhibiting this receptor especially reduces the production of potentially harmful emboli, without affecting the stability of the initial thrombus. Although our data are obtained in small rabbit arterioles, they may represent a general mechanism of action for $\mathrm{P}_{2} \mathrm{Y}_{12}$-inhibiting drugs in diseased human arteries: by shortening embolization duration and decreasing the size of emboli the risk for downstream ischemia will be clearly reduced.

\section{Acknowledgments}

The authors thank AstraZeneca (Loughborough, UK) for kindly providing the compound ARC69931MX and for supporting this study. We also thank Drs. Robert Humphries and Stewart Sage for their valuable contributions to this manuscript, and Els Kosters for technical assistance.

\section{References}

1. Rauch U, Osende J., Fuster V, Badimon JJ, Fayad Z, and Chesebro JH. Thrombus formation on atherosclerotic plaques: pathogenesis and clinical consequences. Ann Intern Med, 2001;134:224-238.

2. Cattaneo M, and Gachet C. ADP receptors and clinical bleeding disorders. Arterioscler Thromb Vasc Biol. 1999;19:2281-2285.

3. Jin J, and Kunapuli SP. Coactivation of two different G protein-coupled receptors is essential for ADP-induced platelet aggregation. Proc Natl Acad Sci USA. 1998:95:8070-8074.

4. Fabre JE, Nguyen M, Latour A, Keifer JA, Audoly LP, Coffman TM, and Koller BH. Decreased platelet aggregation, increased bleeding time and resistance to thromboembolism in $\mathrm{P}_{2} \mathrm{Y}_{1}$-deficient mice. Nat Med. 1999;5:1199-1202.

5. Léon C, Hechler B, Freund M, Eckly A, Vial C, Ohlmann P. Dierich A, LeMeur M, Cazenave JP, and Gachet $C$. Defective platelet aggregation and increased resistance to thrombosis in purinergic $\mathrm{P} 2 \mathrm{Y}_{\mathrm{I}}$ receptor-null mice. J Clin Invest. 1999:104:1731-1737.

6. Foster CJ, Prosser DM, Agans JM, Zhai Y, Smith MD, Lachowicz JE, Zhang FL, Gustafson E, Monsma FJ, Jr., Wiekowski MT, Abbondanzo SJ, Cook DN, Bayne ML, Lira SA, and Chintala MS. Molecular identification and characterization of the platelet ADP' receptor targeted by thienopyridine antithrombotic drugs. J Clin Invest. 2001;107:1591-1598.

7. Hollopeter G, Jantzen HM, Vincent D, Li G, England L, Ramakrishnan V, Yang RB, Nurden P, Nurden A, Julius D, and Conley PB. Identification of the platelet ADP receptor targeted by antithrombotic drugs. Nature, 2001:409:202-207. 
8. Jarvis GE, Humphries RG, Robertson MJ, and Leff P. ADP can induce aggregation of human platelets via both $\mathrm{P}_{2} \mathrm{Y}_{1}$ and $\mathrm{P}_{2 \mathrm{~T}}$ receptors. Br J Pharmacol. 2000;129:275-282.

9. Kauffenstein G, Bergmeier W, Eckly A, Ohlmann P, Léon C, Cazenave JP, Nieswandt B, and Gachet C. The $\mathrm{P} 2 \mathrm{Y}_{12}$ receptor induces platelet aggregation through weak activation of the $\alpha_{1 n} \beta_{3}$ integrin - a phosphoinositide 3-kinase-dependent mechanism. FEBS Lett. 2001;505:281-290.

10. Trumel C, Payrastre B, Plantavid M, Hechler B, Viala C, Presek P, Martinson EA, Cazenave JP, Chap $\mathrm{H}$, and Gachet C. A key role of adenosine diphosphate in the irreversible platelet aggregation induced by the PAR1-activating peptide through the late activation of phosphoinositide 3-kinase. Blood. $1999: 94: 4156-4165$.

11. Geiger J, Brich J, Honig-Liedl P, Eigenthaler M, Schanzenbacher P, Herbert JM, and Walter U. Specific impairment of human platelet $\mathrm{P} 2 \mathrm{Y}_{\mathrm{AC}}$ ADP receptor-mediated signaling by the antiplatelet drug clopidogrel. Arterioscler Thromb Vasc Biol. 1999;19:2007-2011.

12. Hass WK, Easton JD, Adams HPJ, Pryse-Phillips W, Molony BA, Anderson S, and Kamm B. A randomized trial comparing ticlopidine hydrochloride with aspirin for the prevention of stroke in high-risk patients. $N$ Engl J Med. 1989;321:501-507.

13. The Clopidogrel in Unstable Angina to Prevent Recurrent Events Trial Investigators. Effects of clopidogrel in addition to aspirin in patients with acute coronary syndromes without ST-segment elevation. N Engl J Med. 2001;345:494-502.

14. Ingall AH, Dixon J, Bailey A, Coombs ME, Cox. D, Mclnally J, Hunt SF, Kindon ND. Teobald BJ, Willis PA. Humphries RG, Leff P, Clegg JA, Smith JA, and Tomlinson W. Antagonists of the platelet $\mathrm{P}_{2 \mathrm{~T}}$ receptor: a novel approach to antithrombotic therapy. J Med Chem. 1999;42:213-220.

15. Storey RF, Oldroyd KG, and Wilcox RG. Open multicentre study of the $P_{2 \pi}$ receptor antagonist ARC6993IMX assessing safety, tolerability and activity in patients with acute coronary syndromes. Thromb Haemost. 2001;85:401-407.

16. Huang J, Driscoll EM, Gonzales ML, Park AM, and Lucchesi BR. Prevention of arterial thrombosis by intravenously administered platelet P2T receptor antagonist AR-C69931MX in a canine model. $J$ Pharmacol Exp Ther. 2000;295:492-499.

17. oude Egbrink MGA, Tangelder GJ, Slaaf DW, and Reneman RS. Thromboembolic reaction following wall puncture in arterioles and venules of the rabbit mesentery. Thromb Haemost. 1988;59:23-28.

18. oude Egbrink MGA, Tangelder GJ, Slaaf DW, and Reneman RS. Different roles of prostaglandins in thromboembolic processes in arterioles and venules in vivo. Thromb Haemost. 1993;70:826-833.

19. Broeders MAW, Tangelder GJ, Slaaf DW, Reneman RS, and oude Egbrink MGA. Hypercholesterolemia enhances thromboembolism in arterioles but not in venules; complete reversal by L-Arginine. Arterioscler-Thromb Vasc Biol. 2002:680-685. 
20. van Gestel MA, Heemskerk JWM, Slaaf DW, Heijnen VVT, Sage SO, Reneman RS, and oude Egbrink MGA. Real-time detection of activation patterns in individual platelets during thromboembolism in vivo: differences between thrombus growth and embolus formation. $J$ Vasc Res. 2002;39:534-543.

21. Slaaf DW, Rood JPSM, Tangelder GJ, Jeurens TJM, Alewijnse R, Reneman RS, and Arts T. A. bidirectional optical (BDO) three-stage prism grating system for on-line measurement of red blood cell velocity in microvessels. Microvasc Res, 1981;22:110-122.

22. Tangelder GJ, Slaaf DW, Arts T, and Reneman RS. Wall shear rate in arterioles in vivo: least estimates from platelet velocity profiles. Am J Physiol. 1988;254:H1059-H1064.

23. Savi P, Beauverger P, Labouret C, Delfaud M, Salel V, Kaghad M, and Herbert JM. Role of P2Y1 purinoceptor in ADP-induced platelet activation. FEBS Lett. 1998;422:291-295.

24. Heemskerk JWM, Willems GM, Rook MB, and Sage SO. Ragged spiking of free calcium in ADPstimulated human platelets: regulation of puff-like calcium signals in vitro and ex vivo. $J$ Physiol. 2001;535:625-635.

25. Hemker HC, Giesen PL, Ramjee M, Wagenvoord R, and Béguin S. The thrombogram: monitoring thrombin generation in platelet-rich plasma. Thromb Haemost. 2000;83:589-591.

26. Kozma C, Macklin W, Cummins LM, and Mauer R. The anatomy, physiology, and the biochemistry of the rabbit. In: Weisbroth SH, Flat RE, and Kraus AL, eds. The biology of the laboratory rabbit. New York: Academic Press; 1974:49-90.

27. Remijn JA, Wu YP, Jeninga EH, Jsseldijk MJW, van Willigen G, de Groot PG, Sixma JJ, Nurden AT, and Nurden P. Role of ADP receptor $\mathrm{P}_{2} \mathrm{Y}_{12}$ in platelet adhesion and thrombus formation in nlowing blood. Arterioscler Thromb Vasc Biol. 2002;22:686-691.

28. Roald HE, Barstad RM, Kierulf P, Skjorten F, Dickinson JP, Kieffer G, and Sakariassen KS. Clopidogrel - a platelet inhibitor which inhibits thrombogenesis in non-anticoagulated human blood independently of the blood flow conditions. Thromb Haemost. 1994;71:655-662. 
Antithromboembolic effects of blocking ADP receptors $P 2 Y_{1}$ and $P 2 Y_{12}$ in vivo: no addifive effects of simultaneous blockade

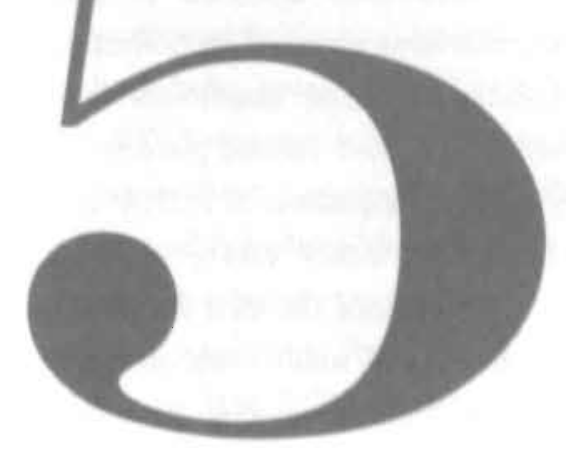

Miriam A. van Gestel, Johan W.M. Heemskerk, Dick W. Slaaf, Sietze Reitsma, Joost C.M. Schrier, Viviane V.Th. Heijnen, Robert S. Reneman, \& Mirjam G.A. oude Egbrink 


\section{Abstract}

Adenosine diphosphate (ADP) is one of the important platelet agonists in thromboembolism. ADP-induced platelet activation involves two receptors, $\mathrm{P} 2 \mathrm{Y}_{1}$ and $\mathrm{P} 2 \mathrm{Y}_{12}$. The role of $\mathrm{P}_{2} \mathrm{Y}_{1}$, as well as the combined role of both receptors in the dynamic process of thromboembolism in vivo is largely unknown. Therefore, we investigated in real-time the effect of blocking $\mathrm{P} 2 \mathrm{Y}_{1}$ and $\mathrm{P} 2 \mathrm{Y}_{12}$, both separately and in combination, on thrombus formation and embolization in vivo.

Mesenteric arterioles of anesthetized rabbits were mechanically injured; subsequent thrombus formation and embolization were visualized using intravital microscopy. Systemic and local fluid dynamic conditions were monitored as well. In addition, the in vivo behavior of individual, fluo-3 labeled platelets and their $\mathrm{Ca}^{2+}$ responses were measured. $\mathrm{P}_{2} \mathrm{Y}_{\mathrm{I}}$ was blocked by topical application of A3P5P or MRS-2179, while P2Y 12 was blocked by AR-C69931MX administered either intravenously or topically. Blocking either $\mathrm{P} 2 \mathrm{Y}_{1}$ or $\mathrm{P} 2 \mathrm{Y}_{12}$ significantly $(\mathrm{P}<0.01$ ) reduced the total duration of embolization (by $75 \%$ and $64 \%$, respectively), in which period less and smaller emboli were produced due to a decreased interaction strength between platelets. Simultaneous blockade of both receptors did not further reduce embolization. During P2 $\mathrm{Y}_{12}$ blockade, the stability of the primary thrombus was unaffected. P2 $\mathrm{Y}_{1}$ blockade, however, reduced thrombus stability since rebleeding occurred more frequently $(\mathrm{P} \leq 0.01)$. Intracellular $\mathrm{Ca}^{2+}$ transients were reduced by $\mathrm{P} 2 \mathrm{Y}$, blockade only.

In conclusion, our results demonstrate that P2Y, blockade has similar anti-embolic effects compared to $\mathrm{P}_{2} \mathrm{Y}_{12}$ blockade, and combined blockade does not further inhibit embolization. The decreased thrombus stability during $\mathrm{P} 2 \mathrm{Y}_{1}$ blockade may be explained by the reduced $\mathrm{Ca}^{2+}$ response in participating platelets. 


\section{Introduction}

When the wall of a blood vessel is damaged or diseased, as in atherosclerosis, blood platelets adhere to the exposed subendothelium, leading to activation and subsequent aggregation. A stable thrombus is formed due to tight platelet-platelet interactions and fibrin formation.' Often, platelets keep adhering to the downstream side of such a thrombus, forming new platelet aggregates that embolize repeatedly. These emboli are considered potentially hazardous, because they may occlude downstream vessels and cause, for instance, cerebral infarction. $^{2}$

Adenosine diphosphate (ADP) is released from platelets upon activation, and contributes to the recruitment of circulating platelets during a thromboembolic process. ADP-induced platelet activation involves two receptors: the $\mathrm{G}_{\mathrm{q}}$-coupled $\mathrm{P} 2 \mathrm{Y}_{1}$ receptor which causes an increase in cytosolic free $\mathrm{Ca}^{2+}\left(\left[\mathrm{Ca}^{2+}\right]\right)$, mediates shape change and initiates aggregation, and the $\mathrm{G}_{1}$-coupled $\mathrm{P} 2 \mathrm{Y}_{12}$ receptor which inactivates adenylate cyclase and completes the aggregation response in vitro. ${ }^{3-5}$ The platelet-specific receptor $\mathrm{P}_{2} \mathrm{Y}_{12}$ is a known target for antithrombotic drugs like ticlopidine and clopidogrel., ${ }^{5,6}$ Defects in this receptor have been found in patients with congenital bleeding diathesis. ${ }^{4,6}$ Recently, we showed in vivo that $\mathrm{P} 2 \mathrm{Y}_{12}$-blocking drugs inhibit the formation of emboli from a thrombus, whereas thrombus stability, i.e. its effectiveness to stop bleeding, is unaffected. ${ }^{7}$ The $\mathrm{P} 2 \mathrm{Y}_{1}$ receptor is also considered a promising target for antithrombotic drugs, because its inhibition has been shown to reduce thrombus formation in mice. -10 $^{8-10}$ Hower, the role of $\mathrm{P} 2 \mathrm{Y}_{1}$ during the dynamic process of thromboembolism is largely unknown. In vitro data indicate that simultaneous blockade of both receptors results in more pronounced reduction of platelet aggregation and thrombus formation than blocking either receptor alone. ${ }^{5,11-13}$ Data from a recent in vivo study on $\mathrm{FeCl}_{3}$-induced thrombus formation in $\mathrm{P} 2 \mathrm{Y}_{1}$ knockout mice also suggest an additive effect of $\mathrm{P} 2 \mathrm{Y}_{12}$ blockade. $^{10}$

The aim of the present study was to investigate in vivo -in real-time- the effects of P2Y, blockade on thrombus formation and embolization using an established rabbit model, ${ }^{7.14,15}$ and to compare these effects to those of $\mathrm{P}_{2} \mathrm{Y}_{12}$ blockade. In addition, we studied the antithromboembolic potential of concurrent blockade of both receptors. It is shown that P2Y, blockade inhibits embolization to a similar extent as blockade of $\mathrm{P} 2 \mathrm{Y}_{12}$. Surprisingly, simultaneous blockade of $\mathrm{P} 2 \mathrm{Y}_{1}$ and $\mathrm{P} 2 \mathrm{Y}_{12}$ does not reduce embolization any further. Besides, $\mathrm{P} 2 \mathrm{Y}$, blockade destabilizes the primary thrombus, resulting in a higher rebleeding frequency; $\mathrm{P} 2 \mathrm{Y}_{12}$ inhibition has no such effect. 


\section{Methods}

\section{Animal preparation and intravital microscopy}

Experiments were approved by the local ethical committee on the use of laboratory animals, and performed on New Zealand White rabbits (1.9-2.7 kg; $n=26)$ of either sex as described before., 74,15 Anesthesia was induced by intramuscular injections of $40 \mathrm{mg}$ ketamine hydrochloride (Nimatek; Eurovet) and $4 \mathrm{mg}$ xylazine hydrochloride (Sedamun; Eurovet) per $\mathrm{kg}$ body weight, and maintained by continuous infusion of ketamine $(40 \mathrm{mg} / \mathrm{kg} / \mathrm{h})$ and xylazine $(5 \mathrm{mg} / \mathrm{kg} / \mathrm{h})$ dissolved in lactetrol $(15 \mathrm{ml} / \mathrm{h}$; Eurovet). Body temperature was kept at $37-38^{\circ} \mathrm{C}$. Arterial pressure and heart rate were continuously monitored via a catheter in the femoral artery. Rabbits were ventilated via a tracheal tube with a mixture of nitrogen ( $74 \%)$, oxygen ( $25.5 \%)$, and carbon dioxide $(0.5 \%)$ to maintain systemic arterial $\mathrm{pH}$ (mean $\pm \mathrm{SEM} 7.48 \pm 0.02), \mathrm{P}_{02}$ $(86 \pm 4 \mathrm{mmHg})$, and $\mathrm{P}_{\mathrm{CO} 2}(43 \pm 2 \mathrm{mmHg})$. Arterial platelet counts and hematocrit were assessed before start of experimentation (Coulter Counter; Coulter Electronics).

Through a midline abdominal incision, a segment of the distal ileum was exteriorized. The mesentery was continuously superfused with buffered Tyrode's solution $\left(37^{\circ} \mathrm{C}, \mathrm{pH} 7.35-7.40\right)$, and visualized with an intravital microscope (Leitz) using a long working distance objective (Leitz LL25. numeric aperture 0.35). Images were projected on a charge-coupled device camera (Hamamatsu) and stored on videotape for off-line analysis. Final optical magnification at the front plane of the camera was x 52 .

\section{Vessel wall puncture and thromboembolic reaction}

After stabilization for 30 min, mesenteric arterioles (diameter $19-41 \mu \mathrm{m}$ ) were mechanically injured by wall puncture using a glass micropipette (tip diameter $6-8 \mu \mathrm{m}$ ). Puncture was considered successful if red blood cells left the vessel, indicating that all wall layers were damaged. In all vessels, bleeding stopped within a few seconds by the formation of a white, platelet-rich thrombus. Circulating platelets continuously adhered to the downstream side of this thrombus; these newly formed aggregates embolized repeatedly without affecting size and shape of the stationary thrombus. Experiments were performed within $150 \mathrm{~min}$ following stabilization; the observation period per vessel was $600 \mathrm{~s}$;

The following parameters were quantified off-line: duration of initial bleeding (microvessel bleeding time), occurrence of rebleeding, total bleeding duration (initial bleeding plus rebleeding time), maximal thrombus height (relative to local vessel diameter), total duration of embolization, number of emboli produced, and size of individual emboli. Emboli were counted when their radial axis was $>5 \mu \mathrm{m}$; smaller aggregates could not be distinguished from the background with sufficient accuracy. The cumulated number of emboli in time was used to determine embolus production rate. Axial sizes of individual emboli were categorized on a semiquantitative scale: 5-10 $\mu \mathrm{m}, 10-15 \mu \mathrm{m}$, etc. Embolus size was squared to determine cross-sectional embolus area; cumulated embolus area in time was used to estimate the growth rate of the embolizing thrombus. 
Vascular diameter was measured off-line with an image-shearing device. Mean red blood cell velocity was measured on-line directly preceding puncture. Wall shear rate was calculated using velocity and diameter data. ${ }^{16}$

\section{Application of ADP' receptor antagonists}

Adenosine-3',5'-biphosphate (A3P5P; Sigma-Aldrich) was used to block P2 $\mathrm{Y}_{1}$, Intravenous infusion of A3P5P, in doses that did not yet affect ex vivo platelet aggregation, reversibly reduced blood pressure (unpublished observations). To avoid such systemic effects, A3P5P was applied to the mesentery topically. Just before wall puncture, the superfusion solution was replaced with $150 \mu \mathrm{A}$ A35P in a high concentration (100 mmol//). After the observation period A3P5P was removed by resuming superfusion with Tyrode's solution. In additional experiments (9 arterioles) P2Y, was blocked with MRS-2179 (10 mmol/ topically; Sigma-Aldrich).

The platelet-specific receptor $\mathrm{P}_{2} \mathrm{Y}_{12}$ was inhibited by continuous intravenous infusion of $\mathrm{AR}$ C69931MX (AR-C; AstraZeneca) in an effective dose of $3 \mu \mathrm{g} / \mathrm{kg} / \mathrm{min}{ }^{7}$ which did not influence blood pressure. To determine whether the route of administration influenced our findings, AR-C ( 1 mmol//) was also applied topically in additional experiments (5 arterioles). Per rabbit ( $n=13)$, on average 4 arterioles were punctured in the presence of either vehicle (saline; control), A3P5P, AR-C, or both, in varying order; we verified that order did not affect the results. Arterioles were assigned to four groups; control $(n-20)$, $\operatorname{A3P5P}(n=17), \operatorname{AR}-\mathrm{C}(n=7)$, and A3P5P+AR-C $(n=11)$.

\section{Single platelet $\mathrm{Ca}^{2+}$ measurements and behavior during embolizution}

Effects of ADP receptor antagonists on single platelet $\mathrm{Ca}^{2+}$ responses in vivo were assessed in 10 rabbits as described before. ${ }^{14}$ In short, isolated platelets were loaded with the $\mathrm{Ca}^{2+}$-sensitive dye fluo-3 acetoxymethylester $(5 \mu \mathrm{mol} / \mathrm{I})$ and injected into anesthetized rabbits so that $0.5-1 \%$ of total circulating platelets were labeled. Subsequently, arterioles were punctured (control $n=8$, AR-C $n=7$, A3P5P or MRS$2179 n=7)$ and fluorescence intensity changes were measured using a fluorescence imaging system (Visitech International) connected to the intravital microscope. In addition, adherence rate and detachment patterns of labeled platelets were determined to assess platelet behavior.

In some vessels, ADP ( $\mathrm{mmol} / \mathrm{l})$ was administered topically at the end of an experiment, i.e. $>3$ min after embolization had stopped. This was done in the presence and absence of AR-C infusion ( $n=3$ and $n=5$ arterioles, respectively).

\section{Platelet aggregation, thrombin generation, and cytosolic $\mathrm{Ca}^{2+}$ measurements in vitro}

Platelet-rich plasma (PRP) was prepared from blood collected in 1/10 volume trisodium citrate $(0.129 \mathrm{~mol} / \mathrm{l})$ from a central ear artery of 3 rabbits. For aggregation measurements, PRP $\left(2 \times 10^{8}\right.$ platelets $/ \mathrm{ml})$ was recalcified with $16.6 \mathrm{mmol} / \mathrm{CaCl}$, and PPACK $(40 \mu \mathrm{mol} / \mathrm{l})$ was added. Aggregation was 
induced by $3 \mu \mathrm{mol} / \mathrm{ADP}$, either alone or combined with U46619 $(0.2 \mu \mathrm{mol} / \mathrm{l})$, and measured at $37^{\circ} \mathrm{C}$ using a Chronolog optical aggregometer.

Platelet-dependent thrombin generation in time was measured using the Thrombogram method. ${ }^{17}$ PRP (1.5 $\times 10^{8}$ platelets $/ \mathrm{ml}$ ) was added to wells of a 96-well plate containing rabbit thromboplastin (1/30,000 volume Thromboplastin-S; Biopool International). Thromboplastin was diluted in such a way that formation of thrombin depended on the presence of platelets. Thrombin formation was started by adding $\mathrm{CaCl}_{2}$ (16.6 mmol/ $)$ and fluorescent thrombin substrate $(417 \mu \mathrm{mol} / \mathrm{Z}$-Gly-Gly-Arg-AMC; Bachem), and continuously measured in time with a microtiter plate fluorometer (Fluoroskan Ascent; Labsystems) at $37^{\circ} \mathrm{C}$.

Intracellular $\mathrm{Ca}^{2+}$ responses were measured in suspensions of isolated rabbit platelets $\left(10^{8}\right.$ platelets $/ \mathrm{ml})$ loaded with fura-2 acetoxymethylester $(3 \mu \mathrm{mol} / \mathrm{l}) .{ }^{14}$ Measurements were performed using a spectrofluorimeter (Aminco-Bowman) at $37^{\circ} \mathrm{C}$ in the presence of $2 \mathrm{mmol} / / \mathrm{CaCl}_{2}$ and $3 \mu \mathrm{mol} / \mathrm{ADP}$.

\section{Statisfical analysis}

In vivo data are presented as median values. with (interquartile) ranges, because of their nonsymmetrical distribution. Differences between experimental groups were tested using the MannWhitney $U$ or Chi-square test. The Spearman rank correlation test was used for correlations. The level of significance was set at $5 \%$.
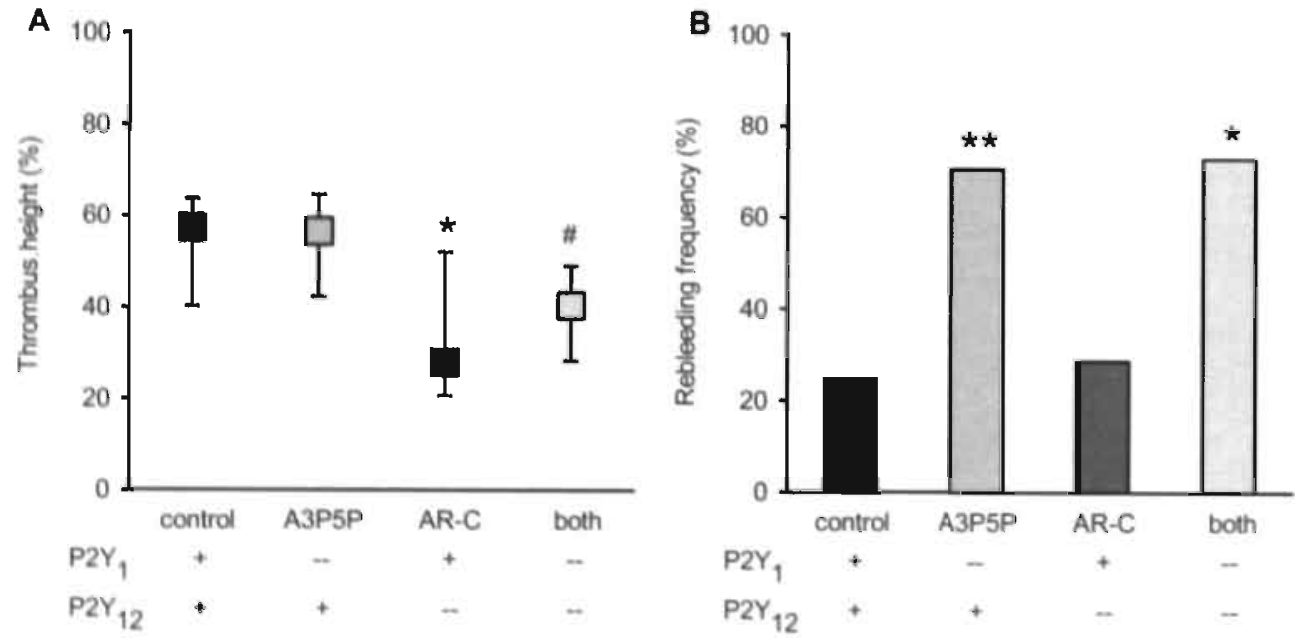

Figure 5.1. In vitwo effects of ADP receptor blockade on thrombus size and stability. (A) Thrombus size: maximal thrombus height expressed as percentage of local vessel diameter; medians and interquartile ranges are shown. (B) Thrombus stability: frequency of rebleeding expressed as percentage of arterioles in which rebleeding occurred. P2Y $+=$ active, P2Y - = blocked; both = A3P5P+AR-C; * PS0,05, * PS0.01, " PC0.10 compared to control. 


\section{Results}

The specificity of A3P5P and AR-C in rabbits was confirmed by measuring ADPinduced platelet $\mathrm{Ca}^{2+}$ responses in vitro. As expected, $\mathrm{P} 2 \mathrm{Y}$, blockade by A3P5P $(100 \mu \mathrm{mol} / \mathrm{l})$ inhibited $\mathrm{Ca}^{2+}$ responses almost completely $(90 \%)$, whereas $\mathrm{P} 2 \mathrm{Y}_{12}$ blockade by AR-C $(1 \mu$ mol/ $)$ had no effect $(<3 \%)$.

\section{Effects of ADP receptor blockade on thrombus formation in vivo}

In all vessels, bleeding and thrombus formation started immediately after puncture; the thrombus was completed within 1-2 s. Initial microvessel bleeding time (control: median $2.8 \mathrm{~s}$, interquartile range 0.7-6.3) was not influenced by A3P5P $(2.1 \mathrm{~s}, 0.6-5.9)$, AR-C $(2.7 \mathrm{~s}, 1.0-5.1)$, or A3P5P+AR-C (2.7 s, 2.2-7.4). Maximal thrombus height (control: $57 \%$ of vessel diameter) was not affected by A3P5P, whereas it was reduced significantly by AR-C $(P \leq 0,05)$ and nonsignificantly by A3P5P+AR-C $(P<0.10$; Figure 5.1A). Despite similar thrombus size, rebleeding occurred more often in A3P5P-treated rabbits ( $71 \%$ of arterioles; $P \leq 0.01)$ than in controls $(25 \%)$ or $\mathrm{AR}$-C-treated ones $(29 \%)$. A3P5P+AR-C increased rebleeding frequency to $73 \%(P \leq 0.05$; Figure 5.1B). Consequently, the total duration of bleeding per vessel (control: $3.3 \mathrm{~s}, 0.8-10.3$ ) was increased by A3P5P $(26.1 \mathrm{~s}, 1.7-79.2 ; P=0.06)$ and $A 3 P 5 P+A R-C(14.4 \mathrm{~s}, 2.9-64.3$; Ps0.05), but not by AR-C (3.2 s, 1.9-11.4). When AR-C was applied topically instead of intravenously, similar effects on thrombus size $(37 \%)$ and rebleeding $(20 \%)$ were found, indicating that data are not influenced by the route of administration. As with A3P5P, the P2Y, inhibitor MRS-2179 increased rebleeding frequency $(67 \% ; P \leq 0.05)$. However, MRS-2179 reduced thrombus height to $40 \%(34-47 ; P \leq 0.05)$, which may be due to the higher potency of this blocker. ${ }^{8}$

Thus, while $\mathrm{P} 2 \mathrm{Y}_{12}$ blockade reduced thrombus height but maintained its effectiveness to stop bleeding, $\mathrm{P} 2 \mathrm{Y}_{1}$ blockade caused more rebleeding indicating decreased thrombus stability.

\section{Effects of $A D P$ receptor blockade on embolization in vivo}

ADF receptor blockade markedly reduced embolus formation on the downstream side of the thrombus. Total duration of embolization was decreased by $75 \%$ during $P 2$ Y, blockade with A3P5P ( $P \leq 0.001)$, by $64 \%$ during P2Y 12 blockade with AR-C $(P \leq 0.001)$, and by $75 \%$ in the A3P5P+AR-C group ( $P \leq 0.005$; Figure $5.2 \mathrm{~A})$. On average 10 visible emboli were produced in control arterioles, and only $3(P \leq 0.001), 2(P \leq 0.01)$, and $3(P \leq 0.01)$ in A3P5P, AR-C. and $\mathrm{A} 3 \mathrm{P} 5 \mathrm{P}+\mathrm{AR}$-C-treated vessels, respectively (Figure 5.2B). In control vessels, embolus production rate was constant in time; during ADP receptor blockade it started to decline after about $50 \mathrm{~s}$ (Figure $5.2 \mathrm{C}$ ). The median embolus size was reduced from $10-15 \mu \mathrm{m}$ in the control group to 5-10 $\mu \mathrm{m}$ in $\mathrm{A} 3 \mathrm{P} 5 \mathrm{P}, \mathrm{AR}-\mathrm{C}$, and $\mathrm{A} 3 \mathrm{P} 5 \mathrm{P}+\mathrm{AR}-\mathrm{C}$ groups. The growth rate of the 
embolizing thrombus was relatively constant over time in control vessels, but leveled off quickly when one or both ADP receptors were blocked (Figure 5.2D), again indicating that emboli produced during ADP receptor blockade were smaller compared to control emboli. Topical administration of AR-C had similar effects on embolization (55\% decrease) as compared to systemic infusion, again indicating that AR-C effects are independent of the administration route. Effects of MRS-2179 on embolization were similar to those of A3P5P: on average 2 emboli were produced in $56 \mathrm{~s}(24-330 ; P \leq 0.05)$, with an overall median size of $5-10 \mu \mathrm{m}$.

Thus, embolization duration and embolus size were reduced to a similar extent during $\mathrm{P} 2 \mathrm{Y}_{1}$ or $\mathrm{P}_{2} \mathrm{Y}_{12}$ blockade. Surprisingly, simultaneous inhibition of both receptors did not cause an additional reduction of embolization.
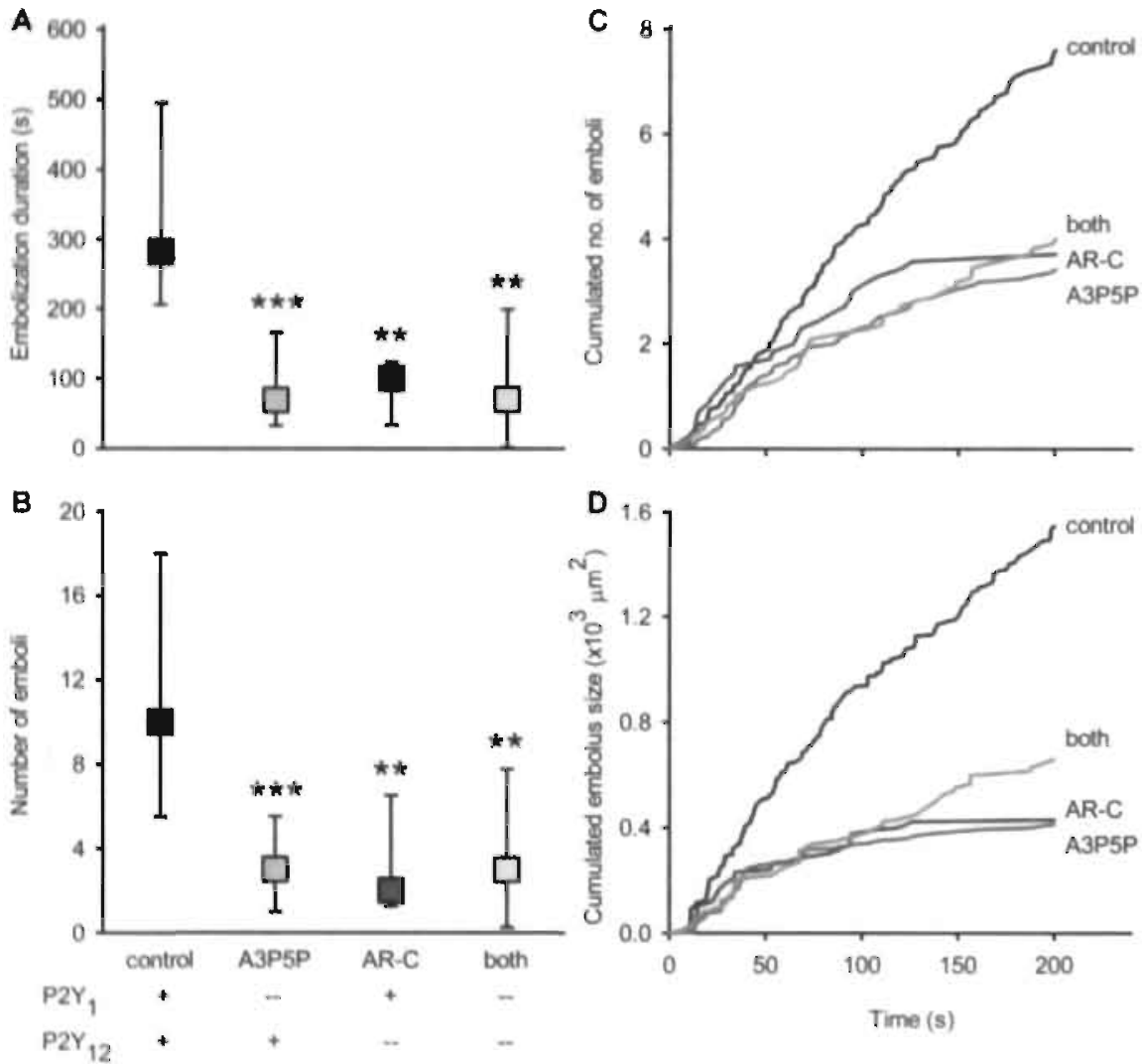

Figure 5.2. In wivo effects of ADP receptor blockade on embolization. Medians and interquartile ranges of (A) total duration of embolization, and (B) number of emboli produced per vessel in the four groups. (C) Cumulated number of emboli produced in the first $200 \mathrm{~s}$ after puncture: in each group data from all vessels were pooled, then averaged. The slope of each curve represents the rate of embolization. (D) Cumulated area of emboli produced in the first $200 \mathrm{~s}$ after puncture; in each group data from all vessels were pooled, then averaged. The slope of cach curve represents the growth rate of the emboli. P2Y + = active, P2Y - = blocked; both = A3P5P+AR-C; * PS0.01, ** Ps0.001 compared to control. 


\section{Effects of ADP receptor blockade on single platelet behavior in vivo}

To investigate whether the decreased embolization during ADP receptor blockade resulted from decreased platelet adhesion rate, decreased attachment strength, or both, the behavior of single platelets participating in a thromboembolic reaction was studied. Blockade of neither $\mathrm{P}_{2} \mathrm{Y}_{1}$ nor $\mathrm{P} 2 \mathrm{Y}_{12}$ significantly influenced the adhesion rate of individual, fluorescently labeled platelets ( $0.5-1 \%$ of circulating platelets) to growing emboli (Figure 5.3A). However, the detachment pattern of labeled platelets was influenced. In the control situation the majority of labeled platelets detached in pairs or in groups of 3 or more, which is representative of relatively large platelet aggregates. Only $26 \%$ of labeled platelets detached individually, representing smaller aggregates (Figure 5.3B). During ADP receptor blockade the percentage of individually detaching labeled platelets was increased to 89\% (A3P5P; PS0.001) and 78\% (AR-C; PS0.001), again indicating that the embolizing aggregates were smaller. P2Y, blockade by MRS-2179 had similar effects as A3P5P: an unaffected platelet adhesion rate (3.5 labeled platelets/min) with $100 \%$ individually detaching labeled platelets.

Summarizing, neither $\mathrm{P}_{2} \mathrm{Y}_{1}$ nor $\mathrm{P}_{2} \mathrm{Y}_{12}$ blockade reduced platelet adhesion rate; however, the detachment of smaller aggregates indicates that the interaction strength between adhering platelets was decreased in both situations. These data are consistent with the finding that $\mathrm{ADP}$ receptor blockade results in smaller emboli.
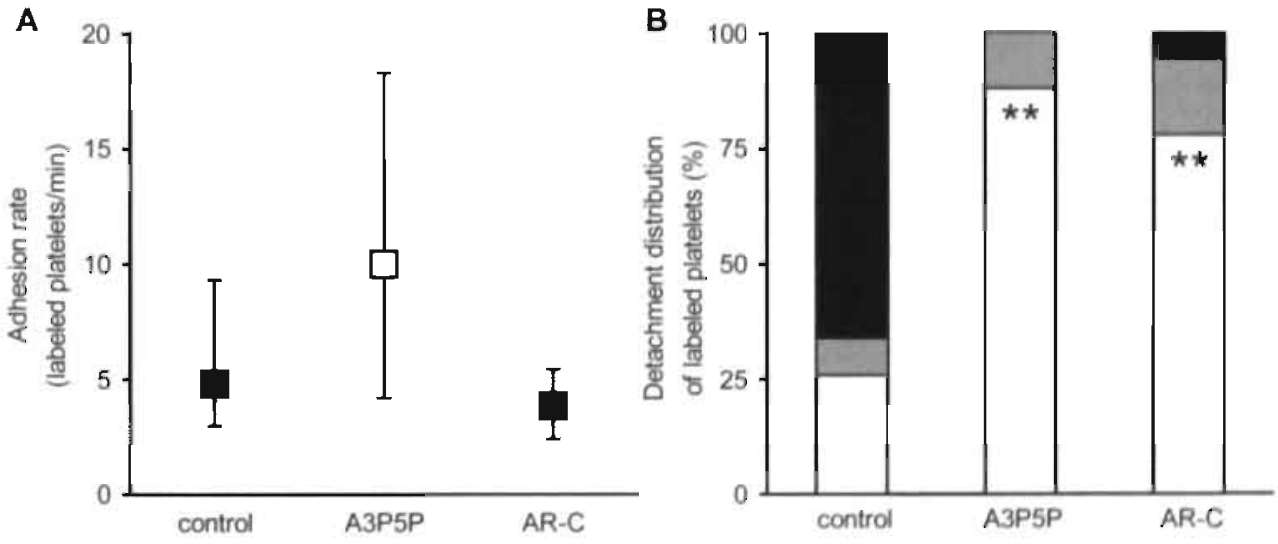

Figure 5.3. In vivo effects of ADP receptor blockade on behavior of individual, fluo-3 labeled platelets. (A) Medians and interquartile ranges of platelet adhesion rate expressed as number of adhering labeled platelets per min. (B) Detachment distribution of platelets: percentage of labeled platelets detaching as single platelet (i.e. one labeled platelet at an time; white), in pairs (grey) or in groups of three or more (black). " P $\leq 0.01$ compared to control. 


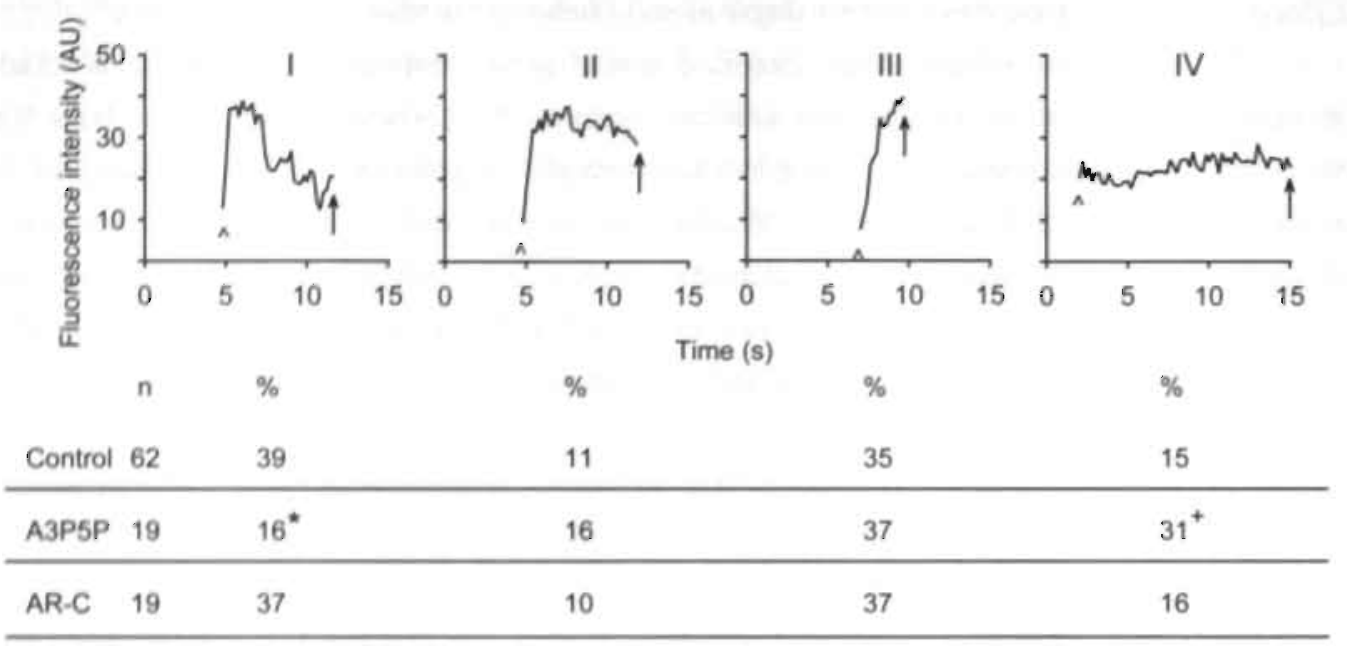

Figure 5.4. In vivo effects of ADP receptor blockade on $\mathrm{Ca}^{2 *}$ responses in single fluo-3 labeled platelets adhering to the embolizing thrombus. Typical examples of different types of $\mathrm{Ca}^{22}$ responses (I-IV), and their distribution within the total population of adhering platelets $(n)$ in each group are shown. Type I: fast, transient $\left[\mathrm{Ca}^{2}\right]$, increase; II: fast, prolonged $\left[\mathrm{Ca}^{2}\right]$, increase; III: fast $\left[\mathrm{Ca}^{2}\right]$, increase, but no further classification possible (i.e, platelets were present for $<2$ s after the increase); IV: slow or no increase in $\left[\mathrm{Ca}^{2+}\right]_{\text {. }}$. Fluorescence intensity is in arbitrary units $(\mathrm{AU}) ;{ }^{\wedge}=\mathrm{moment}$ of adhesion, $\uparrow=$ moment of detachment; $* P \leq 0.05,+P=0.06$ compared to control.

Table 5.1. Effects of exogenous ADP on behavior of labeled platelets ( $0.5-1 \%$ of circulating platelets) during embolization in vivo. ADP was applied topically to the mesentery $>3$ min after initial embolization had stopped.

ADP during

control

ADP

AR-C infusion

\begin{tabular}{|c|c|c|c|}
\hline \multicolumn{4}{|l|}{ Adhesion rate $\left(\min ^{-1}\right)$} \\
\hline median & 4.8 & $18.3^{*}$ & 12.4 \\
\hline interquartile range & $3.1-8.9$ & $10.7-23.8$ & $8.4-12.5$ \\
\hline \multicolumn{4}{|c|}{ Distribution of detachment $(\%)$} \\
\hline single; pair, more & $26 ; 8 ; 66$ & $18 ; 17 ; 65$ & $60^{*} ; 8 ; 32$ \\
\hline \multicolumn{4}{|c|}{ Distribution of $\mathrm{Ca}^{2 *}$ responses } \\
\hline no, of platelets & 62 & 25 & 6 \\
\hline $\mathrm{I} ; \mathrm{II} ; \mathrm{II} \mathbf{\mathrm { i }} ; \mathrm{IV}(\%)$ & $39 ; 11: 35: 15$ & $56 ; 4 ; 32 ; 8$ & $50 ; 16 ; 17 ; 17$ \\
\hline
\end{tabular}

I: fast, transient $\left[\mathrm{Ca}^{2+}\right]$, increase; II: fast, prolonged $\left[\mathrm{Ca}^{2+}\right]$, increase; III: fast $\left[\mathrm{Ca}^{2+}\right]$, increase but no further classification possible; IV: slow or no increase in $\left[\mathrm{Ca}^{2+}\right]_{1}$ (see Figure 5.4); ${ }^{*}$ PSo.05 compared to control; + PS0.001 compared to ADP. 


\section{Effects of $A D P$ receptor blockade on single platelet $\mathrm{Ca}^{2+}$ responses in vivo}

In individual, fluo-3 labeled platelets that adhered to growing emboli four types of $\mathrm{Ca}^{2+}$ responses could be distinguished (Figure 5.4). In the control situation, the majority of platelets $(85 \%)$ showed a fast increase in $\left[\mathrm{Ca}^{2+}\right]$, upon adhesion (rate of increase $>10 \%$ of peak value per second), the increase being either transient (response type I: 39\%), prolonged (II: 11\%), or indeterminable (i.e. detachment within $2 \mathrm{~s}$ after the increase, III: 35\%). The remaining platelets exhibited a slow $\left[\mathrm{Ca}^{2+}\right]$ increase or no increase at all upon adherence (IV: $15 \%$ ). As expected, the distribution of $\mathrm{Ca}^{2+}$ responses was not influenced by AR-C. With A3P5P more platelets exhibited a type IV response $(31 \% ; P=0.06)$ at the expense of type I $\left[\mathrm{Ca}^{2+}\right]_{\text {increases }}(16 \%$; P 50.05$)$.

These results indicate that, in vivo, ADP acting on the $\mathrm{P} 2 \mathrm{Y}$, receptor contributes to the increase in $\left[\mathrm{Ca}^{2+}\right]$, that occurs upon adhesion of platelets to a growing embolus.

\section{Effects of excess $A D P$ on single platelet behavior and $\mathrm{Ca}^{2+}$ responses in vivo}

When ADP was administered at the end of an experiment, new emboli started to grow and were shed from the thrombus (median duration $68 \mathrm{~s}$ ). During the formation of these emboli, the adhesion rate of single, labeled platelets was 18.3 platelets/min, which is significantly higher compared to control ( $P \leq 0.05$; Table 5.1). The detachment pattern of labeled platelets, on the other hand, was not affected (18\% detaching individually). When ADP was applied during AR$\mathrm{C}$ infusion median embolization duration was $30 \mathrm{~s}$, adhesion rate was 12.4 platelets/min, and the percentage of individually detaching platelets was increased to $60 \% \quad(P \leq 0.05$ compared to control and $P \leq 0.001$ compared to ADP; Table 5.1). In the presence of ADP, most adhering platelets showed a fast, transient increase in $\left[\mathrm{Ca}^{2+}\right]_{i}$ (type I), which was not changed by $A R-C$ (Table 5.1).

Thus, in vivo excess ADP opposes the effects of ADP receptor blockade, resulting in the formation of additional emboli. Simultaneous $\mathrm{P}_{2} \mathrm{Y}_{12}$ blockade partially eliminates the ADPinduced increase in platelet adherence rate; apparently, ADP binding to P2Y, is responsible for the rest of the effect. Application of ADP induces a fast, transient $\left[\mathrm{Ca}^{2+}\right]_{i}$ increase (i.e. the type of $\mathrm{Ca}^{2+}$ response that is reduced by $\mathrm{P} 2 \mathrm{Y}$, blockade) in most of the adhering platelets.

\section{Systemic parameters and fluid dynamic conditions}

Whole animal parameters were not different between groups.. Overall medians and ranges were: mean arterial blood pressure $73 \mathrm{mmHg}(47-96)$, heart rate 146 beats/min (67-I81), hematocrit $401 / 1(35-47)$, and platelet count $553 \times 10^{9} / 1$ ( I 76-659); these values are within normal ranges for anesthetized rabbits. ${ }^{7,14,15}$ In addition, ADP receptor blockade had no significant effect on local fluid dynamic parameters (Table 5.2). None of these parameters was significantly correlated with any of the thromboembolic parameters. 
Table 5.2. Fluid dynamic conditions in the punctured arterioles.

\begin{tabular}{|c|c|c|c|c|}
\hline & control & A3P5P & AR-C & A3P5P+AR-C \\
\hline \multicolumn{5}{|c|}{ Diameter $(\mu \mathrm{m})$} \\
\hline median & 27 & 30 & 33 & 31 \\
\hline range & $19-42$ & $21-38$ & $23-35$ & 19.41 \\
\hline \multicolumn{5}{|c|}{$\mathrm{mRBCV}(\mathrm{mm} / \mathrm{s})$} \\
\hline median & 1.7 & 1.7 & 2.8 & 2.6 \\
\hline range & $0.3-5.9$ & $0.7-4.5$ & $1.4-3.9$ & $0.7-5.6$ \\
\hline \multicolumn{5}{|c|}{ Shear rate $\left(s^{-1}\right)$} \\
\hline median & 969 & 921 & 1519 & 1440 \\
\hline range & $132-3167$ & $385-2552$ & $671-2047$ & $330-3114$ \\
\hline
\end{tabular}

$\mathrm{mRBCV}=$ mean red blood cell velocity.

\section{Effects of $A D P$ receptor blockade on rabbit platelets in vitro}

A3P5P reduced maximal ADP-induced aggregation in PRP by $37 \%$ at $1 . \mu \mathrm{mol} / 1,51 \%$ at $10 \mu \mathrm{mol} / \mathrm{I}, 91 \%$ at $100 \mu \mathrm{mol} / \mathrm{l}$, and $100 \%$ at $1 \mathrm{mmol} / \mathrm{l}$. AR-C also inhibited aggregation dosedependently, with a maximal effect of $46 \%$ at $1 \mu \mathrm{mol} / \mathrm{l}$. Preincubation with both $1 \mu \mathrm{mol} / \mathrm{I}$ AR-C and either 10 or $100 \mu \mathrm{mol} / 1$ A3P5P resulted in 89 and $100 \%$ inhibition, respectively, indicating that the two receptor antagonists have additive (but not synergistic) effects on ADP-induced aggregation in vitro. When platelets were stimulated with more than one agonist, i.e. ADP and the thromboxane $\mathrm{A}_{2}\left(\mathrm{TXA}_{2}\right)$ analogue $\mathrm{U} 46619$, no additive effect of combined ADP receptor blockade was seen. Inhibition by A3P5P alone $(100 \mu \mathrm{mol} / \mathrm{I})$ was $30 \%$, while A.R-C ( $1 \mu \mathrm{mol} / \mathrm{I})$ reduced aggregation by $49 \%$; simultaneous blockade resulted in $51 \%$ inhibition.

Platelet-dependent thrombin generation was not significantly affected by P2Y, blockade (A3P5P, I mmol/1: 22\% reduction of peak value $(P=0.22) ; \mathrm{MRS}-2179,100, \mu \mathrm{mol} / \mathrm{l}: \quad$ I $8 \%$ increase). $\mathrm{P} 2 \mathrm{Y}_{12}$ blockade inhibits the peak value of platelet-dependent thrombin generation in rabbit PRP by $25 \%(P=0.06)$.

\section{Discussion}

This study demonstrates that blockade of either one of the platelet ADP receptors, P2Y, or $\mathrm{P} 2 \mathrm{Y}_{12}$, significantly reduces number and size of emboli shed from a thrombus that is formed after vessel wall injury. This is probably due to a decreased interaction strength between platelets in the growing aggregates. Surprisingly, combined blockade of both receptors does not lead to additional reduction of embolization in vivo. When blocking $\mathrm{P} 2 \mathrm{Y}_{12}$ the primary thrombus is small, but stable. In contrast, during both $\mathrm{P}_{2} \mathrm{Y}_{1}$ and combined blockade thrombus stability is 
reduced, as indicated by increased rebleeding frequency. Blockade of $\mathrm{P} 2 \mathrm{Y}_{1}$, but not $\mathrm{P} 2 \mathrm{Y}_{12}$. inhibits the $\mathrm{Ca}^{2+}$ response in platelets participating in a thromboembolic reaction. The effects of the P2Y, blocker A3P5P were similar to those of MRS-2179, whereas the effects of the P2 $\mathrm{Y}_{12}$ inhibitor AR-C are equal to those of clopidogrel in the same model. ${ }^{7}$

Our data indicate that -in vivo- both ADP receptors are essential in embolization: blockade of either receptor significantly decreases the duration of embolization and the number and size of emboli, to a similar extent. We show that this is probably due to reduced plateletplatelet interaction strength, which may be caused by decreased activation of the integrin $\alpha$ llb $\beta 3$ receptor. These findings are in agreement with data from André et al., who showed that in $\mathrm{P}_{2} \mathrm{Y}_{12}$ knockout mice, platelets in a thrombus are less densely packed and less activated than in wildtypes; the $\mathrm{P}_{2} \mathrm{Y}_{12}$ knockouts exhibit reduced thrombosis with more smaller emboli. ${ }^{18}$ In previous experiments with fluorescently labeled platelets, we also showed that $\mathrm{P} 2 \mathrm{Y}_{12}$ blockade results in increased production of small aggregates that are not observed with bright-field microscopy. The present study indicates that $\mathrm{P} 2 \mathrm{Y}_{1}$ blockade has similar effects.

Surprisingly, simultaneous inhibition of $\mathrm{P}_{2} \mathrm{Y}_{1}$ and $\mathrm{P} 2 \mathrm{Y}_{12}$ did not lead to additional reduction of embolization duration or embolus size. In vitro experiments in the present and other studies $^{5,11-13}$ showed enhanced reduction of aggregation with concurrent blockade of both receptors compared to blocking only one of them. The absence of an additive effect in our in vivo model is probably explained by the presence of agonists other than ADP, such as TXA 2 and serotonin. These substances are released from activated platelets and probably preserve platelet aggregation when ADP-mediated responses are partially or totally eliminated. TX $\mathrm{A}_{2}$ has already been shown to contribute to embolus formation in vivo. ${ }^{15}$ Indeed, simultaneous blockade of both ADP receptors in vitro did not result in a larger reduction of platelet aggregation induced by a combination of $\mathrm{ADP}$ and the $\mathrm{TXA}_{2}$ analogue $\mathrm{U} 46619$, compared to blocking $\mathrm{P}_{2} \mathrm{Y}_{12}$ only. In an in vivo study using a $\mathrm{FeCl}_{3}$-induced mouse thrombosis model, combined ADP receptor blockade did result in additional reduction of thrombus formation. ${ }^{10}$ The discrepancy with our results is probably explained by the different methods of inflicting vessel wall damage ( $\mathrm{FeCl}_{3}$ vs. wall puncture), resulting in different contributions of platelet agonists and antagonists to the formation of thrombi and/or emboli.

ADP receptors, particularly $\mathrm{P}_{2} \mathrm{Y}_{12}$, have been proposed to be involved in stabilizing platelet aggregates. ${ }^{18,19}$ Thrombus stability is generally thought to result from the formation of thrombin and, hence, fibrin. We and others have shown that $\mathrm{P} 2 \mathrm{Y}_{12}$ blockade reduces plateletdependent thrombin generation ${ }^{7.20}$ and platelet procoagulant activity. ${ }^{20}$ However, the present in vivo data indicate that, although the thrombus is smaller during $\mathrm{P} 2 \mathrm{Y}_{12}$ blockade, its stability is unaffected. In contrast, P2Y, blockade does not affect thrombin generation (also shown by Léon et al.), ${ }^{20}$ yet significantly reduces thrombus stability. The latter finding indicates that beside. fibrin formation, other mechanisms contribute to thrombus stability as well. Alternative 
pathways leading to thrombus stabilization have been described for CD40L and fibrinogen acting via an integrin $\alpha$ IIb $\beta 3$-dependent mechanism. ${ }^{21.22}$ The present in vivo data show that binding of $A D P$ to $P 2 Y_{1}$ is involved in the platelet $\mathrm{Ca}^{2+}$ response. Because degranulation is $\mathrm{Ca}^{2+}$. dependent, ${ }^{23} \mathrm{ADP}$ binding to $\mathrm{P}_{2} \mathrm{Y}_{\mathrm{I}}$ may contribute to degranulation resulting in the release of CD40L, fibrinogen, and other substances (i.e. fibronectin, von Willebrand factor) that contribute to thrombus stability. ${ }^{1,21,22,24,25}$ Alternatively, it has been suggested that $\mathrm{P} 2 \mathrm{Y}_{1}$ inhibitors may affect the release of tissue factor from other $\mathrm{P}_{2} \mathrm{Y}_{1}$-expressing cells, i.e. endothelial cells or leukocytes, ${ }^{10}$ which would lead to reduced thrombin and fibrin formation independently of platelets.

Intravenous administration of $\mathrm{P}_{2} \mathrm{Y}_{12}$ blockers had no systemic consequences. In contrast, $\mathrm{P} 2 \mathrm{Y}$, blockers were applied locally because blood pressure was affected upon intravenous infusion, probably due to the presence of $\mathrm{P} 2 \mathrm{Y}_{1}$ receptors in vasoactive tissues. ${ }^{26}$ As a result, the effect of $\mathrm{P} 2 \mathrm{Y}_{1}$ blockade on ear bleeding time (which is prolonged during $\mathrm{P} 2 \mathrm{Y}_{12}$ blockade) ${ }^{7}$ could not be measured. The fact that local and systemic administration of AR-C had similar effects on thromboembolism strongly suggests that the differential effects of $\mathrm{P} 2 \mathrm{Y}_{1}$ and $\mathrm{P} 2 \mathrm{Y}_{12}$ blockade were not due to their different routes of administration.

The anti-embolic effects of the $\mathrm{P} 2 \mathrm{Y}_{12}$-blocking agent AR-C may explain the clinical observation that $\mathrm{P} 2 \mathrm{Y}_{12}$-inhibiting drugs reduce the risk of ischemic events in symptomatic atherothrombosis. ${ }^{27}$ Shorter embolization duration and smaller emboli, after all, are likely to be less hazardous. The $\mathrm{P} 2 \mathrm{Y}$, receptor may also be a promising target for antithrombotic drugs, because P2Y, blockade has similar beneficial effects on embolization. However, thrombus stability is decreased during $\mathrm{P} 2 \mathrm{Y}_{1}$ blockade, whereas $\mathrm{P} 2 \mathrm{Y}_{12}$ blockade has no such effect. The pathophysiological consequences of a decreased thrombus stability upon $\mathrm{P} 2 \mathrm{Y}_{1}$ blockade remain to be elucidated. Altogether, our findings show that $\mathrm{P} 2 \mathrm{Y}$, blockade in addition to or as replacement of $\mathrm{P} 2 \mathrm{Y}_{12}$ blockade does not result in improved antithromboembolic activity.

\section{Acknowledgments}

The authors thank AstraZeneca (Loughborough, UK) for kindly providing the compound ARC6993IMX, and Mariska Huls for technical assistance.

\section{References}

1. Ruggeri ZM. Platelets in atherothrombosis. Nat Med. 2002;8:1227-1234.

2. Markus H. Monitoring embolism in real time. Circulation. 2000;102;826-828. 
3. Jin J, and Kunapuli SP. Coactivation of two different G protein-coupled receptors is essential for ADP-induced platelet aggregation. Proc Natl Acad Sci USA. 1998;95:8070-8074.

4. Cattaneo M, Lecchi A, Lombardi R, Gachet C, and Zighetti ML. Platelets from a patient heterozygous for the defect of $\mathrm{P}_{2}$ cre receptors for $\mathrm{ADP}$ have a secretion defect despite normal thromboxane $\mathrm{A}_{2}$ production and normal granule stores - Further evidence that some cases of platelet 'primary secretion defect' are heterozygous for a defect of $\mathbf{P} 2$ cre receptors. Arterioscler Thromb Vase Biol. 2000;20:E101-E106.

5. Foster CJ, Prosser DM, Agans JM, Zhai Y, Smith MD, Lachowicz JE, Zhang FL, Gustafson E, Monsma FJ, Jr., Wiekowski MT, Abbondanzo SJ, Cook DN, Bayne ML, Lira SA, and Chintala MS. Molecular identification and characterization of the platelet ADP receptor targeted by thienopyridine antithrombotic drugs, J Clin Invest. 2001:107:1591-1598.

6. Hollopeter G, Jantzen HM, Vincent D. Li G, England L, Ramakrishnan V, Yang RB, Nurden P, Nurden A, Julius D, and Conley PB. Identification of the platelet ADP receptor targeted by antithrombotic drugs. Nature. 2001:409:202-207.

7. van Gestel MA, Heemskerk JWM, Slaaf DW, Heijnen VVT, Reneman RS, and oude Egbrink MGA. In vivo blockade of the platelet ADP receptor $\mathrm{P}_{2} \mathrm{Y}_{12}$ reduces embolus and thrombus formation, but not thrombus stability. Arterioscler Thromb Vasc Biol. 2003;23:518-523.

8. Baurand A, Raboisson P, Freund M, Léon C, Cazenave JP, Bourguignon JJ, and Gachet C. Inhibition of platelet function by administration of MRS2179, a P2Y, receptor antagonist. Eur $J$ Pharmacol. 200!;412:213-221.

9. Léon C, Freund M, Ravanat C, Baurand A, Cazenave JP, and Gachet C. Key role of the P2Y, receptor in tissue factor-induced thrombin- dependent acute thromboembolism: studies in P2Y,-knockout mice and miçe treated with a $\mathrm{P} 2 \mathrm{Y}_{1}$ antagonist. Circulation. 2001;103:718-723.

10. Lenain N, Freund $M_{2}$ Léon $C$. Cazenave JP, and Gachet $\mathbf{C}$. inhibition of localized thrombosis in $P 2 Y_{1}$ deficient mice and rodents treated with MRS2179, a P2Y, receptor antagonist. I Thromb Haemost. 2003;1:1144-1149.

11. Kauffenstein G, Bergmeier W, Eckly A, Ohlmann P, Léon C, Cazenave JP, Nieswandt B, and Gachet C. The $\mathrm{P} 2 \mathrm{Y}_{12}$ receptor induces platelet aggregation through weak activation of the $\alpha_{11 \mathrm{~b}} \beta_{3}$ integrin - a phosphoinositide 3-kinase-dependent mechanism. FEBS Letl. 2001;505:281-290.

12. Turner NA, Moake JL, and McIntire LV. Blockade of adenosine diphosphate receptors. P2 $Y_{12}$ and $\mathrm{P} 2 \mathrm{Y}_{\mathrm{I}}$ is required to inhibit platelet aggregation in whole blood under flow. Blood. 2001;98:33403345 .

13. Remijn JA, Wu YP, Jeninga EH, IJsseldijk MJW, van Willigen G, de Groot PG, Sixma JJ, Nurden AT, and Nurden P. Role of ADP receptor $\mathrm{P}_{2} \mathrm{Y}_{12}$ in platelet adhesion and thrombus formation in flowing blood. Arterioscler Thromb Vasc Biol. 2002;22:686-691. 
14. van Gestel MA, Heemskerk JWM, Slaaf DW, Heijnen VVT, Sage SO, Reneman RS, and oude Egbrink MGA. Real-time detection of activation patterns in individual platelets during thromboembolism in vivo: differences between thrombus growth and embolus formation. $J$ Vasc Res. 2002;39:534-543.

15. oude Egbrink MGA, Tangelder GJ, Slaaf DW, and Reneman RS. Different roles of prostaglandins in thromboembolic processes in arterioles and venules in vivo. Thromb Haemost. 1993;70:826-833.

16. Tangelder GJ, Slaaf DW, Arts T, and Reneman RS. Wall shear rate in arterioles in vivo: least estimates from platelet velocity profiles. Am J Physiol. 1988;254:H1059-H1064.

17. Hemker HC, Giesen PL, Ramjee M, Wagenvoord R, and Béguin S. The thrombogram: monitoring thrombin generation in platelet-rich plasma. Thromb Haemost. 2000;83:589-591.

18. André P, Delaney SM, LaRocca T, Vincent D, DeGuzman F, Jurek M, Koller B, Phillips DR, and Conley PB. P2 $\mathrm{Y}_{12}$ regulates platelet adhesion/activation, thrombus growth, and thrombus stability in injured arteries. J Clin Invest. 2003:112:398-406.

19. Cattaneo M, Canciani MT, Lecchi A, Kinlough Rathbone RL, Packham MA, Mannucci PM, and Mustard JF. Released adenosine diphosphate stabilizes thrombin-induced human platelet aggregates. Blood. 1990;75:1081-1086.

20. Léon C, Ravanat C. Freund M, Cazenave JP, and Gachet C. Differential involvement of the P2Y, and P2 $\mathrm{Y}_{12}$ receptors in platelet procoagulant activity. Arterioscler Thromb Vasc Biol. 2003;23:1941-1947.

21. Nannizzi-Alaimo L, Alves VL, and Phillips DR. Inhibitory effects of glycoprotein IIb/IIla antagonists and aspirin on the release of soluble CD40 ligand during platelet stimulation. Circulation. 2003;107:1123-1128.

22. Ni H, Papalia JM, Degen J, and Wagner DD. Control of thrombus embolization and fibronectin internalization by integrin $\alpha$ Ilb $\beta 3$ engagement of the fibrinogen $\gamma$ chain. Blood. 2003;102:3609-3614.

23. Heemskerk JWM. Calcium and platelets. In: Pochet R, Donato R, Haiech J, Heizmann C, and Gerke V, eds. The molecular basis of calcium action in biology and medicine. Dordrecht: Kluwer Academic Publishers; 2000:45-71.

24. André P, Prasad KSS, Denis CV, He M, Papalia JM, Hynes RO, Phillips DR, and Wagner DD. CD40L stabilizes arterial thrombi by a $\beta_{3}$ integrin-dependent mechanism. Nat Med. 2002;8:247-252.

25. Ni H, Yuen PST, Papalia JM, Trevithick JE, Sakai T, Fässler R, Hynes RO, and Wagner DD. Plasma fibronectin promotes thrombus growth and stability in injured arterioles. Proc Natl Acad Sci USA. 2003; 100:2415-2419.

26. Kunapuli SP, and Daniel JL. $\mathrm{P}_{2}$ receptor subtypes in the cardiovascular system. Biochem $J$. 1998;336:513-523.

27. The Clopidogrel in Unstable Angina to Prevent Recurrent Events Trial Investigators. Effects of clopidogrel in addition to aspirin in patients with acute coronary syndromes without ST-segment elevation. $N$ Engl J Med. 2001;345:494-502. 


\section{Effects of thrombin inhibition on thrombus}

formation and embolization in arterioles and venules in vivo

Miriam A. van Gestel, Johan W.M. Heemskerk, Dick W. Slaaf, Marion A.H. Feijge, Viviane V.Th. Heijnen, Margareta Elg, Robert S. Reneman, \& Mirjam G.A. oude Egbrink

Submitted as: "Thrombin inhibition reduces thrombus growth and effectiveness but hardly influences embolization in both arterioles and venules in vivo' 


\section{Abstract}

Thrombin plays an important and possibly differential role in arterial and venous thromboembolism, by acting as a potent platelet agonist and by forming fibrin. In the present study, we investigated the involvement of thrombin in primary thrombus formation and downstream embolization in damaged arterioles and venules in vivo.

Rabbit mesenteric vessels were mechanically injured by wall puncture, resulting in a thromboembolic reaction. Primary thrombus formation and subsequent downstream embolization were visualized in real-time using intravital microscopy. Thrombin formation was blocked by means of the direct factor $\mathrm{Xa}$ inhibitor GGACK, whereas thrombin activity was directly blocked with the direct thrombin inhibitors PPACK or melagatran. All three substances significantly reduced platelet-dependent thrombin generation in rabbit blood. In punctured arterioles, inhibition of factor $\mathrm{Xa}$ or thrombin significantly decreased the size of the thrombi, as well as their effectiveness (characterized by increased frequency and duration of rebleeding). In venules, a significant reduction in thrombus size was also found, whereas the increase in rebleeding was smaller. The difference in thrombus effectiveness normally found between arterioles and venules was decreased during inhibition of thrombin formation or activity. Downstream shedding of emboli from the primary thrombus was not influenced by either Xa or thrombin inhibition, regardless of vessel type. The effects of Xa or thrombin inhibition could not be explained by local fluid dynamic changes.

These findings demonstrate that -in the present model- thrombin, formed via the Xa pathway, plays a distinct role in thromboembolism in arterioles as well as venules. Thrombin appears to be particularly important for the formation of a hemostatically effective primary thrombus, its contribution seeming more eminent in the arterial than in the venous system. In contrast, thrombin is hardly involved in secondary embolus formation in either vessel type. 


\section{Introduction}

Thrombin plays a pivotal role in the reaction of blood to vessel wall injury, e.g. in hemostasis and in pathophysiological processes like thromboembolism. Once initial traces of thrombin are formed, several positive feedback mechanisms leading to potentiation of coagulation are initiated. As a result, fibrinogen is converted to fibrin, platelets are activated, and platelet procoagulant activity is induced..$^{1-3}$ Thus, during hemostatic plug formation and thromboembolism thrombin supports growth and stabilization of a plug or thrombus by stimulating platelets as well as coagulation. Thrombin is formed by factor $\mathrm{Xa}$ in the coagulation cascade, which is initiated by tissue factor (TF). ${ }^{1.2}$ Formation of both factor Xa and thrombin is strongly enhanced by phospholipids present at the procoagulant membrane of activated platelets, ${ }^{3,4}$ which illustrates the strong mutual dependency of platelet activation and coagulation.

Thrombus formation in the arterial system is considered to be predominantly mediated by platelets, whereas venous thrombosis is commonly associated with high coagulation activity. Indeed, arterial thrombi are usually rich in platelets, whereas venous thrombi are predominantly composed of fibrin and erythrocytes. ${ }^{5}$ Therefore, venous thrombosis is usually treated with anticoagulant drugs that inhibit e.g. thrombin or factor Xa activity. ${ }^{6}$ In addition to the established (low-molecular-weight) heparins, ${ }^{6}$ novel direct thrombin inhibitors, such as melagatran (the active form of the oral compound ximelagatran; Exanta ${ }^{\mathrm{TM}}$. AstraZeneca), are currently under clinical investigation as anticoagulants. ${ }^{5.7}$ Fibrin, however, is also present in arterial thrombi, and nowadays anticoagulant drugs are also used in the management of arterial thromboembolism, in combination with platelet-inhibiting drugs. ${ }^{6}$ In spite of the strong indications of an important and dual role of thrombin during hemostasis and thromboembolism in both the arterial and venous system, its precise, real-time involvement in these dynamic processes in vivo has not been well characterized.

It was the aim of the present study to investigate the role of thrombin in thromboembolism in both the arterial and venous microcirculation. To this purpose, we used an established in vivo injury model that allows simultaneous investigation of hemostasis and thromboembolism in both arterioles and venules ${ }^{8-13}$ In this model, wall puncture induces a thromboembolic reaction that can be monitored in real-time. This reaction consists of two phases: (1) the formation of a primary thrombus that stops bleeding from the injured vessel (hemostasis), and (2) the growth of new platelet aggregates (emboli) that are repeatedly shed from the downstream side of the thrombus (thromboembolism). Previous investigations in our institute have indicated that these two phases are regulated by different mediators. ${ }^{8,10-12}$ In the present study thrombin formation was blocked using the irreversible direct factor Xa inhibitor GGACK, while thrombin activity was blocked by means of the direct thrombin inhibitors PPACK (irreversible blockade) or melagatran (reversible blockade). We demonstrate that 
thrombin plays an important role in growth and stabilization of the primary thrombus in both arterioles and venules, although its contribution appears to be more eminent in arterioles. In contrast, thrombin is not involved in embolus formation in either vessel type.

\section{Methods}

\section{Animal preparation and intravital microscopy}

Experiments were approved by the local ethical committee on the use of laboratory animals. New Zealand White rabbits (1.5-2.8 kg; $n=23)$ of either sex were anesthetized by intramuscular injections of 40 mg ketamine hydrochloride (Nimatek; Eurovet) and $4 \mathrm{mg}$ xylazine hydrochloride (Sedamun; Eurovet) per $\mathrm{kg}$ body weight. Anesthesia was maintained by continuous infusion of ketamine $(40 \mathrm{mg} / \mathrm{kg} / \mathrm{h})$ and $x y l a z i n e$ $(5 \mathrm{mg} / \mathrm{kg} / \mathrm{h}$ ) dissolved in a lactetrol solution ( $15 \mathrm{~mL} / \mathrm{h}$; Eurovet), through a polyethylene (PE)-50 catheter in the femoral vein. Another catheter (PE-50) was placed in the femoral artery for monitoring of arterial pressure and heart rate (Uniflow external pressure transducer, Baxter). The catheter was kept patent by continuous infusion of saline ( $3 \mathrm{ml} / \mathrm{h})$; no heparin was used. Body temperature was kept at $37-38{ }^{\circ} \mathrm{C}$ using an infrared heating lamp controlled by a thermoanalyzer system connected to a rectal probe. A tracheal cannula (internal diameter $3.5 \mathrm{~mm}$ ) was inserted and connected to an animal ventilator (TSE). Ventilation was performed with a mixture of nitrogen $(74 \%)$, oxygen $(25.5 \%)$, and carbon dioxide $(0.5 \%)$, at a. respiratory rate of 60 per min and a positive end-expiratory pressure of $2 \mathrm{~cm} \mathrm{H}_{2} \mathrm{O}$. After surgery blood was collected from a central ear artery $(0.9 \mathrm{ml}$ in $0.1 \mathrm{ml} 1 \%$ w/v EDTA) for electronic platelet counts and hematocrit assessments (Coulter Counter; Coulter Electronics) as well as blood gas and pH measurements (acid-base analyzer; Radiometer). Throughout the experiments, $\mathrm{pH}$ and blood gas values were as follows: pH 7.43 $\pm 0.02, \mathrm{P}_{\mathrm{CO} 2} 46 \pm 3 \mathrm{mming}, \mathrm{P}_{02} 94 \pm 6 \mathrm{mmHg}$ (mean $\pm \mathrm{SEM}$ ). Ear bleeding time was determined by making incisions ( $1 \mathrm{~mm}$ deep and $10 \mathrm{~mm}$ long) parallel to the long axis of the ear, avoiding macroscopically visible vessels. The incision site was carefully blotted with filter paper at 30-second intervals; bleeding time was assessed from incision until the paper was no longer stained with blood. When bleeding still continued $30 \mathrm{~min}$ after incision, bleeding time was set at $>30 \mathrm{~min}$.

A segment of the distal ileum was exteriorized through a midline abdominal incision. The mesentery was spread over a siliconized glass plate mounted on the electrically heated table of an intravital microscope $\left(37^{\circ} \mathrm{C}\right)$ and continuously superfused with a buffered Tyrode's solution $\left(37^{\circ} \mathrm{C}, \mathrm{pH} 7.35-7.40\right)$ saturated with $95 \% \mathrm{~N}_{2}$ and $5 \% \mathrm{CO}_{2}$. The exteriorized ileum was kept moist with overlying wet gauze. The mesenteric tissue was visualized with an intravital microscope (Leitz), using a long working distance objective (Leitz LL25, numeric aperture 0.35). Transillumination was provided by a tungsten lamp. Images were projected on a CCD camera (Hamamatsu) and stored on videotape for off-line analysis. Final optical magnification at the front plane of the camera was $x 52$. 


\section{Vessel wall puncture and thromboembolic reaction in vivo}

After a stabilization period of $30 \mathrm{~min}$, mesenteric arterioles or venules (diameter 20-45 $\mu \mathrm{m}$ ) were selected and mechanically injured by wall puncture using a glass micropipette (tip diameter $6-8 \mu \mathrm{m}$ ), as described previously. ${ }^{8.13}$ Puncture was considered successful if red blood cells were seen leaving the vessel, indicating that all vessel wall layers were damaged. In all vessels, bleeding stopped immediately by the formation of a white platelet-rich thrombus, the shape and height of which remained constant over time. Circulating platelets continuously adhered to the downstream side of the stationary thrombus, and these newly formed aggregates embolized repeatedly. Embolization stopped after some time, while the thrombus remained unchanged at the site of injury during the observation period of $600 \mathrm{~s}$ per vessel. Several arterioles and venules were punctured during the $150 \mathrm{~min}$ after the stabilization period.

For each vessel, the following parameters were quantified off-line: duration of initial bleeding (initial microvessel bleeding time), number and duration of rebleedings, total microvessel bleeding time (initial bleeding time plus rebleeding duration), maximal thrombus height (relative to local vessel diameter), total duration of embolization, number of emboli produced, size of individual emboli, and median embolus production time per vessel. Emboli were counted when their radial axis was $>5 \mu$; smaller aggregates could not always be distinguished from the background with sufficient accuracy. Axial sizes of individual emboli were categorized on a semiquantitative scale: $5-10 \mu \mathrm{m}, 10-15 \mu \mathrm{m}$, etc. Vascular diameter was measured off-line with an image-shearing device. Mean red blood cell velocity was measured on-line for one minute directly preceding puncture, using a bidirectional optical prism grating system. ${ }^{14}$ Reduced velocity ( $\mathrm{U}$, a first-order approximation of wall shear rate) was calculated by dividing mean red blood cell velocity by vessel diameter.

\section{Experimental proiocol}

In the first set of experiments (16. rabbits), effects of thrombin were blocked in two ways: (1) through blockade of thrombin formation by direct inhibition of factor Xa using 1,5-dansyl-Glu-Gly-Argchloromethylketone (GGACK; Calbiochem), or (2) through direct thrombin inhibition wịth Phe-Pro-Argchloromethylketone (PPACK; Calbiochem). Both substances are irreversible inhibitors and were applied topically to the mesentery to prevent systemic side effects. Just before wall puncture, the superfusion solution was replaced by $150 \mu \mathrm{l}$ of either GGACK $(40 \mu \mathrm{mol} / 1)$, PPACK $(40 \mu \mathrm{mol} / \mathrm{l})$, or vehicle (TyrodeHepes solution, containing $136 \mathrm{mmol} / \mathrm{l} \mathrm{NaCl}, 2.7 \mathrm{mmol} / \mathrm{KCl}, 0.42 \mathrm{mmol} / \mathrm{l} \mathrm{NaH} \mathrm{PO}_{4}, 5 \mathrm{mmol} / \mathrm{Hepes}, 2$ $\mathrm{mmol} / \mathrm{MgCl}, 5.6 \mathrm{mmol} / \mathrm{l}$ glucose, and $0.1 \% \mathrm{BSA} ; \mathrm{pH} 7.45$ ). After a $10 \mathrm{~min}$ observation period the compounds were removed by resuming superfusion with Tyrode's solution. Arterioles (A) and venules (V) were punctured in the presence of either GGACK (A: $n=13, \mathrm{~V}: n=15)$. PPACK (A: $n=15, \mathrm{~V}: n=15)$, or vehicle (control; $\mathrm{A}: n=16, \mathrm{~V}: n=14$; referred to as con-1), in random order.

In a second set of experiments the effects of a clinically relevant direct thrombin inhibitor, melagatran, ${ }^{7}$ were investigated. The reversible thrombin inhibitor melagatran (kindly provided by AstraZeneca, MöIndal, Sweden) was administered systemically via a catheter (PE-50) in an ear vein. The 
animals received either melagatran (bolus dose of $175 \mu \mathrm{g} / \mathrm{kg}$ followed by continuous infusion of 475 $\mu \mathrm{g} / \mathrm{kg} / \mathrm{h} ; 4$ rabbits) or an equal volume of vehicle (saline; 3 rabbits). In both melagatran-treated rabbits (melag: A: $n=17, \mathrm{~V}: n=14$ ) and control rabbits (con-2; A: $n=11, \mathrm{~V}: n=9$ ), vessel wall puncture started at least $20 \mathrm{~min}$ after the start of infusion. Arterial blood was collected in trisodium citrate $(0.129 \mathrm{~mol} / \mathrm{l}, 1 / 10$ volume) before (baseline) and approximately $90 \mathrm{~min}$ after the start of melagatran infusion. From these samples, platelet-rich plasma (PRP) was prepared by centrifugation at $2200 \mathrm{~g}$ for $2 \mathrm{~min}$. Platelet-free plasma (PFP) was obtained from PRP by centrifugating twice at $3400 \mathrm{~g}$ for $10 \mathrm{~min}$, and stored at $-80^{\circ} \mathrm{C}$. Plasma concentrations of melagatran were determined in PFP by liquid chromatographic mass spectrometry, as described before. ${ }^{15}$

\section{Thrombin generation and prothrombin time measurements}

The effects of GGACK, PPACK, and melagatran on thrombin generation were measured using the Thrombogram method. ${ }^{16}$ PRP obtained from arterial rabbit blood (see above) was normalized to $1.5 \times 10^{8}$ platelets/ml, and added to wells of a 96-well plate containing rabbit thromboplastin (1/5,000 volume Thromboplastin-S; Biopool International) in Hepes buffer (20 mmol/ Hepes, $140 \mathrm{mmol} / \mathrm{NaCl}, 0.5 \%$ BSA, pH 7.35). Thromboplastin was diluted in such a way that formation of thrombin depended on the presence of platelets. Thrombin formation was started by adding $\mathrm{CaCl}_{2}(16.6 \mathrm{mmol} / \mathrm{l})$ and fluorescent thrombin substrate (417 $\mu \mathrm{mol} / \mathrm{l}$ Z-Gly-Gly-Arg-AMC; Bachem) in Hepes buffer, and continuously measured in time with a microtiter plate fluorometer (Spectramax Gemini; Molecular Devices) at $37{ }^{\circ} \mathrm{C}$. Accumulation of fluorescence from cleaved thrombin substrate was measured using $390 \mathrm{~nm}$ excitation and $460 \mathrm{~nm}$ emission wavelengths. First derivative curves of fluorescence were converted into thrombin concentration curves after calibration with human thrombin. The $50 \%$ inhibitory concentration (IC50) of thrombin inhibilors was assessed by incubating PRP with various inhibitor doses.

The inhibitory effect of infused melagatran on extrinsic coagulation was also evaluated from the prothrombin time. Coagulation was induced by adding $100 \mu \mathrm{l}$ rabbit thromboplastin to $50 \mu \mathrm{l} \mathrm{PFP}$, and time to coagulation was determined in a coagulometer ( $\mathrm{KC} 4 \mathrm{~A}$; Amelung $\mathrm{GmbH}$ ) as described previously. ${ }^{17}$

\section{Statistical analysis}

Data from in vivo experiments are presented as median values with interquartile ranges because of their nonsymmetrical distribution. Differences between the experimental groups were tested using the nonparametric Mann-Whitney U or Chi-square test; the Spearman rank correlation test was used for correlations. The level of significance was set at $5 \%$. 

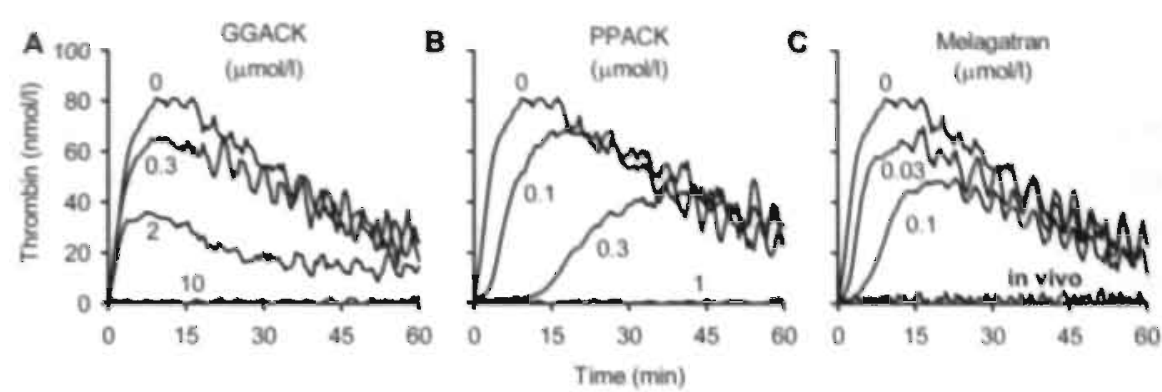

Figure 6.1. Effects of direct factor $\mathrm{Xa}$ or thrombin inhibition on platelet-dependent thrombin generation. Typical examples of thrombin generation curves in PRP obtained from rabbit blood samples and incubated with increasing concentrations of factor $\mathrm{Xa}$ or thrombin inhibitors. (A) Dose-dependent reduction of peak value by GGACK ( 0 -control: $0.3 ; 2$; and $10 \mu \mathrm{mol} / 1)$; IC 50 was $2 \mu \mathrm{mol} / \mathrm{A}$. (B) Dose-dependent reduction of peak value by PPACK (0-control; 0.1; $0.3 ;$ and $1 \mu \mathrm{mol} / \mathrm{I}$ ); IC50 was $0.3 \mu \mathrm{mol} / \mathrm{L}$. (C) Dose-dependent reduction of peak value by melagatran (0-control; 0.03; 0.1 $\mu \mathrm{mol} / \mathrm{I}) ; \mathrm{IC} 50$ was $0.1 \mu \mathrm{mol} / \mathrm{l}$. Infusion of $475 \mu \mathrm{gg} / \mathrm{h}$ melagatran resulted in an average plasma concentration of I.8 $\mu \mathrm{mol} / \mathrm{l}$, which completely blocked platelet-dependent thrombin generation (in vivo).

\section{Results}

\section{Factor Xa and thrombin inhibitors are effective in rabbit blood}

Factor $\mathrm{Xa}$ and thrombin inhibitors were first tested in vitro for their effects on plateletdependent thrombin generation in rabbit plasma. The peak value of thrombin generation was dose-dependently decreased by GGACK (IC50: $2 \mu \mathrm{mol} /$; Figure 6.1A), PPACK (IC50: 0.3 $\mu \mathrm{mol} / \mathrm{l}$; Figure 6.1B), and melagatran (IC50: $0.1 \mu \mathrm{mol} / \mathrm{l}$; Figure 6.1C). Thrombin generation was completely inhibited with $10 \mu \mathrm{mol} / 1$ GGACK, I $\mu \mathrm{mol} / \mathrm{l}$ PPACK (Figure 6.1), or $1 \mu \mathrm{mol} / \mathrm{l}$ melagatran. To ensure optimal inhibition in the in vivo experiments, GGACK and PPACK were applied topicaliy at concentrations at least 20 times higher than their IC50 values. Melagatran was administered via continuous infusion, resulting in a plasma concentration of $1.8 \pm 0.2 \mu \mathrm{mol} / \mathrm{l}$ (mean+SEM), which is 3 to 9 times as high as the effective dose in humans. ${ }^{7}$ This high dose was chosen to ensure blockade of most thrombin activity in the rabbits in vivo. Indeed, plateletdependent thrombin generation in PRP obtained from blood that was collected during melagatran infusion was completely blocked (Figure $6.1 \mathrm{C}$ ). In addition, melagatran significantly increased prothrombin time from $10.3 \pm 2.4 \mathrm{~s}$ (baseline; mean \pm SEM) to $21.0 \pm 2.1 \mathrm{~s}$ in these blood samples ( $P \leq 0.05$ in Student's paired T-test). Together, these results demonstrate that the factor $\mathrm{X} a$ and thrombin inhibitors are effective in rabbits.

The various ways of thrombin inhibition did not affect mean arterial blood pressure (overall median value $67 \mathrm{mmHg}$, range 52-92), heart rate (148 beats/min, 105-239), hematocrit (42 1/, 35-48), and systemic platelet count $\left(495 \times 10^{9} / 1,257-651\right)$; these values are all within normal ranges for anesthetized rabbits. ${ }^{9.13}$ Ear bleeding times, however, were significantly prolonged by systemic infusion of melagatran from $3.0 \mathrm{~min}$ at baseline (median, interquartile range: $2.9-3.1)$ to more than 30 min during infusion $(25.3->30.0 ; P \leq 0.05)$. Ear bleeding times 
were not influenced by topical administration of GGACK or PPACK, indicating the absence of systemic effects.

The involvement of thrombin in the thromboembolic reaction in rabbit arterioles and venules was investigated in two separate sets of experiments (see Methods). In both arterioles and venules, parameters describing the thromboembolic reaction were not significantly different between the control groups of the two experimental sets.
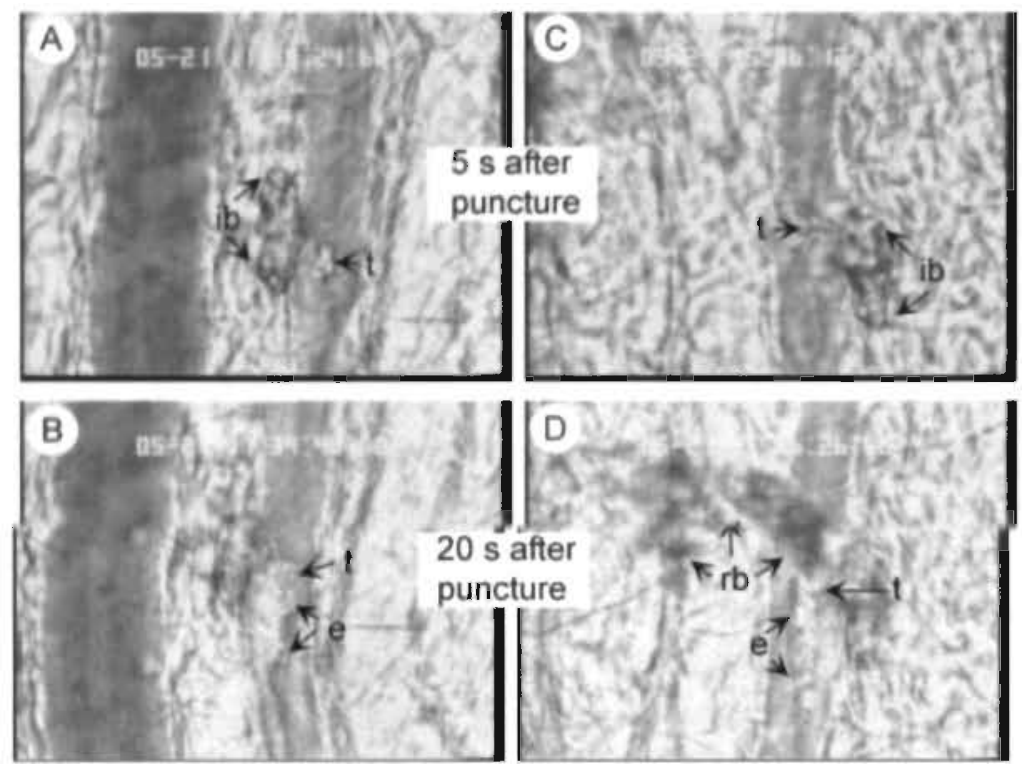

Figure 6.2. Video images of arteriolar thrombi at 5 and $20 \mathrm{~s}$ after vessel wall puncture. (A,B) Thrombus in a control arteriole: effective in the prevention of rebleeding. (C.D) Thrombus in a melagatran-treated arteriole. (C) After initial bleeding has stopped, (D) rebleeding occurs: new red blood cells are leaving the vessel, indicating that the thrombus is ineffective. Blood flow in arterioles is from top to bottom in all panels; diameter of the punctured arterioles is approximately $30 \mu \mathrm{m}$; ib = initial bleeding; $\mathrm{t}=$ thrombus; $\mathrm{c}=$ embolizing aggregate; $\mathrm{rb}=$ rebleeding.

\section{Fackor Xa and thrombin inhibition decrease thrombus size and effectiveness in both arterioles and venules}

In both arterioles and venules, initial microvascular bleeding stopped within 2-4 s in all groups (Table 6.1 ), due to the formation of a primary thrombus that was completed within $1-2 \mathrm{~s}$. In control conditions thrombus formation was slightly different between arterioles and venules, in accordance with previous studies. ${ }^{9-11}$ While the height of the thrombus was similar in the two vessel types, its effectiveness to stop bleeding (Figure 6.2) was lower in venules than in arterioles: rebleedings tended to occur more frequently in venules ( $43 \%$ of venules vs. $22 \%$ of arterioles: $P=0.10$; Figure 6.3 ), while more rebleedings were seen per rebleeding vessel (3 rebleedings per venule vs. 1 per arteriole [overall medians of the two control groups]; $P \leq 0.05$ ). Total bleeding duration was similar in arterioles and venules. 
Tatble 6.1. Thrombus and bleeding parameters in anterioles and venules of the 5 experimental groups.

\begin{tabular}{|c|c|c|c|c|c|c|c|c|c|c|}
\hline & \multicolumn{5}{|c|}{ Arterioles. } & \multicolumn{5}{|c|}{ Venules } \\
\hline & con-1 & GGACK & PPACK & $\operatorname{con}-2$ & melag & con-I & GGACK & PPACK & $\operatorname{con}-2$ & melag \\
\hline \multirow{2}{*}{ Initial mBT (s) } & 3.2 & 3.3 & 3.9 & 2.7 & 2.5 & 4.1 & 3.4 & 4.1 & 1.8 & 2.1 \\
\hline & $(1.0-5.2)$ & $(1.3-6.9)$ & $(1,4-5.1)$ & $(0.3-6.5)$ & $(1.5-4.2)$ & $(0.5-5.3)$ & $(2.3-6.5)$ & $(2.5-17.0)$ & $(0.8-3.0)$ & $(1.0-8.7)$ \\
\hline \multirow{2}{*}{ Thrombus height (\%) } & 45 & $30^{\circ}$ & 41 & 57 & $31 * *$ & 41 & $30^{\circ}$ & 37 & 48 & $28 * *$ \\
\hline & $(40-56)$ & $(28-46)$ & $(35-46)$ & $(49-69)$ & $(26-36)$ & $(32-52)$ & $(21-43)$ & $(24-56)$ & $(44-58)$ & (23-32) \\
\hline \multirow{2}{*}{ Rebleeding (no.) } & 2 & $8^{*}$ & $9 \cdot$ & 1 & 2 & 4 & 6 & 4 & 2 & 5 \\
\hline & $(1-2)$ & $(4-11)$ & $(4-9)$ & $(1-1)$ & $(1-3)$ & $(2-6)$ & $(5-13)$ & $(1-7)$ & $(2-2)$ & $(\mathrm{I}-5)$ \\
\hline \multirow{2}{*}{ Total mBT (s) } & 4 & $11^{*}$ & $46^{\circ}$ & 3 & $5^{\circ}$ & 5 & 617 & $159^{\circ}$ & 3 & 8 \\
\hline & $(3-8)$ & $(5-45)$ & $(5-68)$ & $(1-7)$ & $(3-26)$ & $(1-31)$ & $(5-266)$ & $(8-484)$ & $(1+5)$ & $(3-19)$ \\
\hline
\end{tabular}

Medians with (interyuartile ranges) are shown. $\mathrm{mBT}=$ microvessel bleedmg time; thrombus height: relative to local vessel diameter; rebleeding: no, of rebleedings per rebleeding vessel; total mBT; initial mBT + total duration of rebleedings; " PSD.05; *" PS0.01; *." PS0.001; " P=0.06/0.07 compared with corresponding control. 
In arterioles, active site thrombin inhibition by melagatran significantly reduced relative thrombus height by $46 \%(P \leq 0.001)$, whereas PPACK had no such effect (Figure 6.3A). The stability of the thrombus, however, was reduced by both treatments: rebleedings through the thrombus occurred in $76 \%$ of the arterioles in the melagatran-treated rabbits and in $67 \%$ of PPACK-treated arterioles, a significant difference as compared with $18 \%$ and $25 \%$ of the vessels in their respective control groups ( $P \leq 0.01$; Figure 6.3B). Blockade of thrombin formation through active site factor $\mathrm{Xa}$ inhibition by GGACK significantly reduced thrombus height as well (by $33 \%$; $P \leq 0.05$; Figure $6.3 \mathrm{~A}$ ). In this case, rebleeding frequency was non-significantly increased to $54 \%(P=0.14$; Figure $6.3 \mathrm{~B})$. In arterioles with rebleedings, the number of rebleedings per vessel was higher in the presence of GGACK or PPACK than in the control group ( $P \leq 0.05 ;$ Table 6.1). As a result, total bleeding time per arteriole (initial microvessel bleeding time plus total duration of rebleedings) was significantly increased by these two treatments ( $P \leq 0.05$; Table 6.1). Melagatran also had a significant, but clearly smaller effect on total bleeding duration and did not increase the number of rebleedings per rebleeding vessel (Table 6.1).

In venules, thrombus height was significantly reduced by melagatran $(42 \%$ reduction; PS0.01), but not by PPACK. Treatment with GGACK tended to reduce thrombus height by $27 \%$ $(P=0.07$; Figure $6.3 \mathrm{C}$ ). Rebleeding frequency was increased, albeit non-significantly, by all forms of thrombin inhibition (GGACK 60\%, PPACK 73\%, and melagatran 64\%, as compared with $43 \%$ and $44 \%$ in con-1 and con-2, respectively; Figure 6.3D). Strikingly, rebleeding frequencies in the venules of the 3 treatment groups were very similar to the ones found in the corresponding arterioles. The number of rebleedings per vessel in the treatment groups was not. significantly affected (Table 6.1), but the duration of rebleedings was prolonged, especially in. case of GGACK and PPACK (data not shown). Altogether, thrombin inhibition with PPACK resulted in a significant prolongation of total microvessel bleeding time $(P \leq 0.05$ ), while GGACK had a nearly significant effect $(P=0.06)$. Melagatran, on the other hand, did not increase total bleeding duration in venules (Table 6.1).

Overall, direct inhibition of thrombin or factor Xa decreased both thrombus size and effectiveness in arterioles as well as venules, Strikingly, thrombin inhibition decreased thrombus size (represented by thrombus height) and its effectiveness to prevent bleeding (indicated by more and/or longer rebleedings) to similar levels in both vessel types (all $P>0.1 \|$ for arterioles vs. venules). Hence, the slight difference in thrombus effectiveness normally found between arterioles and venules seems to disappear during thrombin or factor $\mathrm{Xa}$ inhibition. In both vessel types, the irreversible thrombin inhibitor PPACK caused a more pronounced prolongation of total bleeding time than the reversible inhibitor melagatran, although their effect on rebleeding frequency was similar. 

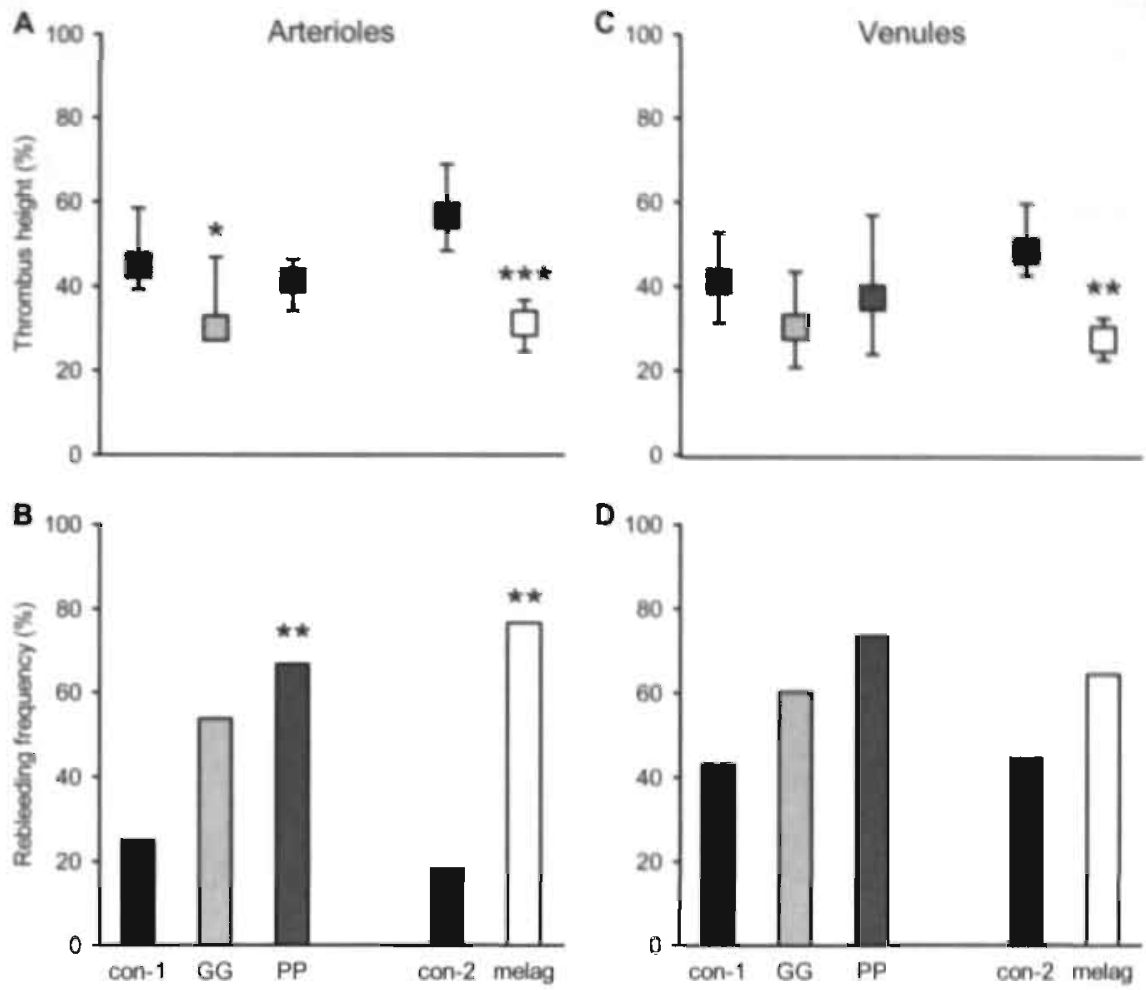

Figure 6.3. In vivo effects of factor $\mathrm{Xa}$ or thrombin inhibition on thrombus size and effectiveness. Effects of direct factor $\mathrm{Xa}$ inhibition by GGACK (GG) and direct thrombin inhibition by PPACK (PP) or melagatran (melag) are shown in $(\mathbf{A}, \mathbf{B})$ arterioles and $(\mathbf{C}, \mathbf{D})$ venules. $(\mathbf{A}, \mathbf{C})$ Thrombus size is represented by thrombus height as percentage of local vessel diameter; medians with interquartile ranges are shown. $(\mathbf{B}, \mathbf{D})$ Thrombus effectiveness is represented by the rebleeding frequency, i.e. the number of vessels in which rebleeding occurred as percentage of the tota! number of vessels. * $P \leq 0.05 ; * P \leq 0.01 ; * * P \leq 0.001$ compared with the corresponding control group. Note that rebleeding frequency in control venules tends to be higher than in control arterioles $(P=0.10)$.

\section{Thrombin inhibition hardly influences embolization in arierioles or venules}

In the control situation, emboli were shed from the downstream side of the primary thrombus for a significantly longer period of ime (7-9 times longer) in arterioles than in venules $(P \leq 0.001$; Table 6.2 and Figure 6.4), with more emboli produced per vessel ( $P \leq 0.001$; Table 6.2 ); this is in agreement with previous observations. ${ }^{9-12}$ These differences in embolization could not be explained by different fluid dynamic conditions, because in the subpopulation of arterioles and venules with similar reduced velocities the degree of embolization was still significantly different.

In arterioles, the effects of various inhibitors on embolization were not consistent (Figure 6.4A and Table 6.2). Whereas direct Xa inhibition by GGACK did not significantly affect any of the embolization parameters, direct thrombin inhibition through PPACK tended to increase 
embolization duration ( $P=0.06$ ), although the number of emboli produced was not influenced (Table 2). In melagatran-treated rabbits embolization duration was not influenced, but median embolus production time was increased and, hence, the rate of embolus production was reduced. As a result, less emboli were produced in this group ( $P \leq 0.01$; Table 6.2). The average size of arteriolar emboli was 7.5-12.5 $\mu \mathrm{m}$ and was not influenced by any of the thrombin inhibitors.

In venules, direct inhibition of neither factor Xa nor thrombin affected embolization. On average 2-3 emboli were produced per venule in all five groups (Table 6.2), and total duration of embolization varied between median 27 and $47 \mathrm{~s}$ (Figure 6.4B and Table 6.2). Median embolus production times and sizes of emboli were similar in all groups (Table 6.2).

Taken together, factor $\mathrm{Xa}$ or thrombin inhibition did not influence the embolization process in venules, while no consistent effect was found in arterioles.
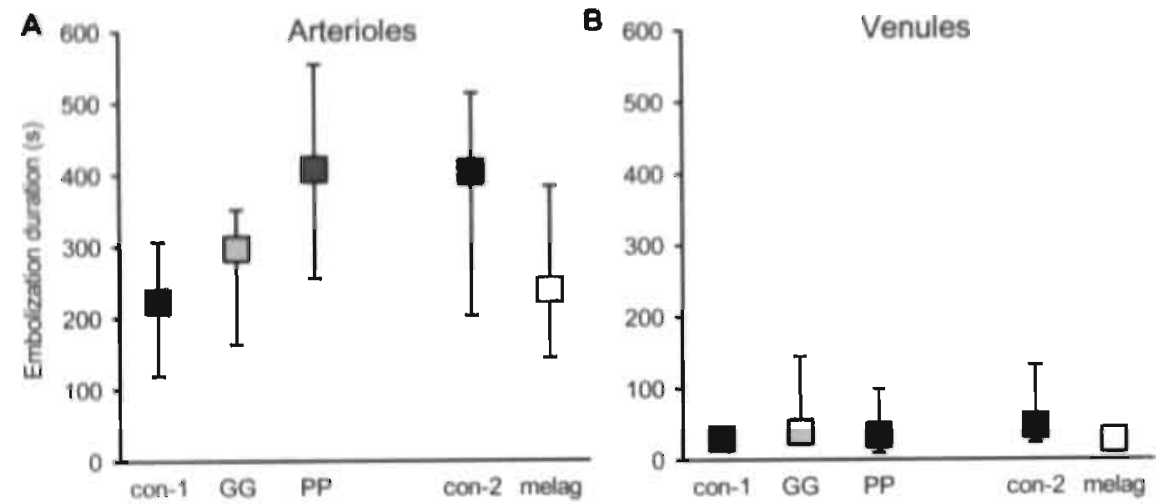

Figure 6.4. In vivo effects of factor $\mathrm{Xa}$ or thrombin inhibition on embolization. Effects of direct factor Xa inhibition by GGACK $(G G)$ and direct thrombin inhibition by PPACK (PP) or melagatran (melag) on embolization duration in (A) arterioles and $(\mathbf{B})$ venules. Medians with interquartile ranges are shown.

\section{Local fluid dynamic conditions}

Neither thrombin inhibition by melagatran or PPACK nor factor Xa inhibition by GGACK had a significant effect on local fluid dynamic parameters in arterioles and venules (Table 6.3), except for a slightly lower reduced velocity in melagatran-treated arterioles compared with their corresponding controls. The latter was significantly correlated with the reduced embolization rate in that group (correlation coefficient $r_{s}: 0.50 ; P \leq 0.05$ ). None of the other fluid dynamic parameters exhibited significant correlations with any of the thromboembolic parameters. 
Table 6.2. Embolization parameters in arterioles and venules of the 5 experimental groups.

\begin{tabular}{|c|c|c|c|c|c|c|c|c|c|c|}
\hline & \multicolumn{5}{|c|}{ Arterioles } & \multicolumn{5}{|c|}{ Venuiles } \\
\hline & con-1 & GGACK & PPACK & $\operatorname{con}-2$ & melag & con-1 & GGACK & PPACK & $\operatorname{con}-2$ & melag \\
\hline Emboli (no.) & $\begin{array}{c}9 \\
(5-14)\end{array}$ & $\begin{array}{c}8 \\
(6-11)\end{array}$ & $\begin{array}{c}11 \\
(7-19)\end{array}$ & $\begin{array}{c}14 \\
(10-17)\end{array}$ & $\begin{array}{l}6^{* *} \\
(3-8)\end{array}$ & $\begin{array}{c}2 \\
(1-4)\end{array}$ & $\begin{array}{c}2 \\
(2-4)\end{array}$ & $\begin{array}{c}2 \\
(1-4)\end{array}$ & $\begin{array}{c}3 \\
(2-4)\end{array}$ & $\begin{array}{c}2 \\
(1-3)\end{array}$ \\
\hline Duration (s) & $\begin{array}{c}223 \\
(121-305)\end{array}$ & $\begin{array}{c}298 \\
(175-344)\end{array}$ & $\begin{array}{c}408^{7} \\
(260-546)\end{array}$ & $\begin{array}{c}404 \\
(224-509)\end{array}$ & $\begin{array}{c}239 \\
(162-344)\end{array}$ & $\begin{array}{c}30 \\
(22-47)\end{array}$ & $\begin{array}{c}39 \\
(23-141)\end{array}$ & $\begin{array}{c}35 \\
(13-80)\end{array}$ & $\begin{array}{c}47 \\
(27-104)\end{array}$ & $\begin{array}{c}27 \\
(11-42)\end{array}$ \\
\hline mEPT (s) & $\begin{array}{c}20 \\
(18-26)\end{array}$ & $\begin{array}{c}24 \\
(19-35)\end{array}$ & $\begin{array}{c}26 \\
(20-34)\end{array}$ & $\begin{array}{c}15 \\
(14-26)\end{array}$ & $\begin{array}{c}33 * \\
(28-48)\end{array}$ & $\begin{array}{c}15 \\
(10-23)\end{array}$ & $\begin{array}{c}17 \\
(13-23)\end{array}$ & $\begin{array}{c}19 \\
(16-23)\end{array}$ & $\begin{array}{c}13 \\
(11-24)\end{array}$ & $\begin{array}{c}13 \\
(12-15)\end{array}$ \\
\hline Size $(\mu \mathrm{m})$ & $\begin{array}{c}12.5 \\
(10-20)\end{array}$ & $\begin{array}{c}12.5 \\
(10-15)\end{array}$ & $\begin{array}{c}12.5 \\
(10-20)\end{array}$ & $\begin{array}{l}12.5 \\
(5-15)\end{array}$ & $\begin{array}{c}7.5 \\
(5-15)\end{array}$ & $\begin{array}{l}12.5 \\
(5-15)\end{array}$ & $\begin{array}{c}12.5 \\
(10-15)\end{array}$ & $\begin{array}{c}12.5 \\
(5-20)\end{array}$ & $\begin{array}{l}12.5 \\
(5-15)\end{array}$ & $\begin{array}{c}7.5 \\
(5-15)\end{array}$ \\
\hline
\end{tabular}

Medians with (interquartile ranges) are shown. Emboli: number of emboli produced per vessel; duration: total duration of embolization; mEPT = median embolus production time: " PS0.05: * P P $0.01:$ : P=0.06 compared with corresponding control 
Table 6.3. Fluid dynamic parameters in arterioles and venules of the 5 experimental groups.

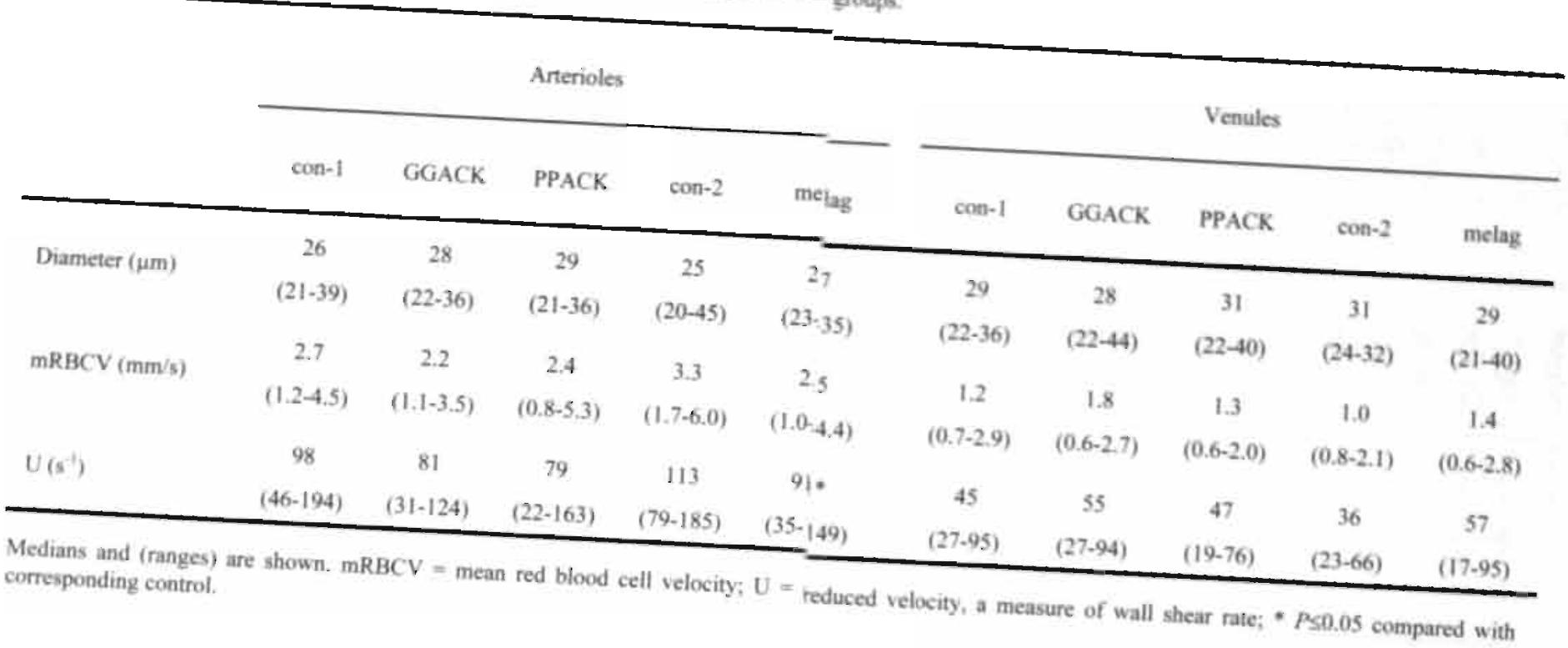




\section{Discussion}

Traditionally, arterial thromboembolism is thought to be more dependent on activation of platelets, while the thromboembolic process in veins is usually associated with high coagulation activity. ${ }^{5}$ Because of its important functions in both platelet activation and coagulation, thrombin may be differentially involved in thromboembolism in the arterial and venous circulation. The present study shows that, in arterioles as well as in venules, thrombin is involved in the formation of a hemostatically effective thrombus in reaction to local vessel wall puncture. In both vessel types, direct factor Xa or thrombin inhibition affects the formation of a platelet-rich thrombus at the site of vessel wall injury: both thrombus height and its effectiveness to prevent rebleeding are reduced. These findings indicate that -in reaction to vessel wall injury- thrombin activates blood platelets to form a thrombus and catalyzes fibrin formation for its stability in both the arterial and venous microcirculation. The subsequent formation of emboli on the downstream side of the primary thrombus is not clearly influenced by factor $\mathrm{Xa}$ or thrombin inhibition, suggesting that the involvement of thrombin is largely restricted to the first part of the thromboembolic reaction.

The finding that, in control conditions, arteriolar thrombi are slightly more effective in rebleeding prevention than venular thrombi is in agreement with previous studies. ${ }^{211}$ Inhibition of thrombin formation or activity decreases this difference, suggesting that thrombin and also fibrin play a more significant role in stabilizing the platelet-rich thrombus in arterioles than in venules. This is probably due to different endothelial properties. Anticoagulant factors from endothelial origin may oppose the effects of thrombin more strongly in venules than arterioles. This idea is supported by the finding that endothelial expression of thrombomodulin, which is involved in the protein $\mathrm{C}$ anticoagulant pathway and especially prominent in the microcirculation, ${ }^{18}$ is higher in venous than in arterial flow conditions. ${ }^{19,20}$ In addition, deficiencies of the protein $\mathrm{C}$ pathway such as factor $\mathrm{V}$ Leiden are more often accompanied by venous than arterial thromboembolism. ${ }^{21}$

In the current model, thrombin does not seem to be involved in the formation of emboli on the downstream side of the primary thrombus. This is in agreement with our previous finding that emboli consist of relatively weakly activated platelets that are only loosely aggregated, ${ }^{8}$ which argues against a prominent role of thrombin and fibrin. In contrast, the primary thrombus contains highly activated, tightly connected platelets that can become procoagulant. ${ }^{8}$ In support of these observations is the finding of Furie and colleagues, who showed in a laser-induced injury model in mice that tissue factor and fibrin were present throughout platelet-rich thrombi, but were absent at their downstream side, ${ }^{22,23}$ which is the side where emboli are shed in our model. As a result of our finding that thrombin and fibrin are not involved in embolization, the difference in embolization between arterioles and venules as observed in control conditions is 
still apparent during thrombin inhibition, i.e. arteriolar thrombi embolize longer than venular thrombi. The duration of embolization is probably determined by the balance between local platelet-activating and inhibiting factors. In previous studies we have shown that platelet activation and aggregation during embolus formation strongly depend on soluble agonists such. as TXA $A_{2}$ and $A D P$, released by activated platelets and/or injured endothelial cells, ${ }^{10,13}$ while endothelium-derived nitric oxide and prostacyclin are involved in the inhibition of embolization. $^{10-12}$

The direct thrombin inhibitor melagatran causes a less pronounced increase in total bleeding duration than PPACK in arterioles as well as venules, although both substances increase the rebleeding frequency to a similar extent. This may be explained by the fact that -in contrast to PPACK- melagatran is a reversible thrombin inhibitor. As a result, some free thrombin may still circulate in melagatran-treated rabbits and stop rebleeding once it occurs.. In arterioles and venules, inhibitors of both thrombin formation (i.e. Xa activity) and thrombin activity are effective in reducing thrombus formation. The formation of thrombin through $\mathrm{Xa}$ as well as the activation of factor $\mathrm{X}$ itself are strongly dependent on the presence of procoagulant phospholipids. ${ }^{13,4}$ This procoagulant surface can be provided by activated platelets, and possibly also by leukocytes and/or vascular cells. ${ }^{4}$ Thus, thrombin inhibition reduces platelet activation in vivo, which results in diminished platelet recruitment (and, hence, the formation of a smaller thrombus); as a result the procoagulant surface area necessary for the formation of fibrin is also reduced.

The present data clearly show that a primary thrombus can still be formed in the absence. of active thrombin, indicating that thrombin is not the only factor crucial for the formation and stabilization of such a thrombus in vivo. Although we cannot exclude that small traces of thrombin were still present in the treatment groups, it is ciear that other mediators have to be involved in thrombus formation as well. The first stimulus for platelet adhesion to a damaged vessel wall is probably subendothelial collagen, ${ }^{24}$ which is a strong platelet activator and causes the release of platelet activating substances, such as ADP. ${ }^{25}$ We and others have shown that ADP" is also involved in thrombus formation in vivo. ${ }^{13,26}$ ADP and thrombin-inhibiting drugs have been shown to synergistically inhibit thrombus formation, ${ }^{27}$ but whether this observation is relevant in our in vivo model remains to be investigated.

In conclusion, the present study provides new insight in the role of thrombin in the dynamic thromboembolic process after vessel wall damage. We show that thrombin plays a distinct role during the formation of a hemostatically effective thrombus in arterioles as well as venules, by stimulating both platelets and coagulation. This contribution seems to be more prominent in the arterial than in the venous microcirculation. In contrast, thrombin is hardly involved in secondary embolus formation in either vessel type. 


\section{Acknowledgments}

The authors would like to thank AstraZeneca (Molndal, Sweden) for kindly providing melagatran and for performing melagatran concentration measurements in plasma. We also thank Sietze Reitsma for technical assistance.

\section{References}

1. Monroe DM, Hoffman M, and Roberts HR. Platelets and thrombin generation. Arterioscler Thromb Vasc Biol. 2002;22:1381-1389.

2. Mann KG, Brummel $\mathrm{K}$, and Butenas $\mathrm{S}$. What is all that thrombin for? $J$ Thromb Haemost. 2003;1:1504-1514.

3. Heemskerk JWM, Bevers EM, and. Lindhout T. Platelet activation and blood coagulation. Thromb Haemost, 2002;88:186-193.

4. Zwaal RFA, and Schroit AJ. Pathophysiologic implications of membrane phospholipid asymmetry in blood cells. Blood. 1997;89:1121-1132.

5. Bates SM, and Weitz J. Emerging anticoagulant drugs. Arterioscler Thromb Vasc Biol. 2003;23:149\}- 1500 .

6. Turpie AG. State of the art - a journey through the world of antithrombotic therapy. Semin Thromb Hemost, 2002;28 Suppi 3:3-11.

7. Gustafsson $\mathrm{D}$, and Elg M. The pharmacodynamics and pharmacokinetics of the oral direct thrombin inhibitor ximelagatran and its active metabolite melagatran: a mini review. Thromb Res. 2003;109:S9S15.

8. van Gestel MA, Heemskerk JWM. Slaaf DW, Heijnen VVT, Sage SO, Reneman RS, and oude Egbrink. MGA, Real-time detection of activation patterns in individual platelets during thromboembolism in vivo: differences between thrombus growth and embolus formation. $J$ Vasc Res. 2002;39:534-543.

9. oude Egbrink MGA, Tangelder GJ, Slaaf DW, and Reneman RS. Thromboembolic reaction following wall puncture in arterioles and venules of the rabbit mesentery. Thromb Haemost. 1988;59:23-28.

10. oude Egbrink MGA. Tangelder GJ, Slaaf DW, and Reneman RS. Different roles of prostaglandins in thromboembolic processes in arterioles and venules in vivo. Thromb Haemost. 1993;70;826-833.

11. Broeders MAW, Tangelder GJ, Slaaf DW, Reneman RS, and oude Egbrink MGA. Endogenous nitric oxide protects against thromboembolism in venules but not in arterioles. Arterioscler Thromb Vasc Biol. 1998;18:139-145.

12. Broeders MAW, Tangelder GJ, Slaaf DW, Reneman RS, and oude Egbrink MGA. Endogenous nitric oxide and prostaglandins synergistically counteract thromboembolism in arterioles but not in venules. Arterioscler Thromb Vasc Biol. 200 I;21:163-169. 
13. van Gestel MA, Heemskerk JWM, Slaaf DW, Heijnen VVT, Reneman RS, and oude Egbrink MGA. In vivo blockade of the platelet $\mathrm{ADP}$ receptor $\mathrm{P} 2 \mathrm{Y}_{12}$ reduces embolus and thrombus formation, but not thrombus stability. Arterioscler Thromb Vasc Biol. 2003;23:518-523.

14. Slaaf DW, Rood JPSM, Tangelder GJ, Jeurens TJM, Alewijnse R, Reneman RS, and Arts T. A bidirectional optical (BDO) three-stage prism grating system for on-line measurement of red blood cell velocity in microvessels. Microvasc Res. 1981;22:110-122.

15. Larsson M, Ahnoff M, Abrahamsson A, Logren U, Fakt C, Ohrman I, and Persson BA. Determination of ximelagatran, an oral direct thrombin inhibitor, its active metabolite melagatran, and the intermediate metabolites, in biological samples by liquid chromatography-mass spectrometry. $J$ Chromatogr B. 2003:783:335-347.

16. Hemker HC, Giesen PL, Ramjee M, Wagenvoord R, and Béguin S. The thrombogram: monitoring thrombin generation in platelet-rich plasma. Thromb Haemost. 2000;83:589-591.

17. Nieuwenhuys CMA, Béguin S, Offermanns RF, Emeis JJ, Hornstra G, and Heemskerk JWM. Hypocoagulant and lipid-lowering effects of dietary n-3 polyunsaturated fatty acids with unchanged platelet activation in rats. Arterioscler Thromb Vasc Biol. 1998;18:1480-1489.

18. Esmon CT. Role of coagulation inhibitors in inflammation. Thromb Haemost. 2001;86:51-56.

19. Gosling M, Golledge J, Turner RJ, and Powell JT. Arterial flow conditions downregulate thrombomodulin on saphenous vein endothefium. Circufation. 1999;99:1047-1053.

20. Sperry JL, Deming CB, Bian C, Walinsky PL, Kass DA, Kolodgie FD, Virmani R, Kim AY, and Rade JJ. Wall tension is a potent negative regulator of in vivo thrombomodulin expression. Circ Res. 2003;92:41-47.

21. Dörfller-Melly J, De Kruif M, Schwarte LA, Franco RF, Florquin S, Spek CA, Ince C, Reitsma PH, and ten Cate H. Functional thrombomodulin deficiency causes enhanced thrombus growth in a murine model of carotid artery thrombosis. Basic Res Cardiol, 2003;98:347-352.

22. Falati S, Gross P, Merrill-Skoloff G, Furie BC, and Furie B. Real-time in vivo imaging of platelets, tissue factor and fibrin during arterial thrombus formation in the mouse. Nat Med. 2002;8:1175-1181.

23. Falati S, Liu Q, Gross P. Merrill-Skoloff G, Chou J, Vandendries E, Celi A, Croce K, Furie BC, and Furie B. Accumulation of tissue factor into developing thrombi in vivo is dependent upon microparticle P-selectin glycoprotein ligand 1 and platelet P-selectin. J Exp Med. 2003;197:15851598.

24. Massberg S, Gawaz M, Grüner S, Schulte V, Konrad I, Zohlnhöfer D, Heinzmạnn U, and Nieswạnḍt B. A crucial role of glycoprotein VI for platelet recruitment to the injured arterial wall in vivo. $J$ Exp Med. 2003; 197:41-49.

25. Ruggeri ZM. Platelets in atherothrombosis. Nat Med. 2002;8:1227-1234.

26. Andre P. Delaney SM. LaRocca T, Vincent D, DeGuzman F. Jurek M, Koller B, Phillips DR, and Conley PB. P2 $\mathrm{Y}_{12}$ regulates platelet adhesion/activation, thrombus growth, and thrombus stability in injured arteries. J Clin Invest. 2003;112:398-406. 
27. André P, LaRocca T, Delaney SM, Lin PH, Vincent D, Sinha U, Conley PB, and Phillips DR. Anticoagulants (thrombin inhibitors) and aspirin synergize with $\mathrm{P}_{2} \mathrm{Y}_{12}$ receptor antagonism in thrombosis. Circulation. 2003;108:2697-2703. 
Chapter 6 
General discussion

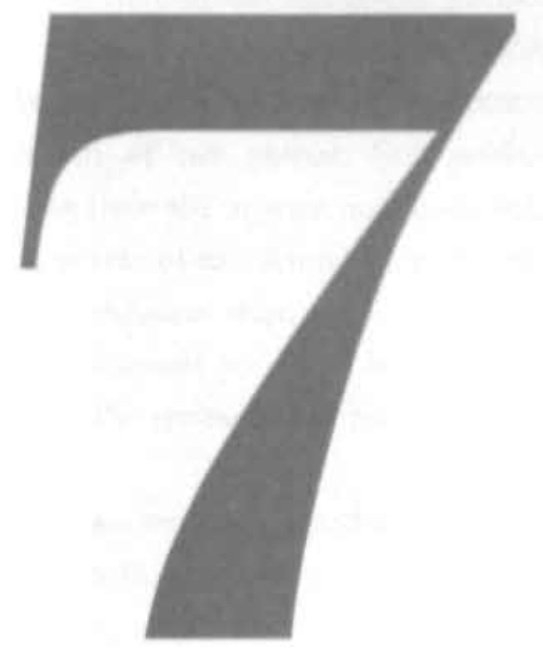




\subsection{Introduction}

Thromboembolism is a major cause of cardiovascular disease. The aim of the studies presented in this thesis was to obtain a better insight in the pathogenesis of thromboembolism, in particular in the behavior of individual blood platelets and in the contribution of two key platelet agonists: ADP and thrombin. The studies were performed using an established in vivo rabbit model in which platelet-vessel wall interactions were induced by wall puncture of mesenteric microvessels. The resulting thromboembolic reaction consists of two phases: first, within seconds, a platelet-rich thrombus is formed that stops bleeding from the injured vessel; second, platelets continuously adhere and aggregate at the downstream side of this thrombus, and these aggregates (emboli) are shed repeatedly. This process of embolization stops after some time, whereas the primary thrombus remains at the site of injury. The results presented in this thesis indicate in which phase(s) of the thromboembolic process ADP (released by platelets) and thrombin (formed through coagulation) are functionally active.

Because the majority of experiments described in this thesis were performed in arterioles, the main part of this discussion will focus on the thromboembolic reaction in arterioles. The differences in thrombus formation and embolization between arterioles and venules are discussed in a separate paragraph.

\subsection{Thromboembolism: a vital imaging approach}

In the studies described in this thesis, intravital microscopy was applied to visualize platelet-vessel wall interactions in real-time; systemic and local hemodynamic parameters were assessed as well. This approach provides detailed information on thrombus formation and embolization in vivo. In chapter 3, an extension of the established method is presented that allows real-time imaging of cytosolic $\mathrm{Ca}^{2+}$ responses in individual platelets that adhere to a growing thrombus or embolus in vivo, after labeling platelets with a $\mathrm{Ca}^{2+}$-sensitive fluorescent probe. At the same time, the behavior of individual, labeled platelets $(0.5-1 \%$ of the circulating platelet population) during a thromboembolic reaction can be determined. Their rate of adhesion to the growing thrombus is a measure of total platelet adhesion, whereas their detachment pattern (individually or in groups) is an indication of the size of embolizing aggregates. Thus, this new method enables quantification of the thromboembolic reaction at the cellular and intracellụlar level, while simultaneously monitoring the reaction as a whole. 


\subsection{The thromboembolic reaction in arterioles}

The course and outcome of a thromboembolic process in general and in the present rabbit model, are determined by the local balance between prothrombotic and antithrombotic factors. In undamaged vessels, endothelial antithrombotic properties prevent platelets from. interacting with the vessel wall.' Upon vessel wall damage (e.g. as induced by puncture), however, prothrombotic factors derived from damaged endothelial cells, subendothelium, platelets, or flowing blood may temporarily overrule the antithrombotic factors, leading to thrombus formation and embolization. According to this concept, the thromboembolic process ends when balance is restored. Our current knowledge (as derived from the studies in this thesis and previous studies with the same model) of the role of cells and of prothrombotic and antithrombotic factors during the two stages of a thromboembolic reaction (i.e. thrombus formation and embolization) in the arterial microcirculation in vivo is summarized in Figure 7.1.

\section{Thrombus formation}

In the present model, initial bleeding from the punctured vessel, i.e. extravasation of red. blood cells directly following vessel wall puncture, indicates that this intervention damages all layers of the vessel wall. Bleeding is stopped within a few seconds by the formation and stabilization of the primary thrombus. This short initial bleeding time (overall median $3.5 \mathrm{~s}$ ) is relatively constant, i.e. it is not significantly influenced by administration of substances affecting. platelet activation or coagulation. Apparently, puncture results in exposure of highly thrombogenic subendothelial components, leading to recruitment and activation of a high number of passing platelets during thrombus formation. The efficiency of this reaction can be calculated using data on platelet count $\left(529 \times 10^{9} / 1\right)$, relative thrombus height $(60 \%)$, red blood cell velocity $(2.1 \mathrm{~mm} / \mathrm{s})$, and vessel diameter $(28 \mu \mathrm{m}$; overall median values obtained from all control groups in this thesis). With an average platelet volume of $4.2 \mu \mathrm{m}^{3}$ (Packham et al., 1992), ${ }^{2}$ platelet volume flow passing by the site of injury is about $3000 \mu \mathrm{m}^{3} / \mathrm{s}$. Thrombus volume can be estimated from its cross-sectional area at peak (derived from the degree of stenosis in vivo, according to a previously described method) ${ }^{3}$ and some form of taper with a certain base length $(20 \mu \mathrm{m})$. Assuming that the form of this taper lies between that of a cone and an ellipsoid, thrombus volume is estimated to be in the order of $3000 \mu \mathrm{m}^{3}$. Therefore, thrombus formation can, theoretically, be completed in about $1 \mathrm{~s}$ provided that all passing platelets are captured. Indeed, we observed that thrombus formation is completed within $1-2$ s following puncture (chapters $4,5,6$ ). ${ }^{4}$ Of the exposed subendothelial components, collagen (being a potent platelet agonist) is most likely responsible for this high. level of thrombogenicity. ${ }^{5.6}$ As described in chapter 3 of this thesis, platelets in the primary thrombus are tightly packed, heavily shape changed, and degranulated. This is consistent with the prolonged rise in the cytosolic free 
calcium concentration $\left(\left[\mathrm{Ca}^{2+}\right]_{i}\right)$ found in platelets adhering to the thrombus, indicating a high level of activation (see chapter 3; Figure 7.1). Indeed, platelet activation by collagen induces a similar, prolonged $\left[\mathrm{Ca}^{2+}\right]$, rise in vitro (chapter 3 ; Kuijpers et al., 2003). ${ }^{7.8}$

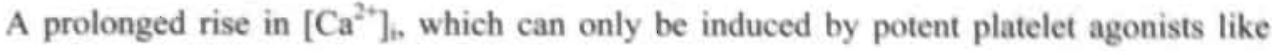
collagen or thrombin, is a prerequisite for platelets to become procoagulant and, hence, promote thrombin generation at their surface. ${ }^{9}$ Thrombin is a moderately potent platelet agonist and a coagulation factor (factor Ila), which catalyzes fibrin formation. The results in chapter 6 demonstrate that -in the present model- thrombin is involved in both thrombus growth and thrombus stability (Figure 7.1). It is known from in vitro studies that the weaker platelet agonist adenosine diphosphate (ADP) amplifies platelet responses to collagen and thrombin. ${ }^{10}$ ADP is released from activated platelets and possibly from damaged endothelial cells; in addition, NTPDase2, which is expressed by pericytes in the microvascular wall and converts ATP to ADP, can become exposed to blood during vessel wall damage and increase local ADP levels. "' Indeed, chapters 4 and 5 show that ADP plays an important role in thrombus formation (Figure 7.1). Thus, part of the effect of thrombin on thrombus growth may be mediated by released ADP. On the other hand, the effects of ADP on thrombus size may partially be achieved via thrombin, through $\mathrm{P}_{2} \mathrm{Y}_{12}$-mediated potentiation of platelet-dependent thrombin generation (chapter 4). ${ }^{4}$ This "cross-talk" of agonists can explain why blocking the actions of either thrombin or ADP reduces thrombus size. However, once a thrombus is formed, its size and shape remain largely the same both in the presence and absence of functionally active thrombin or ADP, and regardless of the shedding of emboli (chapters $4,5,6)^{3,4,7,12-14}$ or the occurrence of rebleedings (chapters 5,6).

Thrombus stabilization is generally thought to result from the formation of fibrin. The results presented in chapter 6 show that blocking the formation or activity of thrombin increases the frequency and duration of rebleedings, indicating that fibrin is indeed involved in forming stable thrombi. However, blockade of the platelet ADP receptor P2Y, causes rebleeding without affecting thrombin generation (chapter 5). This indicates that platelet-platelet interactions, as induced by ADP binding to $\mathrm{P} 2 \mathrm{Y}_{1}$, also contribute to thrombus stability. Proteins like CD40 ligand (CD40L) and fibrinogen have been described to stabilize platelet aggregates through an integrin $\alpha$ IIb $\beta 3$-dependent mechanism. ${ }^{15-17}$ Since $\mathrm{P} 2 \mathrm{Y}_{\mathrm{I}}$ is known to initiate ADP-induced aggregation, ${ }^{18}$ and because it is involved in the platelet $\mathrm{Ca}^{2 *}$ response in vivo (chapter 5), ADP binding to $\mathrm{P} 2 \mathrm{Y}_{1}$ may contribute to $\mathrm{Ca}^{2+}$-dependent degranulation and, hence, evoke release of CD40L, fibrinogen, and other factors that can contribute to thrombus stability. Alternatively, it has been suggested from studies in mice that $\mathrm{P}_{2} \mathrm{Y}_{1}$ inhibition downregulates the release of tissue factor (TF) from endothelial cells or leukocytes. ${ }^{19}$ This may provide a mechanism for $\mathrm{P} 2 \mathrm{Y}_{1}$ inhibitors to decrease thrombus stability, by reducing thrombin generation independently of platelets. 
Figure 7.1. Schematic representation of thrombus formation and subsequent embolization in punctured arterioles. The figure is shown in full color on the back cover flap; here, it is presented in black \& white.

Thrombus formation: After endothelial cell (EC) disnuption, platelets adhere to exposed subendothelial matrix components, e.g. collagen fibers, and become activated. This strong activation is characterized by a prolonged increase in $\left[\mathrm{Ca}^{2}\right]$, (yellow field in color figure), formation of pseudopods (shape change), degranulation and release of ADP and TXA (dashed arrows), the appearance of procoagulant phospholipids (PS). on the platelet surface, and aggregation in dense packing. Thrombin (lla), formed at the surface of procoagulant platelets via factor Xa (brown arrows in color figure), activates other platelets supporting thrombus growth, and converts fibrinogen to fibrin which stabilizes the thrombus and helps to effectively stop bleeding. Released ADP also contributes to thrombus growth (via $\mathrm{P} 2 \mathrm{Y}_{12}$ ) and

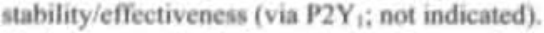

Embolization: Emboli are formed due to the release of TXAz and ADP from platelets on the downstream side of the thrombus, and probably also from platelets in the embolus itself or from damaged endothelial cells (not indicated). This leads to weak activation of platelets, which is accompanied by a transient increase in $\left[\mathrm{Ca}^{2}\right]$. (yellow fiefd in color figure). Platelets in the emboli generally keep their discoid shape, with part of their storage granules intact. The aggregate is kept together by fibrinogen (Fbg) -and' probably vWF and fibronectin- crosslinks and breaks loose when it reaches a certain size; afterwards a new embolus may start to grow. Duration of embolization is determined by the local balance between prothrombotic factors (like ADP and TXA $\mathrm{A}_{3}$ ) and antithrombotic factors, like nitric oxide (NO) and prostacyelin $\left(\mathrm{PGI}_{2}\right)$. The latter substances are released from the endothelium and inhibit platelet activation $(\perp)$ :

Blood flow is from top to bottom; solid grey arrows (brown in color figure) indicate formation; dashed black arrows indicate release; solid black arrows indicate effects.

\section{Embolization}

After formation of a primary thrombus in the punctured rabbit arterioles, emboli are repeatedly shed from its downstream side. These emboli consist of loosely packed platelets, that have hardly shape changed and still contain granules (chapter $3 ;^{7}$ Figure 7.1 ); the finding that thrombin inhibition does not influence embolization (chapter 6) indicates that the emboli are not stabilized by fibrin. This is in agreement with the finding of Furie and colleagues, using a different mouse model, that fibrin is not formed on the downstream side of a thrombus, ${ }^{20}$ which is the side where emboli are shed in our wall puncture model. This indicates that platelets in the emboli are not activated by potent platelet agonists like thrombin; instead, they are weakly activated and are probably held together via crosslinks provided by integrin $\alpha \mathrm{Ilb} \beta 3$ binding of fibrinogen (Figure 7.1), and possibly also von Willebrand factor (vWF) or fibronectin. ${ }^{2 !}$ This is confirmed by the iransient increase in $\left[\mathrm{Ca}^{2+}\right]_{1}$ measured in most platelets adhering to a growing embolus (chapter 3$)^{7}$ which resembles the response occurring in vitro when platelets are activated by 'weak' agonists like thromboxane $\mathrm{A}_{2}\left(\mathrm{TXA}_{2}\right)$, and $\mathrm{ADP}$ (chapter 3; Heemskerk et al., 2001). ${ }^{7,22}$ Both. substances have indeed been shown to contribute to embolus formation in vivo (chapters 4,5; oude Egbrink et al., 1993), 4,12 They are probably released from activated platelets in the primary thrombus and, to a lesser degree, from platelets in the growing embolus. The effects of the platelet-stimulating factors are counteracted by platelet-inhibiting substances released by damaged and/or activated endothelial cells, like nitric oxide (NO) and prostacyclin $\left(\mathrm{PGI}_{2}\right)^{12.14}$ which inhibit aggregate formation and, hence, embolization in the present model (Figure 7.1). When either TXA $\mathrm{A}_{2}$ or ADP function is inhibited, the balance between pro- and antithrombotic factors more easily shifts towards the antithrombotic side, resulting in a 


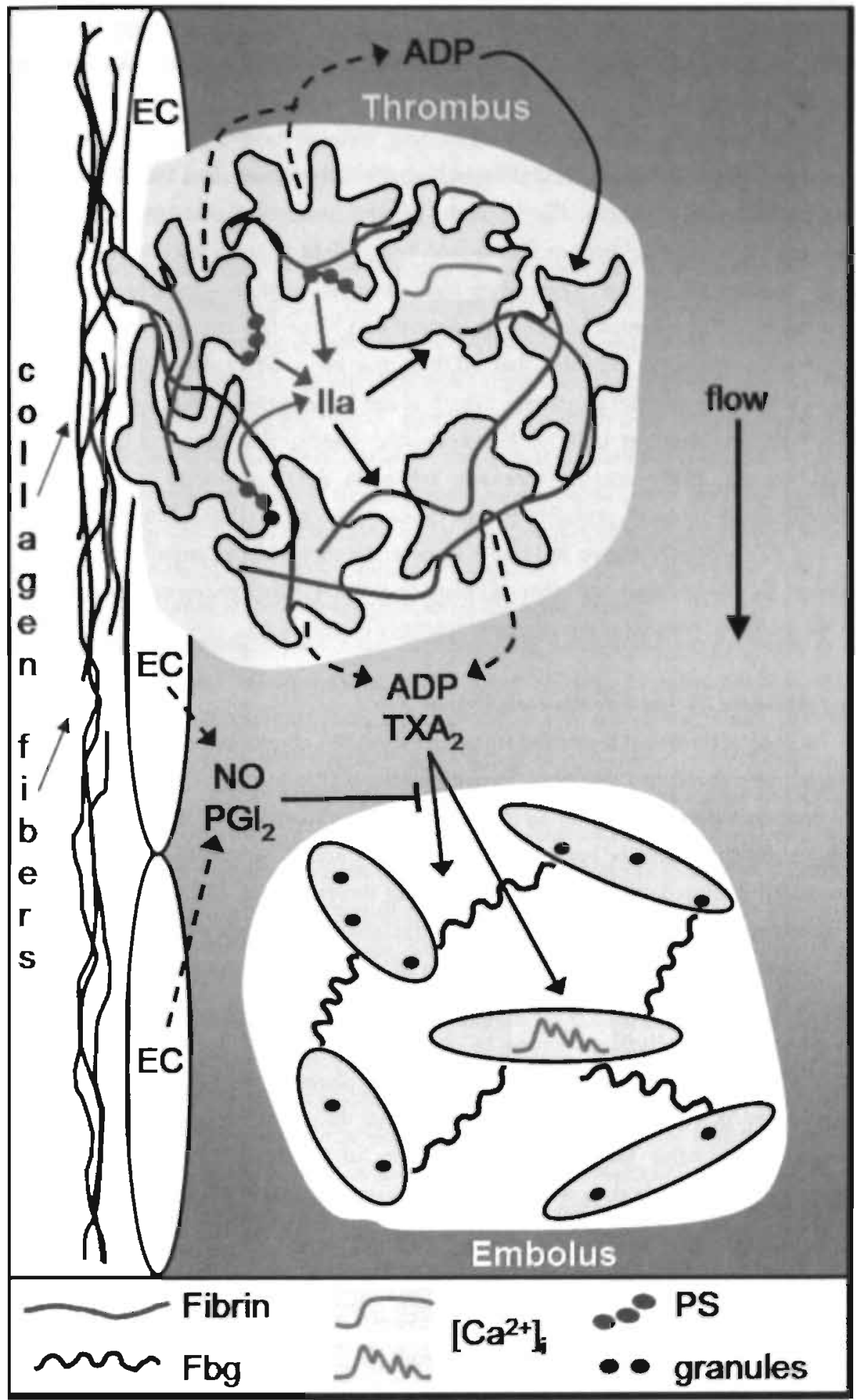


significant reduction of embolization duration. ${ }^{4,12}$ Conversely, when the production of NO and/or $\mathrm{PGI}_{2}$ is inhibited, the balance shifts towards the prothrombotic side and embolization is significantly prolonged. ${ }^{12-14}$

ADP is involved in production of emboli through both $\mathrm{P}_{2} \mathrm{Y}_{1}$ and $\mathrm{P} 2 \mathrm{Y}_{12}$ receptors (chapters 4,5 ). ${ }^{4}$ Besides duration of embolization, ADP also determines the size of the emboli. The data on behavior of single, fluorescently labeled platelets show that, in addition to the (reduced number of) emboli that are visible with bright-field microscopy (short axis $>5 \mu \mathrm{m}$ ), an increasing number of smaller aggregates (not observed with bright-field microscopy) are produced during ADP receptor blockade (chapters 4,5 ). ${ }^{4}$ The fact that platelet adhesion rate is unchanged (chapters 4,5$)^{4}$ indicates that ADP is not involved in the initial contact of new platelets to a growing platelet aggregate, which at the local shear conditions is likely mediated by GPIb-V-IX and integrin $\alpha \mathrm{Ilb} \beta 3$. However, the finding that platelets detach in smaller aggregates during ADP receptor blockade (chapters 4,5$)^{4}$ points to a role of ADP in strengthening these contacts, probably by activation of integrin $\alpha$ Illb $\beta 3$. Simultaneous blockade of $\mathrm{P}_{2} \mathrm{Y}_{1}$ and $\mathrm{P}_{2} \mathrm{Y}_{12}$ does not have additive effects on the formation of emboli. This can probably be explained by the presence of other agonists (e.g. $\mathrm{TXA}_{2}$ ) that preserve platelet aggregation when ADP-mediated responses are partially or totally eliminated.

\section{ADP and thrombin during thromboembolism in vivo}

Blockade of thrombin formation (through factor Xa inhibition) or its activity (using direct thrombin inhibitors) reduces thrombus formation after wall puncture. The decrease in thrombus size observed with thrombin inhibition is similar to that achieved by ADP receptor blockade, i.e. thrombus height is maximally reduced to $50 \%$ of the control value (chapters $4,5,6$ ) ${ }^{4}$ Hence, a thrombus reaches its maximum size only when both thrombin and ADP are functionally active. Similarly, both agonists are necessary to achieve full thrombus stability; when either thrombin or the $\mathrm{ADP}$ receptor $\mathrm{P} 2 \mathrm{Y}_{1}$ is blocked, the incidence of rebleedings increases from about 25 to $75 \%$ of arterioles (chapters 5,6).

Embolization is clearly affected by ADP receptor blockade (chapters 4,5 ), ${ }^{4}$ whereas thrombin inhibition has no consistent effect on this phase of the arteriolar thromboembolic reaction (chapter 6). Thus, while the effects of ADP on thrombus formation may be mediated by thrombin and vice versa (see above), the effects of ADP on embolization are probably independent of thrombin. In the punctured arterioles, the formation of emboli hardly depends on the size of the thrombus. Nevertheless, it seems plausible that a very small thrombus (which may be formed when both ADP and thrombin are blocked) would generate less and/or smaller emboli than a relatively large thrombus, because it will generate reduced levels of prothrombotic factors. Altogether, it will be interesting to study the effects of combined blockade of ADP and thrombin on thrombus formation and embolization, especially considering the fact that $\mathrm{P} 2 \mathrm{Y}_{12}$ 
antagonism and inhibition of the thrombin pathway were described to have synergistic effects in vitro, and in a $\mathrm{FeCl}_{3}$-induced mouse thrombosis model in vivo. ${ }^{23}$

\subsection{Involvement of platelets and coagulation in arterial and venous thromboembolism}

In the arterial system, thrombus formation is considered to be predominantly mediated by platelets. Venous thrombi, on the other hand, are more enriched in fibrin and erythrocytes, and their formation is commonly associated with high coagulation activity. ${ }^{24}$ However, platelet activation and coagulation are highly interdependent processes ${ }^{9}$ that are likely to occur together. Indeed, arterial thrombi also contain fibrin, ${ }^{20}$ pointing to a role for coagulation in arterial as well as in venous thrombus formation. Arterial and venous thromboembolism also show similarities in the reaction to vessel wall injury: in the present model, vessel wall puncture results in the formation of a platelet-rich thrombus followed by the shedding of multiple emboli, both on the arterial and venous side of the microcirculation (chapter 6). ${ }^{3,12-14,25}$ Yet, typical differences are found between the thromboembolic reaction in arterioles and venules.

The most consistent difference in the thromboembolic reaction observed in the two vessel types is the fact that embolization duration is significantly longer in arterioles than in venules. (chapter 6). ${ }^{3,12-14,25}$ Earlier findings indicate that this is at least partially due to a different contribution of endothelial platelet-inhibiting factors $\mathrm{NO}$ and $\mathrm{PGI}_{2 .}{ }^{12-14}$ Platelet-stimulating factors, like ADP or TXA 2 , may also be differentially involved in embolization in arterioles and venules. Upon $\mathrm{TXA}_{2}$ receptor blockade, arteriolar embolization duration is reduced to a level similar to that in control venules, whereas blocking TXA $\mathrm{A}_{2}$ receptors in venules has a slight, nonsignificant inhibitory effect. ${ }^{12}$ The effects of ADP receptor blockade in venules are, at present, unknown. The data in chapter 6 indicate that thrombin is not involved in embolization in either arterioles or venules.

Arterioles and venules also differ in the stability of their thrombi. When the results of chapter 6 and those of previous studies with the same model ${ }^{12,13,25}$ are taken together, $33 \%$ of all punctured control venules $(n=79)$ exhibit rebleeding compared to only $18 \%$ of the arterioles $(n=99 ; P \leq 0.05)$. This points to a lower stability of venular than arteriolar thrombi, and can probably be explained by a higher contribution of (endothelial) anticoagulant factors in venules, since thrombin inhibition was shown to abolish the difference (chapter 6). Increased anticoagulation in venules will counteract the procoagulant effects of thrombin, which then can lead to decreased fibrin formation and reduced thrombus stability. Indeed, venous flow conditions were found to induce a higher expression of the anticoagulant thrombomodulin than arterial flow conditions. ${ }^{26,27}$ Beside a differential role of endothelial anticoagulant factors, 
$\mathrm{ADP} / \mathrm{P} 2 \mathrm{Y}_{1}$-mediated platelet responses (which are involved in thrombus stability; chapter 5) may also play a role in the observed difference in thrombus stability between arterioles and venules.

\subsection{Clinical implications of the present research}

Care should be taken in translating data from animal models to the situation in human patients. Nevertheless, the thromboembolic reactions observed in mechanically damaged rabbit microvessels resemble -in certain aspects- those occurring at the surface of atherosclerotic plaques in humans. For example, in patients with atherothrombotic disease in the carotid arteries, emboli are shed from a thrombus and flow towards cerebral vessels. ${ }^{28}$ These emboli are often asymptomatic, but with high frequency or long duration of embolization they can result in transient ischemic attacks or stroke. ${ }^{29}$ This is compatible with our finding that emboli mainly consist of weakly activated platelets, that are loosely packed and exhibit temporary increases in $\left[\mathrm{Ca}^{2+}\right]_{i}$ (chapter 3 ). ${ }^{7}$ As a result, they may disintegrate before or shortly after occluding a downstream vessel; this was occasionally observed in our model (unpublished observations). On the other hand, when emboli contain a relatively high number of highly activated platelets (e.g. indicated by prolonged $\left[\mathrm{Ca}^{2+}\right]_{1}$ increases, as observed in about $30 \%$ of platelets adhering to a growing embolus: chapter 3 ), ${ }^{7}$ they may be more stable and persist in the circulation sufficiently long to cause clinical symptoms of ischemia. The chances of producing such stable emboli are likely to be higher with increasing rate or duration of embolization.

ADP (chapters 4,5$)^{4}$ and $\mathrm{TXA}_{2}$-inhibiting drugs ${ }^{12}$ reduce the duration of embolization as well as the size of the emboli in the current model. This is compatible with clinical evidence that both clopidogrel and aspirin lower the risk of ischemic events in patients with coronary artery disease. ${ }^{30,31}$ Combined blockade of the ADP and TXA $\mathrm{A}_{2}$ pathway leads to additional reduction of ischemic risk, ${ }^{30}$ but wheiher this is due to an additive effect on embolus formation remains to be elucidated. Combination therapy of aspirin and the direct thrombin inhibitor ximelagatran reduced the risk of ischemic events compared to treatment with aspirin alone, in the same order of magnitude as achieved with the combination of aspirin and clopidogrel ${ }^{32}$ This may be achieved via combined effects on thrombus formation (ximelagatran) and embolization (aspirin). and suggests that a combination of all three inhibitors (i.e. aspirin, clopidogrel, ximelagatran) may be even more effective.

Treatment of thromboembolism is often accompanied by an increased bleeding risk. In this thesis, both ADP receptor blockade with AR-C69931MX (chapter 4) and thrombin inhibition with melagatran (chapter 6) resulted in increased bleeding times in large rabbit (ear) vessels. Thrombin inhibition and $\mathrm{P} 2 \mathrm{Y}_{1}$ blockade also increased the frequency of rebleedings and 
the total duration of bleeding in punctured microvessels; $\mathrm{P} 2 \mathrm{Y}_{12}$ blockade had no such effect. When translated to the human situation, these findings suggest that treatment with $\mathrm{P}_{2} \mathrm{Y}_{12}$ * inhibiting drugs provide a lower risk for bleeding than $\mathrm{P} 2 \mathrm{Y}_{1}$ or thrombin inhibiting drugs. Clinical studies with either melagatran or clopidogrel suggest that both have a similar bleeding risk when administered in combination with aspirin. ${ }^{30.32}$ The $\mathrm{P}_{2} \mathrm{Y}_{12}$-inhibiting agent $\mathrm{AR}$ C69931MX is, however, expected to have a relatively wide therapeutic window; ${ }^{33}$ the results of current clinical trials will elucidate whether bleeding risk of $\mathrm{P} 2 \mathrm{Y}_{12}$ blockade can be reduced by using AR-C69931 MX instead of clopidogrel. To date, no clinical studies have been performed with $\mathrm{P} 2 \mathrm{Y}_{1}$-inhibiting drugs.

\subsection{Different animal models of thromboembolism}

Platelet-vessel interactions have been studied using various models, both in vivo and in vitro, which sometimes have yielded contrasting results. Differences in results from various in vivo models may be due to the use of different species or different blood vessels, but they may also result from various ways of inflicting vessel wall damage. For example, simultaneous P2Y, and $\mathrm{P}_{2} \mathrm{Y}_{12}$ blockade has additive antithrombotic effects in a $\mathrm{FeCl}_{3}$-induced arterial thrombosis model in mice, ${ }^{19}$ which is in contrast with our findings in chapter 5 , where such additive effects were not found. This difference can be explained by the use of different animal species (with perhaps different $\mathrm{P} 2 \mathrm{Y}$ receptor densities), or by different involvement of platelet activating and inhibiting mediators in both models, resulting from a different kind of vessel wall damage. $\mathrm{FeCl}_{3}$ induces endothelial disruption and denudation through formation of reactive oxygen species, ${ }^{21}$ and is usually applied to a relatively large tissue area (i.e. by superfusion or by using filter papers of $\geq 2 \mathrm{~mm}^{2}$ ), exposing relatively large vessels (diameter $60-150 \mu \mathrm{m}$ ). ${ }^{17,34}$ In this thesis, vessel wall puncture is performed on smaller vessels $(20-40 \mu \mathrm{m})$ using micropipettes with a tip diameter of 6-8 $\mu \mathrm{m}$, which not only denudes the endothelium but also damages the deeper layers of the vessel wall. Hence, the damage is smaller and more localized, and extends deeper into the vessel wall. This probably leads to a different involvement of prothrombotic substances like collagen (present in the subendothelium) and the ADP-producing NTPDase2 (expressed by subendothelial cells in the vascular wall ${ }^{11}$ ), which may contribute to a different outcome of the thromboembolic process in the two models.

Another difference between the $\mathrm{FeCl}_{3}$ and wall puncture models of thromboembolism is the fact that no bleeding occurs upon application of $\mathrm{FeCl}_{3}$. In addition, reduced stability of the thrombus is characterized by rupturing and embolizing of (parts of) the thrombus. ${ }^{17.21}$ In contrast, in the wall puncture model the thrombus maintains its size and shape and remains at the site of injury for at least three hours after puncture, irrespective of the formation of emboli on its 
downstream side. In the latter model, reduced thrombus stability is characterized by increased rebleeding through the thrombus.

In view of differences as mentioned above, results obtained with various animal thrombosis models should be interpreted with care. The wall puncture model used in this thesis has the advantage that the process of hemostasis and the thromboembolic process can be investigated simultaneously, and that responses of single, participating platelets can be measured as well. In addition, data on systemic parameters are easily available in rabbits, and blood samples can repeatedly be collected. Altogether, this allows direct assessment of the effects of platelet inhibitors or anticoagulants on hemostasis and thromboembolism, as well as on platelet function, thrombin generation, and systemic parameters like blood pressure and heart rate.

\subsection{Conclusions and future directions}

The data gathered in this thesis provide new insight in the reactions of platelets during the two distinct phases of the thromboembolic reaction as induced by local vessel wall damage, i.e. thrombus formation and embolization. The two phases of thromboembolism are characterized by different levels of platelet activation and differential involvement of ADP and thrombin. Platelets in an arterial thrombus are more strongly activated, and partially kept together by a thrombin-dependent mechanism (probably fibrin formation); thrombus stabilization is also dependent on A.DP binding to $\mathrm{P} 2 \mathrm{Y}_{1}$. Although literature points to a prominent role for collagen in initial platelet adhesion, ${ }^{6,35}$ and to a role for TF in thrombus formation, ${ }^{20}$ the exact role of these factors in the thromboembolic reaction following wall puncture remains to be elucidated. This could be established by using specific antibodies, but to date such antibodies are unavailable for rabbits. Thrombus size is, among others, determined by $\mathrm{ADP}$ via the $\mathrm{P} 2 \mathrm{Y}_{12}$ receptor and by thrombin. Simultaneous inhibition of both these pathways has been shown to have synergistic effects on thrombus formation. ${ }^{23}$ Therefore, it will also be interesting to investigate the combined effect of ADP and thrombin inhibition in our model of thromboembolism. In addition, the role of VWF and its platelet receptor GPIb-V-IX, which is especially prominent in conditions of high shear stress, ${ }^{5}$ may be investigated. The latter is probably involved in the initial adhesion of platelets to the arterial wall, but can also play a role in the adhesion of platelets to a stable thrombus, leading to embolus production.

In contrast to the thrombus, platelets in the emboli are only weakly activated; embolization seems unaffected by the presence or absence of active thrombin. Blockade of either ADP receptor reduces embolization duration and embolus size, but simultaneous blockade of $\mathrm{P} 2 \mathrm{Y}_{1}$ and $\mathrm{P} 2 \mathrm{Y}_{12}$ does not add to this effect. The possible synergism of ADP and TXA inhibiting drugs, ${ }^{23,30}$ on the other hand, may result in further reduction of embolization, and is 
therefore an promising subject of study. In recent literature, many other factors have been proposed to play a role in thromboembolism, e.g. endothelial CD39 (NTPDase1), ${ }^{11,36}$ NTPDase2," and platelet-derived substances like CD40L ${ }^{17}$ and Gas6. ${ }^{37}$ The current model of wall puncture in the rabbit microcirculation provides excellent opportunity to study the contribution of these factors to a thromboembolic process in vivo.

\section{$7.8 \quad$ References}

1. Cines DB, Pollak ES, Buck CA, Loscalzo J, Zimmerman GA, McEver RP, Pober JS, Wick TM, Konkle BA, Schwartz BS, Barnathan ES, McCrae KR, Hug BA, Schmidt AM, and Stem DM. Endothelial cells in physiology and in the pathophysiology of vascular disorders. Blood. 1998;91:3527-3561.

2. Packham MA, Rand ML, and Kinlough Rathbone RL. Similarities and differences between rabbit and human platelet characteristics and functions. Comp Biochem Physiol Comp Physiol. 1992:103:35-54.

3. oude Egbrink MGA. Tangelder GJ, Slaaf DW, and Reneman RS. Fluid dynamics and the thromboembolic reaction in mesenteric arterioles and venules. Am J Physiol. 1991;260:111826-\$1833.

4. van Gestel MA, Heemskerk JWM, Slaaf DW, Heijnen VVT, Reneman RS, and oude Egbrink MGA. In vivo blockade of the platelet ADP receptor $\mathrm{P} 2 \mathrm{Y}_{12}$ reduces embolus and thrombus formation, but not thrombus stability. Arterioscler Thromb Vasc Biol. 2003;23:518-523.

5. Ruggeri ZM. Platelets in atherothrombosis. Nat Med. 2002;8:1227-1234.

6. Massberg S, Gawaz M, Grüner S, Schulte V, Konrad I, Zohlnhöfer D, Heinzmann U, and Nieswandt B. A crucial role of glycoprotein VI for platelet recruitment to the injured arterial wall in vivo. J Exp Med. 2003;197:41-49.

7. van Gestel MA, Heemskerk JWM, Slaaf DW, Heijnen VVT, Sage SO. Reneman RS, and oude Egbrink MGA. Real-time detection of activation patterns in individual platelets during thromboembolism in vivo: differences between thrombus growth and embolus formation. $J$ Vasc Res. 2002:39:534-543.

8. Kuijpers MJE, Schulte V, Bergmeier W, Lindhout T, Brakebusch C, Offermanns S, Fassler R, Heemskerk IWM, and Nieswandt B. Complementary roles of glycoprotein VI and $\alpha_{2} \beta_{1}$ integrin in collagen-induced thrombus formation in flowing whole blood ex vivo. Faseb J. 2003;17:685-687.

9. Heemskerk JWM, Bevers EM, and Lindhout T. Platelet activation and blood coagulation. Thromb Haemost. 2002;88:186-193.

10. Conley PB, and Delaney SM. Scientific and therapeutic insights into the role of the platelet $\mathrm{P} 2 \mathrm{Y}_{12}$ receptor in thrombosis. Curr Opin Hematol. 2003;10:333-338. 
11. Sevigny J, Sundberg C, Braun N, Guckelberger O, Csizmadia E, Qawi L, Imai M, Zimmermann H, and Robson SC. Differential catalytic properties and vascular topography of murine nucleoside triphosphate diphosphohydrolase I (NTPDase1) and NTPDase2 have implications for thromboregulation. Blood. 2002;99:2801-2809.

12. oude Egbrink MGA, Tangelder GJ, Slaaf DW, and Reneman RS. Different roles of prostaglandins in thromboembolic processes in arterioles and venules in vivo. Thromb Haemost. 1993;70:826-833.

13. Broeders MAW, Tangelder GJ, Slaaf DW, Reneman RS, and oude Egbrink MGA. Endogenous nitric oxide protects against thromboembolism in venules but not in arterioles. Arterioscler Thromb Vasc Biol. 1998;18:139-145.

14. Broeders MAW, Tangelder GJ, Slaaf DW, Reneman RS, and oude Egbrink MGA. Endogenous nitric oxide and prostaglandins synergistically counteract thromboembolism in arterioles but not in venules. Arterioscler Thromb. Vasc Biol. 2001;21:163-169.

15. Nannizzi-Alaimo L, Alves VL, and Phillips DR. Inhibitory effects of glycoprotein IIb/IIla antagonists and aspirin on the release of soluble CD40 ligand during platelet stimulation. Circulation. 2003;107:1123-1128.

16. Ni H, Papalia JM, Degen JL, and Wagner DD. Control of thrombus embolization and fibronectin internalization by integrin $\alpha / \mathrm{lb} \beta 3$ engagement of the fibrinogen $\gamma$ chain. Blood. 2003;102:3609-3614.

17. André P, Prasad KSS, Denis CV, He M, Papalia JM, Hynes RO, Phillips DR, and Wagner DD. CD40L stabilizes arterial thrombi by a $\beta_{3}$ integrin-dependent mechanism. Nat Med. 2002:8:247-252.

18. Jin J, and Kunapuli SP. Coactivation of two different G protein-coupled receptors is essential for ADP-induced platelet aggregation. Proc Natl Acad Sci USA, 1998;95:8070-8074.

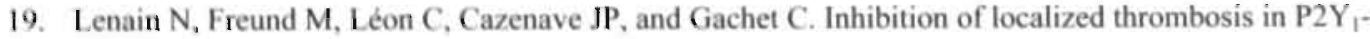
deficient mice and rodents treated with MRS2179, a P2Y! receptor antagonist. J Thromb Haemost. 2003:1:1144-1149.

20. Falati S, Gross P. Merrill-Skoloff G, Furie BC, and Furie B. Real-time in vivo imaging of platelets, tissue factor and fibrin during arterial thrombus formation in the mouse. Nat Med. 2002;8:1175-1181.

21. Ni H, Denis CV, Subbarao S, Degen JL, Sato TN, Hynes RO, and Wagner DD. Persistence of platelet thrombus formation in arterioles of mice lacking both von Willebrand factor and fibrinogen. J Clin Invest. 2000:106:385-392.

22. Heemskerk JWM, Willems GM, Rook MB, and Sage SO. Ragged spiking of free calcium in ADPstimulated human platelets: regulation of puff-like calcium signals in vitro and ex vivo. $J$ Physiol. 2001:535:625-635.

23. André P, LaRocca Ts, Delaney SM, Lin PH, Vincent D, Sinha U, Conley PB, and Phillips DR. Anticoagulants (thrombin inhibitors) and aspirin synergize with $\mathrm{P} 2 \mathrm{Y}_{12}$ receptor antagonism in thrombosis. Circulation. 2003;108:2697-2703.

24. Bates SM, and Weitz J. Emerging anticoagulant drugs. Arterioscler Thromb Vasc Biol. $2003 ; 23: 1491-1500$. 
25. oude Egbrink MGA, Tangelder GJ, Slaaf DW, and Reneman RS. Thromboembolic reaction following wall puncture in arterioles and venules of the rabbit mesentery. Thromb Haemast, 1988;59:23-28.

26. Gosling M, Golledge J, Turner RJ, and Powell JT. Arterial flow conditions downregulate thrombomodulin on saphenous vein endothelium. Circulation. 1999;99:1047-1053.

27. Sperry J, Deming CB, Bian C, Walinsky PL, Kass DA, Kolodgie FD, Virmani R, Kim AY, and Rade J. Wall tension is a potent negative regulator of in vivo thrombomodulin expression. Cinc Res. 2003;92:41-47.

28. Spencer MP. Transcranial Doppler monitoring and causes of stroke from carotid endarterectomy. Stroke. 1997;28:685-691.

29. Markus H. Monitoring embolism in real time. Circulation. 2000;102:826-828.

30. The Clopidogrel in Unstable Angina to Prevent Recurrent Events Trial Investigators. Effects of clopidogrel in addition to aspirin in patients with acute coronary syndromes without ST-segment elevation. $N$ Engl J Med. 2001:345:494-502.

31. Mehta P. Aspirin in the prophylaxis of coronary artery disease. Curr Opin Cardiol. 2002;17:552-558.

32. Wallentin L, Wilcox RG, Weaver WD, Emanuelsson H, Goodvin A, Nystrom P, and Bylock A. Oral ximelagatran for secondary prophylaxis after myocardial infarction: the ESTEEM randomised controlled trial. Lancet. 2003;362:789-797.

33. Storey RF, Oldroyd KG, and Wilcox RG. Open multicentre study of the $\mathrm{P}_{2 \mathrm{~T}}$ receptor antagonist ARC69931MX assessing safety, tolerability and activity in patients with acute coronary syndromes. Thromb Haemost. 2001;85:401-407.

34. André P, Delaney SM, LaRocca T, Vincent D, DeGuzman F, Jurek M, Koller B, Phillips DR, and Conley PB. P2 $\mathrm{Y}_{12}$ regulates platelet adhesion/activation, thrombus growth, and thrombus stability in injured arteries. J Clin Invest, 2003;112:398-406.

35. Nieswandt B, and Watson SP. Platelet collagen interaction: is GPVI the central receptor? Blood. 2003;20:449-461.

36. Pinsky DJ, Broekman MJ, Peschon JJ, Stocking KL, Fujita T, Ramasamy R, Connolly ES, Jr., Huang J, Kiss S, Zhang Y, Choudhrì TF. McTaggart RA, Liao H, Drosopoulos JHF, Priçe VE, Marcus AJ, and Maliszewski CR. Elucidation of the thromboregulatory role of CD39/ectoapyrase in the ischemic brain. J Clin Invest. 2002;109:1031-1040.

37. Angelillo-Scherrer A, de Frutos PG, Aparicio C. Melis E, Savi P, Lupu F, Arnout J, Dewerchin M, Hoylaerts M, Herbert JM, Collen D, Dahlbäck B, and Carmeliet P. Deficiency or inhibition of Gas6 causes platelet dysfunction and protects mice against thrombosis. Nat Med, 2001;7:215-221. 
Chapter 7 
Summary/Samenvatting

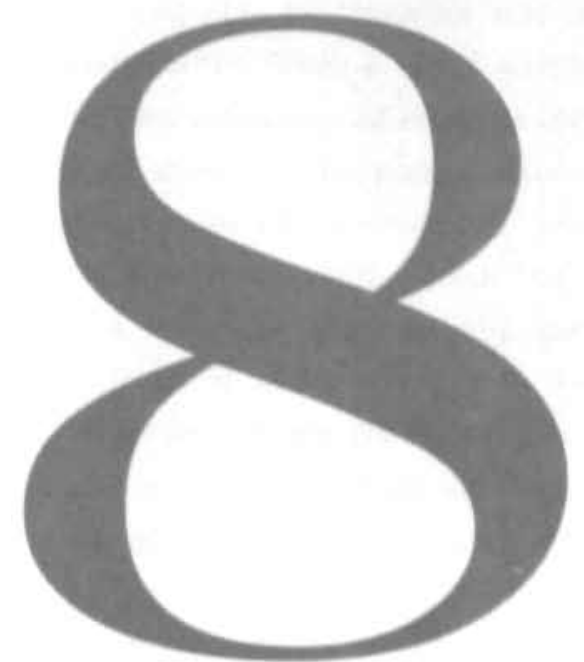


(Bupies: 


\section{Summary}

\section{$A D P$ and thrombin during thromboembolism in vivo: a vital imaging approach}

Interactions between blood platelets and the vessel wall play an important role in hemostasis and in many vascular diseases such as thromboembolism. When a vessel wall is damaged, platelets adhere to the exposed subendothelium, become activated, and assemble into an aggregate (thrombus). This thrombus can be stabilized through tight platelet-platelet interactions and via formation of fibrin. On the downstream side of the thrombus, new aggregates are often formed due to the continuous recruitment of platelets from the blood. These aggregates are repeatedly shed from the thrombus as emboli, a process called embolization. Such a thromboembolic process may lead to vessel occlusion, either at the site of injury (by the thrombus) or downstream (by the emboli). The aim of the studies described in this thesis was to obtain a better insight in the pathogenesis of thromboembolism in vivo and, in particular, in the behavior of individual platelets and in the contribution of the prothrombotic factors adenosine diphosphate (ADP) and thrombin.

All studies (chapters 3-6) were performed using an in vivo model in which rabbit mesenteric microvessels were mechanically injured by puncturing the vessel wall. The resulting thromboembolic reaction was visualized in real-time using intravital microscopy. In all vessels, red blood cells were seen leaving the vessel upon puncture, indicating that all layers of the vessel wall were damaged. Bleeding was stopped by the quick formation of a thrombus, from which emboli were shed repeatedly. Whereas embolization stopped after some time, the primary thrombus remained unchanged at the site of injury during the observation period.

Knowledge on single platelet behavior and intracellular mechanisms during thromboembolism in vivo is scarce. Chapter 3 describes an extension of the established in vivo method to detect in real-time and to quantitate activation of single platelets participating in a thromboembolic reaction, using their cytosolic free calcium concentration $\left(\left[\mathrm{Ca}^{2+}\right]_{1}\right)$ as an activation marker. To this purpose, isolated platelets were labeled with the calcium-sensitive fluorescence probe fluo-3 and injected into anesthetized rabbits so that $0.5-1 \%$ of their circulating platelets were labeled. Subsequently, a thromboembolic reaction was induced in arterioles, and fluorescence intensity changes (representing changes in $\left[\mathrm{Ca}^{2+}\right]_{i}$ ) of labeled platelets participating in this reaction were quantified. The method was validated by assessing that labeled platelets behave similarly to native platelets and that fluorescence intensity is not influenced by dye leakage. In addition, defocusing artifacts can be distinguished from intensity changes due to changes in $\left[\mathrm{Ca}^{2+}\right]_{i}$. The results show that the activation patterns of single platelets participating in thrombus formation are different from those involved in embolization. Upon adherence to the primary thrombus, platelets exhibited a prolonged $\left[\mathrm{Ca}^{2+}\right]_{i}$ increase, 
accompanied by shape change and degranulation. This indicates a high level of activation and is consistent with a role for strong platelet agonists like collagen and thrombin. In contrast, when platelets adhered to a growing embolus their $\left[\mathrm{Ca}^{2+}\right]_{i}$ rise was transient and they hardly showed shape change and degranulation, indicating a lower level of activation and suggesting the involvement of weaker agonists such as ADP.

ADP is considered to be a key platelet agonist during thromboembolism, because it is released from platelets upon activation and can amplify the responses to other agonists. ADPinduced platelet activation involves two receptors, $\mathrm{P} 2 \mathrm{Y}_{1}$ and $\mathrm{P} 2 \mathrm{Y}_{12}$. The role of the $\mathrm{P} 2 \mathrm{Y}_{12}$ receptor during a thromboembolic reaction in arterioles was investigated in chapter 4 . Rabbits were treated with the selective P2 $\mathrm{Y}_{12}$ antagonists AR-C69931 MX or clopidogrel, the latter being a widely used antithrombotic drug in humans. Both substances significantly reduced the total duration of embolization, in which period less and smaller emboli were produced. The size of the initial thrombus was also reduced, but its stability was not influenced, i.e. plug formation was still effective in stopping bleeding and preventing rebleeding. These results may explain the beneficial effects of $\mathrm{P} 2 \mathrm{Y}_{12}$ receptor antagonists in the prevention of ischemic events in patients with arterial thrombosis.

$\mathrm{P} 2 \mathrm{Y}_{1}$ is also considered a potential target for antithrombotic therapy, but its role, as well. as the combined role of both receptors in the dynamic process of thromboembolism in vivo is largely unknown. In chapter 5 , the effects were studied of blocking $\mathrm{P}_{2} \mathrm{Y}_{1}, \mathrm{P} 2 \mathrm{Y}_{12}$, or both during a thromboembolic reaction in arterioles. Blocking of $\mathrm{P} 2 \mathrm{Y}_{1}$ (using the compound A3P5P) significantly reduced total duration of embolization to a similar extent as blocking P2 $\mathrm{Y}_{12}$, and again less and smaller emboli were produced. Experiments with fluo-3 labeled platelets showed that this was not due to decreased platelet adherence, but rather to decreased interaction strength between platelets. Surprisingly, simultaneous blockade of both receptors did not further reduce embolization. Unlike $\mathrm{P}_{2} \mathrm{Y}_{12}$ blockade, $\mathrm{P} 2 \mathrm{Y}_{1}$ blockade reduced the stability of the thrombus, since rebleeding occurred more frequently in the A3P5P-treated vessels. The latter is probably not mediated via reduced fibrin formation, since inhibition of $\mathrm{P} 2 \mathrm{Y}_{1}$, did not influence plateletdependent thrombin generation in vitro. The effect of $\mathrm{P} 2 \mathrm{Y}_{1}$ blockade on thrombus stability could, however, be due to the fact that $\mathrm{P}_{2} \mathrm{Y}_{1}$ (but not $\mathrm{P} 2 \mathrm{Y}_{12}$ ) blockade reduced the transient intracellular calcium signals in single platelets, which reduces secretion of substances involved in thrombus stabilization. Altogether, the findings in chapters 4 and 5 show that both platelet ADP receptors are involved in the formation of emboli on the downstream side of the primary thrombus. Beside this role in embolization, $\mathrm{P}_{2} \mathrm{Y}_{12}$ is partially responsible for the size of the thrombus, whereas $\mathrm{P}_{2} \mathrm{Y}_{1}$ is important for its stability.

Accumulating evidence shows that the processes of platelet activation and blood coagulation are mutually dependent. Thrombin, being a major platelet agonist and a crucial coagulation product responsible for the formation of fibrin, plays an important role in this 
interdependency. Because arterial thromboembolism is thought to be mainly dependent on activated platelets, whereas fibrin is considered more important in venous thromboembolism, the role of thrombin was investigated in both arterioles and venules (chapter 6). In punctured arterioles, inhibition of factor $\mathrm{Xa}$ or thrombin significantly decreased the size of the thrombi as well as their effectiveness (characterized by increased frequency and duration of rebleeding). In venules, a significant reduction in thrombus size was also found, whereas the increase in rebleeding was smaller. Downstream shedding of emboli from the primary thrombus was not influenced by either $\mathrm{Xa}$ or thrombin inhibition, regardless of vessel type. These findings demonstrate that -in the present model- thrombin, formed via the Xa pathway, plays a distinct role in thromboembolism in arterioles as well as venules. Thrombin appears to be particularly important for the formation of a hemostatically effective primary thrombus, its contribution being more eminent in the arterial than in the venous system.

In the General discussion (chapter 7), an overview is given of the current knowledge of factors involved in thromboembolism. The two phases of this process, i.e. thrombus formation and embolization, are characterized by different levels of platelet activation and different contributions of ADP and thrombin. Platelets in a thrombus are more strongly activated; their initial activation is probably achieved through exposure of collagen after endothelial celi damage. Platelets activated by collagen can release ADP and become procoagulant and, hence, promote thrombin formation at their surface, and both ADP and thrombin were shown to be involved in determining thrombus size. Thrombus stability is largely dependent on thrombin (probably via formation of fibrin and by stimulating platelets), but ADP binding to P2Y, was also demonstrated to play an important role. The platelets in the emboli are only weakly activated, and embolization seems unaffected by the presence or absence of thrombin. The formation of emboli seems to depend mainly on prothrombotic substances released from activated platelets such as thromboxane $A_{2}$ and ADP, the latter being involved via both its receptors. Endothelium-derived platelet-inhibiting substances like nitric oxide and prostacyclin can inhibit aggregate formation, and counteract the platelet stimulating effects of these factors. Hence, embolization ends when the balance between prothrombotic and antithrombotic factors shifts towards the antithrombotic side.

The data gathered in this thesis have increased the knowledge on the pathogenesis of thromboembolic processes in vivo, especially regarding the role of single platelets and of the prothrombotic factors ADP and thrombin. Combined with the results from in vitro studies, studies in other animal models, and studies in humans, this knowledge will help to improve the treatment strategies for thromboembolic disorders in patients with cardiovascular disease. 
Chapter 8 


\section{Samenvatting}

\section{De rol van ADP en trombine tijdens trombo-embolisme in vivo, bestudeerd met behulp van vitale imaging technieken}

Bloedplaatjes zijn de kleinste cellulaire elementen in het bloed, en zijn onmisbaar bij het stoppen van bloedingen in beschadigde bloedvaten (hemostase). Zij zijn echter ook betrokken bij verscheidene ziekteprocessen in het hart en vaatstelsel, waaronder trombose. Als bloed door een intact bloedvat stroomt, bevinden de meeste bloedplaatjes zich relatief dicht bij de vaatwand. Soms maken ze ook contact met die wand, maar hechting wordt voorkomen door de zogenaamde antitrombotische eigenschappen van de endotheelcellen, die de binnenbekleding van de vaatwand vormen. Wanneer het endotheel echter beschadigd raakt, gaan bloedplaatjes zich hechten aan de beschadigde vaatwand (adhesie) en worden ze geactiveerd. Door stoffen die daarbij vrijkomen raken vervolgens ook andere bloedplaatjes geactiveerd. Doordat de geactiveerde bloedplaatjes aan elkaar gaan hechten (aggregatie), vormt zich op de plaats van beschadiging een bloedplaatjesprop of -plug die de beschadiging afdicht en -als dat nodig is- het bloeden stopt. Deze plug wordt ook wel trombus genoemd, en dankt zijn stevigheid aan de sterke binding tussen de bloedplaatjes en aan de vorming van een netwerk van fibrine-draden. Fibrine is het eindproduct van de bloedstolling, een proces dat verloopt via een aantal opeenvolgende reacties tussen eiwitten uit het bloed. Bloedstolling kan, net als bloedplaatjesactivatie, in gang worden gezet door een vaatwandbeschading.

In veel gevallen gaat het proces van bloedplaatjes-activatie door nadat een trombus eenmaal gevormd is. Hierdoor kunnen aan de stroomafwaartse zijde van de trombus steeds nieuwe bloedplaatjes aanhechten. Deze aggregaten breken van tijd tot tijd van de trombus af en worden als emboli meegevoerd door het bloed (embolisatic). Het totale proces van trombus vorming en embolisatie wordt ook wel trombo-embolisme genoemd. Wanneer de trombus voldoende groot is, kan deze een bloedvat afsluiten en de bloedstroom stoppen; ook de emboli kunnen stroomafwaarts kleinere vaten afsluiten. In beide gevallen zal het achterliggende weefsel (tijdelijk) geen zuurstof en voedingsstoffen krijgen, wat erg schadelijke gevolgen kan hebben; een dergelijk proces ligt bijvoorbeeld ten grondslag aan een hart- of herseninfarct. Om dit soort trombo-embolische processen zo goed mogelijk te kunnen bestrijden of voorkomen, is het belangrijk dat we meer inzicht krijgen in de ontstaanswijze en het verloop ervan. Dit was dan ook het doel van het onderzoek in dit proefschrift. Meer in het bijzonder is gekeken naar het gedrag van individuele bloedplaatjes tijdens zo'n trombo-embolisch proces, en naar de bijdrage van enkele belangrijke factoren die plaatjes kunnen activeren: adenosine difosfaat (ADP) en trombine. 
Veel van de kennis omtrent de reacties van bloedplaatjes en endotheelcellen kan worden uitgezocht met behulp van bloedmonsters of geïsoleerde cellen "in vitro" (in buisjes). In zo'n geval ontbreken echter belangrijke factoren afkomstig uit het omringende weefsel. Experimenten in proefdieren maken gebruik van de kennis die is opgedaan bij in vitro experimenten en testen wat er gebeurt in de situatie zoals die in het levende dier "in vivo" optreedt. In de studies die in dit proefschrift staan beschreven is met behulp van een speciale lichtmicroscoop, een zgn. intravitaal microscoop, de trombo-embolische reactie bestudeerd in levende, verdoofde konijnen. Deze reactie werd opgewekt door een vaatwandbeschadiging in kleine bloedvaten in het darmvlies. Arteriolen (de kleinste slagaders) en venulen (de kleinste aders) werden aangeprikt met een glazen naaldje (micropipet), waardoor een gat in de vaatwand ontstond. Hierdoor ontstond een bloeding waarbij rode bloedcellen het vat verlaten. Deze bloeding werd binnen enkele seconden gestopt door de vorming van een trombus (bestaande uit geactiveerde bloedplaatjes), waarvan herhaaldelijk emboli afbraken die werden meegevoerd door het bloed. Hoewel deze embolisatie na enige tijd stopte, bleef de trombus zelf onveranderd op de plek van beschadiging zitten.

Er is nog maar weinig bekend over het gedrag van individuele bloedplaatjes die deelnemen aan een trombo-embolisch proces in vivo. Om dit gebrek aan kennis op te vullen is een methode ontwikkeld die het mogelijk makt om activatie van individuele bloedplaatjes tijdens een trombo-embolische reactie zichtbaar te maken en te meten (hoofdstuk 3 ). We hebben gebruik gemaakt van de wetenschap dat activiteit van bloedplaatjes gepaard gaat met veranderingen in de intracellulaire calcium concentratie $\left(\left[\mathrm{Ca}^{2+}\right]_{i}\right)$. Geïsoleerde bloedplaatjes, afkomstig uit donor-konijnen, werden verbonden met een fluorescente probe die gevoelig is voor veranderingen in $\left[\mathrm{Ca}^{2+}\right]$. Deze 'gelabelde' bloedplaatjes werden ingespoten in verdoofde konijnen, met als gevolg dat $0.5-1 \%$ van alle bloedplaatjes in deze konijnen gelabeld waren. Vervolgens werd in arteriolen een trombo-embolische reactie opgewekt, waar de gelabelde bloedplaatjes aan deelnamen. Terwijl deze hechtten aan de trombus of een embolus werden veranderingen in fluorescentie gemeten. Controles wezen uit dat deze fluorescentieveranderingen representatief waren voor veranderingen in $\left[\mathrm{Ca}^{2+}\right]_{i}$. en dat de gelabelde bloedplaatjes zich hetzelfde te gedroegen als de overige, niet-gelabelde bloedplaatjes. Met behulp van deze methode kon worden vastgesteld dat bloedplaatjes in een trombus veel sterker geactiveerd zijn dan bloedplaatjes in de emboli. Wanneer bloedplaatjes aan een trombus hechten, stijgt het $\left[\mathrm{Ca}^{2+}\right]_{1}$ onmiddellijk en blijft het niveau hoog. Bij bloedplaatjes die aan een embolus hechten stijgt het $\left[\mathrm{Ca}^{2+}\right]_{i}$ ook, maar zakt het vrijwel meteen weer terug naar het beginniveau. Samen met verscheidene uiterlijke kenmerken van bloedplaatjes in trombus en emboli wijst dit erop dat tijdens trombusvorming sterke plaatjes-activerende factoren (zoals collageen en trombine) een belangrijke rol spelen, terwijl in de embolisatie-fase vooral de minder sterke factoren (zoals ADP) van belang zijn. 
ADP komt vrij uit geactiveerde bloedplaatjes, en kan vervolgens andere plaatjes activeren, waardoor het de reactie van plaatjes op andere stoffen kan versterken. Blocdplaatjes hebben aan hun oppervlak twee typen receptoren die ADP kunnen binden: $\mathrm{P} 2 \mathrm{Y}_{1}$ en $\mathrm{P} 2 \mathrm{Y}_{12}$. Binding van ADP aan deze receptoren start vervolgens intracellulaire signalen die ervoor zorgen dat bloedplaatjes geactiveerd worden. In hoofdstuk 4 is gekeken naar de rol van binding van ADP aan de $\mathrm{P} 2 \mathrm{Y}_{12}$ receptor tijdens de trombo-embolische reactie. Sommige konijnen werden behandeld met stoffen die $\mathrm{P}_{2} \mathrm{Y}_{12}$ blokkeren, en dus voorkomen dat deze receptor plaatjes activeert. In deze konijnen bleek na het aanprikken van arteriolen vooral de embolisatie geremd te zijn: zowel de embolisatieduur als het aantal en de grootte van de emboli waren afgenomen ten opzichte van konijnen die niet met $\mathrm{P}_{2} \mathrm{Y}_{12}$-remmers behandeld waren. Ook de trombus was kleiner in de behandelde groep, maar deze was nog steeds 'stabiel', d.w.z. effectief in staat om het bloeden te stoppen en nieuwe bloedingen (herbloedingen) te voorkomen. Omdat het remmen van $\mathrm{P}_{2} \mathrm{Y}_{12}$ de embolisatie (en dus ook de kans op bloedvatverstopping) vermindert, zonder daarbij de trombus minder stabiel te maken. bieden deze resultaten een mogelijke verklaring voor de effectiviteit van $\mathrm{P}_{2} \mathrm{Y}_{12}$-remmers bij de behandeling van trombo-embolisme bij patiēnten.

Ook de andere ADP receptor, $\mathrm{P} 2 \mathrm{Y}_{1}$, wordt gezien als een mogelijk aangrijpingspunt voor antitrombotische medicijnen. $\mathrm{Er}$ is echter nog maar weinig bekend over de rol van $\mathrm{P} 2 \mathrm{Y}_{1}$, alsmede over de gezamenlijke rol van $\mathrm{P}_{2} \mathrm{Y}_{1}$ en $\mathrm{P}_{2} \mathrm{Y}_{12}$, tijdens trombo-embolische processen in vivo. In hoofdstuk 5 is daarom het effect van $\mathrm{P} 2 \mathrm{Y}_{1}$ blokkade op een trombo-embolische reactie vergeleken met dat van $\mathrm{P} 2 \mathrm{Y}_{12}$ blokkade; daarnaast is het effect van gelijktijdige remming van beide receptoren onderzocht. Het remmen van $\mathrm{P} 2 \mathrm{Y}_{1}$ verminderde de embolisatieduur en het aantal en de grootte van de emboli, in dezelfde mate als werd gezien bij remming van $\mathrm{P}_{2} \mathrm{Y}_{12}$. Experimenten met fluorescent gelabelde bloedplaatjes lieten zien dat dit niet het gevolg was van een afgenomen aanhechting van plaatjes, maar dat de stevigheid van de verbinding tussen de plaatjes verminderd was. Tegen de verwachting in bleek bij gelijktijdige blokkade van P2Y, en $\mathrm{P}_{2} \mathrm{Y}_{12}$ geen verdere remming van de embolisatie op te treden. Bovendien resulteerde $\mathrm{P} 2 \mathrm{Y}_{1}$ remming (in tegenstelling tot $\mathrm{P}_{2} \mathrm{Y}_{12}$ remming) in een verminderde stabiliteit van de trombus, wat gekenmerkt werd door het vaker optreden van herbloedingen. Dit laatste is waarschijnlijk niet het gevolg van verminderde aanwezigheid van fibrine, aangezien P2Y, remming geen effect had op trombine vorming in vitro, en trombine juist verantwoordelijk is voor fibrine-vorming. Het effect van P2Y, blokkade op trombus stabiliteit heeft, daarentegen, waarschijnlijk te maken mẹt de remming van de intracellulaire calcium respons door P2Y, blokkade, wat kan leiden tot verminderde afgifte van stoffen die kunnen zorgen voor stevige binding tussen de plaatjes. Samenvattend wijzen de bevindingen uit hoofdstuk 4 en 5 erop dat beide ADP receptoren in sterke mate betrokken zijn bij de vorming van emboli aan stroomafwaartse zijde van de trombus. Daarnaast is $\mathrm{P} 2 \mathrm{Y}_{12}$ betrokken bij de groei van de trombus, terwijl P2Y, een belangrijke rol speelt bij de effectiviteit van de trombus tot het voorkomen van herbloedingen. 
Het wordt steeds meer duidelijk dat de processen van bloedplaatjes-activatie en bloedstolling niet los van elkaar optreden, maar dat zij afhankelijk zijn van elkaar. Trombine is zowel een sterke bloedplaatjes-stimulerende factor als een belangrijk onderdeel van de bloedstolling: het is namelijk direct verantwoordelijk voor de vorming van fibrine. Daarom speelt trombine een cruciale rol bij deze onderlinge afhankelijkheid. De vorming van trombine wordt gekatalyseerd door het eiwit factor $\mathrm{Xa}$, en deze reactie wordt sterk versneld wanneer er een zogenaamd procoagulant oppervlak aanwezig is. Sterk geactiveerde bloedplaatjes kunnen zo'n procoagulant oppervlak hebben, en zodoende kunnen bloedplaatjes de trombinevorming beïnvloeden. Omdat in het algemeen wordt aangenomen dat trombo-embolisme in arteriën vooral afhankelijk is van bloedplaatjes, terwijl bij trombo-embolisme in venen juist fibrine erg belangrijk wordt geacht, is de rol van trombine bestudeerd in zowel arteriolen als venulen (hoofdstuk 6). In aangeprikte arteriolen bleek dat tijdens trombine remming een kleinere trombus werd gevormd, en dat deze ook minder effectief was in het voorkomen van herbloedingen: ze traden vaker op en de totale bloedingstijd was verlengd. In venulen trad ditzelfde fenomeen op, maar de toename in het aantal herbloedingen was veel kleiner. De vorming van emboli aan de stroomafwaartse zijde van de trombus werd niet beìnvloed door het remmen van trombine, noch in arteriolen noch in venulen. Deze resultaten laten zien dat trombine in zowel arteriolen als venulen een rol speelt in het trombo-embolisch proces, en dat trombine met name belangrijk is bij de vorming van een stabiele (of effectieve) trombus. Dit komt waarschijnlijk doordat trombine zorgt voor de vorming van fibrine en voor een hechte binding tussen de bloedplaatjes. Trombine is meer betrokken bij trombusvorming in arteriolen dan in venulen, en lijkt geen rol te spelen bij de embolisatie.

In hoofdstuk 7 staat beschreven wat er -uit dit en ander onderzoek- bekend is over de factoren die een rol spelen bij trombo-embolisme. De twee fases van het trombo-embolische proces, $\mathrm{nl}$. trombus vorming en embolisatie, worden o.a. gekarakteriseerd door verschillende mate van bloedplaatjes activatie en door verschillende bijdragen van ADP en trombine. Plaatjes in een trombus zijn zeer sterk geactiveerd, waarschijnlijk ten gevolge van blootstelling aan collageen. Collageen is een vaatwandbestanddeel dat zich onder het endotheel bevindt en dus in pas contact komt met het bloed wanneer het endotheel wordt beschadigd. Het is een sterke plaatjes activator, die er o.a. voor kan zorgen dat ADP vrijkomt en dat trombine wordt gevormd aan het plaatjesoppervlak. ADP en trombine kunnen dan zorgen voor verdere trombusgroei. De stabiliteit van een trombus, d.w.z. zijn effectiviteit tot het stoppen van bloedingen en het voorkomen van herbloedingen, is grotendeels afhankelijk van trombine, maar ADP binding aan de $\mathrm{P} 2 \mathrm{Y}$, receptor is hierbij ook belangrijk. Bloedplaatjes die zich bevinden in de emboli zijn minder sterk geactiveerd dan die in de trombus, en embolisatie is nauwelijks beînvloed door de aan- of afwezigheid van trombine. De vorming van emboli is wel afhankelijk van protrombotische factoren als tromboxane $\mathrm{A}_{2}$ en ADP, waarbij in het geval van ADP beide 
receptoren belangrijk zijn. Het plaatjes-stimulerende effect van deze stoffen wordt tegengegaan door plaatjes-remmende factoren die vrijkomen uit het endotheel: NO (stikstofoxide) en prostacycline. Het embolisatie-proces stopt dan ook wanneer deze laatste factoren de overhand krijgen.

Dit proefschrift levert een bijdrage aan de kennis omtrent het ontstaan en het verloop van trombo-embolische processen in vivo, met name betreffende de rol van individuele bloedplaatjes en de factoren ADP en trombine. Samen met de resultaten uit in vitro onderzoek, onderzoek met andere proefdiermodellen en onderzoek bij de mens zal dit leiden tot een betere behandelingsstrategie van trombo-embolisme bij patiěnten met hart- en vaatziekten. 


\section{Dankwoord}

Dit proefschrift zou er niet zijn geweest zonder de hulp van vele anderen. lk wil dan ook iedereen die, op welke manier dan ook, zijn steentje heeft bijgedragen aan de totstandkoming van dit proefschrift heel erg bedanken. Een aantal personen verdienen hierbij bijzondere aandacht:

Allereerst natuurlijk mijn promotor en copromotors: Dick, Mirjam en Johan. Zonder jullie 'multidisciplinaire' input was het proefschrift niet geworden wat het nu is. Bedankt dat ik van jullie heb mogen leren! Dick: je lette altijd op de details. Je dwong me tot nadenken, ook als ik dacht dat mijn keuze allang vaststond. Hierdoor bleef ik altijd met beide benen op de grond staan. Bedankt voor al je adviezen. Mirjam: jij was, als directe begeleider, mijn eerste aanspreekpunt. Je leerde me de kunst van het 'prikken' en stond me altijd met raad en daad bij. Of het nu ging om experimenten, artikelen, resultaten of hele andere dingen: je was altijd erg betrokken en dit heb ik heel erg gewaardeerd. Bedankt voor alles! Johan: ondanks je drukke agenda had je altijd een gaatje voor me vrij. Na een brainstormsessie met jou kwam ik altijd met mijn hoofd vol informatie en mijn armen vol artikelen naar buiten. Bedankt voor je enthousiasme! En dan is er nog Rob: als onofficieel begeleider ben jij ook altijd bij mijn project betrokken geweest. Je wist altijd de puntjes op de ' $i$ ' te zetten bij het schrijven van artikelen, dus bedankt voor het veelvuldige gebruik van je rode pen!

Tijdens de jaren in Maastricht was er heel wat lief en heel wat leed te delen. Hier had ik gelukkig mijn kamergenoten voor. Om te beginnen was daar Selma, die me op weg hielp in mijn beginnende dagen als AlO en daarna Xander, ook wel bekend als ' $\mathrm{X}$ '. Toen kwamen Anita, Susan en Veerle: dames, ons kameruitje naar de Efteling was zeer geslaagd! Suus: we warẹn in meerdere opzichten buren, bedankt voor al je steun in het afgelopen jaar en succes met je promotie! En laat ik ook de tijdelijke 'bewoners' niet vergeten, Hanneke, Lucy en Jacqueline: jullie droegen allemaal bij aan de gezelligheid op de kamer, of het nu de jongleerballen, de rollende leukocyten of de ingewikkelde vraagstukken over mannen waren die me om de oren vlogen.....

Verder wil ik iedereen van Microcirculatie bedanken voor de leuke samenwerking en voor alle gezelligheid tijdens en naast het werk: Viviane, Mirjam, Marc, Alexandra, Geertje, Ferdi, Veerle, Anita, Marijke, Mark, Dick, Remco en Wim. Viviane: bedankt voor al je hulp bij de konijnen-experimenten. Marc: carnaval in Maastricht is een traditie geworden die we hopelijk zullen blijven voortzetten! Geertje: bedankt dat ik altijd mijn verhaal bij je kwijt kon. Ook een woord van dank aan de medewerkers van de Centrale Proefdier Voorzieningen voor hun onmisbare bijdrage aan de experimenten. Verder wil ik nog de studenten die aan mijn onderzoek hebben meegewerkt: Joost, Els en Sietze, en de overige leden van de vakgroepen Fysiologie 
(Jos: bedankt voor je hulp bij de laatste loodjes) en Biochemie (Marion: bedankt voor je hulp bij mijn in vitro proeven) bedanken voor de samenwerking. Mijn collega-AIO's: Marijke, Imke, Danny, Debby, Roy, Daniêlle, Maurice, Susan, Andries, Veerle, Sander, Jacqueline en Dominique wil ik heel veel succes wensen met hun promotie en/of met hun verdere carrière. Dominique: bedankt voor alle gezellige lunches en andere (eet)afspraken!

En dan de twee mensen die op de grote dag achter me zullen staan: mijn paranimfen. Anita: eerst collega's, toen vriendinnen, vervolgens kamergenoten en dan ook nog elkaars paranimfen. Het was af en toe een dolle boel op onze kamer, vooral het uitwerken van de videobanden bracht vaak de nodige hilariteit ('Hoe kan dat nou? Hij gaat vanzelf!' is slechts een voorbeeld...). Het was echt afkicken toen we elkaar niet meer elke dag zagen, maar het is nu des. te leuker als we elkaar wel zien en dat blijven we zeker doen!! Succes met je eigen promotie, veel geluk met Michel en Tycho enne... je mag voor mij 'annie' time als spion fungeren! Ruth: in het studentenhuis in Nijmegen deelden we al lief en leed, en het was dus behoorlijk wennen toen ik naar Maastricht verhuisde om AIO te worden... Maar daarna haalden we de schade in als we samen op vakantie gingen. Zo kon ik telkens weer de promotie-perikelen even vergeten en hebben we per auto heel wat van Europa gezien ('Ben ik al bruin?' Of is dit rood?' was een jaarlijks terugkerend thema). En tja, 'we bellen als het nodig is' kan natuurlijk heel ruim worden opgevat, soms is het gewoon even nodig om gezellig bij te kletsen! De telefoonrekeningen spreken voor zich... Bedanki voor je altijd luisterende oor.

Natuurlijk vergeet ik ook mijn ouders niet: pap en mam, bedankt dat jullie er altijd zijn, ook al ga ik dan steeds verder weg wonen. Gelukkig weten jullie Delft ook goed te vinden!! Ook wil ik hier Sandra en Marieke en mijn zwagers, ooms, tantes, nichtjes (José en Joe: succes in lerland!) en vrienden bedanken die me 'op afstand' hebben bijgestaan.

En dan, last but not least, is er natuurlijk nog Marcel. Mijn rustige leventje kwam ineens in een stroomversnelling terecht toen jij op het toneel verscheen. Sindsdien hebben we samen al heel wat 'stormen' overwonnen, en mede dankzij jou heb ik ook de 'orkaan' die Promoveren heet doorstaan. Bedanki dat je steeds achter me hebt gestaan, en ik hoop dat we nu in wat rustiger vaarwater terecht zullen komen......! 


\section{Curriculum vitae}

Miriam van Gestel werd geboren op 21 oktober 1976 te Tegelen en kreeg de doopnamen Marie-Antonette, Zij groeide op in Blerick, waar ze in 1988 haar VWO-opleiding begon aan het Blariacum College. In 1994 behaalde ze haar VWO-diploma, waarna ze startte met de opleiding Biomedische Gezondheidswetenschappen aan de Katholieke Universiteit Nijmegen. Tijdens haar studie behaalde ze onder andere de status van artikel 9-deskundige volgens de Wet op de Dierproeven en liep ze enkele stages binnen de vakgroep Farmacologie. Voor haar afstudeerstage vertrok ze naar Londen, Engeland, om onderzoek te doen bij het Department of Clinical Pharmacology van het St. Mary's Hospital. Het doctoraal diploma werd Cum Laude behaald in 1999, waarna ze als Assistent in Opleiding (AIO) begon bij de vakgroep Fysiologie aan de Universiteit Maastricht (UM). Het onderzoek dat ze daar deed en wat beschreven staat in dit proefschrift vond plaats in het laboratorium voor Microcirculatie binnen het Cardiovascular Research Institute Maastricht (CARIM). $\mathrm{Na}$ het volgen van verscheidene cursussen werd haar in 2003 het CARIM PhD-Training Certificate uitgereikt. Tijdens de periode aan de UM bezocht ze congressen in onder andere Londen, Maastricht, Stockholm, Parijs en New Orleans en won ze diverse 'young investigator awards' voor haar abstracts en mondelinge presentaties. Naast het onderzoek was zij onder meer actief in zeilen en handbal, en was ze mede-oprichtster en penningmeester van de Maastrichise studenten handbalvereniging Manos. Tegenwoordig woont zij in Delft, en sinds het afronden van haar proefschrift in december 2003 is zij zich aan het oriënteren op de arbeidsmarkt. 


\section{Publications}

\section{Papers}

- $\quad$ oude Egbrink MGA, van Gestel MA, Broeders MAW, Slaaf DW, Reneman RS, Heemskerk JWM, and Tangelder GJ. Platelet-vessel wall interactions in vivo: stimulation and inhibition. In: Tooke J, Shore A, and Whatmore J, eds. The microcirculation and vascular biology, 22nd Meeting of the European Society for Microcirculation. Bologna: Monduzzi Editore; 2002:293-298.

- van Gestel MA, Heemskerk JWM, Slaaf DW, Heijnen VVTh, Sage SO, Reneman RS, and oude Egbrink MGA. Real-time detection of activation patterns in individual platelets during thromboembolism in vivo: differences between thrombus growth and embolus formation. $J$ Vasc Res: 2002;39:534-543.

- van Gestel MA, Heemskerk JWM, Slaaf DW, Heijnen VVTh, Reneman RS, and oude Egbrink MGA. In vivo blockade of the platelet ADP receptor $\mathrm{P}_{2} \mathrm{Y}_{12}$ reduces embolus and thrombus formation, but not thrombus stability. Arterioscler Thromb Vasc Biol. $2003 ; 23: 518-523$.

- van Gestel MA, Heemskerk JWM, Slaaf DW, Reitsma S, Schrier JCM, Heijnen VVTh, Reneman RS, and oude Egbrink MGA. Antithromboembolic effects of blocking ADP receptors $\mathrm{P}_{2} \mathrm{Y}_{1}$ and $\mathrm{P}_{2} \mathrm{Y}_{12}$ in vivo. No additive effects of simultaneous blockade. Submitted.

- van Gestel MA, Heemskerk JWM, Slaaf DW, Feijge MAH, Heijnen VVTh, Elg M, Reneman RS, and oude Egbrink MGA. Thrombin inhibition reduces thrombus growth and effectiveness but hardly influences embolization in both arterioles and venules in vivo. Submitted.

\section{Abstracts}

- van Gestel M, Heemskerk JWM, Slaaf DW, Heijnen VVTh, and oude Egbrink MGA. A new method to measure cytosolic calcium in activated rabbit platelets in vivo. $J$ Vasc Res. 2000;37:suppl I.

- van Gestel M, Heemskerk JWM. Slaaf DW, Sage SO, and oude Egbrink MGA. ADPinduced rabbit platelet activation during thromboembolism involves the $\mathrm{P}_{\text {2TAC }}$ receptor. $J$ Physiol. 2001;531P;8P.

- van Gestel MA, Heemskerk JWM, Slaaf DW, Sage SO, and oude Egbrink MGA. The platelet ADP-receptor P2Y 12 is involved in embolization but not in thrombus formation in vivo. Thromb Haemost. 2001;Suppl:OC1013. 
- van Gestel MA, Heemskerk JWM, Slaaf DW, Heijnen V, and oude Egbrink MGA. A new method to measure cytosolic calcium in activated rabbit platelets in vivo. Platelets. 2002;13:60.

- van Gestel MA, Heemskerk JWM, Reitsma S, Heijnen VVTh, Slaaf DW, Reneman RS, and oude Egbrink MGA. The involvement of $\mathrm{ADP}$ and its receptors $\mathrm{P} 2 \mathrm{Y}_{1}$ and $\mathrm{P} 2 \mathrm{Y}_{12}$ in thromboembolism in vivo. $J$ Vasc Res. 2002;39:suppl 1.

- van Gestel MA, Heemskerk JWM, Slaaf DW, Reneman RS, and oude Egbrink MGA. In vivo involvement of $\mathrm{ADP}$ in thromboembolism through its receptors $\mathrm{P} 2 \mathrm{Y}_{1}$ and $\mathrm{P}_{2} \mathrm{Y}_{12}, J$ Thromb Haemost. 2003;1(suppl 1):P0777.

\section{Awards}

- 'Lars-Erik Gelin Conference Travel Award' van de European Society for Microcirculation (ESM), voor het abstract getiteld: 'A new method to measure cytosolic calcium in rabbit platelets in vivo' (Stockholm, juni 2000)

- 'Young Investigators Travel Award' van de International Society on Thrombosis and Haemostasis. (ISTH), voor het abstract getiteld: 'The platelet ADP-receptor P2Y12 is involved in embolization but not in thrombus formation in vivo' (Parijs, juli 2001)

- 'Dr. J. Stibbe bokaal' voor de beste AIO-presentatie tijdens het jaarlijkse symposium van de Nederlandse Vereniging voor Trombose en Hemostase (NVTH; Houthalen, januari 2002)

- 'Young Investigator Award' voor de beste presentatie tijdens de jaarlijkse bijeenkomst van de Nederlandse Vereniging voor Microcirculatie en Vasculaire Biologie (MiVaB; Heeswijk, januari 2003) 


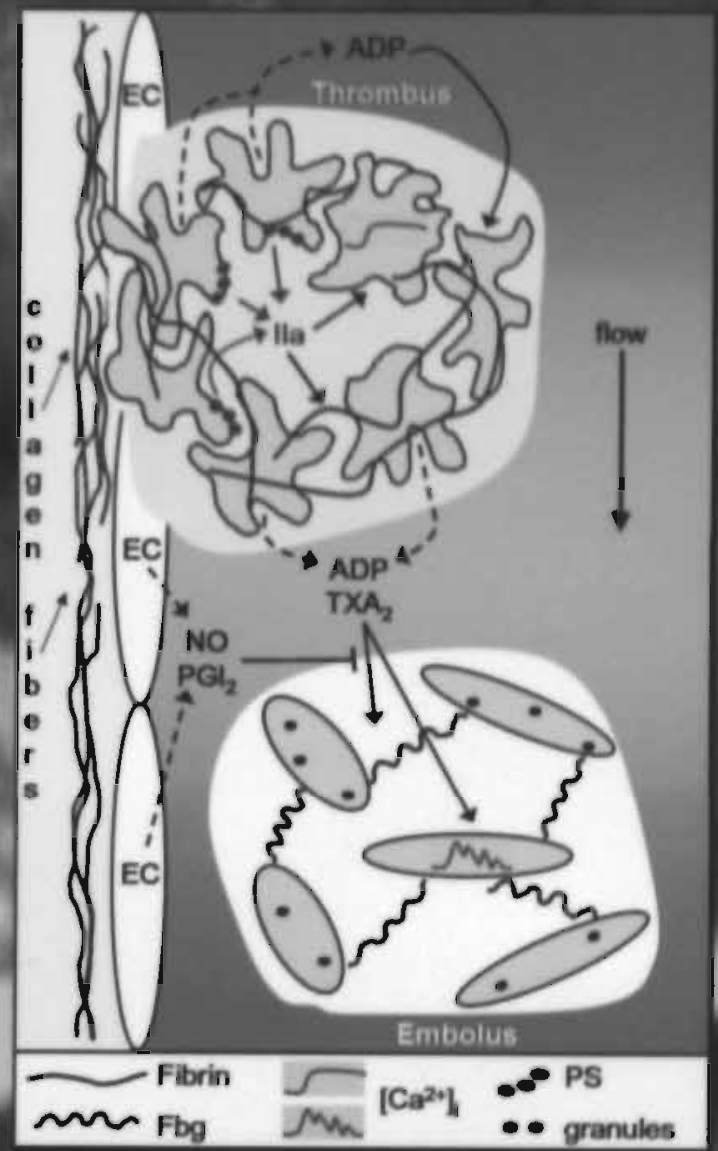

Figure 7.1 (see page 116 for legend) 

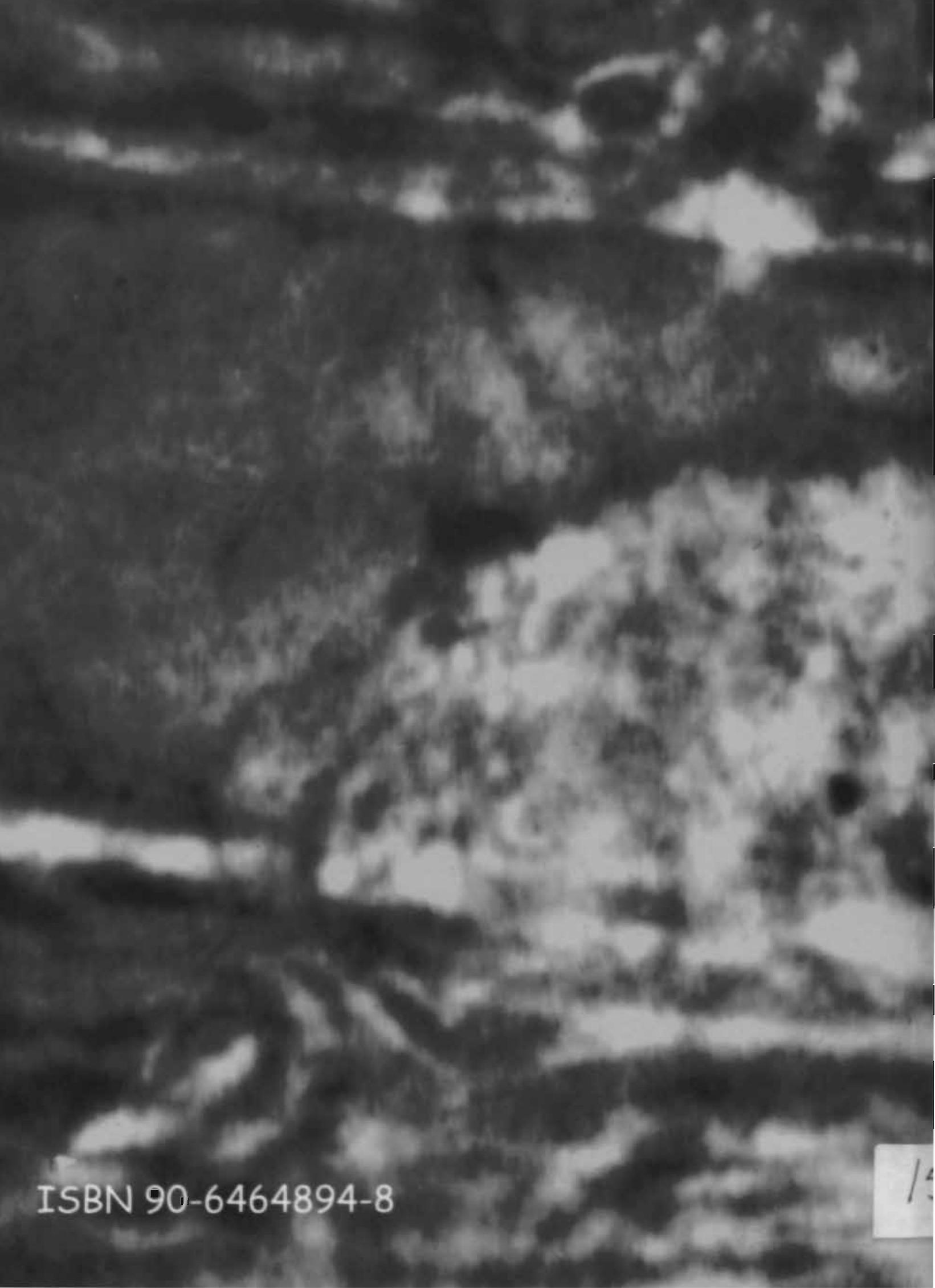